University of Louisville

ThinkIR: The University of Louisville's Institutional Repository

$12-2005$

\title{
Fabrication of a microfluidic platform for impedance analysis of cultured endothelial cell monolayers.
}

Stuart J. Williams 1981-

University of Louisville

Follow this and additional works at: https://ir.library.louisville.edu/etd

\section{Recommended Citation}

Williams, Stuart J. 1981-, "Fabrication of a microfluidic platform for impedance analysis of cultured endothelial cell monolayers." (2005). Electronic Theses and Dissertations. Paper 1577.

https://doi.org/10.18297/etd/1577

This Master's Thesis is brought to you for free and open access by ThinkIR: The University of Louisville's Institutional Repository. It has been accepted for inclusion in Electronic Theses and Dissertations by an authorized administrator of ThinkIR: The University of Louisville's Institutional Repository. This title appears here courtesy of the author, who has retained all other copyrights. For more information, please contact thinkir@louisville.edu. 


\title{
FABRICATION OF A MICROFLUIDIC PLATFORM FOR IMPEDANCE ANALYSIS OF CULTURED ENDOTHELIAL CELL MONOLAYERS
}

\author{
By
}

Stuart J. Williams

B. S., University of Louisville, 2005

\author{
A Thesis \\ Submitted to the Faculty of the \\ University of Louisville \\ Speed School of Engineering \\ as Partial Fulfillment of the Requirements \\ for the Professional Degree \\ MASTER OF ENGINEERING \\ Department of Mechanical Engineering
}

December 2005 


\section{FABRICATION OF A MICROFLUIDIC PLATFORM FOR IMPEDANCE ANALYSIS OF CULTURED ENDOTHELIAL CELL MONOLAYERS}

Submitted by:

Stuart J. Williams

A Thesis Approved on

August $9^{\text {th }}, 2005$

by the Following Reading and Examination Committee:

Robert Keynton, Ph.D., Thesis Director

Ellen G. Brehob, Ph.D.

Kevin M. Walsh, Ph.D. 


\section{ACKNOWLEDGEMENTS}

I would like to thank Dr. Robert Keynton for his patience, guidance, and tutelage throughout graduate school. I couldn't have created the devices without Mark Crain's cleanroom instruction, training, and fabrication opinions. Dave Morgan, fellow classmate and friend, showed me how to culture the studied cells. Thanks to Scott Cambron, Thomas Roussel, and others in the BioMEMS and Cardiovascular group for their support. Sara Clemons accompanied me many late nights in the clean room and laboratory. Last, but not least, my parents, Joe and Ellen Williams. I couldn't have made it through this without their continued support (and proofreading tips). 


\begin{abstract}
Fabrication of a Microfluidic Platform For Impedance Analysis of Cultured Endothelial Cell Monolayers

Stuart J. Williams

August $9^{\text {th }}, 2005$
\end{abstract}

Assessing the functionality of the endothelium can provide insight into the initiation and formation of arterial diseases. One of the most important functions of the endothelial layer is its permeability. The integrity of the cell monolayer and its ability to transport molecules can be assessed in vitro by investigating the electrical impedance.

In this study, a microfluidic platform was created using an electrode-patterned glass substrate and microfluidic poly(dimethyl siloxane) (PDMS) substrate. The electrode glass base of the structure was fabricated with platinum square electrodes of various sizes ranging from $10 \times 10 \mu \mathrm{m}^{2}$ to $160 \times 160 \mu \mathrm{m}^{2}$ and a larger, common counter electrode. Master microfluidic molds for PDMS casting were created by micro-milling Lexan $^{\circledR}$ and photolithographically patterning SU-8. The microfluidic PDMS substrates reversibly and conformally bonded to the glass-electrode substrate. The microfluidic platforms were characterized by loading the microchannels with cell growth media alone, cell growth media and fibronectin, and cell growth media, fibronectin and human 
umbilical vein endothelial cells and obtaining impedance spectra. The experiments were performed under both no flow and flow conditions.

Fibronectin did not significantly alter the collected impedance spectrum compared to media alone under no flow conditions. Under no flow conditions, impedance spectra measurements were able to detect the presence of cultured cells on the electrodes. The presence of fibronectin and various tested flow rates did not alter the impedance spectrum compared to media alone under static conditions. After further investigations, the microfluidic platform will become a versatile means of characterizing endothelial cell layer behavior. 
TABLE OF CONTENTS

PAGE

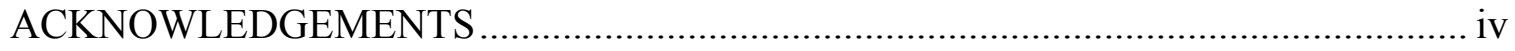

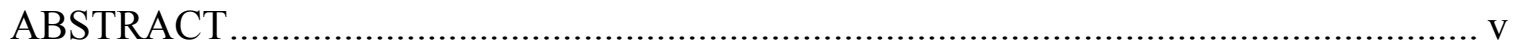

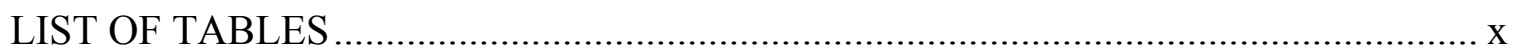

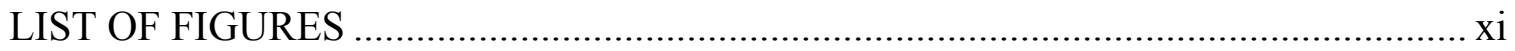

\section{CHAPTERS}

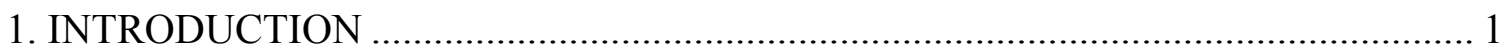

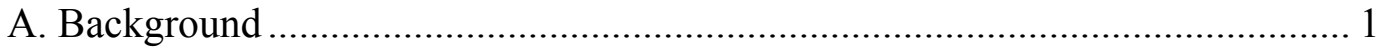

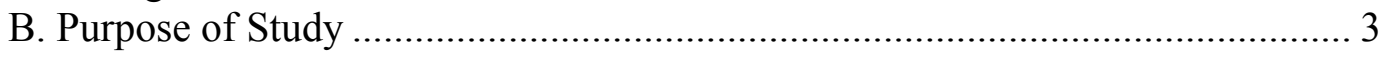

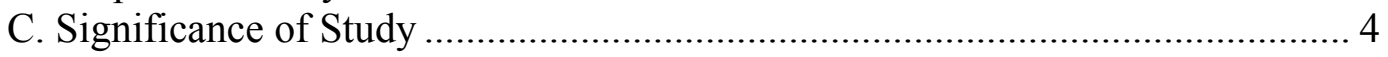

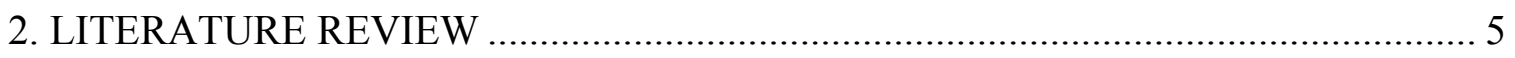

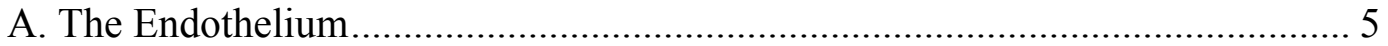

1. Anatomy of the Blood Vessel .................................................................. 5

2. Endothelium Function.................................................................................. 5

3. Applied Mechanical Forces on Endothelium.................................................. 7

B. Endothelial Function Characterization........................................................ 8

1. Transendothelial Electrical Resistance .................................................... 9

2. Modeling of Measuring Electrodes.......................................................... 10

3. Existing Electrical Systems.................................................................... 12

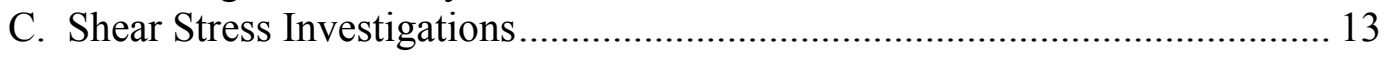

1. Shear Stress Analysis of Endothelial Cells .................................................. 14

2. Electrical Analysis of Endothelial Cells Under Applied Shear .................... 16

3. Comparison of Methodologies.................................................................. 18

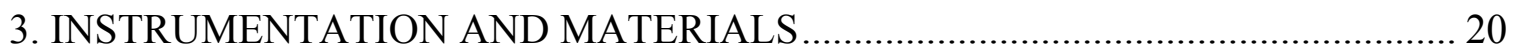

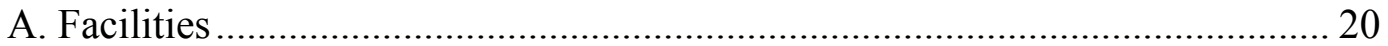

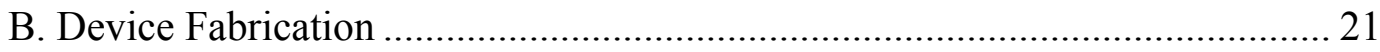

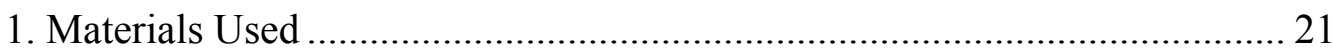

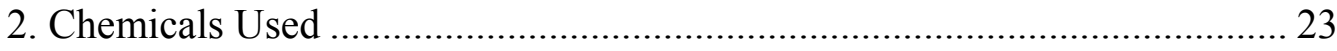

3. Instrumentation Used ........................................................................... 24

C. Cell Culture and Device Testing .............................................................. 28

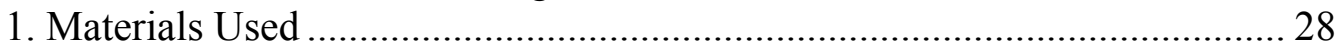




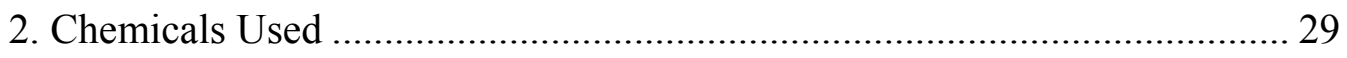

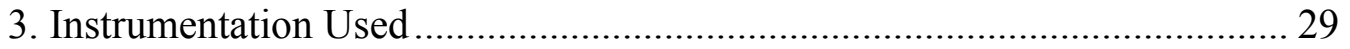

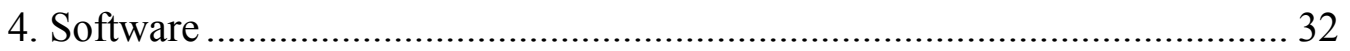

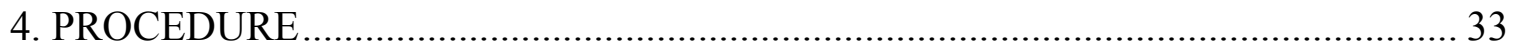

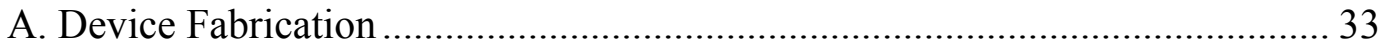

1. Electrode Substrate Design .......................................................................... 33

2. Electrode Substrate Fabrication ................................................................ 35

3. Microfluidic Substrate Design .................................................................. 38

4. Microfluidic Substrate Fabrication ............................................................. 39

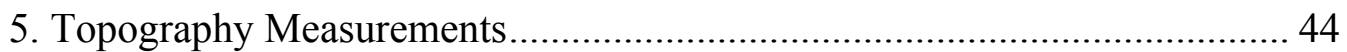

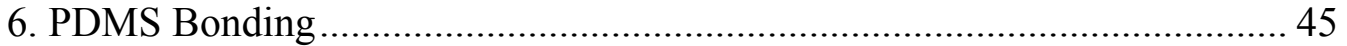

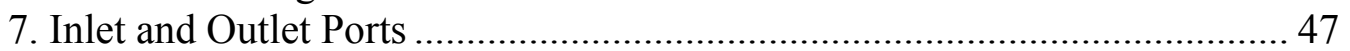

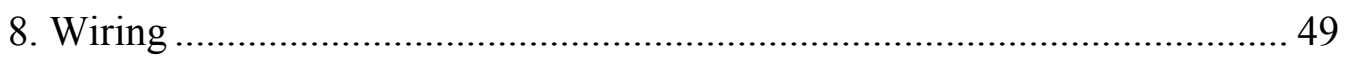

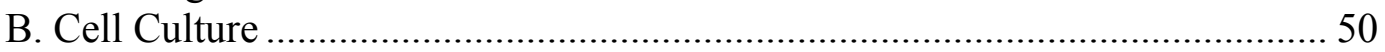

1. Preparations of Cell Suspensions.............................................................. 50

2. Cell Culturing in Microchannels............................................................... 51

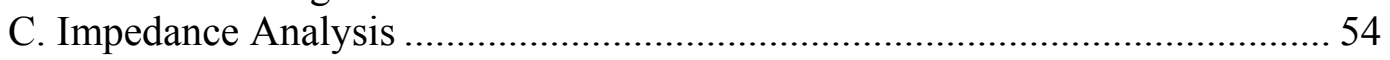

1. Impedance Analyzer Settings .................................................................. 54

2. Impedance Analysis Tests......................................................................... 54

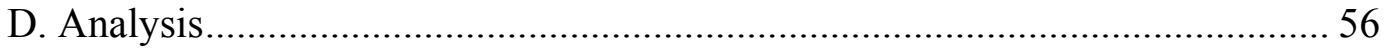

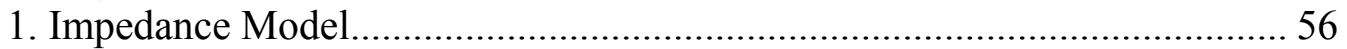

2. Impedance Analysis .................................................................................. 57

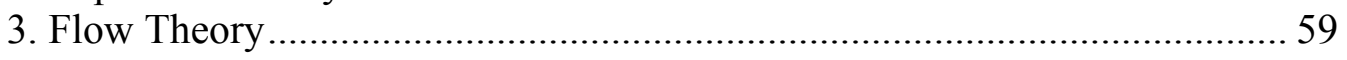

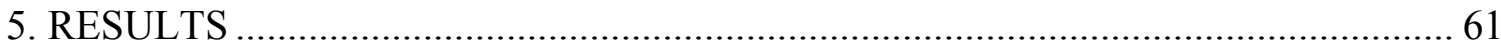

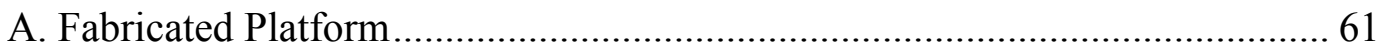

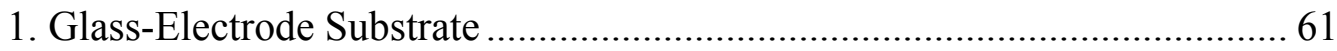

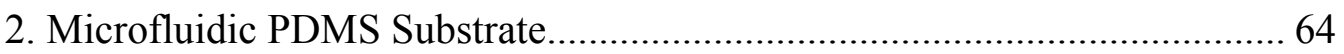

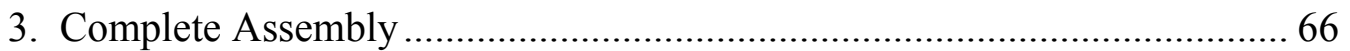

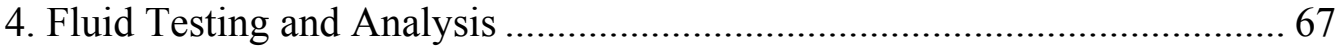

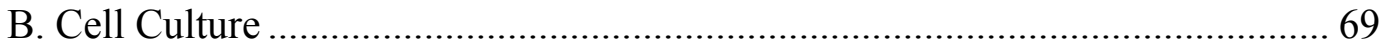

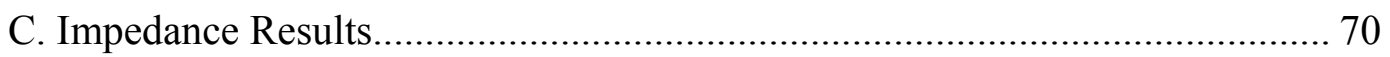

1. Impedance Measurements in Microchannels with No Flow........................... 70

2. Impedance Measurements in Microchannels with Flow ............................... 77

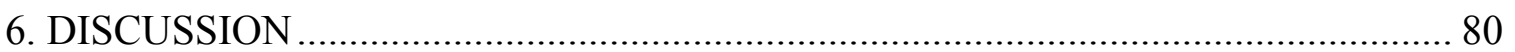

A. Fabricated Platform.................................................................................. 80

1. Glass-Electrode Substrate Topography..................................................... 80

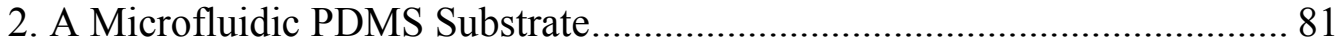

3. Fluid Testing and Analysis ........................................................................ 83

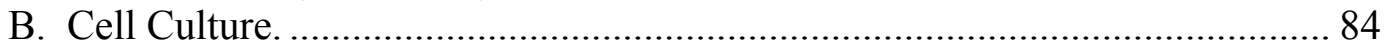

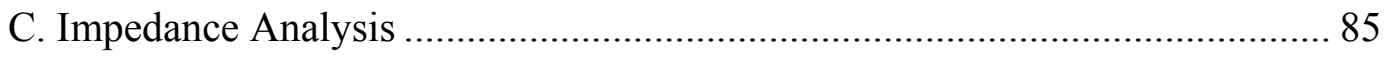

1. Impedance Measurements in Microchannels................................................ 86

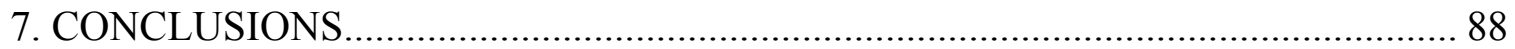


RECOMMENDATIONS

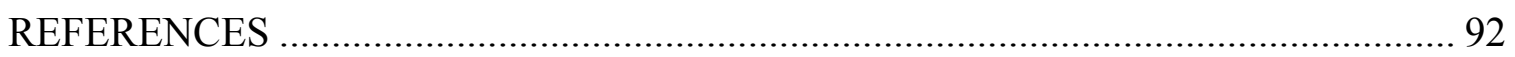

\section{APPENDIX}

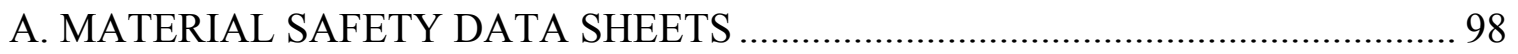

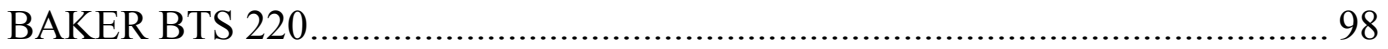

BOE

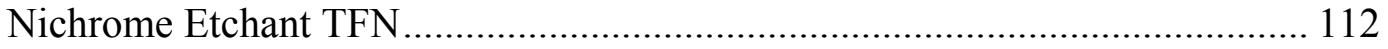

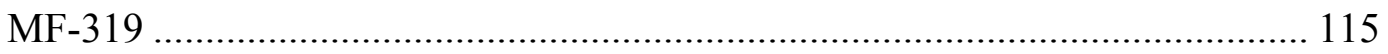

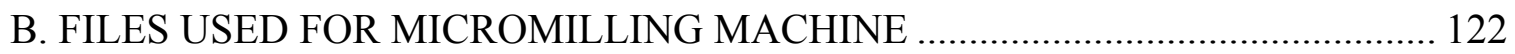

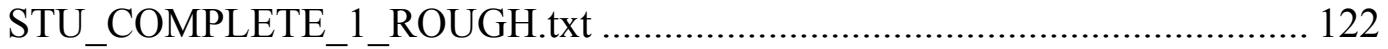

STU_COMPLETE_1_FINISH.txt............................................................... 135

C. MANUFATURER DATA SHEETS FOR SYLGARD 184 AND SU-8-50 ............. 137

D. DERIVATIONS OF IMPEDANCE MODEL EQUATIONS …………………........ 146

E. SAMPLE WORKSHEET OF COLLECTED IMPEDANCE DATA.......................... 147

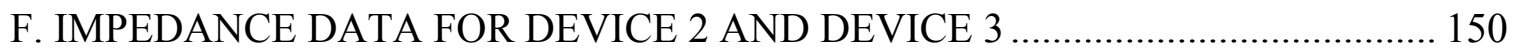

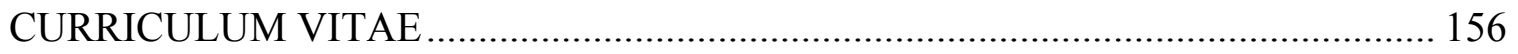




\section{LIST OF TABLES}

TABLE

PAGE

Table 1. Trials for SU-8 fabricated molds.

Table 2. Topography measurements at different locations of the device.

63

Table 3. Expected and actual dimensions of electrodes and traces for each tested device.

Table 4. Percent error of dimensions of electrodes and traces for all three devices......... 64

Table 5. Summary of results for the first four SU-8 fabricated molds. ......................... 64

Table 6. Summary of results for the no-bake SU-8 fabricated molds. ............................65

Table 7. Showing calculated fluid flow parameters for $1 \mathrm{rpm}, 5 \mathrm{rpm}, 10 \mathrm{rpm} . . . \ldots \ldots \ldots \ldots \ldots . . . . .69$

Table 8. Standard deviations for the measured electrodes for with medium alone........ 72

Table 9. Mathematical model fit with medium alone.................................................. 72

Table 10. Standard deviations for the measured electrodes for with medium and

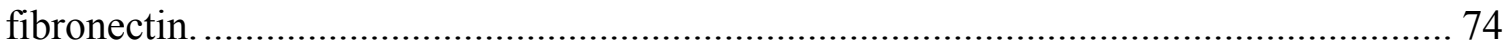

Table 11. Mathematical model fit with medium and fibronectin. ................................ 74 


\section{LIST OF FIGURES}

$\begin{array}{ll}\text { FIGURE } & \text { PAGE }\end{array}$

Figure 1. Electrical model used for impedance analysis of cultured monolayers. .......... 11

Figure 2. Port assembly, adaptor, and adhesive rings (Upchurch Scientific)................. 23

Figure 3. Heidelberg Laser Pattern Generator, DWL 66.......................................... 24

Figure 4. AB-M IR Mask Aligner............................................................................. 25

Figure 5. Technics Sputtering System Series 4604 ................................................... 25

Figure 6. Veeco Dektak 8 Advanced Development Profiler. .......................................... 26

Figure 7. Ultra-High-Precision Micro Milling Machine ............................................ 27

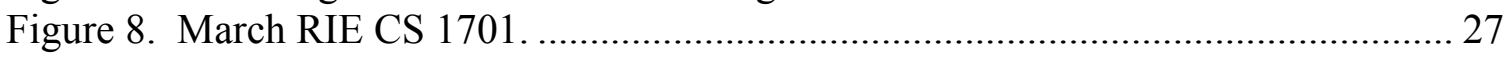

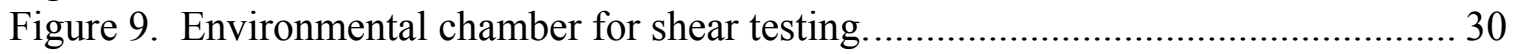

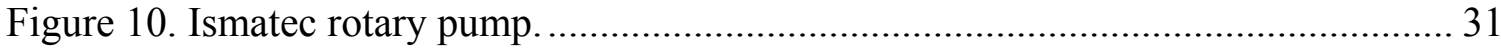

Figure 11. Agilent 4294A impedance analyzer. ........................................................ 31

Figure 12. Electrode pattern of the substrate (not to scale). ......................................... 34

Figure 13. Electrode pattern of the 80 and $40 \mu \mathrm{m}$ square electrodes (not to scale)......... 35

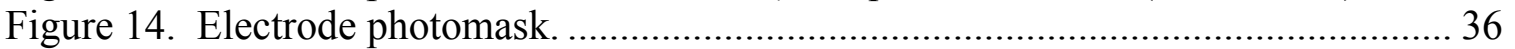

Figure 15. Summation of electrode fabrication (Keynton 2004) .................................. 38

Figure 16. Superimposed drawings of microchannels and patterned electrodes ............. 39

Figure 17. The micro-milled Lexan ${ }^{\circledR}$ mold for the PDMS microfluidic piece.................. 40

Figure 18. Photomask used for SU-8 microfabricated mold. ....................................... 41

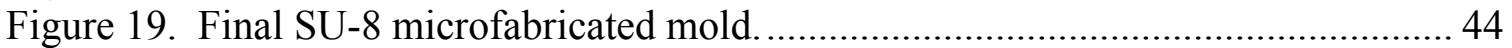

Figure 20. Schematic of the environment for fluid flow testing....................................56

Figure 21. An example of the Excel worksheet and Premium Solver package.............. 59

Figure 22. The resulting fabricated glass-electrode substrate................................... 61

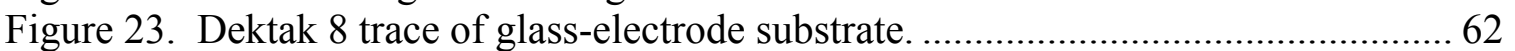

Figure 24. Profile results at different Y-coordinates $(\mathrm{mm})$ of the fourth trial...................65

Figure 25. Profile results at different Y-coordinates $(\mathrm{mm})$ of the fifth trial.....................66

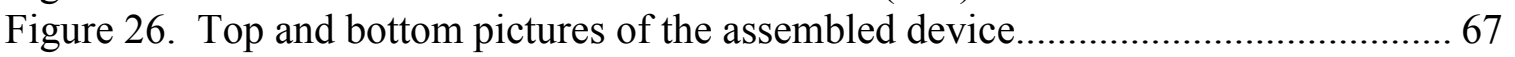

Figure 27. Normalized impedance spectrum for each electrode geometry with medium

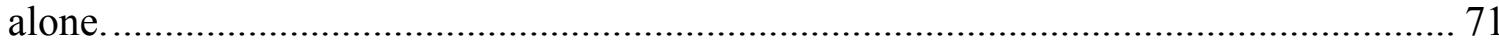

Figure 28. Normalized impedance spectrum for each electrode geometry with medium

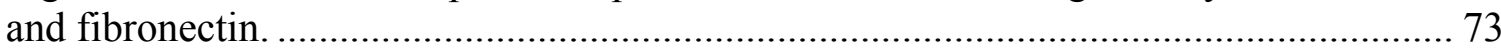

Figure 29. Device 3 impedance spectrum across two measuring electrodes................. 75

Figure 30. Device 2 impedance spectrum across measuring electrodes over time.......... 76

Figure 31. Impedance spectrum of cultured $40 \times 40 \mu \mathrm{m}^{2}$ electrodes with a referenced measurement. 
Figure 32. Impedance spectra under fluid flow for Device 1 with media alone.

Figure 33. Impedance spectra under fluid flow for Device 1 with media and fibronectin. 78

Figure 34. Impedance spectra under fluid flow for $40 \times 40 \mu \mathrm{m}^{2}$ electrodes (Device 1) with media alone. 79

Figure 35. Impedance spectra under fluid flow for $40 \mathrm{x} 40 \mu \mathrm{m}^{2}$ electrodes (Device 1) with media and fibronectin. 79 


\title{
CHAPTER 1 \\ INTRODUCTION
}

\begin{abstract}
A. Background
In the last half century, investigations have been conducted to better understand the role of cardiovascular disease. As a result, death rates from cardiovascular disease have declined and American's are living longer, healthier lives. However, cardiovascular disease continues to be the leading cause of morbidity and mortality in the United States. Coronary heart disease, congestive heart failure, stroke, hypertension, and arterial diseases are just a few of the leading types of cardiovascular disease, claiming more than 900 thousand lives in 2001 (Morbidity and Mortality: 2004 Chart Book). A number of investigators have theorized that transport across the endothelium is the primary cause of cardiovascular disease (Davies 1989, Grander 1986, Ross 1993). Thus, the role of endothelium permeability has been investigated in the function of cardiovascular diseases.

The endothelium is a confluent layer of flattened endothelial cells that line arteries, veins, and capillaries. This monolayer provides a multifunctional interface between blood and the vessel wall. Common endothelial activities include intracellular signaling, interaction between the surface and the underlying smooth muscle layer, and the exchange of molecular substances (Davies 1989, Grander 1986, Ross 1993). One of
\end{abstract}


the most important ways to characterize the endothelial cell monolayer is by investigating its barrier function, defined as the behavior of the transportation of molecules through the cell monolayer.

The permeability of an endothelial cell monolayer is determined by the diffusion of molecules through the individual cells themselves or between their clefts. Investigations of intracellular junctions were used to describe the access of medium to the underlying layers. This characteristic of the barrier function is important for the study of cardiovascular diseases when foreign substances diffuse through the endothelium. A number of factors affect the permeability of the endothelium, including shear induced forces from blood flow. A number of methods have been developed to investigate the behavior of the permeability of a cell monolayer (DePaola 1994, Gojova 2005, James 1995, Jo 1991, Takahashi 1997, Traub 1998). Unlike these methods, which can take an extended period of time to obtain results, electrical measurement techniques to analyze the cell monolayer provide "real time" data collection for barrier function characterization.

Initial endothelial electrical measurement techniques investigated cells cultured on permeable, filtered dishes (Cereijido 1978, Erben 1995, Hein 1992). The measured resistances across the cultured filter were directly related to the transcellular permeability of the endothelial cell layer, as lower resistance values were associated with more permeable monolayers. This technique would later be adapted to cell-culture well plates with gold electrodes (Giaever 1991, Keese 2002, Janshoff 1996, Wegener 1996, Wegener 2000, Seebach 2000). Experiments in a static environment were valid techniques but did 
not provide physiologically relevant information since the cells were not exposed to fluid shear stress.

Two types of transendothelial electrical resistance apparatii were developed to investigate endothelial cells under applied fluid shear (DePaola 2001, Seebach 2000). The method developed by Seebach, et al. (2000) incorporated an applied shear force using a cone-and-plate device, whereby the plate contained the cultured cells and electrodes. An impedance analyzer recorded the transendothelial resistance, which was incorporated in a mathematical model to characterize the barrier function across the endothelial lining. Though the mathematical model is a sensible method of describing monolayer permeability, the cone-and-plate apparatus is not a reliable system and does not mimic physiological flow conditions. DePaola, et al. (2001) integrated an impedance system, called Electrical Cell Impedance Sensing (ECIS) (Giaever 1984, 1991, Keese 1990, 2002), into a parallel plate flow device. A major disadvantage of the ECIS analysis system is that it collects data at a predetermined frequency. A frequency spectrum of the measured impedance is needed to apply a comprehensive model describing the barrier function. Although both of these systems are viable, none of them are capable of determining endothelial cell permeability under physiological flow conditions.

\section{B. Purpose of Study}

The purpose of this study is to develop a microfluidic platform that uses impedance spectrum analysis to determine the permeability of cultured endothelial monolayers. 


\section{Significance of Study}

The impedance analysis of a cultured endothelial monolayer directly gives insight to its behavior, including the permeability of the endothelial cells (Giaever 1984, 1991, Janshoff 1996, Keese 1990, 2002, Wegener 1996, 2000). Endothelium permeability is an important characteristic associated with the initiation and progression of some cardiovascular diseases (Davies 1989). The method of electrical analysis is advantageous over other permeability characterization studies since this method offers a "real-time" data collection and analysis of the monolayer. The proposed platform can also expose cultured cells to applied shear stress under fluid flow, which more closely mimics physiological conditions. Though impedance analysis studies of endothelial cells under

induced shear have been developed by other authors (DePaola 2001, Seebach 2000), this study is the first microfabricated platform to incorporate continual flow conditions. Additionally, the measuring electrodes vary in size in order to analyze local inhomogeneities in cultured endothelial cells. 


\section{CHAPTER 2}

\section{LITERATURE REVIEW}

\section{A. The Endothelium}

\section{Anatomy of the Blood Vessel}

The endothelium is a single layer of flattened, confluent cells that line all arteries and veins, including capillaries. Endothelial cell monolayers are the innermost layer of arteries and are in direct contact with blood. The endothelium is the innermost layer of the tunica intima, one of three main layers of an artery (Langley 1974). The monolayer rests on a layer of tissue connecting it to the underlying elastic membrane (Langley 1974). The next layer is the tunica media, composing of smooth muscle cells and connective tissue. The third, outermost layer is the tunica adventitia that consists mostly of loose collagen fibers (Langley 1974). By understanding the function of the endothelium and its interaction with the underlying layers the relationship between the formation of arterial disease and endothelial cell monolayer behavior can be understood.

\section{Endothelium Function}

The monolayer of endothelial cells provides a functional barrier between the blood and the underlying blood vessel layers. The endothelium is able to alter the arterial geometry, thus controlling aspects of fluid flow through the vessel. The monolayer 
regulates molecular transport through the endothelium to the subendothelium. These functions are executed through a complex process of biological/biochemical signals sent by the endothelial cells in response to their environment.

Endothelial cells have the ability to control vascular tone with the production of vasodilators or vasoconstrictors. Types of vasodilators include nitric oxide, which causes smooth muscles cells to contract or relax and prostacyclin which is released by endothelial cells prevents platelet formation and blood clotting (Verrier, 1996). Vasoconstrictors such as endothelin-1, leukotrienes, and angiotensin II narrow the lumen of blood vessels. Through the production of vasodilators and vasoconstrictors, the endothelial cells control the diameter of the vessel; however, they also control solute interaction across the monolayer itself.

The endothelium is a regulator that mediates the molecular flux between the vessel wall and flowing blood. This permeability function is the most important characteristic of the monolayer. Substances are transported into the subendothelium by permeating through the intercellular junctions (paracellular) or through the cells themselves (transcellular).

Paracellular transport is characterized by the passage of molecules through a number of intercellular junctions. The four main types of intercellular junctions are tight junctions, adherens junctions, gap junctions, and desmosomes (Furuse 1993). Tight junctions prevent the passage of molecules and ions through the intercellular clefts, while adherens junctions provide strong mechanical attachment between cells. Gap junctions, on the other hand, are intercellular channels that provide passage of ions and molecules from cell-to-cell and desmosomes tightly join adjacent cells. 
Transcellular transport describes the passage of ions and molecules through the cell itself by passing through the lipid bilayers to the subendothelium layers. The movement of ions through the cell membrane is determined by the size of the ion, its solubility in lipids, its size, and the concentration gradient (Langley 1974). Characteristics of the paracellular and transcellular behavior under different environments provide insight into the permeability function of the endothelium.

In addition, the endothelium controls other circulatory processes including blood coagulation, growth of underlying smooth muscle cells, white blood cell adhesion, transmigration, and lipoprotein uptake (Traub 1998). Thus, it is important to characterize the monolayer's ability to control and regulate the diffusion of molecules, proteins, and other nutrients into the underlying layers of the artery in order to better understand the initiation and development of cardiovascular disease. In addition to chemical and biological regulation, the endothelium has been found to be highly responsive to mechanical forces which have been identified to potential initiators of cardiovascular disease (Davies 1988, Gojova 2005, Jo 1991, Keynton 2001, Phelps 2000, Traub 1998).

\section{Applied Mechanical Forces on Endothelium}

Throughout the circulatory system, the flow of blood subjects endothelial cells to two mechanical forces: a normal pressure force and a tangential shear force. The pressurized, pulsating nature of blood exerts a force on the vessel wall, causing the arteries to expand and contract. The vessel wall cushions most of this normal force; however, the endothelial cells absorb all of the shear force (Davies 1988). The tangential shear force is generated from the viscous flowing fluid through the arteries. Typically, 
blood flow is laminar in vessels, but turbulence can occur in regions of stenosis or at sites of flow separation, (Davies 1989).

This applied shear force is directly related to the regulation of monolayer functionality, cell morphology, and motility (DePaola 2001). These mechanical forces alter endothelial permeability by modifying the responsive biochemical signaling pathway in endothelial cells. These signaling changes affect the endothelium's function on both the cellular and molecular levels leading to rapid responses in the underlying tissue (Davies 1993). Furthermore, endothelial cells exposed to shear will rearrange their orientation to align with the direction of flow and elongate. The final shape of the endothelial cell is dependent on the microfilament structure of the cell and its rigidity under shear (Davies 1993, Gray 2002, Levesque 1986, Malek 1996). Permeability between the cell-to-cell junctions in the monolayer is directly related to this morphological adaption to shear stress (Seebach 2000). The monolayer's reaction to hemodynamic forces is reversible as well as shear and time dependent (Davies 1989, Jo 2001).

\section{B. Endothelial Function Characterization}

A number of investigators have studied the effect of disturbed flow and/or applied shear on endothelial cell behavior (DePaola 1994, DePaola 2000, Gojova 2005, James 1995, Jo 1991, Phelps 2000, Seebach 2000, Takahashi 1997, Traub 1998). The function of the monolayer has been monitored by either chemical or electrical methods. Before 
these investigations can be explained, it is important to understand the background behind the electrical techniques to describe the endothelial monolayer.

\section{Transendothelial Electrical Resistance}

The implementation of measured electrical resistances to characterize the behavior of cultured biological substances is not an uncommon practice. For example, transendothelial resistance (TER) provides insight into endothelium permeability. One common method of TER testing requires cells to be cultured on permeable filters, which divide the apparatus into two compartments (Cereijido 1978, Erben 1995, Hein 1992). Resistance measurements are recorded using a series of probes that provide a simple and direct method for real-time data collection and behavior analysis. One pair of electrodes is used to apply a DC voltage across the insert while a second pair detects the corresponding voltage drop. Ohm's Law is used to determine the resistance across the filter using the resistance across an uncultured container as a correction factor.

Another methodology utilizes impedance analysis of an AC signal across a series of coplanar electrodes fabricated on a base substrate with cultured cells (Giaever 1991, Keese 2002, Janshoff 1996, Wegener 1996, Wegener 2000, Seebach 2000). The AC signal is sent across the electrodes and the impedance spectrum is recorded. This impedance verses frequency spectra is used to determine TER measurements as well as other parameters. The mathematical model used to determine these parameters is described in the next section below. The TER values describe the transcellular permeability of the cultured EC monolayer per unit area of covered electrode. Typical values of TER range from $3 \mathrm{ohm}-\mathrm{cm}^{2}$ to $1000 \mathrm{ohm}-\mathrm{cm}^{2}$ (Seebach 2000). Additionally, 
TER can be monitored over a period of time to characterize cell motility and cell shape over a defined period (Giaever 1991, Keese 2002, Seebach 2000). However, a limitation to this technique is that a mathematical model for the electrical analysis of endothelial cell behavior is needed to perform offline calculations to quantify permeability.

\section{Modeling of Measuring Electrodes}

The most simplified electrical model that fully describes the characteristics of a cultured cell layer on an electrode using the minimum number of parameters is shown in Figure 1 (Janshoff 1996, Wegener 1996). The capacitor and resistor in parallel characterize or model the behavior of the cultured cell layer, while the resistor and capacitor in series deal with the interaction of the electrode to the electrolytic medium. $R_{\text {cell layer }}$ represents the transendothelial resistance describing the passage of molecules through the junctions between the cells. $C_{\text {cell layer }}$ symbolizes the behavior of transcellular activity through the cytoplasm of the cell itself; this transcellular path is close to $1 \mu \mathrm{F} / \mathrm{cm}^{2}$ for most cell types (Seebach 2000). Ionic solutions, like cell culture medium, form an electrical boundary layer at the interface between the measuring electrode surface and the liquid. $C_{E}$ describes the dielectric properties of this interface and the interaction between the medium and the electrode. Last, $R_{\text {medium }}$ describes the conductivity of the cell culture medium. Note, the measured values of $C_{\text {cell layer }}$ and $R_{\text {cell layer }}$ are interpreted as an average value of the cells resting on the surface area of the electrode. 

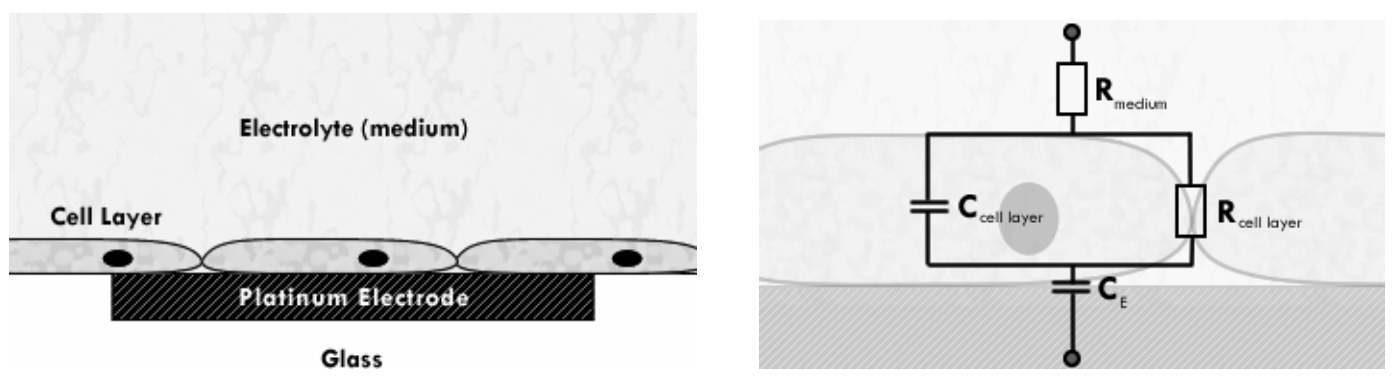

Figure 1. Electrical model used for impedance analysis of cultured monolayers.

Parameters of the model are derived from impedance spectra obtained from the input of a low-peak $(<0.5 \mathrm{~V})$ AC signal. The range of frequencies for analysis varies but is typically within $1 \mathrm{~Hz}$ to $1 \mathrm{MHz}$; the presence of cultured cells noticeably changes the spectrum at $100 \mathrm{~Hz}$ to $100 \mathrm{kHz}$ (Janshoff 1996). The impedance spectra collected is inputted into a mathematical model and the variables are determined. Deviations of the model from the experimental data, at points below $1 \mathrm{kHz}$, may be attributed to the simplified treatment of the electrode/electrolyte interface as an ideal capacitor in series with the bulk conductivity (Janshoff 1996).

The measured electrical impedance of the endothelium is dependent on the input frequency and size of the measuring electrodes. Coplanar electrode analysis of cultured cells has been integrated in the systems of Wegener, et al (1996), Janshoff, et al (1996) and the Electric Cell-Substrate Impedance Sensing (ECIS) system developed by Giaever and Keese (Giaever 1984, 1991, Keese 1990, 2002). Due to the very large size of the counter electrode compared to the smaller, working electrodes the overall impedance of the system is dominated by the small electrodes, even if the larger electrode is covered with cells (Greve 2003). The cell layer cultured on top of the measuring electrodes needs to be confluent in order to monitor accurate impedance behavior. Larger intercellular 
gaps will influence the impedance spectra, but if the electrodes are uncovered the model is less accurate at predicting the electrical properties (Seebach 2000).

In previous work investigating this electrical analysis technique, the measuring electrodes were substantially larger than the cells they were measuring. Although large measuring electrodes interrogate the mean behavior of a cluster of cells, smaller electrodes provide insight into local cell/monolayer inhomogeneities. Greve, et al. (2003) produced a finite element model depicting the behavior of cells grown on small measuring electrodes. As cellular impedance analysis reaches a smaller scale, considerations for changing the model depicted in Figure 1 must be made in order to accommodate for more precise analysis of cellular characteristics previously ignored, such as focal adhesion sites.

\section{Existing Electrical Systems}

Two types of systems for impedance analysis of cell monolayers have been developed. The first is the Electronic Cell-Substrate Impedance Sensing (ECIS) system (Giaever 1984, Keese 1990, Giaever 1991) that monitors the behavior of cells at one defined frequency. The second type of system scans over a range of frequencies for impedance analysis (Janshoff 1996, Wegener 1996).

ECIS used one defined frequency $(40 \mathrm{kHz})$ for rapid observation of impedance fluctuations due to cell motility. The investigated culture was grown in well plates that have one gold electrode of $250 \mu \mathrm{m}$ in diameter and a larger, counter electrode in a coplanar arrangement. One of the well plates was uncultured, which was used to normalize the measured results in the other cultured wells. Impedance measurements 
were taken with a lock-in amplifier and data was acquired and processed using a personal computer. By assuming the shape of cultured cells as a flat, circular disc, ECIS techniques can determine morphological parameters including the barrier function, spacing between the cell and the substrate, and cell membrane capacitance.

The other impedance analysis systems (Wegener 1996, Janshoff 1996) were used for the investigation of cultured endothelial cell layers. Electrodes of various sizes were fabricated on the culturing well base using gold films and an impedance analyzer is utilized to sweep through a range of frequencies. The measured values are fit to the model described in Figure 1 using least-squares methods. The disadvantage of these systems, compared to ECIS, is the frequency sweep data collection takes longer, i.e. from seconds to minutes, depending on the number of points and precision.

\section{Shear Stress Investigations}

Disturbed laminar flow occurs physiologically at sites of sharp curvature, abrupt narrowing and branching of blood flow. At junctions of redirected flow there exists complex flow patterns including regions of relatively high shear, stagnation (zero shear), and low shear varying with the cardiac cycle, resulting in reverse flow (Davies 1988, Keynton 1991). There have been a number of in vitro investigations that examined the endothelial cells' response to applied shear in an attempt to analyze these regions of disturbed flow (DePaola 1994, 2000, Gojova 2005, James 1995, Jo 1991, Phelps 2000, Seebach 2000, Takahashi 1997, Traub 1998). 
The most commonly used devices for investigating, in vitro, the effects of applied shear stress on the endothelial monolayer are parallel plate flow systems (DePaola 1994, 2000, Phelps 2000) and cone-and-plate systems (DePaola 1994, Seebach 2000). Parallel plate flow devices consist of plates arranged in parallel with a top plate being a glass substrate for culturing cells and a bottom substrate which contains the measuring electrodes. The gap between the two plates is small $(<1 \mathrm{~mm})$ in order to produce a laminar, fully developed, two-dimensional flow. Shear forces of cone-and-plate systems are determined by the rotational velocity of the cone, the viscosity of the medium, and the angle between the cone and stationary plate (Davies 1988). The applied shear stress investigations are generally used to determine the relationship between hemodynamic forces, the endothelial layer, and the initiation of arterial disease.

Arterial vessel wall diseases have been linked to damaged or altered endothelium due to the effects of altered flow (Davies 1988, Satcher 1994). Erratic shear stress and disturbed flow hinder barrier function, which alters the permeability of molecules and thus, changes the intercellular signaling (Jo 1991, Phelps 2000). In some cases, endothelial cells do not reorient themselves to the direction of flow due to the disturbance (Traub 1998).

\section{Shear Stress Analysis of Endothelial Cells}

There are methods, other than electrical analysis, to determine and monitor the activities of endothelial monolayers under induced shear. Jo, et al. (1991) demonstrated that albumin permeability across the endothelial monolayer is acutely sensitive to shear stress. They subjected bovine aortic endothelial cells grown on polycarbonate filters to 
shear stresses of $1 \mathrm{dyne} / \mathrm{cm}^{2}$ and $10 \mathrm{dyne} / \mathrm{cm}^{2}$. Albuminal levels increased by a factor of approximately 4 and 10 for lower and higher shear stresses, respectively, compared to static flow conditions.

James, et al. (1995) characterized the effect of shear on bovine aortic endothelial cell intracellular calcium transport. A shear rate of $15 \mathrm{dyne} / \mathrm{cm}^{2}$ was applied to the cells through a confocal cell chamber constructed from polycarbonate. Fluorescence microscopy sensitive to intracellular calcium was used to analyze the cultured endothelial cells. They found that the cells responded to elevated shear levels by increasing intracellular calcium levels.

DePaola, et al. (1994) monitored the effects of shear stress gradients on bovine aortic endothelial cells in both a cone-and-plate system and a parallel plate flow chamber. Flow separation and disturbance was created by placing a rectangular strip in the system. DNA synthesis associated with cell proliferation was monitored by in situ monoclonal antibody detection of Bromodeoxyuridine (BrdU) incorporation. Their results showed that the cell proliferation rate was significantly reduced (only $8-10 \%$ of the cells in the disturbed region showed BrdU incorporation compared to $25 \%$ of the cells exposed to flow alone) in disturbed flows with shear gradients of $300 \mathrm{dynes} / \mathrm{cm}^{2}-\mathrm{cm}$.

Takahashi, et al. (1997) studied the mechanisms that induce endothelial cell shear stress response and signaling. They studied various signaling responses of bovine aortic endothelial cells to induced shear including the production of nitric oxide, activation of extracellular-regulated kinases, and tyrosine phosphorylation of focal adhesion kinase. These signaling events in endothelial cells were described as a string of temporary and mechanically distinct events. However, they determined that a more extensive 
investigation is needed to compare these results with those induced by other stimuli besides mechanical forces, such as cytokines, growth factors, and hormones.

Traub, et al. (1998) examined data and reviewed investigations that involved stimulation of cellular responses via applied laminar shear stress that are crucial to endothelial cell function and atheroprotective. Coagulation, leukocyte adhesion, migration and proliferation, lipoproteins, endothelial cell survival and other characteristics of the endothelium were reviewed in correlation with past shear investigations. They determined that shear stress influences many of the processes relevant to the development of the atherosclerotic lesion. Additionally, they stated it is unlikely that fluid forces are the sole positive or negative atherogenic stimuli.

Gojova, et al. (2005) visually monitored the wound healing of bovine aortic endothelial cells cultured in parallel plate flow chambers subjected to shear levels of 3 to $19 \mathrm{dyne} / \mathrm{cm}^{2}$. Image analysis was used to quantify the cellular response. The presence of shear decreased the rate of cellular spreading and wound closure compared to static conditions. Additionally, the presence of exogenous cholesterol significantly slowed cell migration.

\section{Electrical Analysis of Endothelial Cells Under Applied Shear}

Seebach, et al. (2000) setup an impedance spectroscopy system to investigate TER under an applied shear using a cone-and-plate apparatus. The rotating cone produced levels of shear stress ranging from 0 to 200 dynes $/ \mathrm{cm}^{2}$. An impedance spectra was obtained in the frequency range of $10 \mathrm{~Hz}$ to $1 \mathrm{MHz}$. TER values were normalized with TER values collected at the onset of shear $(t=0)$. Confluent cultures of porcine 
pulmonary trunk endothelial cells showed a 15\% increase in TER within fifteen minutes of applied shear, which was followed by a reduction in TER that continued to decrease by $20 \%$ below the initial value. The TER reduction was accompanied by an acceleration in endothelial shape change (monitored visually) and TER levels began to recover as the rate of endothelial shape change decreased.

Research conducted by Phelps, et al. (2000) used two separate parallel plate flow chambers for the analysis of endothelial cells under applied flow. In each apparatus, a rectangular step was introduced to create a disturbance in the flow. The first integrated a porous membrane for dextran extraction at different areas downstream from the site of initial disturbance. The second used electrodes connected to an ECIS device for TER analysis. After 5 hours of flow, areas of high shear stress gradients showed a 5.5 -fold increase in transendothelial transport of dextran compared to a 2.9-fold increase in areas of undisturbed, fully developed flow. The TER values collected by ECIS were lowest in the vicinity of the highest shear stress gradients. They concluded these results demonstrate that endothelial permeability is regulated by spatial variation in shear stress, in vitro.

DePaola, et al. (2001) modified the ECIS and incorporated a parallel-flow apparatus to apply a shear force. This parallel plate flow system contained two channels with electrodes, one cultured with cells and the other no cells. Results in the cultured channel were normalized with data collected in the no cells chamber. Periods of uninterrupted flow were followed by time intervals of no-flow. TER values decreased on the onset of flow, started to recover after $15 \mathrm{~min}$ and after slightly overshooting its baseline values, decreased again with a prolonged exposure to flow. The observed 
changes were reversible and varied with the duration of the preceding flow exposure. The results demonstrated that the impedance changes dramatically with changing endothelial parameters.

\section{Comparison of Methodologies}

As shown, there are many methodologies to characterize the behavior of endothelial cells under applied shear force. The disadvantage with monitoring endothelial cell behavior chemically or by other substance extractions is that the results are not immediate and the behavior of the system cannot be tracked in "real-time". However, endothelial biochemical signaling behavior can be monitored. The impedance analysis methodologies are viable, but they too have disadvantages. The ECIS system takes into consideration an assumed disc-shape for a cell in its mathematical model. One of the characteristics of the endothelial cells under shear is their ability to change shape, and hence its permeability. The assumed shape of the cells under investigation would change under applied shear and the derived ECIS mathematical morphological model would be inaccurate. Additionally, the predefined frequency used in ECIS investigations was optimized for static analysis of cell motility and not to characterize the dynamic changes of the monolayer. In order to analyze a comprehensive mathematical model describing the endothelial layer, a frequency spectrum is needed.

The impedance analysis system described by Seebach, et al. (2001) applied shear via a plate-and-cone apparatus. Although it is a viable technique for applying shear to cultured endothelial cells, these systems to not represent the behavior of physiological fluid/endothelial cell interactions. Parallel-plate fluid flow systems are closer at 
representing physiological conditions, but it is limited in the assumption of uniform parallel plate flow. Existing parallel-plate flow systems that integrate ECIS for data collection are also limited, with the disadvantages being the same as with the analysis system described above. Therefore, electrical impedance analysis in characterizing the behavior of cultured endothelial cells is preferred. A microfluidic platform would present a more complex fluid profile, thus more closely representing anatomical fluid flow conditions. However, the impedance analysis of cultured endothelial cells on a fabricated microfluidic platform has yet to be investigated. 


\section{CHAPTER 3}

\section{INSTRUMENTATION AND MATERIALS}

A microfluidic platform was created for the purpose of impedance analysis of cultured monolayers. The device consisted of two components, a glass-electrode base for electrical measurements and a microfluidic substrate containing two channels. The fabricated electrode base contains the measuring electrodes of various sizes and a common, larger counter-electrode. The microchannels envelop these measuring electrodes while allowing the culturing of the cells. Before the design and procedures for the fabrication are explained, it is necessary to understand the use and purpose of equipment and materials.

\section{$\underline{\text { A. Facilities }}$}

All fabrication and bonding steps occurred at the University of Louisville's Lutz Microfabrication Laboratory. The 1500 square foot cleanroom facility is classified as class 100 and 1000. The glass-electrode substrates and SU-8 fabricated microchannel molds were created in the cleanroom environment. Device testing occurred on the University of Louisville's Health Sciences campus where there was access to endothelial cells, cell culture media and additional testing instruments. 


\section{B. Device Fabrication}

\section{Materials Used}

An ultra-flat low reflective chrome soda-lime glass substrate (Nanofilm, Westlake Village, CA) was used for the electrode substrate base. A thin layer of chrome separates the base glass layer and the photoresist surface. The soda-lime glass substrate (4"x4"x0.060") contained photoresist type AZ 1518 with a thickness of 5300A. The AZ 1518 photoresist is a positive resist, which means any part of the film exposed to UV light will be washed away in the developing solution. The baking step hardens the photoresist and prevents any contamination from additional solutes in the film.

The material chosen for the micro-milled microfluidic master mold base was Lexan $^{\circledR}$ polycarbonate. A second, microfabricated mold using a negative photoresist for high aspect ratio features was investigated as another possibility for a master mold. A microfabrication process using a viscous, negative photoresist called SU-8-50 (MicroChem, Newton, MA) was developed to create a mold for the PDMS microfluidic substrate. The concentration of solvent (EPON SU-8 resin) in the solution determines the viscosity, which controls the film thickness. Using SU-8-50 produced many microstructures with films of more than $500 \mu \mathrm{m}$ and aspect ratios of more than 50 (Zhang 2001). These characteristics are advantageous for its application in microfluidics and patterning with PDMS. The data sheet for SU-8-50 can be found in Appendix C.

SU-8 is a negative resist, meaning that areas of the photoresist film exposed to UV light will harden and remain after submersing it in developing solution. The 
developing solution for SU-8 is Baker BTS 220 (J. T. Baker, Phillipsburg, NJ). The time it takes to develop depends on the thickness of the applied SU-8.

Poly(dimethyl siloxane) (PDMS) was chosen as the material to be used for the microfluidic piece of the system. PDMS is also known as Sylgard 184 (Dow Corning, Midland, MI). PDMS is a low-cost material that has numerous, versatile microsystem applications. PDMS is used for rapid prototyping of microfabricated masters. Resulting molds are sealed directly to the substrate through irreversible and reversible techniques. The versatility of PDMS for microfluidic systems, cellular applications, and fabrication techniques led to its application for the microfluidic platform under investigation. Additionally, it is important to note that none of the previous electrical impedance studies have incorporated PDMS into their systems.

Nanoport assemblies (Upchurch Scientific, Oak Harbor, WA) were applied to the microfluidic platform. The components from Upchurch were made of an inert, biocompatible PEEK polymer and consisted of a nanoport reservoir assembly (part number N-131) that included a nanoport (1/4-28 FB), gasket, insert (10-32/1/4-28), and an adhesive ring (N-100). A mechanical clamp, supplied in this assembly, was used to apply the pressure required for successful bonding during adhesive curing. The curing process occurred simultaneously with the curing of the conductive epoxy (H31D, Epoxy Technology, Billerica, MA) applied to the substrate later. This adaptor (P-664) fit into the 10-32 end of the nanoport insert and had a barb on the other end to fit the Pharmed tubing used in experimentation. Teflon tape was applied to the threads of the reservoir and adaptor to ensure a leak-free seal. Each of the parts used from Upchurch is shown in Figure 2 . 

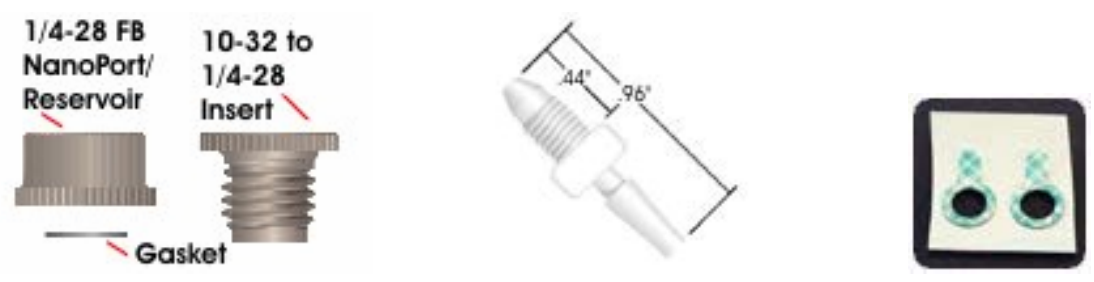

Figure 2. Port assembly, adaptor, and adhesive rings (Upchurch Scientific).

Copper wires were stripped and attached to the electrode bonding pads with H31D conductive epoxy (Epoxy Technology, Billerica, MA). This is a 100\% solids (no solvents) single component, electrically conductive silver epoxy designed for chip bonding. H31D is a soft, smooth, thixotropic paste with high conductivity $(<0.005 \mathrm{ohm}-$ $\mathrm{cm})$.

\section{Chemicals Used}

After exposure, the substrate was placed in a developing bath. For positive resist type AZ 1518, the developing solution was a bath of MF-319 (Rohm Haas, Malborough, MA). The UV-exposed electrode pattern was washed away leaving the chrome surface exposed. The remaining hardened photoresist covered the rest of the substrate.

Nichrome Etchant TFN (Transene Company, Inc., Danvers, MA) was used to dissolve exposed chrome layers from the soda-lime substrate, leaving the underlying layer of glass. The glass was etched with Buffered Oxide Etch (BOE, Honeywell/GEM3, Morristown, NJ). At room temperature and manual agitation, BOE etched the glass at a rate of approximately $100 \AA$ /s. Material Safety Data Sheets for these chemicals can be found in Appendix A. 


\section{$\underline{\text { 3. Instrumentation Used }}$}

Masks used for the fabrication processes were created in-house with a laser pattern generator (DW 66, Heidelberg Instruments, Torrance, CA) (Figure 3). The laser pattern generator is an extremely high-resolution imaging system where over half of a million dpi is achieved using a 40 nanometer writable access grid for exposing chrome plates or wafers. These masks were used to transfer patterns to the photoresist films after exposure to UV light.

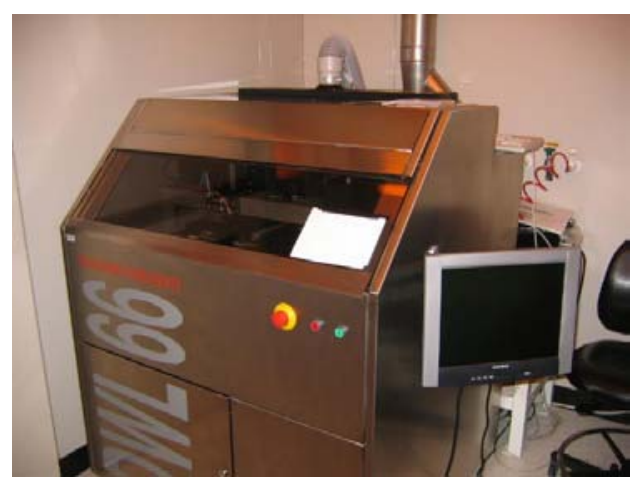

Figure 3. Heidelberg Laser Pattern Generator, DWL 66.

The patterned masks were exposed to UV light from a mask aligner (Mask Aligner, AB-Manufacturing Inc., San Jose, CA) (Figure 4) and transferred it to the photoresist film. This system was designed to produce improved patterning results due to its ability to precisely control the intensity of UV light. The user-defined intensity/time function was controlled by the system, which reports an accuracy of better than $\pm 2 \%$. 


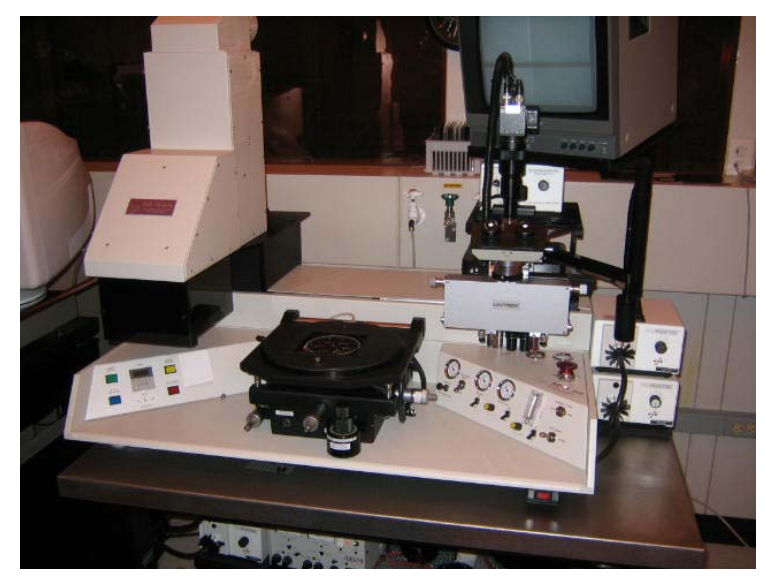

Figure 4. AB-M IR Mask Aligner.

Metal films for the electrodes were sputtered on the patterned layered-glass substrate using an RF/DC sputtering system (Series 4604, Technics Inc., Dublin, CA) (Figure 5). This device was used for the deposition of metallic materials onto the desired substrates. A high-voltage power supply was used to create a potential difference, causing the source material to be bombarded with ions from a plasma gas in the chamber (Argon). This bombardment releases molecules from the source into the chamber, depositing the material onto the substrate.

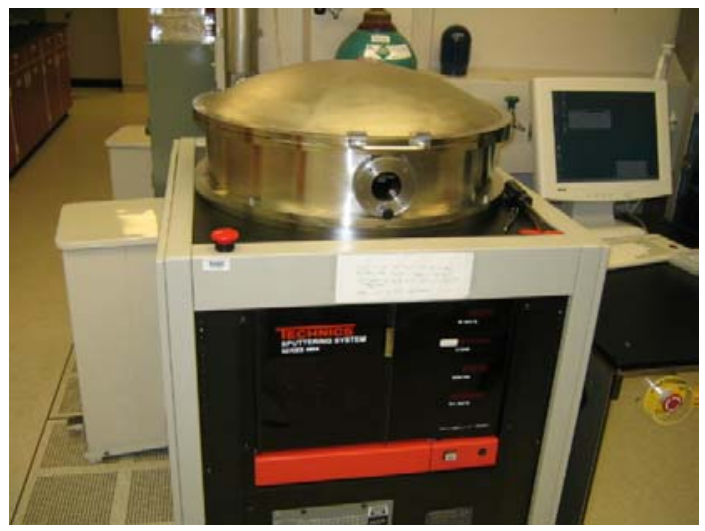

Figure 5. Technics Sputtering System Series 4604. 
The topography of the glass-electrode and, later, the microfluidic channel dimensions were tested using a profilometer (Veeco, Dektak 8, Woodbury, New York) (Figure 6). The system has a vertical resolution of $7.5 \AA$, 1 sigma step height repeatability and a vertical range up to $1 \mathrm{~mm}$. This profiler was fitted with a $12.5 \mu \mathrm{m}$ radius stylus and used to measure the height of the microfabricated electrodes.

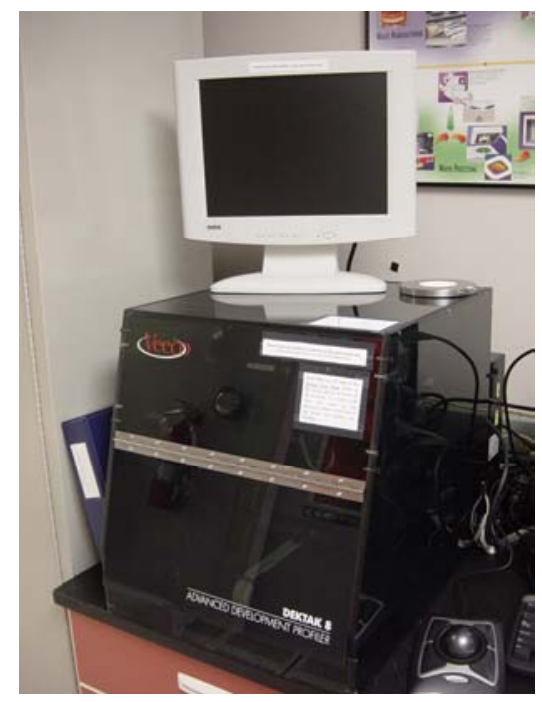

Figure 6. Veeco Dektak 8 Advanced Development Profiler.

A custom-made ultra-high-precision micro milling machine (Dover Instruments, Westboro, MA) (Figure 7) was used to create a master mold for fabricating the PDMS microfluidic substrates. The milling machine has three-axis resolutions of $1.25 \mathrm{~nm}, 1.25$ $\mathrm{nm}$, and $20 \mathrm{~nm}$ in the $\mathrm{X}-, \mathrm{Y}-$, and Z-directions, respectively. Micro-endmills and drills were made of micrograin tungsten carbide and can be as small as $10 \mu \mathrm{m}$ in diameter. Endmills of $1 \mathrm{~mm}$ and $330 \mu \mathrm{m}$ in diameter were used to fabricate the PDMS molds. 


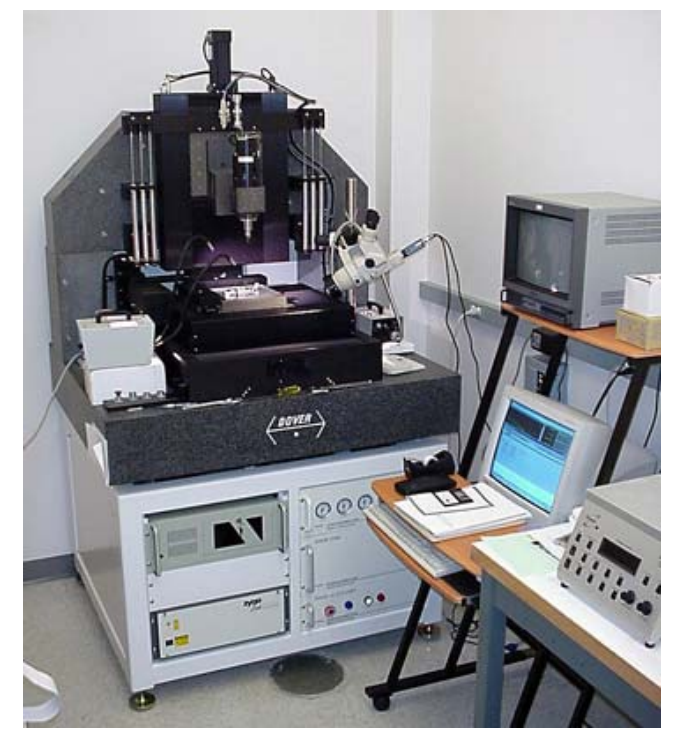

Figure 7. Ultra-High-Precision Micro Milling Machine.

Plasma exposure was achieved using the cleanroom's plasma asher/etcher (CS1701, March Inc., Concord, CA) (Figure 8). This device is typically used to strip resist or etch patterns in wafers after photolithography. Particles from the substrate are released when high energy ions bombard the surface in the vacuum chamber. It is equipped with a process controller and solid state RF power generator.

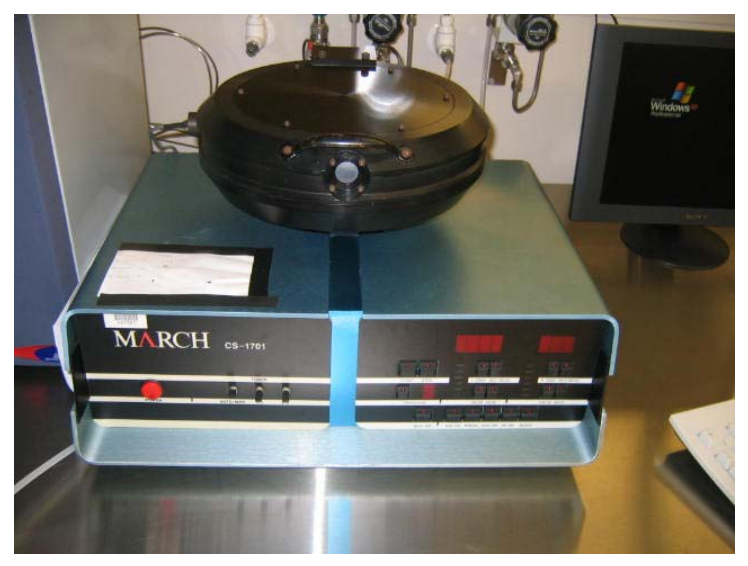

Figure 8. March RIE CS 1701. 
An ultrasonic cleaner (8892, Cole Palmer Instruments, Chicago, IL) was used for the degassing of SU-8 photoresist. This instrument is equipped with a heater, digital timer, temperature monitor, and degas feature. This cleaner transforms low-frequency AC current into $42 \mathrm{kHz}$ high-frequency sound waves via an electroacoustic transducer. A hot plate (Dataplate PMC 720 Series, Barnstead International, Dubuque, IA) was used for all fabrication baking steps and PDMS curing. This hotplate is a direct entry, programmable model. A microprocessor accurately controls and monitors the temperature. It has a digital display of all parameters as well as a digital count down timer with an "auto-off” control set.

\section{Cell Culture and Device Testing}

\section{Materials Used}

Frozen vials of "passage" 1 Human Umbilical Vein Endothelial Cells (HUVECs) were ordered from Cambrex (Pittsburg, PA) and arrived at "passage" 1. The "passage" of the HUVECs describes the number of times the cells were plated and grown on an artificial surface from the time they were harvested. The cells arrived frozen suspended in a solution of 90\% PBS (phosphate buffered saline) and 10\% DMSO (dimethyl sulfoxide). When thawed, these cells were plated and cultured with different media solutions. 
Pharmed tubing with an inner diameter of $2.79 \mathrm{~mm}$ was used for experimentation. When applied with the rotary pump (MCP, ISM 915, Ismatec, Wertheim-Mondfeld, Germany), it is capable of producing a flow rate range of $0.21-52 \mathrm{~mL} / \mathrm{min}$. This tubing was also used for the injection of fibronectin and cell suspensions into the PDMS microchannels.

\section{Chemicals Used}

Trypsin Neutralizing Solution (Cambrex, Pittsburg, PA) was used to detach the cells from their adhered surface. HEPES buffered saline $(\mathrm{pH}=7.4$, Clonetics, BioWhittaker, Inc., Walkersville, MD) was used as a washing/cleansing solution for the cells, to ensure no traces of the previous medium existed. Endothelial Growth Media-2, EGM-2 (Clonetics, BioWhittaker, Inc., Walkersville, MD) was used as the HUVEC culturing medium. In some tests, a solution of fibronectin (Sigma Aldrich, Inc., St. Louis, MO) was applied. Fibronectin, an extracellular matrix protein, was applied to increase the adhesion of the cultured cells onto the substrate. Each of these solutions were used in sterile environments for the purposes of cell culturing and testing.

\section{Instrumentation Used}

All cell growth activities were monitored with an inverted, fluorescent microscope (Diaphot Phase Contrast-2, Nikon, Kanagawa, Japan). Impedance measurements and cell growth in the microchannels occurred inside a custom-made environmental chamber (Figure 9). The glove box chamber was constructed out of Lexan and was outfitted with sensors, including a temperature controlled heater and $\mathrm{CO}_{2}$ 
infusion mechanism. The temperature controlled heater (Electro-tech Systems, Inc., Model $513 \mathrm{~A}$, Glenside, PA) kept the temperature near $37^{\circ} \mathrm{C}$. The custom-made $\mathrm{CO}_{2}$ controller was developed by the Bio-MEMS and Cardiovascular Research Group at the University of Louisville. The device consisted of a wall-mounted infrared $\mathrm{CO}_{2}$ sensor that produced an output voltage that corresponded to the $\mathrm{CO}_{2}$ concentration in the chamber. This voltage was converted and interpreted by the program in order to keep the $\mathrm{CO}_{2}$ level of the chamber constant at 5\%. A 9"x9" pan of water was placed in the chamber to maintain a constant relative humidity.

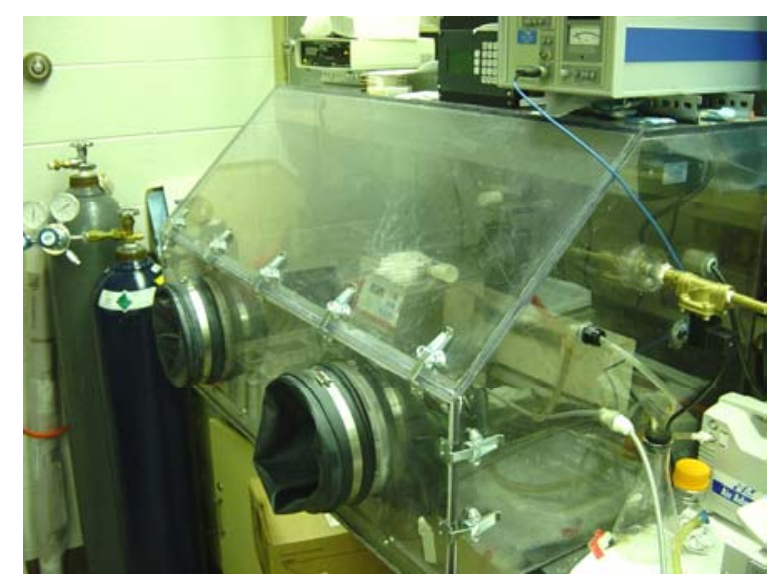

Figure 9. Environmental chamber for shear testing.

A rotary pump (MCP, ISM 915, Ismatec, Wertheim-Mondfeld, Germany) was used for the application of fluid flow through the system (Figure 10). It is capable of generating flow rates of 0.001-3700 $\mathrm{ml} / \mathrm{min}$ depending on the pump head mounted and tubing diameter used. This pump was equipped with a pump head (MS/CA4-12, ISM 735) capable of flow rates of $0.001-57 \mathrm{~mL} / \mathrm{min}$ depending upon the size of the applied tubing and the rotational speed (1.0-240.0rpm at a resolution of $0.1 \mathrm{rpm})$. With the Pharmed tubing described previously, flow rates of $0.21-52 \mathrm{~mL} / \mathrm{min}$ are possible. 


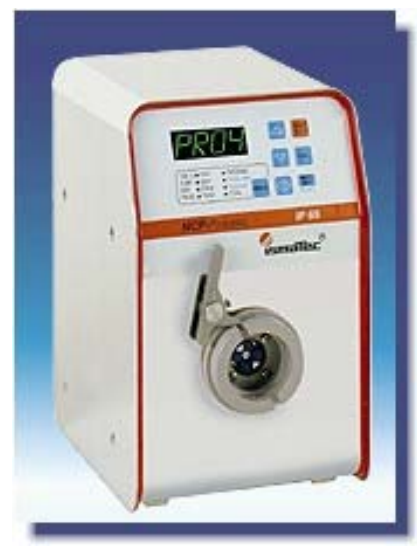

Figure 10. Ismatec rotary pump.

A high-precision impedance analyzer (Agilent 4294A) and impedance probe (Agilent 42941A) were used for data collection (Figure 11). The analyzer has a frequency range of $40 \mathrm{~Hz}$ to $100 \mathrm{MHz}$ with the ability to sweep linearly, logarithmically, or run through a list of given frequencies. The analyzer has an impedance range of $3 \mathrm{~m} \Omega$ to $500 \mathrm{M} \Omega$ and it is capable of oscillation levels between $5 \mathrm{mV}$ to $1 \mathrm{Vrms}$. The 42941A impedance probe enabled in-circuit impedance measurements of electrical components. This probe was used to analyze the measuring electrodes on the microfluidic platform.

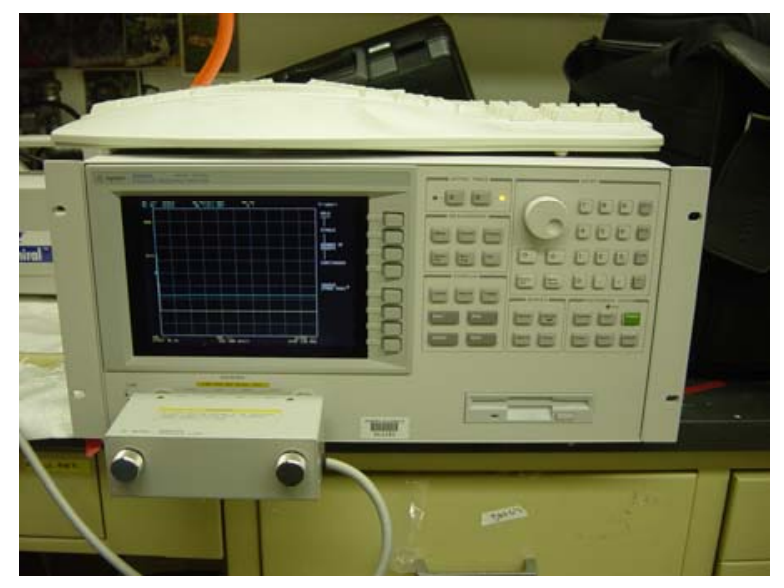

Figure 11. Agilent 4294A impedance analyzer. 


\section{Software}

The Premium Solver Platform (Frontline Systems, Incline Village, NV) expansion for the Excel Solver tool package was used to optimize the fit between the collected data and the mathematical model. It replaced the standard Solver and provided two and a half times the number of decision variables and constraints. The Premium Solver Platform performed better on difficult models, including those involving very large and very small values. It has improved solving conditions for nonlinear problems where the standard Solver stops due to slow improvement in the target cell. This program analyzed collected data on a personal laptop equipped with a $3.20 \mathrm{GHz}$ Pentium 4 processor and Windows XP Professional operating system. 


\section{CHAPTER 4}

\section{PROCEDURE}

\section{A. Device Fabrication}

\section{$\underline{1 . \text { Electrode Substrate Design }}$}

Two similar arrays of different sized square electrodes were used for impedance analysis of the endothelium (Figures $12 \& 13$ ). One set was for reference measurements in a microchannel with no cells and the second monitored the behavior of the cultured endothelial cell monolayer. Each array shared a larger, common grounded counter electrode. Five measuring electrodes of sizes $160 \mu \mathrm{m}, 80 \mu \mathrm{m}, 40 \mu \mathrm{m}, 20 \mu \mathrm{m}$, and $10 \mu \mathrm{m}$ square were implemented. With endothelial cells being approximately $10 \mu \mathrm{m}$ in diameter, these series of electrodes were large enough to determine the behavior of a group of cells within the monolayer and small enough for localized detection.

These square electrodes were arranged in a straight line, with decreasing size, spaced $2.5 \mathrm{~mm}$ apart. This set of five decreasing electrodes was repeated within the same channel, for two similar electrodes per channel for a total of ten measuring electrodes. This process was repeated for the second microchannel in parallel for a total of 20 measuring electrodes. Similar sized electrodes from each channel were adjacent to one another, divided by the counter electrode. The counter electrode straddled the two 
electrode arrays with a size of $400 \mu \mathrm{m}$ by $25 \mathrm{~mm}$. The center of each measuring microelectrode is $200 \mu \mathrm{m}$ from the edge of the counter electrode. A series of twenty-two $1.5 \mathrm{~mm}$-square bonding pads were connected to the electrodes by a series of wire traces. The larger wire trace from the bonding pads is $200 \mu \mathrm{m}$ wide. The trace sizes from the microelectrodes, going from the largest to the smallest, are $40 \mu \mathrm{m}, 20 \mu \mathrm{m}, 10 \mu \mathrm{m}, 10 \mu \mathrm{m}$, and $5 \mu \mathrm{m}$ respectively. The bonding pads are spaced $2.5 \mathrm{~mm}$ apart. The two sets of parallel bonding pads are spaced $51.4 \mathrm{~mm}$, leaving room for the PDMS microchannel substrate to be placed on top of the electrode substrate.

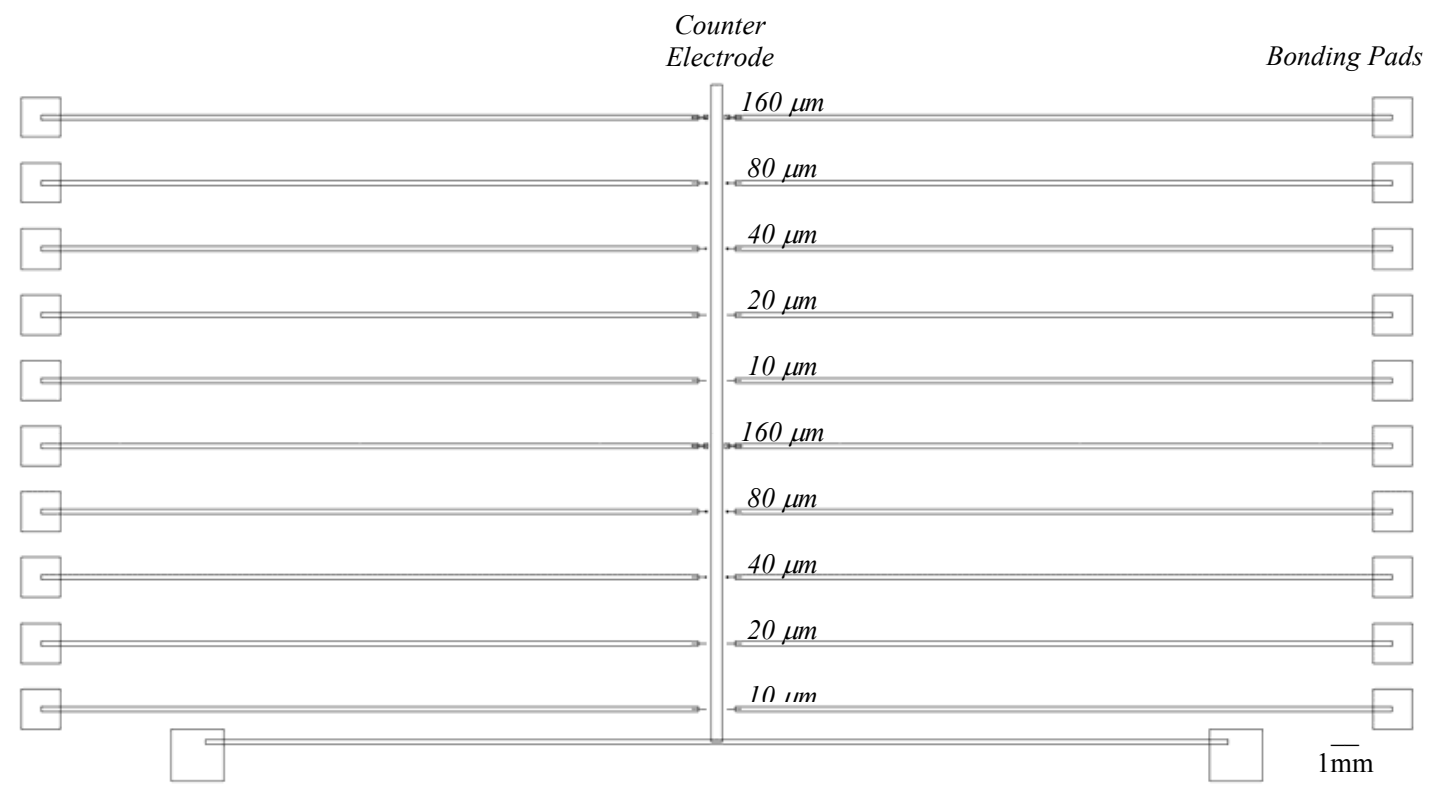

Figure 12. Electrode pattern of the substrate (not to scale). 

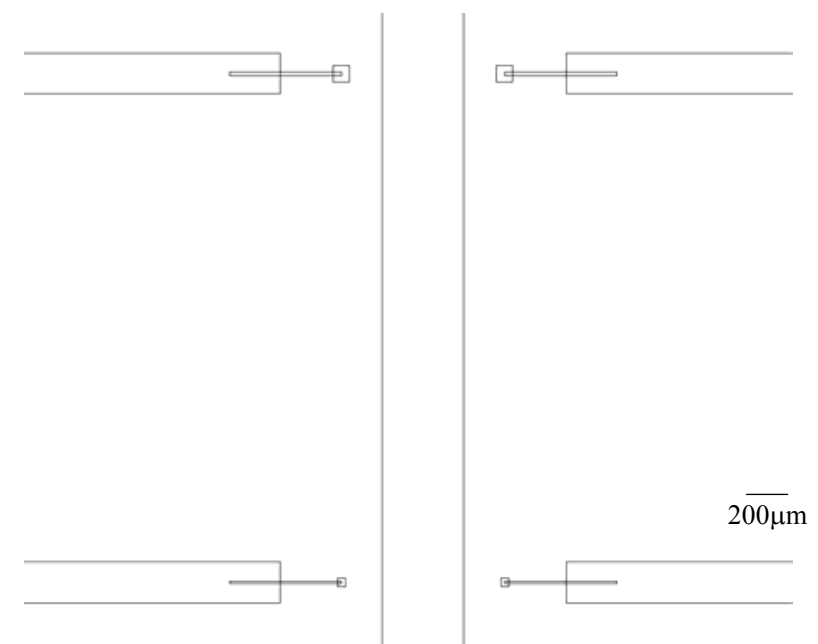

Figure 13. Electrode pattern of the 80 and $40 \mu \mathrm{m}$ square electrodes (not to scale).

\section{Electrode Substrate Fabrication}

A technique developed at the University of Louisville for the fabrication of capillary electrophoresis devices was utilized for the fabrication of the designed glasselectrode substrate (Baldwin 2002, Keynton 2004). Metal electrodes were recessed in a glass substrate using an existing chrome/photoresist layer as a masking layer. The resulting flat surface permits the resolution and integrity of the fabricated electrodes to be maintained.

The AutoCAD electrode design file was converted to a Caltech Intermediate Format (CIF) file and uploaded on the laser pattern generator. The pattern was transferred to a six-inch, square, low reflective chrome-glass photomask (Nanofilm) with the electrodes and traces being transparent and the chrome remaining on the rest of the mask (Figure 14). The laser pattern generator was equipped with a $40 \mathrm{~mm}$ head and the mask had G-line exposure at a rate of $150 \mathrm{~mJ} / \mathrm{cm}$. 


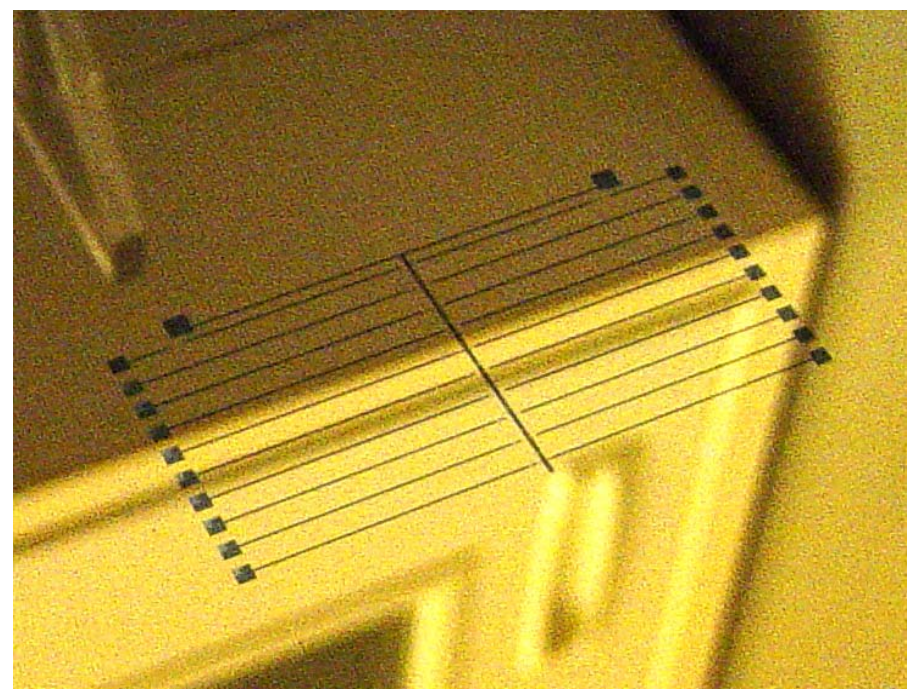

Figure 14. Electrode photomask.

An ultra-flat low reflective chrome soda-lime glass substrate (Nanofilm) was used for the base of the electrode substrate. The patterned electrode photomask was placed directly on the chrome/photoresist substrate. It was exposed to UV light for $1.7 \mathrm{~s}$ from the ABM IR Mask Aligner to transfer the pattern. After exposure, the substrate was developed in a bath of MF-319 (Rohm Haas, Malborough, MA) for one minute. The UV-exposed electrode pattern was washed away leaving the chrome surface exposed and the hardened photoresist covered the remainder of the substrate.

Next, a DI wash followed with drying by a nitrogen gun before it was submerged in Nichrome Etchant TFN for three minutes. The exposed patterned chrome layer was etched away, leaving exposed glass (Figure 15, a). The substrate was cleaned and dipped in a solution of BOE under mild, manual agitation for one minute. The exposed glass was etched at a rate of approximately $100 \AA / \mathrm{s}$. The resulting recessed pattern provided the space necessary for the subsequent step of the deposition of the near-flush metal electrodes (Figure 15, b). Titanium and platinum were sputtered onto the substrate using 
the Technics RF/DC Sputterer. After a ten-minute presputter at $300 \mathrm{~W}$, titanium was RF sputtered for 1.5 minutes at $300 \mathrm{~W}$. The substrate was plasma etched for $30 \mathrm{~s}$ before platinum DC sputtering for ten minutes at $120 \mathrm{~W}$. The resulting substrate was covered with the two layers of deposited metal (Figure 15, c).

After deposition, a "lift off" process was performed by placing the substrate in an acetone bath. The remaining photoresist layer dissolved when exposed to acetone, "lifting off" the metal deposited directly on the resist (Figure 15, d). Last, the substrate was placed in a Nichrome Etchant TFN to remove the final layer of chrome. The desired patterned electrodes resulted with the electrodes being nearly-flush with the flat soda lime glass base (Figure 15, e). 


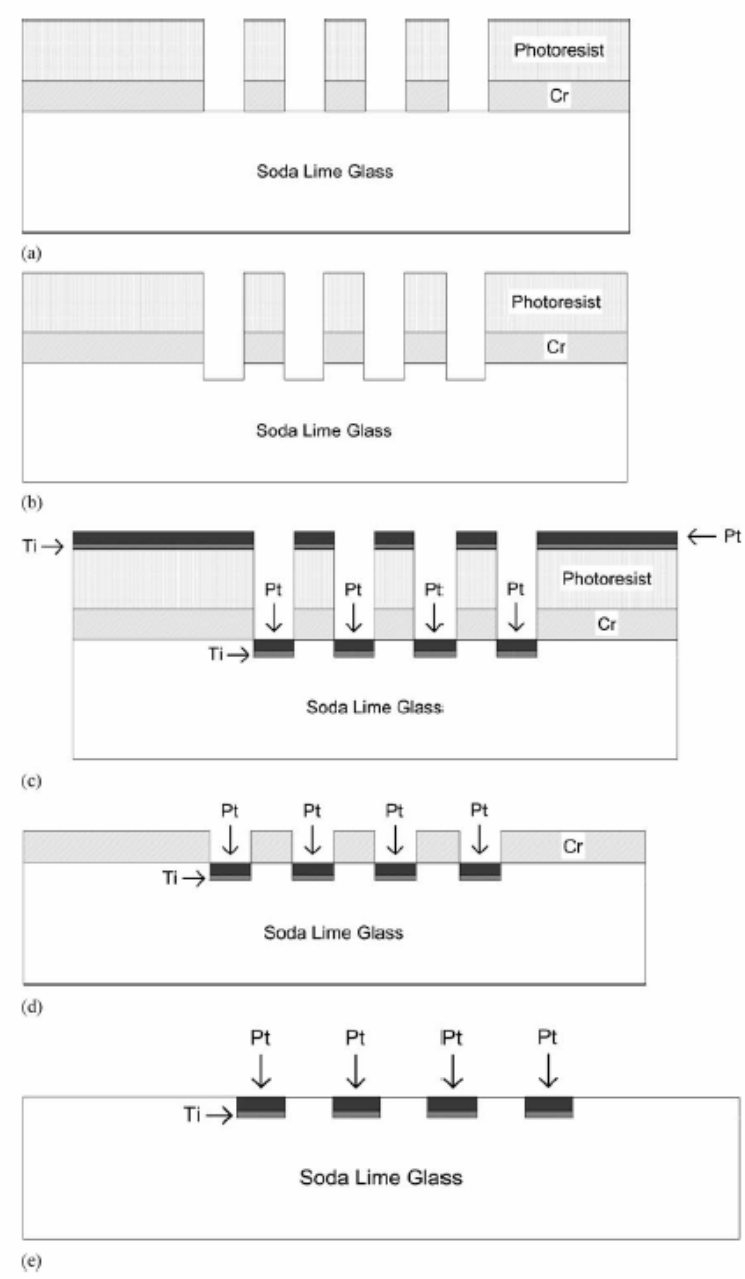

Figure 15. Summation of electrode fabrication (Keynton 2004).

\section{Microfluidic Substrate Design}

The PDMS substrate has two microchannels, which were designed to accommodate the dimensions of the platinum electrode arrays. These channels contained one array of ten microelectrodes and share a portion of the larger counter electrode. The microfluidic PDMS substrate was sized to allow for adherence by conformal contact to the base substrate, leaving sufficient surface area for the insertion of nanoports. An AutoCAD drawing showing the alignment of the PDMS substrate to the electrode base is shown below (Figure 16). 


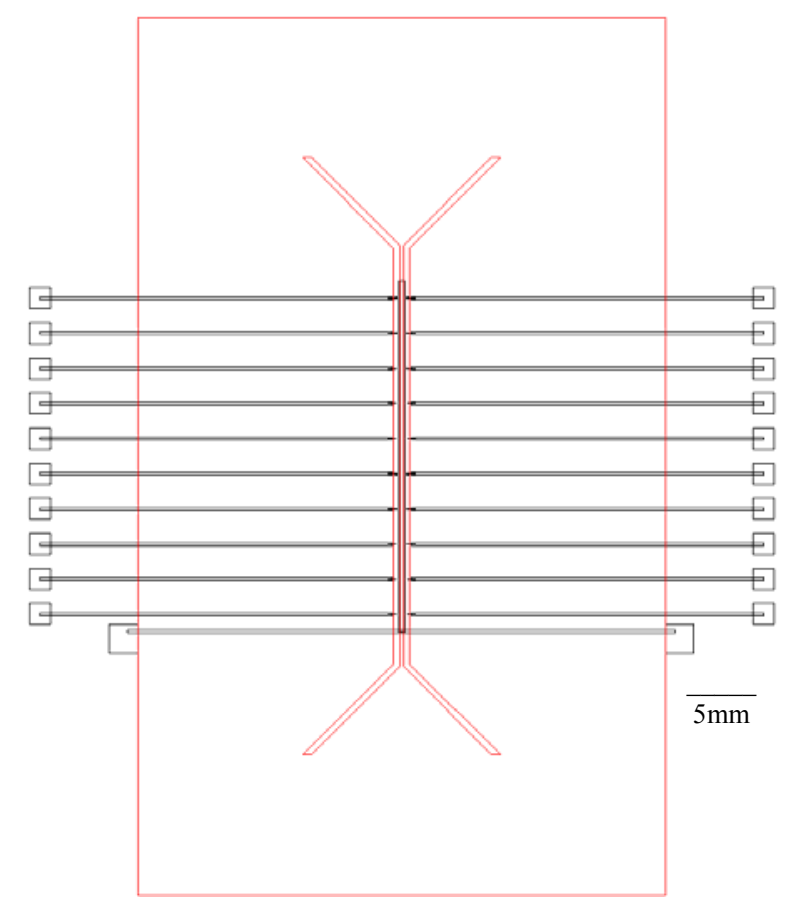

Figure 16. Superimposed drawings of microchannels and patterned electrodes.

The width of each channel is $450 \mu \mathrm{m}$ and is spaced $250 \mu \mathrm{m}$ apart from one another. The parallel channels run $30 \mathrm{~mm}$ before they veer $45^{\circ}$ towards the port insertion sites. Two methods of creating the molds for the microfluidic substrate were considered; one technique utilized micro-milling and the other used microfabrication techniques to create the relief features. The height of the microchannel structures depended on the type of fabrication method used for the mold. Micro-milling yielded better control over the height of the relief structures compared to photolithography.

\section{Microfluidic Substrate Fabrication}

a. Micro-Milled Mold. The Ultra-High-Precision Micro Milling Machine was used to create a mold constructed out of Lexan ${ }^{\circledR}$ for the PDMS microfluidic substrate 
(Figure 17). A solid model was developed in Solid Edge and later programmed into EdgeCAM. Two separate files in EdgeCAM were generated (printouts of these files can be found in Appendix B). The first program file was designed to use $1 \mathrm{~mm}$ diameter, 4flute micro-grain tungsten carbide endmill for bulk machining of the substrate, which operated at a spin rate of $4000 \mathrm{rpm}$. The second program file was designed to machine with a $330 \mu \mathrm{m}(0.013$ ") 2-flute micro-grain tungsten carbide endmill that operated at a spin rate of $6000 \mathrm{rpm}$. The smaller endmill was used to "finish" the mold in order to produce more well-defined edges on the microchannel relief structure. The depth of the mold was 0.25 " with the microchannel features contained within a 1.5 " x 2.5 " rectangular perimeter.

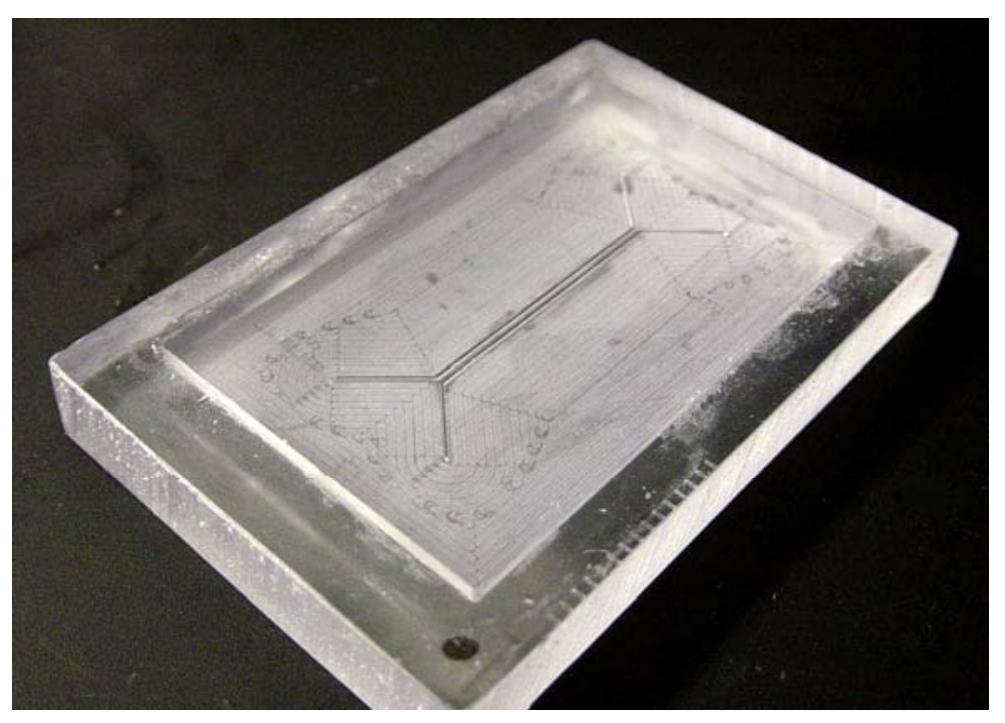

Figure 17. The micro-milled Lexan ${ }^{\circledR}$ mold for the PDMS microfluidic piece.

b. SU-8 Fabricated Mold. A second mold for the PDMS microfluidic substrate was created using traditional microfabrication methods. The pattern for the microchannels were designed in AutoCAD, converted to CIF, and uploaded into the laser 
pattern generator (Figure 18). The settings and procedure for the laser pattern generator were the same as in the creation of the electrode-pattern photomask. The photomask was created with the microfluidic features being transparent to allow for exposure of the negative photoresist (SU-8-50) to the UV light from the mask aligner. Prior to the application of the SU-8, a small quantity of refrigerated SU-8-50 was poured into a small bottle and degassed by placing the bottle in an ultrasonic cleaner (Cole Palmer 8892) for $30 \mathrm{~min}$. This transfer process was performed in order to minimize bubble formation in the SU-8 during the application step.

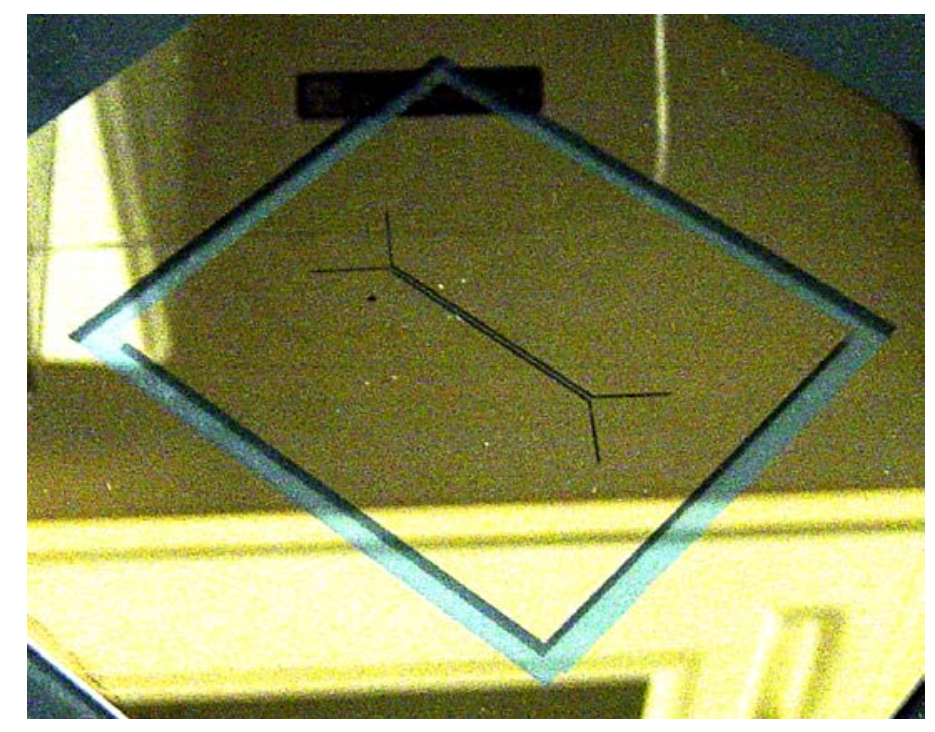

Figure 18. Photomask used for SU-8 microfabricated mold.

Prior to SU-8 application onto the silicon wafer, an adhesion promoter solution was prepared by combining $95 \mathrm{~mL}$ of methanol, $5 \mathrm{~mL}$ of DI water, and $1 \mathrm{~mL}$ of adhesion promoter VM-651 (HD MicroSystems, Wilmington, DE). The wafers used in this study were single-side polished, $\mathrm{n}$-type $<100>$, silicon $(\mathrm{d}=100 \mathrm{~mm}, \mathrm{t} \approx 525 \mu \mathrm{m})$. The 
adhesion promoter was applied to the polished side of the wafer and spun at $3000 \mathrm{rpm}$ for $20 \mathrm{~s}$, followed by the application of SU-8-50. It is important to note that the thickness of the resulting SU-8 film was determined by the amount of resist poured, the spin speed, and the duration of the rotation. For each fabricated mold, SU-8 was carefully poured onto the center of the wafer until the solution covered one-third of the surface. Due to its high viscosity, it was difficult to accurately control the amount of applied photoresist through direct pouring.

For the first trial, the SU-8 coated wafer was spun-on at $500 \mathrm{rpm}$ for $30 \mathrm{~s}$ followed by a soft bake at $95^{\circ} \mathrm{C}$ for $45 \mathrm{~min}$ on a hotplate. Due to the SU-8 thickness, a large glass beaker covered the sample on the hotplate to contain the heat. The wafer was then aligned to the photomask and exposed to UV light for $100 \mathrm{~s}$ in the ABM mask aligner. The photomask was utilized in the proximity mode rather than contact mode since the photoresist film was not in a solid state after soft-baking.

After exposure, the wafer was post baked at $95^{\circ} \mathrm{C}$ for $45 \mathrm{~min}$ on a covered hotplate and allowed to cool overnight. The next day, the SU-8 was developed in fresh Baker BTS 220 (J. T. Baker, Phillipsburg, NJ) for 45 min followed by a $30 \mathrm{~s}$ rinse in Isopropanol. The wafer was washed with DI water and blow dried with a nitrogen gun. The fabricated mold was characterized with the Dektak 8 Profilometer to determine the dimensions of the relief structures at different locations on the wafer. This process was repeated three times with other fabricated, silicon wafers at different spin rates and bake times (Table 1). Unfortunately, each of these wafers produced uneven relief structures and the fabrication process had to be reconsidered. 


\begin{tabular}{|c|c|c|c|}
\hline Trial & Spin Rate & Soft Bake & Hard Bake \\
\hline \hline 1 & $500 \mathrm{rpm}$ for $30 \mathrm{~s}$ & $95 \mathrm{C}$ for $15 \mathrm{~min}$ & $95 \mathrm{C}$ for $45 \mathrm{~min}$ \\
\hline 2 & $500 \mathrm{rpm}$ for $30 \mathrm{~s}$ & $95 \mathrm{C}$ for $50 \mathrm{~min}$ & $95 \mathrm{C}$ for $60 \mathrm{~min}$ \\
\hline 3 & $300 \mathrm{rpm}$ for $60 \mathrm{~s}$ & $95 \mathrm{C}$ for $45 \mathrm{~min}$ & $95 \mathrm{C}$ for $15 \mathrm{~min}$ \\
\hline 4 & $400 \mathrm{rpm}$ for $50 \mathrm{~s}$ & $95 \mathrm{C}$ for $45 \mathrm{~min}$ & $95 \mathrm{C}$ for $15 \mathrm{~min}$ \\
\hline
\end{tabular}

Table 1. Trials for SU-8 fabricated molds.

The absence of precise leveling tools required a new approach to the fabrication process. The alternative approach selected, omitted the use of the hot plates completely, thereby eliminating the pre-exposure or post-exposure bakes on the uneven surfaces. Since the baking steps were primarily used to decrease the amount of foreign solvents in the resist and to improve adhesion of the resist to the wafer, these steps could be eliminated without adversely affecting the final product. Two wafers were fabricated using the non-baking process and a SU-8 spin rate of $500 \mathrm{rpm}$ for $60 \mathrm{~s}$, UV exposure time of $100 \mathrm{~s}$, and developed in Baker BTS 220 for 45 min. Each wafer was profiled with the Dektak 8. The relief structures on these devices were profiled with the Dektak 8 and found to be more uniform than those fabricated previously.

After the wafer was developed, a layer of chrome and gold were sputtered on the substrate. This metallization layer was necessary because, through trial-and-error, it was discovered that a film of cured PDMS on the bare, patterned silicon wafer could not be easily removed and adhered to parts of the wafer. The chrome and gold were RF and DC sputtered at rates of $300 \mathrm{~W}$ for $1.5 \mathrm{~min}$ and $120 \mathrm{~W}$ for $4 \mathrm{~min}$, respectively. With this addition of the gold surfaces, cured PDMS films were easily removed. 
A retaining barrier for the PDMS was necessary to produce semi-consistent thicknesses for the PDMS microfluidic substrates. Many materials were tried, but the best border material was PDMS itself. A thick layer of PDMS was applied to the finished wafer and the microfluidic substrate was cut with a razor and removed by hand. The remaining PDMS served as a border for future poured molds (Figure 19).

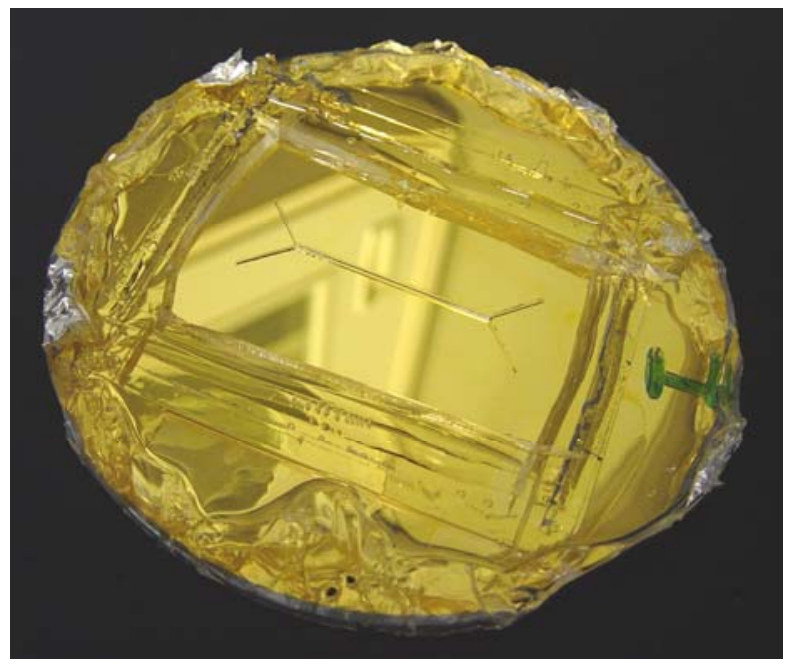

Figure 19. Final SU-8 microfabricated mold.

\section{Topography Measurements}

The topography of the fabricated substrates was measured using the Dektak 8 Profilometer. Profiling was necessary to determine whether the patterned electrodes were flush to the glass surface. A near-flush surface would provide a flat base for culturing the endothelial cells and maintain electrode integrity for impedance measurements. Additionally, the laminar profile of the fluid flow would not become disturbed, so a consistent applied shear could be maintained throughout the microchannel. The sample was loaded in the Dektak 8 with settings of a $12.5 \mu \mathrm{m}$ radius stylus, force of $5 \mathrm{mg}$, and 
measuring resolution of $65 \mathrm{kA}$. Various electrodes, traces, and points along the counter electrode were profiled.

\section{$\underline{\text { 6. PDMS Bonding }}$}

PDMS was formed by combining ten parts of the viscous, liquid silicone rubber base and one part of the curing agent. Once mixed, poured, and degassed it was heated to an elevated temperature of $65^{\circ} \mathrm{C}$ for four hours. During solidification, the elastomer was cross-linked via the hydrosilylation reaction between the vinyl $\left(\mathrm{SiCH}=\mathrm{CH}_{2}\right)$ groups and hydrosilane ( $\mathrm{SiH}$ ) groups (Xia 1998). A data sheet for Sylgard 184 can be found in Appendix C.

PDMS has a few advantages over other polymers. Its surface can be oxidized for electro-osmotic flow applications $(\mathrm{Ng} 2002)$ and other methods are used to control its surface chemistry after oxidation (Duffy 1999). In a report published by Xia, et al. (1998) PDMS has good chemical stability, does not swell with humidity, is gas permeable, and is thermally stable up to $186^{\circ} \mathrm{C}$. In addition, it is optically transparent up to $300 \mathrm{~nm}$, it is isotropic, homogeneous, durable, and has the ability to bend. Disadvantages of PDMS include 1\% shrinkage upon curing, its softness limits aspect ratio structures in design considerations, and it is subject to thermal expansion.

Once peeled from the molds, the PDMS microfluidic substrates were visually aligned and bonded to the glass-electrode substrate. Initial bonding protocol consisted of relying on conformal contact between the two, clean surfaces. However, leaking occurred, so an alternative approach was investigated. The alternative approach 
consisted of exposing the two surfaces to oxygen plasma then meshing the two substrates together to form an irreversible bond.

The technique to irreversibly bond PDMS to glass, gold films, and other PDMS surfaces has been used in microfluidic applications for the past decade (Ma 1999, Owen 1994, Xia 1998). This bonding process occurs at a much lower temperature than glass fusion bonding, which is a major advantage. Both surfaces of interest were exposed to oxygen plasma which oxidizes the surfaces, creating dangling bonds that allow PDMS to covalently bond to the glass (Owen 1994). This produced a strong, irreversible bond between the PDMS substrate and the glass substrate.

Reversible bonding between the PDMS samples and the glass-electrode substrate was easily achieved with the conformal approach. As the surfaces were peeled and reapplied, the PDMS pieces would collect particles and residue which were difficult to remove from the microfluidic substrate. As the surfaces became more contaminated with particles or residue, the bond between PDMS and the glass surfaces became weaker. Additionally, the smooth surface of the PDMS microfluidic substrate obtained from the SU-8 mold exhibited better adhesion than the micro-milled Lexan ${ }^{\circledR}$ mold since the micromilling procedure yielded a rougher surface.

PDMS substrates casted via the micro-milled and SU-8 molds and glass microscope slides were cleaned with ethanol then dried with a nitrogen gun. No DI water was used since the presence of water would inhibit the bonding process. The PDMS and glass were placed in the March RIE with the bonding surfaces faced upwards. The oxygen was set at 200 mTorr and the testing power and time settings varied from 1-300 s and 10-150 W, respectively. The variation of exposure was necessary since reports of 
irreversible bonding with PDMS varied over that range (Chiu 2000, Duffy 1998, 1999, Kenis 1999, 2000, Khademhosseini 2004, Ma 1999, Ng 2002, Owen 1994, Rhee 2005, Schueller 1998, Sundararajan 2004, Takayama 1999, 2000, Xia 1998). Utilizing this technique, an irreversible, tight seal was obtained.

\section{Inlet and Outlet Ports}

The next step was to create an interface to attach the inlet and outlet tubing. Multiple techniques to accomplish this were considered for this device. First, holes were punched through the PDMS microfluidic substrate with different sized punchers $(1 / 4,3 / 8$, and 1/2-inch diameters). The punched PDMS substrate was visually aligned and bonded with the glass-electrode substrate. Tubing of respective outer diameters was inserted into the PDMS punched holes. The exerted force on the PDMS holes from inserting the tubing caused the PDMS to deform and lift around the ports. Additionally, the movement of the attached tubing itself caused the microfluidic substrate to mechanically bend.

A second approach was explored where a hole-punched PDMS microfluidic substrate was sandwiched between the glass-electrode substrate and a separate piece of glass to prevent bending of the PDMS substrate. Four holes were drilled in the nonelectrode piece of glass for the application of adhered nanoports. A water-lubricated drilling process was performed using a standard drill press operated at 3100rpm and fitted with a $5 \mathrm{~mm}$ diameter diamond-tipped drill bit. The holes were drilled slowly to prevent cracking and a piece of scrap glass was affixed underneath the sample to prevent additional chipping as the drill bit completely bored through the hole. These samples were placed in an ultrasonic cleaner with DI water and cleaning solution to remove 
particles from its surface. Since the top surface of the PDMS was not exposed to oxygen plasma, an irreversible bond between the non-electrode piece of glass and the PDMS substrate was not achieved, and thus, leaking occurred.

The reversibly bonded PDMS microfluidic substrate proved to be sensitive to direct port adherence, thus, an alternative technique was developed to gain fluid access. First, the patterned glass-electrode substrate was drilled (using the same protocol as above) at the desired location for the nanoports. The nanoports, which provide tubing access to the inlet and outlets of the microchannels, were mounted on the bottom surface (non-electrode surface) of the electrode glass substrate to apply fluid flow from underneath the device. The advantage of this technique is that the forces exhibited by the tubing/nanoports were absorbed in the rigid glass base. Second, the PDMS microfluidic substrates were easily replaced and the electrode surfaces were cleaned without having to replace the tubing or ports.

The nanoport reservoir assembly and substrate were cleaned with Isopropanol and dried with nitrogen to aid in adhesion. The gasket was inserted into the nanoport with the adhesive ring applied to the bottom of the nanoport. The nanoport was visually aligned with the machined hole then pressed against the glass-electrode substrate. This procedure was repeated for a total of four port assemblies. Adhesive curing was accomplished simultaneously with the curing of the conductive epoxy, which will be described below. After curing, Teflon tape was applied to the threads and the nanoport insert was screwed into the port. Similarly, the adaptor was trimmed to fit into the device and was inserted into the nanoport assembly until hand-tight. 
Leak tests were performed manually with a plastic syringe. Additional leak testing with the SU-8 molded PDMS microfluidic substrate was performed using the rotary pump equipped with a pump head and Pharmed tubing capable of delivering flow rates of $0.21-52 \mathrm{~mL} / \mathrm{min}$. After the PDMS microfluidic substrate was aligned and bonded to the glass-electrode substrate, Pharmed tubing was connected to one of the ports. Fluid was injected until leaking or PDMS separation was noticed visually. DI water was the medium used for these initial leak tests. There was no need to color the injected water as fluid flow through the PDMS was easily visualized through the semi-transparent material.

\section{Wiring}

Copper wires about $3 / 4$ " long were stripped using a wire stripping tool and attached to the twenty-two electrode bonding pads with H31D conductive epoxy (Epoxy Technology, Billerica, MA). One end of the wire was manually dipped in the epoxy medium and carefully placed on the bonding pads. This wiring process was repeated for the remaining 21 bonding pads. The substrate was placed in an oven at $150^{\circ} \mathrm{C}$ for $30 \mathrm{~min}$ to cure the epoxy. The adhesive rings on the base of the nanoport assembly, which were clamped during heating, also simultaneously cured with the epoxy. After curing, the remaining port assembly was constructed. 


\section{B. Cell Culture}

\section{Preparations of Cell Suspensions}

All procedures describing the passaging and injection of cells were performed in a sterile environment under a laminar flow hood to prevent cells from exposure to contaminants. All fluids were first heated to $37^{\circ} \mathrm{C}$ in a hot water bath. Microfluidic devices, tubing, and reservoir systems were sterilized by ethylene oxide gas at the University of Louisville Research Resource Center.

The cryogenically frozen vials of Human Umbilical Vein Endothelial Cells (HUVECs) were thawed at room temperature. Subsequently, the cells were suspended in $1 \mathrm{~mL}$ of media (90\% PBS, $10 \%$ DMSO), extracted with a micropipette then inserted into a sterile centrifuge tube. Trypsin Neutralizing Solution $(1 \mathrm{~mL})$ was used to wash out the original vial to retrieve any remaining HUVECs and added to the centrifuge tube medium. An additional $0.5 \mathrm{~mL}$ of Trypsin was added to equal the $2.5 \mathrm{~mL}$ countersolution used to balance the centrifuge during the $3 \mathrm{~min}, 3000 \mathrm{rpm}$ spinning process.

Cells accumulated in the form of a pellet at the base of the tube. When the bulk of the medium was aspirated by means of a vacuum line, a pellet of concentrated cells remained. Endothelial Growth Media-2 (EGM-2) was introduced to the centrifuge tube and aspirated similarly to ensure removal of the old medium. Growth media $(1 \mathrm{~mL})$ was added to the centrifuge tube by a micropipette. Repeated injection and suction was applied to the tube to break up the cell pellet. This cell-suspended solution was added to a T-75 flask with additional EGM-2 for a total of $10 \mathrm{~mL}$ of growth media. The mixture was placed in the incubator at a temperature of $37^{\circ} \mathrm{C}$ and $5 \% \mathrm{CO}_{2}$. 
The endothelial cells in the T-75 flask were grown to approximately $80 \%$ confluency. Confluency characterizes the percentage of monolayer coverage of the endothelial cells. Upon achieving this level of confluency, the cell medium in the T-75 flask was aspirated. The cells were washed with $\sim 5 \mathrm{~mL}$ of HEPES buffered saline then the solution was aspirated. Trypsin $(2.5 \mathrm{~mL})$ was added to the T-75 flask and placed in the incubator for approximately one minute. The T-75 flask was taken out of the incubator and the cell suspended medium was collected and placed in a centrifuge tube. The previously mentioned centrifuge and plating processes were used to divide the larger pellet of cells three separate T-75 flasks. These samples were grown to $80-90 \%$ confluency and similarly plated on Petri dishes for testing or placed in vials to be cryogenically frozen. Through this economical growth and division process, the cells have reached passage 3 or 4 .

\section{Cell Culturing in Microchannels}

A number of procedures were attempted to inject and culture the cells inside the microfluidic channels. Before the passaging and injection of the HUVECs, the microchannels were coated with fibronectin to provide an extracellular matrix for the cells to attach and grow. Fibronectin was manually injected with a sterile, one-time use, syringe. The syringe and nanoports were connected with Pharmed tubing that was manufactured to fit the rotary pump. Every three to four minutes, for a total of twenty minutes, the medium was circulated via manual injection. After this period, air was injected into the microchannels and the device was set aside during cell preparation. 
The endothelial cells cultured on the Petri dishes were removed and centrifuged in the process described above. During this process, a separate Petri dish containing $10 \mathrm{~mL}$ of growth medium was placed in the incubator to acclimate the solution to the proper $\mathrm{CO}_{2}$ level and temperature $\left(37^{\circ} \mathrm{C}\right)$. This medium was then used to break up the concentrated pellet and created a cell-suspended solution that was later injected in the microchannels. The fibronectin coating and cell suspension processes defined above were the only two common procedures executed for culturing the cells inside the microchannels. The cell growth process was monitored visually with an inverted, fluorescent microscope for both the Petri dish and microchannel cell cultures. Upon inspection of the plated Petri dishes, HUVEC cell adherence appeared to occur in the first 1.5 to 2 hours after injection.

Initially, cell culturing inside the channels were performed using a closed system between the microfluidic platform and Pharmed tubing. Detachment and reattachment of Pharmed tubing to components of the system lead to trapping of air bubbles, which resulted in detachment of the cells as the bubbles passed through the channels. To prevent air trapping, clamps were applied to the inlet and outlet Pharmed tubing ports. However, inspection at 2 hours revealed no signs of cell adherence. After these attempts to culture cells inside the channels failed, it was decided to develop an alternative procedure to ensure cell attachment.

First, static cell culturing techniques were implemented by placing suspended HUVEC cells directly on the sterilized glass-electrode substrate. The culture dish containing the glass-electrode substrate was filled with growth medium, placed in an incubation chamber and monitored for attachment and growth. After 1.5 hours 
incubating the cell culture dish was covered with a sterile Petri dish lid and visually inspected. The cells showed signs of spreading, which verified that the HUVEC cells were capable of growing on the glass-electrode substrate.

Next, films of either PDMS, Lexan ${ }^{\circledR}$ or Teflon were used in conjunction with the substrate to determine if a reaction between the PDMS substrate and cell culture medium and/or cells was occurring, which may inhibit cell growth. These materials were placed on top of the measuring electrodes and a solution of growth medium with suspended cells was injected on their surface. Openings were created on these films to expose the underlying measuring and counter electrodes to the suspended cells. The PDMS films (less than $3 \mathrm{~mm}$ thick) were cured and small slits were cut with a razor or holes were punched for the electrodes. A $1 \mathrm{~mm}$ thick slide of $\operatorname{Lexan}^{\circledR}$ was machined with a $1.5 \mathrm{~mm}$ wide slit milled the length of the electrode arrays. The Lexan ${ }^{\circledR}$ slide was mechanically clamped to the glass surface, but leaking occurred during cell suspension so this material was abandoned from further testing. Finally, two strips of Teflon tape were visually aligned and pressed onto the substrate. A suspension of cells was applied to the PDMS and Teflon and, upon successful cell adhesion, impedance readings were taken and recorded.

This culturing technique was applied to culture cells inside the PDMS microfluidic channels. First, Teflon tape was aligned on the glass-electrode substrate to completely cover one set of electrodes as these were later used as referenced measurements. Next, another piece of Teflon tape was placed parallel to the first piece, leaving a small slit in between exposing the measuring electrodes. A suspension of cells was applied and left to adhere for $8 \mathrm{hrs}$. The medium was aspirated and the Teflon tape 
was removed, leaving a narrow strip of cultured cells on the measuring electrodes. A sterile PDMS substrate was visually aligned and bonded to the glass-electrode base. EGM-2 growth medium was immediately injected in both channels. The device was transferred to the environmental chamber and impedance readings were recorded.

\section{Impedance Analysis}

\section{Impedance Analyzer Settings}

The input signal for the impedance analyzer was set at $10 \mathrm{mV}$ peak-to-peak amplitude for a 100-point logarithmic frequency sweep of $40 \mathrm{~Hz}$ to $1 \mathrm{MHz}$. A bandwidth setting of " 3 " was selected from a scale of 1 to 5. Lower bandwidth settings decreased collection time at the expense of data precision. The different sized electrodes were manually probed and the impedance spectrum (impedance versus frequency) was collected from each electrode. Immediately following data collection, a spectrum was obtained from the adjacent channel containing the similar sized electrode. All of the saved trials were transferred to a 3.5" floppy disk in ASCII format. Data files were transferred to a laptop and analyzed within Excel.

\section{Impedance Analysis Tests}

Three different types of analyses were performed to determine the functionality and viability of the platform. First, the PDMS microfluidic substrate was aligned and injected with HUVEC cell growth medium, EGM-2. Measurements were taken and 
recorded to compare the impedance spectrums and possible relationships between electrode sizes in each of the three fabricated devices. Additionally, one channel of the sterilized devices was injected with fibronectin in the same procedure explained previously for cell culturing. Next, EGM-2 medium was injected into the channels, being careful not to leave bubbles suspended in the microchannels. An impedance spectrum for each electrode was obtained and analyzed. Electrical analysis was also conducted for the cells cultured inside the PDMS microchannels mentioned above.

Additional experiments were conducted to determine the viability of the devices. The counter electrode should not contribute to the obtained impedance spectra. To test this, the impedance across the two largest electrodes (80x80 and 160x160) within the same channel was obtained. These results were compared to the sum of the impedances of the same electrodes collected across the counter electrode. Tests were also conducted to determine if the dielectric properties of the measuring electrode, or other electrical characteristics of the system, changed over time. In all cases, the impedance spectrums fit the mathematical model discussed previously (Figure 1).

Similar tests were conducted under flow conditions. Three microfluidic devices were tested under rotary pump settings of $1.0 \mathrm{rpm}, 5.0 \mathrm{rpm}$, and $10.0 \mathrm{rpm}$, equivalent to flow rates of $0.21 \mathrm{~mL} / \mathrm{min}, 1.05 \mathrm{~mL} / \mathrm{min}$, and $2.10 \mathrm{~mL} / \mathrm{min}$, respectively. Impedance spectra for static conditions ( $0 \mathrm{rpm})$ were also collected. Previous to impedance measurements under fluid flow, one microchannel was coated with fibronectin as described in the procedure for cell culturing via injection. The microfluidic platform was placed in the incubation chamber with the rotary pump and a custom-made reservoir assembly. The reservoirs were constructed out of Lexan ${ }^{\circledR}$ and were cylindrical in shape 
with a diameter of $31.75 \mathrm{~mm}$. Four pieces of Pharmed tubing were injected with the gasexchanged EGM-2 medium and an additional $20 \mathrm{~mL}$ of medium were added to two reservoirs. The solution-filled tubes were attached to the inlet and outlet connectors to the reservoir and microfluidic device. The Pharmed tubing was arranged on the rotary pump and, at different flow rates, impedance spectra were collected. A schematic of the testing environment is show in Figure 20.

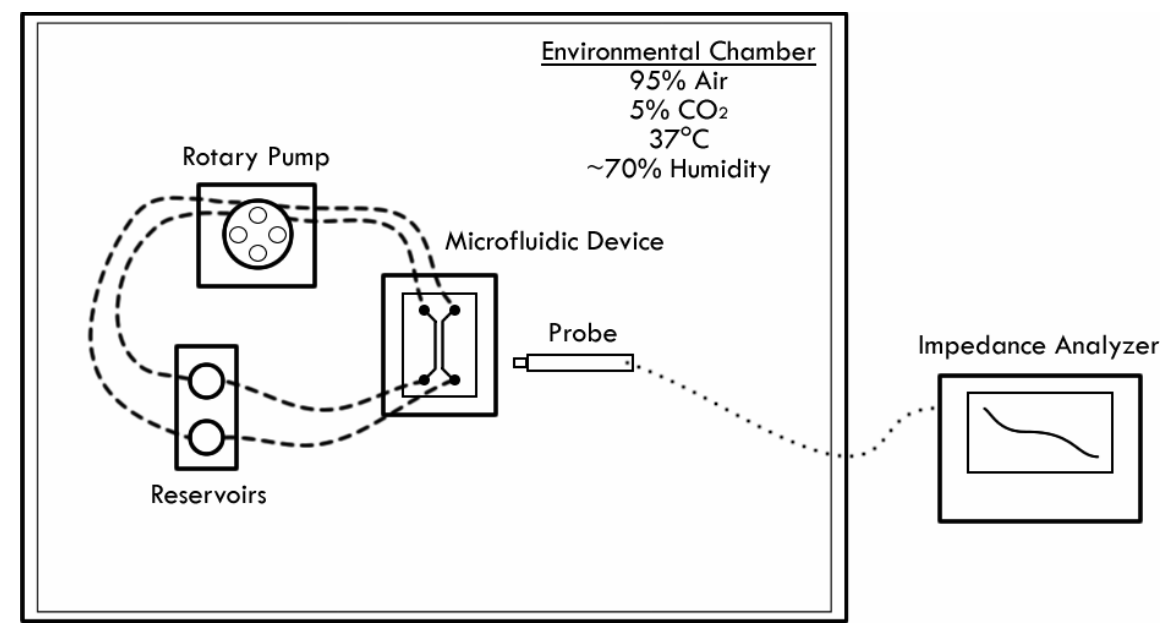

Figure 20. Schematic of the environment for fluid flow testing.

\section{Analysis}

\section{Impedance Model}

Impedance spectra profiles were analyzed with Microsoft Excel and fit to the simplified model (Figure 1) to determine the resistance and capacitance values. The total impedance of the circuit, $Z$, in terms of frequency, $R_{\text {cell layer }}, C_{\text {cell layer }}, C_{E}$, and $R_{\text {medium }}$ is given as: 


$$
Z=\sqrt{\left(Z_{1} \cos \left(\theta_{1}\right)+Z_{2} \cos \left(\theta_{2}\right)\right)^{2}+\left(Z_{1} \sin \left(\theta_{1}\right)+Z_{2} \sin \left(\theta_{2}\right)\right)^{2}}
$$

where

$$
\begin{gathered}
Z_{1}=\frac{\sqrt{1+\left(R_{\text {medium }} C_{E} \omega\right)^{2}}}{C_{E} \omega}, \quad \theta_{1}=\arctan \left(\frac{-1}{R_{\text {medium }} C_{E} \omega}\right) \\
Z_{2}=\frac{R_{c . l .}}{\sqrt{1+\left(R_{\text {c.l. }} C_{c . l .} \omega\right)^{2}}}, \quad \theta_{2}=-\arctan \left(R_{c . l .} C_{c . l .} \omega\right) \\
\omega=2 \pi f
\end{gathered}
$$

Where $Z_{l}$ is the total impedance contributed to the resistance of the electrolyte and the capacitance due to the electrode/electrolyte interaction and $Z_{2}$ is the total impedance contributed from the presence of a cell monolayer. Calculations from these derived values can be found in Appendix D.

\section{Impedance Analysis}

The Premium Solver Platform expansion for the Excel Solver tool package was used to optimize the fit between the collected data and the mathematical model. After data for the investigated trial was imported, Excel cells for the four mathematical model variables $\left(R_{\text {cell layer }}, C_{\text {cell layer }}, C_{E}, R_{\text {medium }}\right)$ were established with an initial, arbitrary guess $\left(R_{\text {cell layer }}, R_{\text {medium }}=3000\right.$ and $\left.C_{\text {cell layer }}, C_{E}=5 \mathrm{E}-10\right)$. Next, five columns for calculated values of $Z_{1}, \theta_{1}, Z_{2}, \theta_{2}$, and $Z$ referencing the four variable cells and the respective frequency in each row were created. A column taking the squared difference of

measured and calculated values $\left(\left(Z_{\text {measured }}-Z_{\text {calculated }}\right)^{2}\right)$ for each row was established. The creation of a cell calculating the summation of these values followed. The Solver was executed to minimize this referenced summation cell. A range of nonnegative values for 
the four variables was also established. The range of values for the two resistance and capacitance variables are 0 to $100 \mathrm{M} \Omega$ and 0 to $1 \mu \mathrm{F}$, respectively; each were well within the expected range of values. The method of optimization for the Solver was chosen as "Standard Evolutionary". The Solver changed the four variable cells until it reached a specified time, iterations, precision, and/or convergence. Although rare, if the solver calculated a solution that did not correspond to the data (i.e. a flat line or a variable reached its limit), the Solver executed again with new initial guesses for the variables based on previous iterations. This process was repeated and variables were obtained for each recorded impedance spectrum. Similarly, this technique was applied for the analyses of uncultured surfaces where, with the absence of a cell monolayer, $Z_{2}, R_{c . l .}$, and $C_{c . l .}$ are 0 . An example of the Excel Worksheet with the Solver parameters is shown below (Figure 21). 


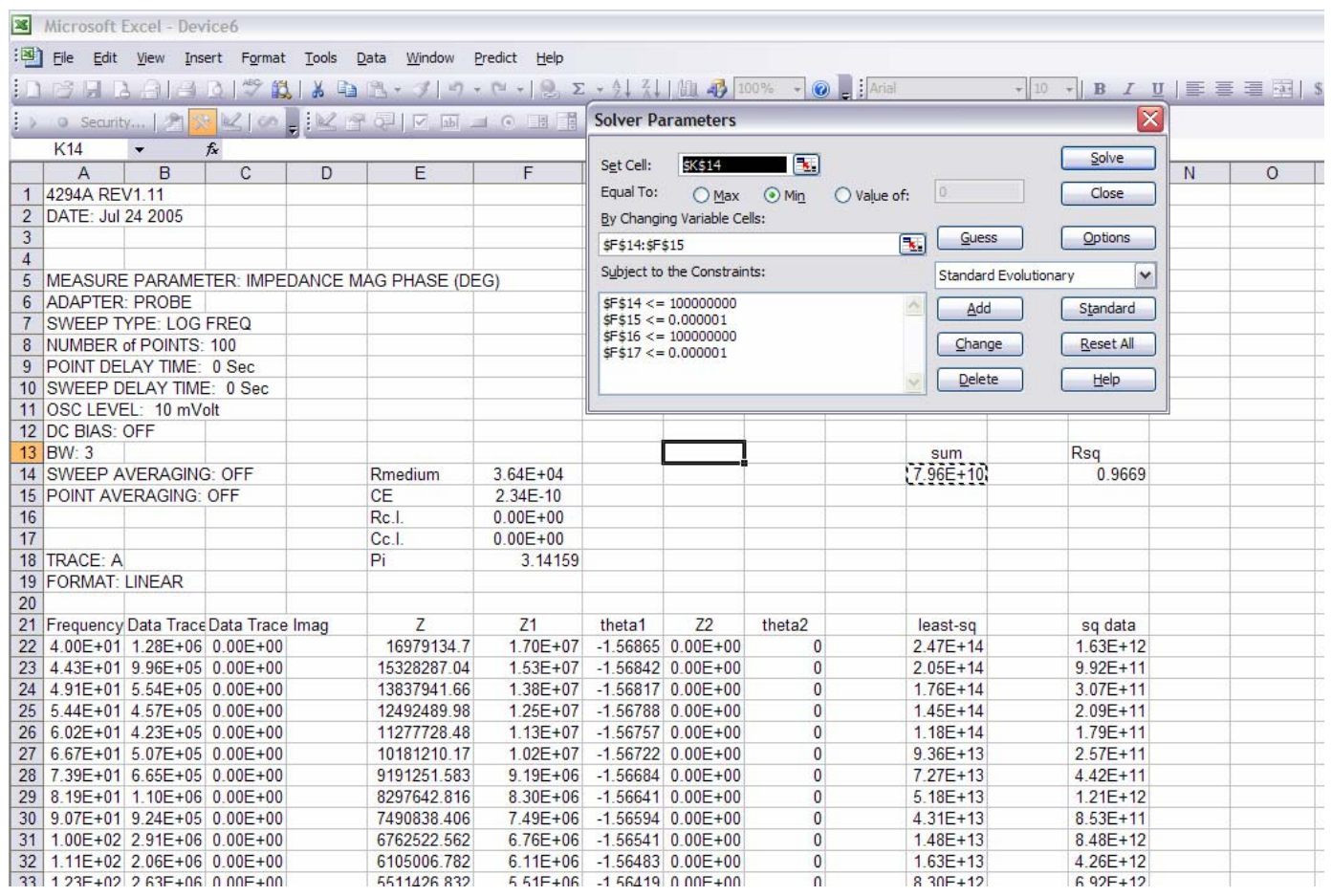

Figure 21. An example of the Excel worksheet and Premium Solver package.

\section{Flow Theory}

It is important to determine the applied fluid force with respect to the channel geometry and fluid flow for the application of shear stress testing. Additionally, derivations for laminar flow verification and entrance length were calculated. Viscosity and other fluidic parameters for the working medium, EGM-2, could not be found in literature. The fluid was assumed Newtonian and the viscosity was assumed similar to water. The flow rate and cross sectional area were assumed constant throughout the microfluidic channel.

All equations and values for the proceeding calculations were referenced from F. M. White (2002). Shear measurements for fluid flow associated with this investigation is expressed in dyne $/ \mathrm{cm}^{2}\left(1\right.$ dyne $=1 \times 10^{-5} \mathrm{~N}, 10$ dyne $\left./ \mathrm{cm}^{2}=1 \mathrm{~N} / \mathrm{m}^{2}=1 \mathrm{~Pa}\right)$. The rotary 
pump with the current pump head and Pharmed tubing produces a volumetric flow rate range of $0.21-52 \mathrm{~mL} / \mathrm{min}$. It is assumed that this flow rate increases at a linear rate proportional with the rotational settings range of $1.0-240.0 \mathrm{rpm}$. Calculations were recorded at $1.0 \mathrm{rpm}$ at a volumetric flow rate of $210 \mu \mathrm{L} / \mathrm{min}$, or $3.5 \times 10^{-9} \mathrm{~m}^{3} / \mathrm{s}$. At $37^{\circ} \mathrm{C}$ the density, $\rho$, and viscosity, $\mu$, of EGM-2 are $993.37 \mathrm{~kg} / \mathrm{m}^{3}$ and $0.000692 \mathrm{~kg} / \mathrm{m}^{3}$, respectively. With the channel width of $w$ and height of $h$ the Reynolds number, Re, was calculated from the hydraulic diameter, $D_{H}$, and velocity, $V$, by

$$
\begin{gathered}
D_{H}=2 h w /(h+w) \\
V=Q / h w \\
\operatorname{Re}=\rho V D_{H} / \mu
\end{gathered}
$$

The entrance length, $L_{e}$, for fully developed laminar flow is given as

$$
L_{e}=0.06 \operatorname{Re} D_{H}
$$

The shear stress applied to the confluent cell layer was also calculated. Shear was calculated from the average frictional force around the perimeter of a rectangular duct. The product of the frictional factor and Reynolds's number, $f R e$, is determined from the aspect ratio of the width and height of the microchannel. The average shear associated with this geometry is calculated by

$$
\begin{gathered}
f=\frac{8 \tau}{\rho V^{2}} \\
\tau=\frac{f \rho V^{2}}{8}
\end{gathered}
$$

This applied shear force is linearly proportional to the rotational velocity of the pump head. 


\section{CHAPTER 5}

\section{RESULTS}

\section{$\underline{\text { A. Fabricated Platform }}$}

\section{Glass-Electrode Substrate}

A total of three glass-electrode substrates were fabricated as described above.

Figure 22 represents a typical glass-electrode substrate. Shown is the patterned metal deposited on the glass surface. Twenty-two bonding pads are at the ends of the wire traces. A common, grounding electrode divides the two sets of ten measuring electrodes.

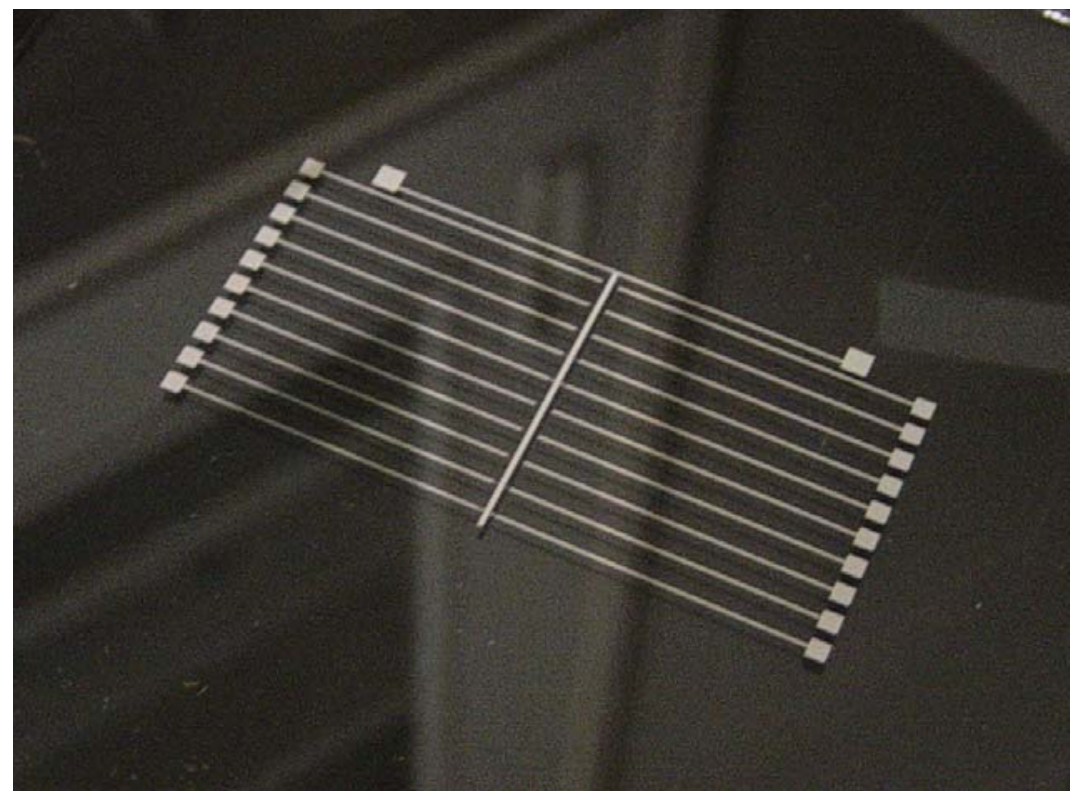

Figure 22. The resulting fabricated glass-electrode substrate. 
Topography measurements with the profilometer were performed and a representative graphical result of two $200 \mu \mathrm{m}$-wide bonding pad wire traces is depicted in Figure 23. The sputtered metal layers protruded about $90 \mathrm{~nm}$ above the surface of the glass. Similar traces were obtained from each of the tested microfabricated glasselectrode substrates and a summary of the results can be found in Table 2 .

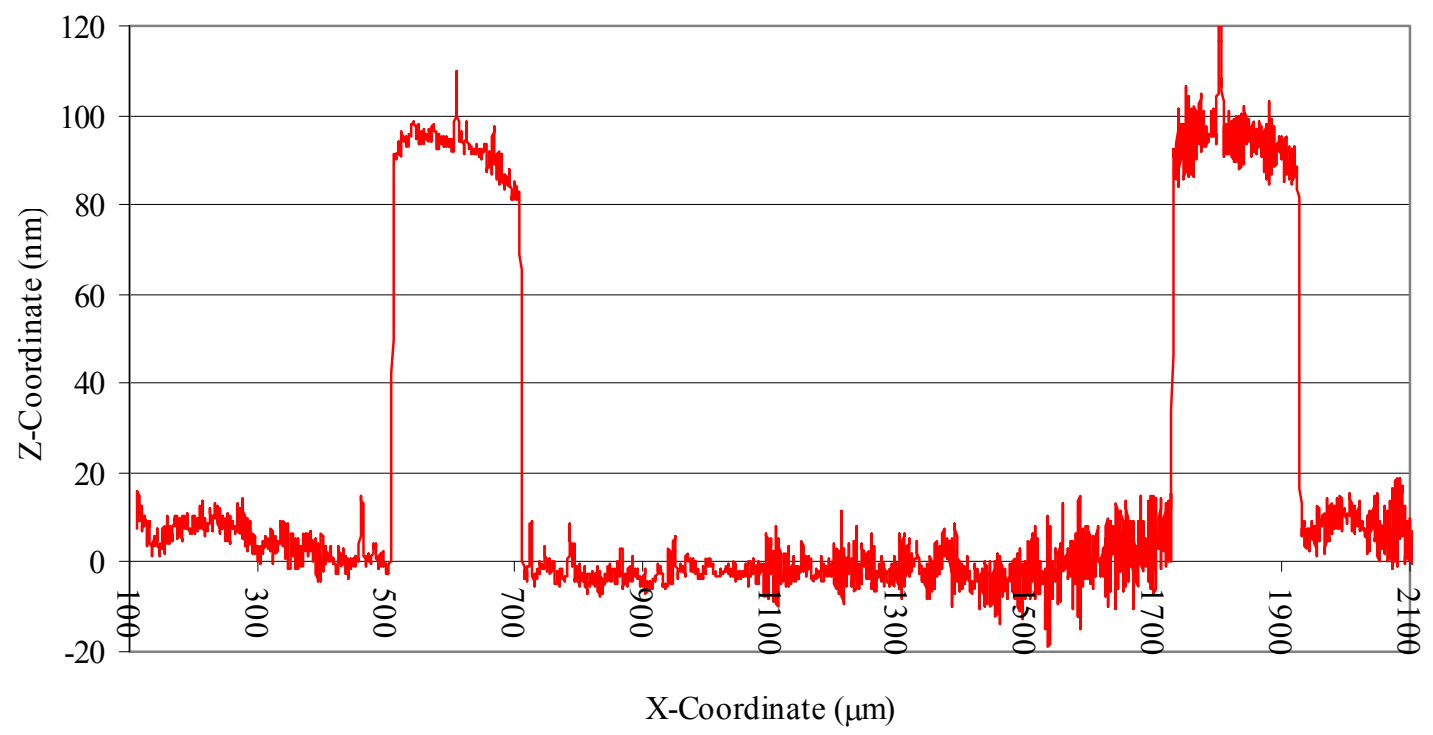

Figure 23. Dektak 8 trace of glass-electrode substrate. 


\begin{tabular}{|c|c|}
\cline { 2 - 2 } \multicolumn{1}{c|}{} & Average Height (nm) \\
\hline Counter Electrode & $92 \pm 5$ \\
\hline 200mm Wire Trace & $91 \pm 4$ \\
\hline Bonding Pad & $89 \pm 4$ \\
\hline Measuring Electrodes & $93 \pm 5$ \\
\hline
\end{tabular}

Table 2. Topography measurements at different locations of the device.

The surface dimensions of the measuring electrodes were visually inspected under a microscope. The electrode shapes and sizes were different than the dimensions specified in the AutoCAD drawing for mask creation. For example, the expected $10 \mu \mathrm{m}$ square electrode was nearly elliptical in shape with the major and minor axes being 15 $\mu \mathrm{m}$ and $12 \mu \mathrm{m}$, respectively. The wire trace from this electrode was measured at $10 \mu \mathrm{m}$ instead of the expected width of $5 \mu \mathrm{m}$. These actual measured geometries were used in all the impedance analysis calculations. Table 3 summarizes the expected and actual geometries for each substrate. Table 4 shows the percent error for all three devices. Measured values of these surface areas were accurate within $10 \%$.

\begin{tabular}{|c|c|c|c|c|c|c|c|c|}
\cline { 2 - 8 } \multicolumn{1}{c|}{} & \multicolumn{2}{c|}{ Expected } & \multicolumn{2}{c|}{ Device 1 } & \multicolumn{2}{c|}{ Device 2 } & \multicolumn{2}{c|}{ Device 3 } \\
\hline Electrode & $\begin{array}{c}\text { Area } \\
\left(\mu \mathrm{m}^{2}\right)\end{array}$ & $\begin{array}{c}\text { Trace } \\
(\mu \mathrm{m})\end{array}$ & $\begin{array}{c}\text { Area } \\
\left(\mu \mathrm{m}^{2}\right)\end{array}$ & $\begin{array}{c}\text { Trace } \\
(\mu \mathrm{m})\end{array}$ & $\begin{array}{c}\text { Area } \\
\left(\mu \mathrm{m}^{2}\right)\end{array}$ & $\begin{array}{c}\text { Trace } \\
(\mu \mathrm{m})\end{array}$ & $\begin{array}{c}\text { Area } \\
\left(\mu \mathrm{m}^{2}\right)\end{array}$ & $\begin{array}{c}\text { Trace } \\
(\mu \mathrm{m})\end{array}$ \\
\hline \hline 10 & 100 & 5 & 141 & 7 & 165 & 10 & 153 & 9 \\
\hline 20 & 400 & 10 & 660 & 13 & 720 & 15 & 696 & 14 \\
\hline 40 & 1600 & 10 & 2230 & 13 & 2480 & 15 & 2480 & 14 \\
\hline 80 & 6400 & 20 & 7060 & 23 & 7400 & 25 & 7400 & 24 \\
\hline 160 & 25600 & 40 & 27100 & 43 & 27900 & 46 & 27900 & 45 \\
\hline
\end{tabular}

Table 3. Expected and actual dimensions of electrodes and traces for each tested device. 


\begin{tabular}{|c|c|c|}
\cline { 2 - 3 } \multicolumn{1}{c|}{} & \multicolumn{2}{c|}{ Percent Error } \\
\hline Electrode & Area (\%) & Trace (\%) \\
\hline \hline 10 & $53.0 \pm 12.0$ & $73.3 \pm 30.6$ \\
\hline 20 & $73.0 \pm 7.5$ & $40.0 \pm 10.0$ \\
\hline 40 & $49.8 \pm 9.0$ & $40.0 \pm 10.0$ \\
\hline 80 & $13.9 \pm 3.1$ & $20.0 \pm 5.0$ \\
\hline 160 & $7.9 \pm 1.8$ & $11.7 \pm 3.8$ \\
\hline
\end{tabular}

Table 4. Percent error of dimensions of electrodes and traces for all three devices

\section{Microfluidic PDMS Substrate}

The dimensions of micro-milled mold were within $\pm 5 \mu \mathrm{m}$ of the design

parameters. Table 5 summarizes the first four SU-8 fabricated molds and Figure 24

shows typical profile data obtained on one of the four molds. The fabrication of these

molds used baking procedures on an uneven hotplate surface. This fabrication technique

led to uneven microchannel profiles with a difference in almost $100 \mu \mathrm{m}$. Figure 24

continues to exhibit the fabricated uneven surface as shown in the resulting near-linear height profile as it is measured at different locations from its inlet. Note that the Dektak 8 profiler cannot determine the aspect ratio of the SU- 8 structures, only their height. The pointed feature between the two relief structures in Figure 24 is the result of the profiler not able to "touch-down" in between the structures.

\begin{tabular}{|c|c|c|c|c|cc|}
\hline Trial & Spin Rate & Soft Bake & Hard Bake & Highest Profile & Lowest Profile & Channel Width \\
\hline \hline 1 & $500 \mathrm{rpm}$ for 30s & $95 \mathrm{C}$ for $15 \mathrm{~min}$ & $95 \mathrm{C}$ for $45 \mathrm{~min}$ & $223 \mu \mathrm{m}$ & $130 \mu \mathrm{m}$ & $580 \mu \mathrm{m} \pm 5 \mu \mathrm{m}$ \\
\hline 2 & $500 \mathrm{rpm}$ for 30s & $95 \mathrm{C}$ for $50 \mathrm{~min}$ & $95 \mathrm{C}$ for $60 \mathrm{~min}$ & $>300 \mu \mathrm{m}$ & $167 \mu \mathrm{m}$ & $515 \mu \mathrm{m} \pm 5 \mu \mathrm{m}$ \\
\hline 3 & $300 \mathrm{rpm}$ for $60 \mathrm{~s}$ & $95 \mathrm{C}$ for $45 \mathrm{~min}$ & $95 \mathrm{C}$ for $15 \mathrm{~min}$ & $462 \mu \mathrm{m}$ & $366 \mu \mathrm{m}$ & $490 \mu \mathrm{m} \pm 5 \mu \mathrm{m}$ \\
\hline 4 & $400 \mathrm{rpm}$ for $50 \mathrm{~s}$ & $95 \mathrm{C}$ for $45 \mathrm{~min}$ & $95 \mathrm{C}$ for $15 \mathrm{~min}$ & $353 \mu \mathrm{m}$ & $264 \mu \mathrm{m}$ & $440 \mu \mathrm{m} \pm 5 \mu \mathrm{m}$ \\
\hline
\end{tabular}

Table 5. Summary of results for the first four SU-8 fabricated molds. 


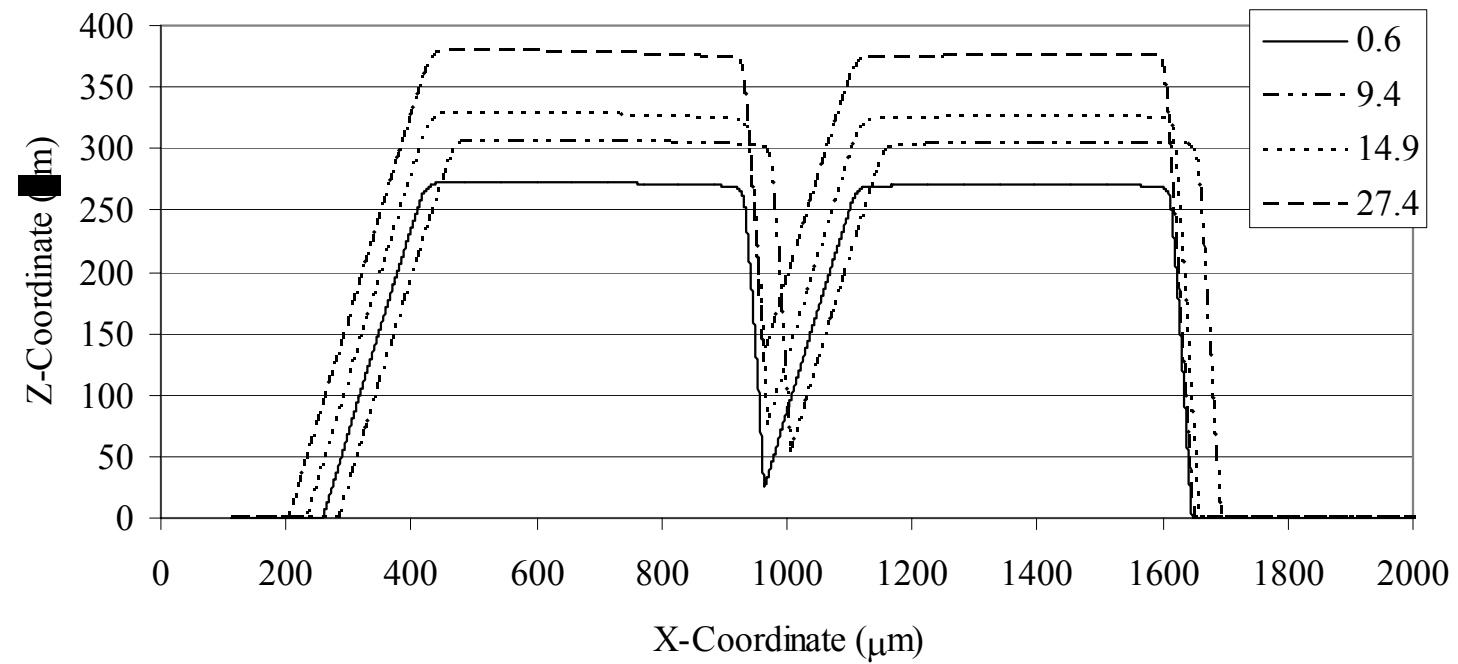

Figure 24. Profile results at different Y-coordinates $(\mathrm{mm})$ of the fourth trial.

Two SU-8 molds were created without the baking steps as described in Table 6 . The absence of the uneven baking surfaces allows the relief structures to have a level topography (Figure 25). The difference between the highest and lowest profiles is almost $10 \mu \mathrm{m}$. The average height and width of the "H" and "I" wafer microchannel relief were $232 \mu \mathrm{m}$ and $441 \mu \mathrm{m}$, respectively, with a channel division width of $230 \mu \mathrm{m}$. The length of the channel was within $1 \mathrm{~mm}$ of designed length.

\begin{tabular}{|c|c|c|c|c|cc|}
\hline Trial & Spin Rate & Soft Bake & Hard Bake & Highest Profile & Lowest Profile & Width \\
\hline \hline 5 & $500 \mathrm{rpm}$ for 60s & N/A & N/A & $227 \mu \mathrm{m}$ & $236 \mu \mathrm{m}$ & $438 \mu \mathrm{m} \pm 5 \mu \mathrm{m}$ \\
\hline 6 & $500 \mathrm{rpm}$ for 60s & N/A & N/A & $229 \mu \mathrm{m}$ & $237 \mu \mathrm{m}$ & $428 \mu \mathrm{m} \pm 5 \mu \mathrm{m}$ \\
\hline
\end{tabular}

Table 6. Summary of results for the no-bake SU-8 fabricated molds. 


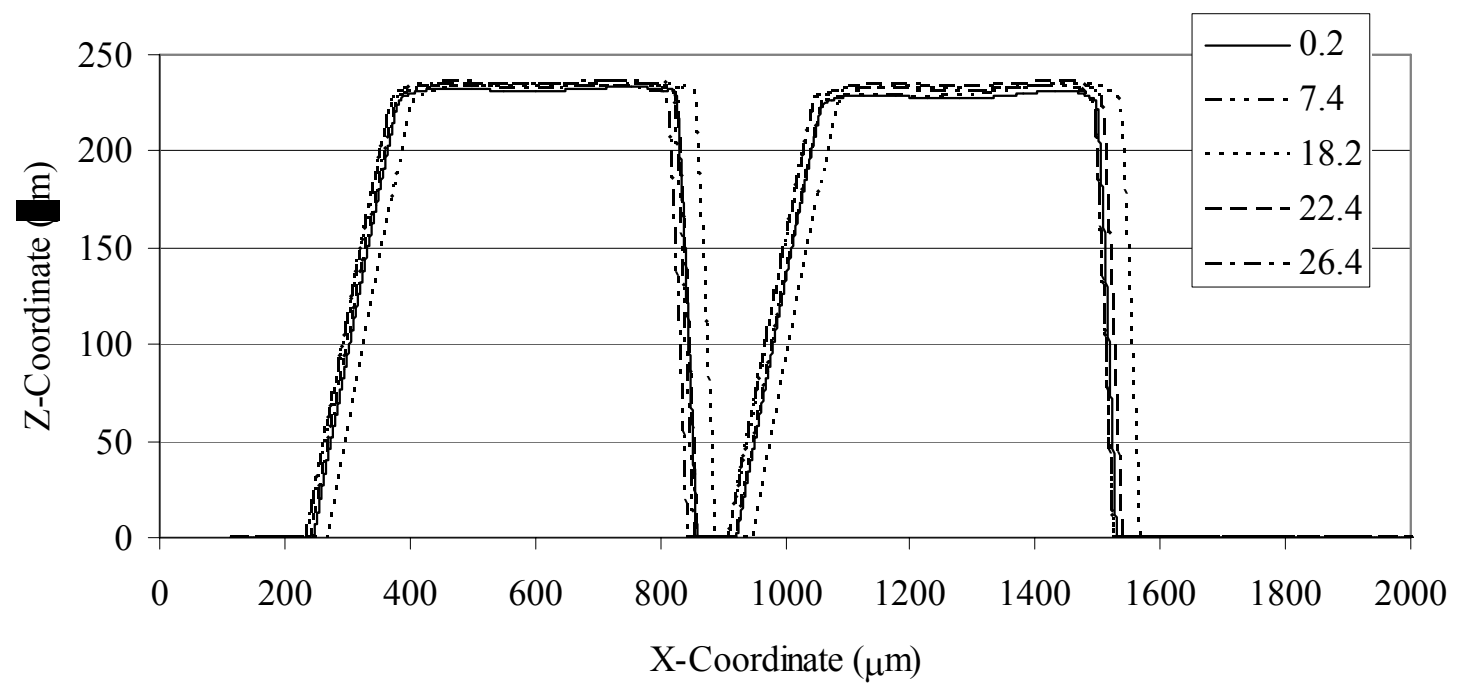

Figure 25. Profile results at different Y-coordinates $(\mathrm{mm})$ of the fifth trial.

\section{Complete Assembly}

After the glass-electrode substrate was drilled, wires were bonded, and nanoports adhered, PDMS microfluidic substrates were cured in the SU-8 no-bake molds and aligned visually to the substrate (Figure 26). On the electrode side of the substrate, the PDMS microfluidic piece is aligned such that the ends of the microchannels are at the drilled holes for the nanoports. The PDMS structure dividing the two microchannels straddles the counter-electrode, leaving exposed surface area in each channel. The wires were arranged as to not impede the PDMS adherence and prevent accidental shorting. Ports were adhered on the backside to of the glass-electrode substrate. 

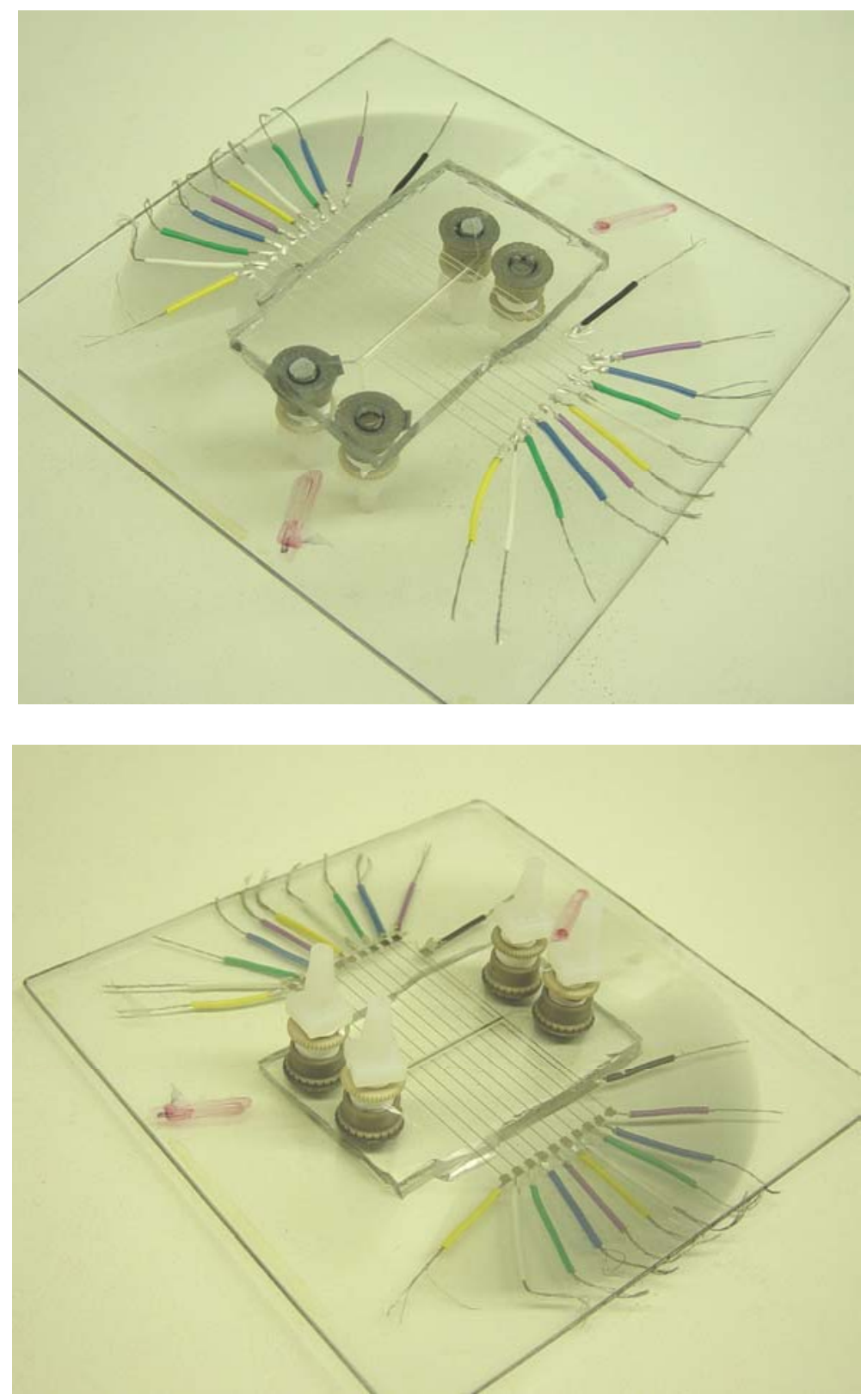

Figure 26. Top and bottom pictures of the assembled device.

\section{$\underline{4 . \text { Fluid Testing and Analysis }}$}

The PDMS substrate from the SU-8 mold did not leak during manual injection at low flow rates $(<1 \mathrm{~mL} / \mathrm{min})$, however, the PDMS substrates produced from the micro- 
milled piece leaked easily. Very thin PDMS microfluidic films $(<5 \mathrm{~mm})$ also leaked under injected flow. The PDMS microfluidic substrate did not leak with the rotary pump connected to the system using a pump rate of $15.0 \mathrm{rpm}$ (equivalent to flow rates of 3.25 $\mathrm{mL} / \mathrm{min})$.

With a channel width of $441 \mu \mathrm{m}$ and height of $232 \mu \mathrm{m}$ the Reynolds number, $R e$, hydraulic diameter, $D_{H}$, velocity, $V$, and entrance length, $L_{e}$, were calculated for a flow rate associated with the $1.0 \mathrm{rpm}$ setting on the rotary pump $(0.21 \mathrm{ml} / \mathrm{min})$. Calculated values of $R e$ and $L_{e}$ are proportional to the applied pump settings.

$$
\begin{gathered}
D_{H}=2 h w /(h+w)=304 \mu \mathrm{m} \\
V=Q / h w=3.42 \mathrm{~cm} / \mathrm{s} \\
\operatorname{Re}=\rho V D_{H} / \mu=14.9 \\
L_{e}=0.06 \operatorname{Re} D_{H}=272 \mu \mathrm{m}
\end{gathered}
$$

Under these conditions, the profile is laminar and the flow field was fully developed at $272 \mu \mathrm{m}$ per applied $1.0 \mathrm{rpm}$.

With an assumed rectangular cross sectional area, the aspect ratio was $h / w=0.53$. The product of the frictional factor and Reynolds's number, $f R e$, was interpolated from a table of values (White 2002) to be 61.74. The average shear associated with this geometry was calculated by

$$
\begin{gathered}
f R e=61.74 \\
f=\frac{8 \tau}{\rho V^{2}}=\frac{61.74}{\operatorname{Re}} \\
\tau=\frac{61.74 \rho V^{2}}{8 \operatorname{Re}}=\frac{61.74 V \mu}{8 D_{H}}=6.01 \mathrm{dyne} / \mathrm{cm}^{2}
\end{gathered}
$$


Thus, the applied shear for a flow rate of $0.21 \mathrm{~mL} / \mathrm{min}$ was found to be $6.01 \mathrm{dyne} / \mathrm{cm}^{2}$. This applied shear force was linearly proportional to the rotational velocity of the pump head, so at 15.0rpm, which is the maximum pump rate before leaking occurred, the applied shear was over $90 \mathrm{dyne} / \mathrm{cm}^{2}$. Table 7 shows some of these calculated fluid parameters at 1,5 , and $10 \mathrm{rpm}$.

\begin{tabular}{|c|c|c|c|c|c|c|}
\cline { 2 - 7 } \multicolumn{1}{c|}{} & \multicolumn{6}{c|}{ Fluid Flow Parameters } \\
\hline Pump Setting & $\mathrm{Q}\left(\mathrm{mm}^{3} / \mathrm{s}\right)$ & $\mathrm{V}(\mathrm{mm} / \mathrm{s})$ & $\mathrm{Re}$ & $\mathrm{f}$ & $\mathrm{L}_{\mathrm{e}}(\mathrm{mm})$ & $\tau\left(\right.$ dyne $\left./ \mathrm{cm}^{2}\right)$ \\
\hline \hline $1.0 \mathrm{rpm}$ & 3.5 & 34.2 & 14.9 & 4.14 & 0.272 & 6.01 \\
\hline $5.0 \mathrm{rpm}$ & 17.5 & 171 & 74.7 & 0.83 & 1.36 & 30.04 \\
\hline $10.0 \mathrm{rpm}$ & 35.0 & 342 & 149 & 0.41 & 2.72 & 60.09 \\
\hline
\end{tabular}

Table 7. Showing calculated fluid flow parameters for 1rpm, 5rpm, $10 \mathrm{rpm}$.

\section{B. Cell Culture}

After fibronectin coating, attempts were made to seed suspended HUVECs into microchannels; however, endothelial cell attachment/adherence to the fibronectin coated microchannels was limited. During the application of fluid flow, all cells were removed from the microchannel, so alternative HUVEC plating/growth techniques were developed. As described in the procedures chapter, a series of experiments were performed to investigate the effect of the PDMS material on cell attachment and culturing. Specifically, PDMS, Lexan ${ }^{\circledR}$ and Teflon films were applied to the glasselectrode substrate and solutions of suspended HUVECs were placed in the openings of the material onto the glass-electrode substrate. 
Cells on PDMS films showed signs of attachment within the first two hours, as expected, but the cells that were suspended in the slit above the measuring electrodes did not attach until after three to four hours. Similar results were observed with the Lexan ${ }^{\circledR}$ slide; however, due to a lack of adhesion between the Lexan ${ }^{\circledR}$ and glass surfaces, the growth medium (and a few cells) between the interface layers. Growth was observed on the device with Teflon tape as well.

Using this technique, cells could be easily patterned and transferred to the PDMS microchannels without the need for injecting cell-suspension media. The cell adhesion was strong enough that, upon the injection of EGM-2 medium, air bubbles flowing through the channels would not detach the adhered HUVECs. Through careful PDMS alignment, only a minimal amount of cells would detach or become trapped at the interface. Additionally, the bulk of the residue left behind by the original cell culturing was removed with the Teflon tape, improving the adhesion between the PDMS substrate and the glass-electrode base. There were no signs that Teflon tape inhibited cell growth or attachment.

\section{Impedance Results}

\section{Impedance Measurements in Microchannels with No Flow}

Impedance spectrum for each of the measuring electrodes was obtained for each device for media alone, media and fibronectin, and media, fibronectin and HUVECs under no flow conditions. After fabrication and sterilization, media was injected into the 
channels and impedance measurements were obtained for Device 1 (Figure 27), Device 2 (Appendix F) and Device 3 (Appendix F). These impedance values for each of the four similar electrodes were averaged and normalized with respect to the exposed surface area of the electrodes. As anticipated, the normalized impedance values decreased as the area of the electrodes increased. The standard deviations for these values at $1.0 \mathrm{kHz}, 10 \mathrm{kHz}$, $100 \mathrm{kHz}$, and $1 \mathrm{MHz}$ are shown in Table 8 . As frequency increased, the standard deviation of each electrode decreased.

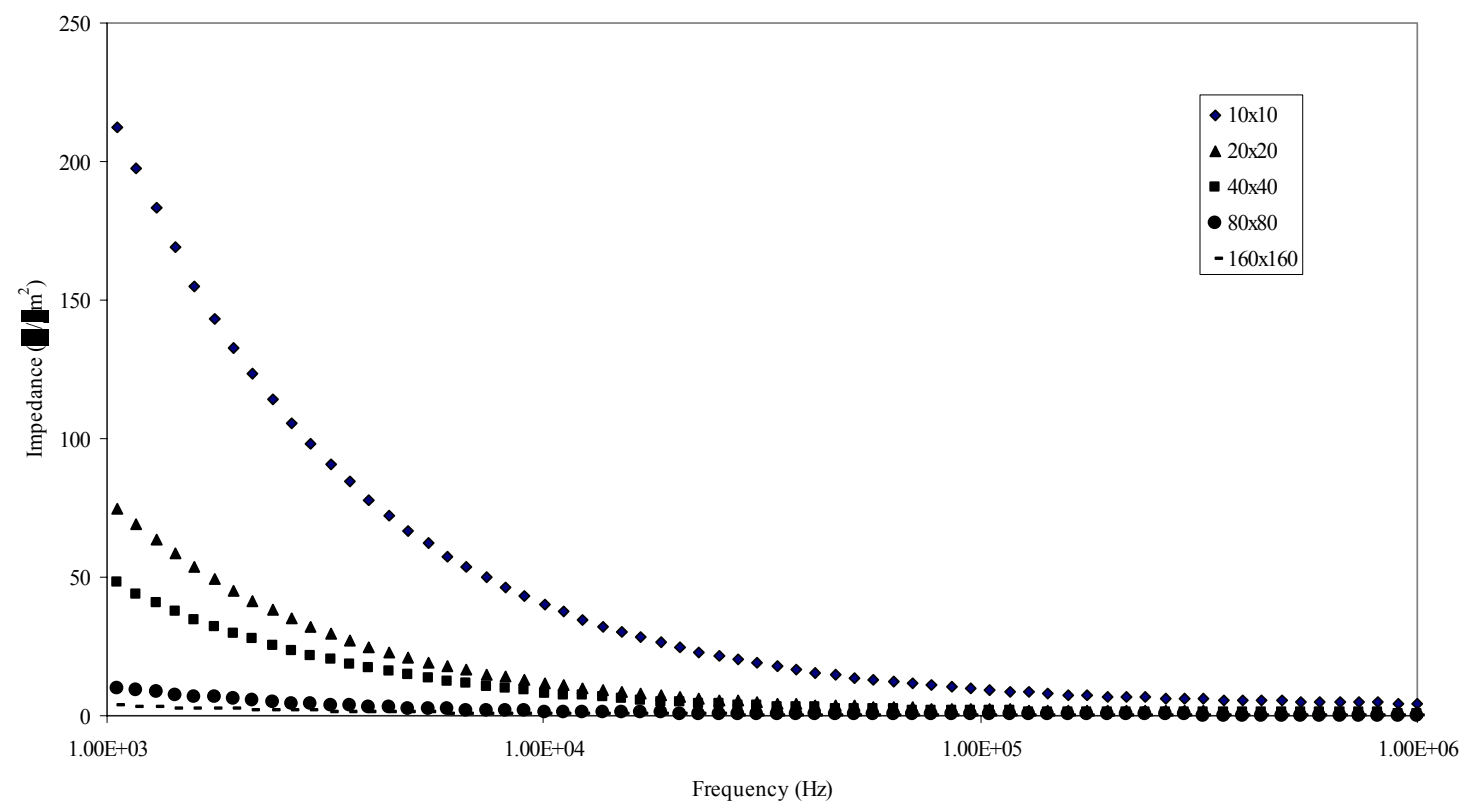

Figure 27. Normalized impedance spectrum for each electrode geometry with medium alone. 


\begin{tabular}{|c|c|c|c|c|c|}
\cline { 2 - 6 } \multicolumn{1}{c|}{} & \multicolumn{5}{c|}{ Standard Deviation $(\Omega / \mu \mathrm{m} 2)$} \\
\hline Frequency & $10 \times 10$ & $20 \times 20$ & $40 \times 40$ & $80 \times 80$ & $160 \times 160$ \\
\hline \hline $1 \mathrm{kHz}$ & 39.93 & 6.06 & 19.39 & 2.02 & 3.35 \\
\hline $10 \mathrm{kHz}$ & 10.00 & 1.00 & 3.16 & 0.26 & 0.63 \\
\hline $100 \mathrm{kHz}$ & 3.42 & 0.17 & 0.46 & 0.05 & 0.11 \\
\hline $1 \mathrm{MHz}$ & 1.47 & 0.09 & 0.08 & 0.03 & 0.02 \\
\hline
\end{tabular}

Table 8. Standard deviations for the measured electrodes with medium alone.

Impedance results from Device 1 were analyzed with the Premium Solver and fit to the mathematical model (Figure 1) with $R_{\text {cell layer }}=C_{\text {cell layer }}=0$. Without the presence of cells, these parameters were omitted. The results of this fit are shown in Table 9. Similar results for Device 2 and Device 3 can be found in Appendix F. Generally, the resistance of the bulk electrolyte decreases and the capacitance increases as the size of the electrode increases.

\begin{tabular}{|c|c|c|c|c|}
\cline { 2 - 5 } \multicolumn{1}{c|}{} & \multicolumn{4}{c|}{ Model Fit } \\
\hline Electrode & $\mathrm{R}(\Omega)$ & $\mathrm{C}(\mathrm{F})$ & $\mathrm{C}\left(\mathrm{F} / \mathrm{cm}^{2}\right)$ & $\mathrm{R}^{2}$ \\
\hline \hline $10 \times 10$ & 28000 & $2.52 \mathrm{E}-10$ & $9.99 \mathrm{E}-06$ & 0.9833 \\
\hline $20 \times 20$ & 12500 & $3.68 \mathrm{E}-10$ & $7.29 \mathrm{E}-06$ & 0.9921 \\
\hline $40 \times 40$ & 12400 & $4.39 \mathrm{E}-10$ & $6.78 \mathrm{E}-06$ & 0.9866 \\
\hline $80 \times 80$ & 6200 & $9.53 \mathrm{E}-10$ & $6.46 \mathrm{E}-06$ & 0.9938 \\
\hline $160 \times 160$ & 6700 & $9.34 \mathrm{E}-10$ & $2.24 \mathrm{E}-06$ & 0.9867 \\
\hline
\end{tabular}

Table 9. Mathematical model fit with medium alone.

After testing with media alone, fibronectin was injected in the left channel and media was injected in the right channel for a comparative study. Subsequently, impedance measurements were acquired for each electrode. Upon completion of these experiments, the devices were cleaned, fibronectin was loaded in the right channel and 
media in the left channel and impedance measurements were again obtained. Figure 28 summarizes the results obtained with the fibronectin-coated channels for Device 1 (Device 2 and Device 3 data can be found in Appendix F). Again, as anticipated, the impedance values increased as electrode size decreased. Comparing the impedance values to the media alone (Figure 27), it was noticed that the presence of fibronectin does not affect the impedance spectrum. The standard deviations at various frequencies and results from the model fit can be found in Table 10 and Table 11, respectively. The observations of the devices with the presence of fibronectin were similar to the previous study of media alone.

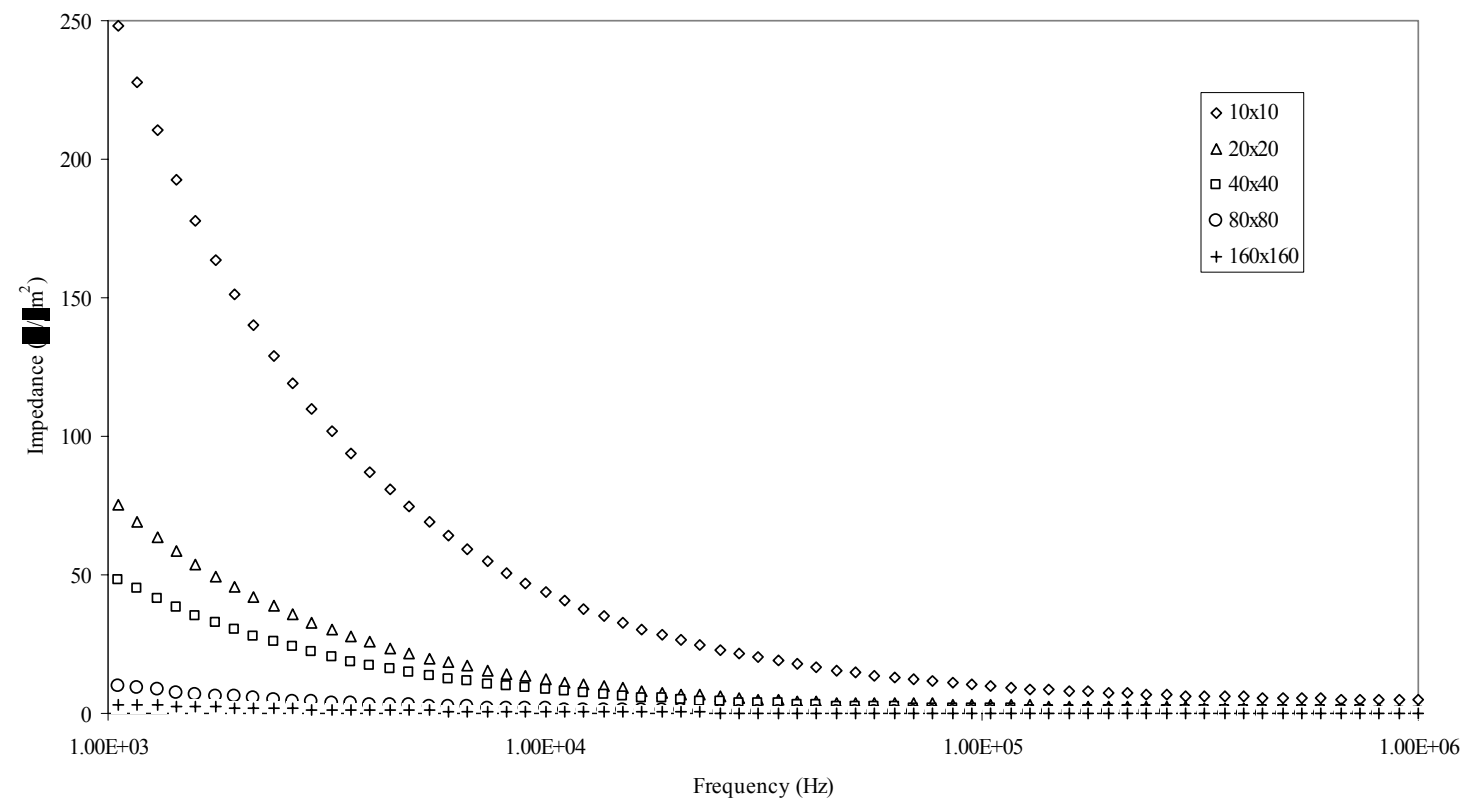

Figure 28. Normalized impedance spectrum for each electrode geometry with medium and fibronectin. 


\begin{tabular}{|c|c|c|c|c|c|}
\cline { 2 - 6 } \multicolumn{1}{c|}{} & \multicolumn{5}{c|}{ Standard Deviation $(\Omega / \mu \mathrm{m} 2)$} \\
\hline Frequency & $10 \times 10$ & $20 \times 20$ & $40 \times 40$ & $80 \times 80$ & $160 \times 160$ \\
\hline \hline $1 \mathrm{kHz}$ & 20.35 & 6.01 & 14.33 & 0.48 & 2.50 \\
\hline $10 \mathrm{kHz}$ & 2.92 & 1.15 & 2.17 & 0.19 & 0.45 \\
\hline $100 \mathrm{kHz}$ & 1.90 & 1.57 & 0.34 & 0.04 & 0.07 \\
\hline $1 \mathrm{MHz}$ & 0.90 & 0.39 & 0.08 & 0.01 & 0.01 \\
\hline
\end{tabular}

Table 10. Standard deviations for the measured electrodes for with medium and fibronectin.

\begin{tabular}{|c|c|c|c|c|}
\cline { 2 - 5 } \multicolumn{1}{c|}{} & \multicolumn{4}{c|}{ Model Fit } \\
\hline Electrode & $\mathrm{R}(\Omega)$ & $\mathrm{C}(\mathrm{F})$ & $\mathrm{C}\left(\mathrm{F} / \mathrm{cm}^{2}\right)$ & $\mathrm{R}^{2}$ \\
\hline \hline $10 \times 10$ & 28600 & $2.20 \mathrm{E}-10$ & $8.73 \mathrm{E}-06$ & 0.9868 \\
\hline $20 \times 20$ & 15800 & $3.64 \mathrm{E}-10$ & $7.21 \mathrm{E}-06$ & 0.9909 \\
\hline $40 \times 40$ & 12800 & $4.30 \mathrm{E}-10$ & $6.64 \mathrm{E}-06$ & 0.9861 \\
\hline $80 \times 80$ & 6470 & $9.57 \mathrm{E}-10$ & $6.48 \mathrm{E}-06$ & 0.9921 \\
\hline $160 \times 160$ & 6180 & $9.91 \mathrm{E}-10$ & $2.38 \mathrm{E}-06$ & 0.9867 \\
\hline
\end{tabular}

Table 11. Mathematical model fit with medium and fibronectin.

In order to determine whether the impedance of the counter electrode contributed to the output obtained from the measuring electrodes, the spectrum across the two largest measuring electrodes were analyzed. Figure 29 illustrates the impedance values across the $80 \times 80 \mu \mathrm{m}^{2}$ and $160 \times 160 \mu \mathrm{m}^{2}$ electrodes compared to the sum of their individual impedance values obtained across the counter electrode. The counter electrode did not contribute to the impedance output signal as evidenced by the curve for the sum of the individual impedance values directly overlying on top of the impedance values for the counter electrode. 


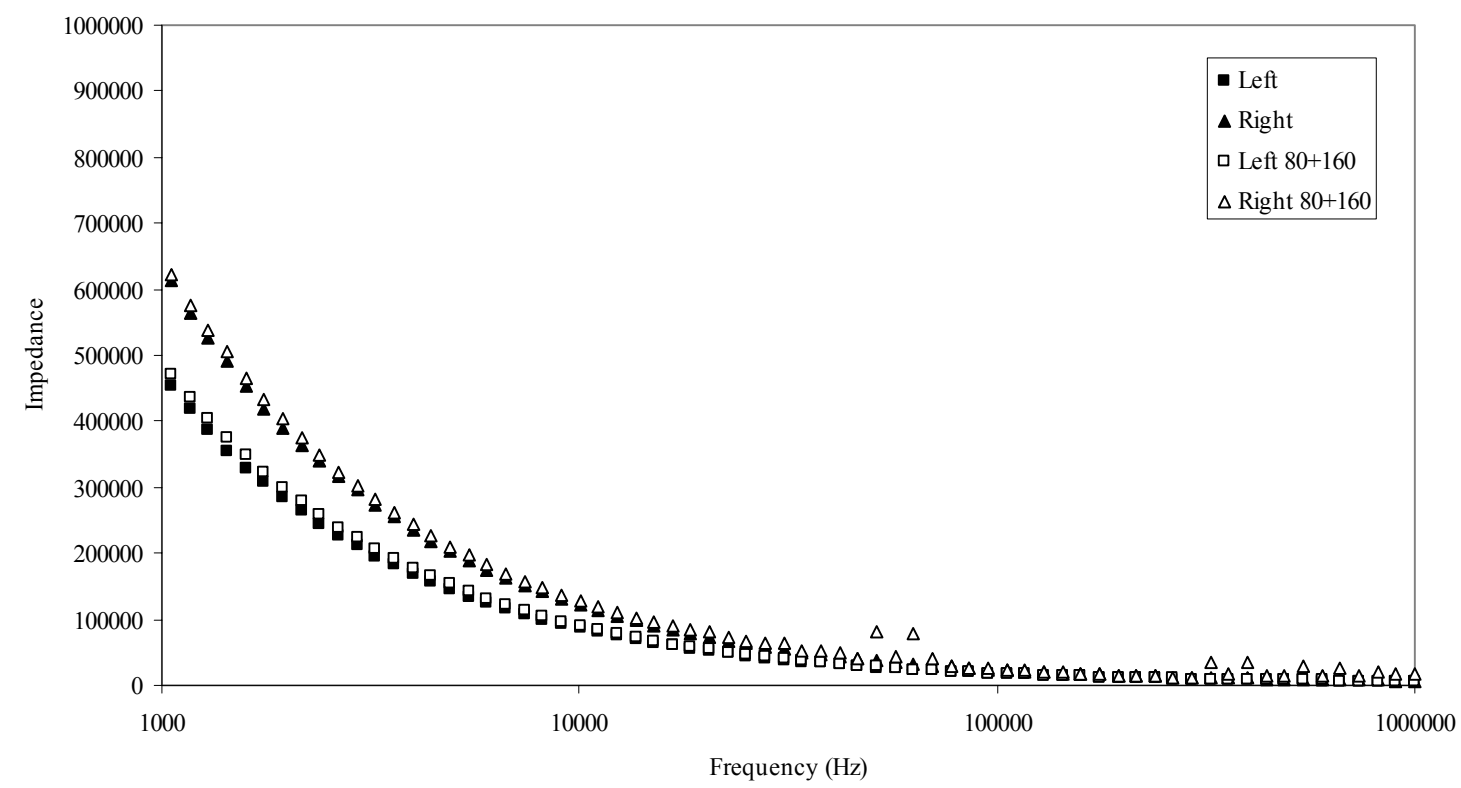

Figure 29. Device 3 impedance spectrum across two measuring electrodes.

Additionally, the electrode's dielectric properties were monitored over time as the electrode was exposed to the cell growth media. Impedance spectra from the five measuring electrodes from Device 2 were measured repeatedly in approximately five minute intervals (Figure 30). The magnitude of the impedance decreases over time as the electrodes are exposed to the cell growth medium (EGM-2). The magnitude of this drop in impedance decreases as the size of the measuring electrode increases. The smaller the electrode, the greater the influence of dielectric properties. The relationship between this trend and the model (Figure 1) without the presence of cells is that the capacitance $\left(C_{E}\right)$ and resistance of the bulk electrolyte $\left(R_{\text {medium }}\right)$ increases and decreases with time, respectively. 


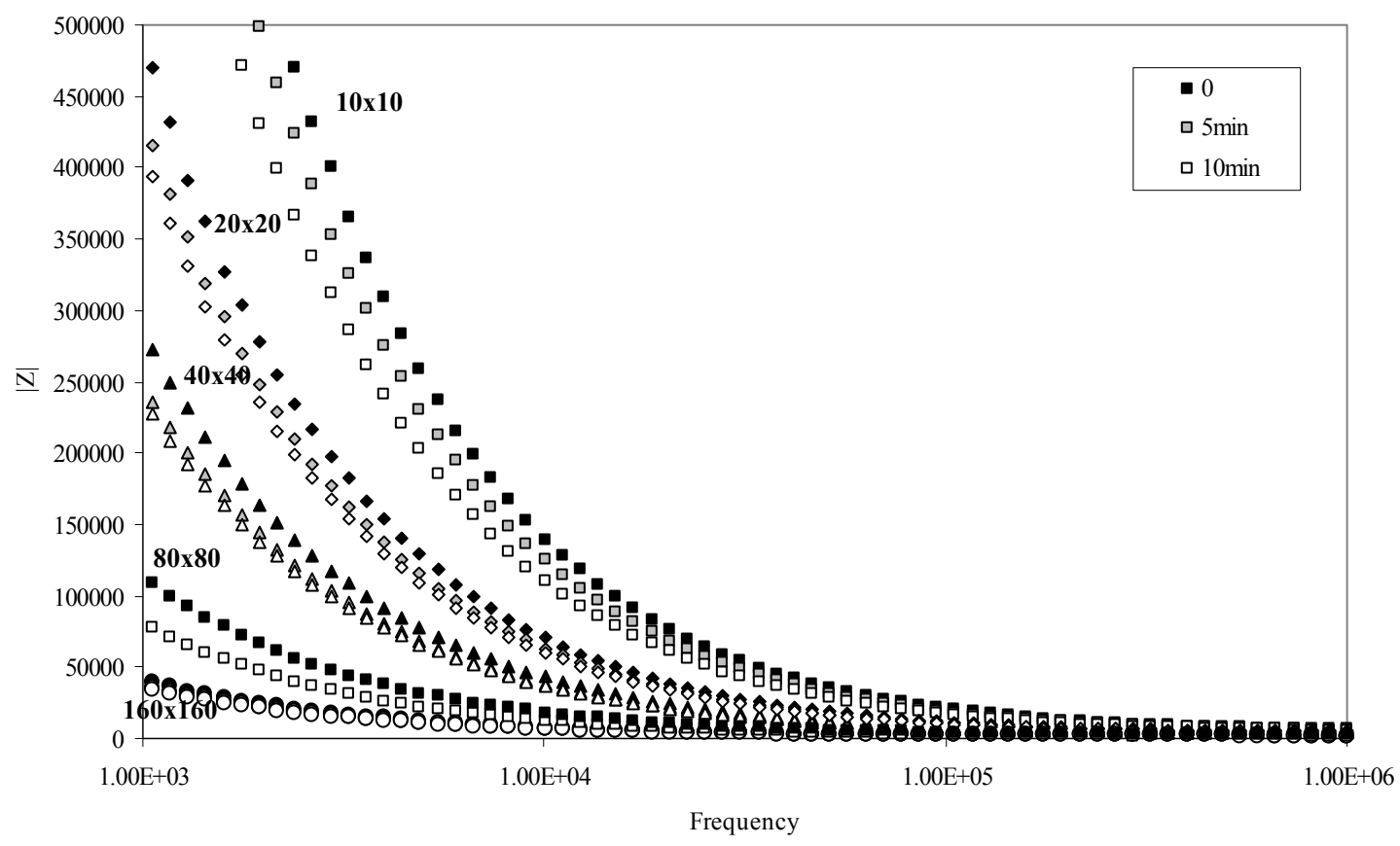

Figure 30. Device 2 impedance spectrum across measuring electrodes over time.

Impedance spectra were obtained from cells adhered to the channels inside the PDMS substrate. One channel contained the HUVEC culture and the other only growth media, the latter was used as a reference reading to compare to the cell culture data. The following data was obtained from Device 2. Figure 31 shows a set of $40 \times 40 \mu \mathrm{m}^{2}$ impedance spectrums with two cultured electrodes having approximately $70 \%$ and $30 \%$ of their surfaces covered with attached HUVECs. Included with the data is the measured, reference electrode. The magnitude of impedance shifted as the concentration of cells covering the measuring electrode increased. Very little or no cell coverage resulted in a minimal impedance shift. 


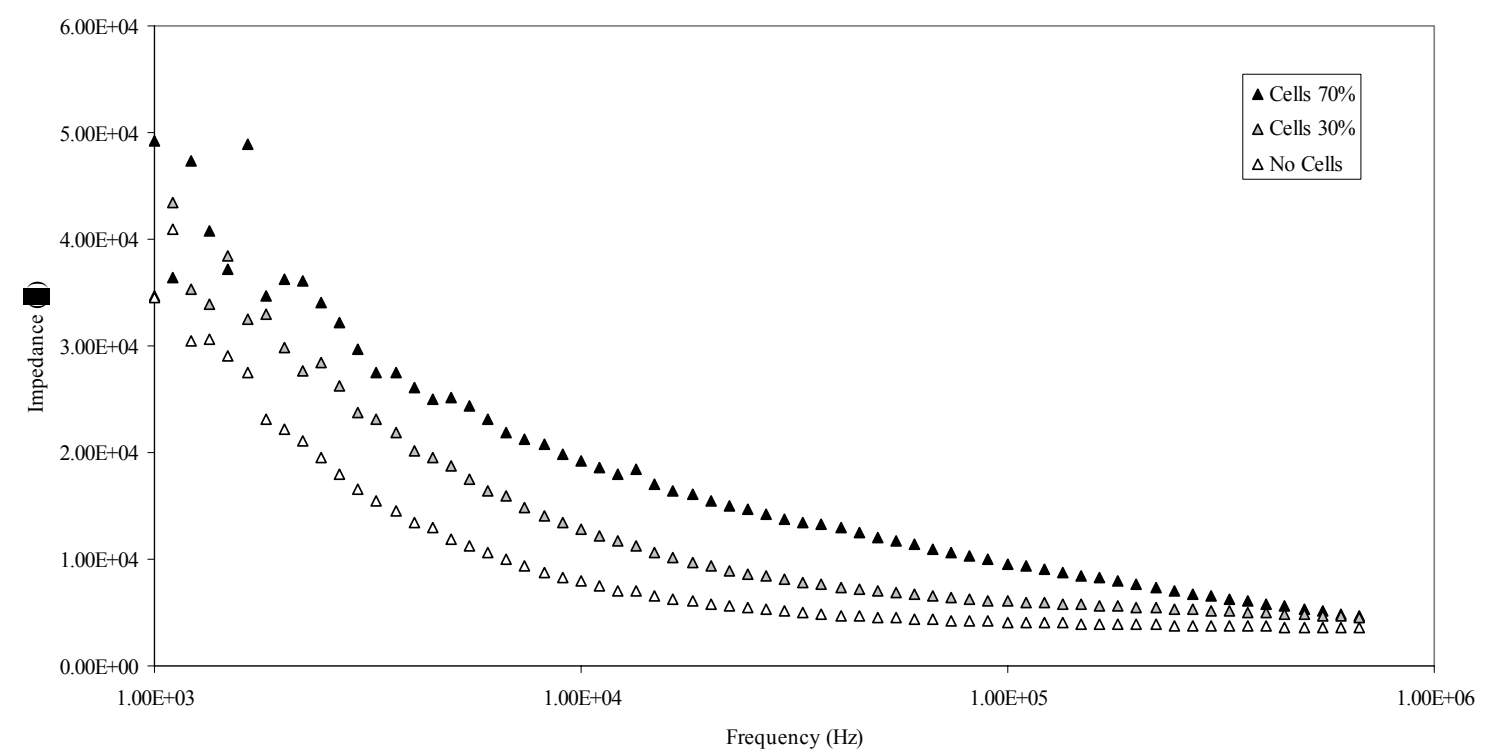

Figure 31. Impedance spectrum of cultured $40 \mathrm{x} 40 \mu \mathrm{m}^{2}$ electrodes with a referenced measurement.

\section{Impedance Measurements in Microchannels with Flow}

The impedance spectra for Device 1 were collected at $1.0 \mathrm{rpm}, 5.0 \mathrm{rpm}, 10.0 \mathrm{rpm}$ and under static conditions ( $0 \mathrm{rpm}$ ) for a channel filled with media alone (Figure 32) and the other coated with fibronectin (Figure 33). The normalized impedance spectra of the $40 \mathrm{x} 40 \mu \mathrm{m}^{2}$ electrodes in the two channels are shown in Figures $34 \& 35$. Since the collected impedance spectrum for each electrode was time dependent, the order in which the flow rates were induced were $0 \mathrm{rpm}, 5.0 \mathrm{rpm}, 1.0 \mathrm{rpm}$, then $10.0 \mathrm{rpm}$. As expected, the magnitude of the impedance spectrum decreased as the electrode size increased. As shown in previous static trials, the presence of fibronectin does not alter the spectra. Additionally, the studied volumetric flow rates did not alter the impedance spectra. To verify this trend, impedance spectrum were collected from the $40 \times 40 \mu \mathrm{m}^{2}$ electrode from Device 2 and the $10 \mathrm{x} 10 \mu \mathrm{m}^{2}$ and 160x $160 \mu \mathrm{m}^{2}$ electrodes from Device 3 (Appendix F). 


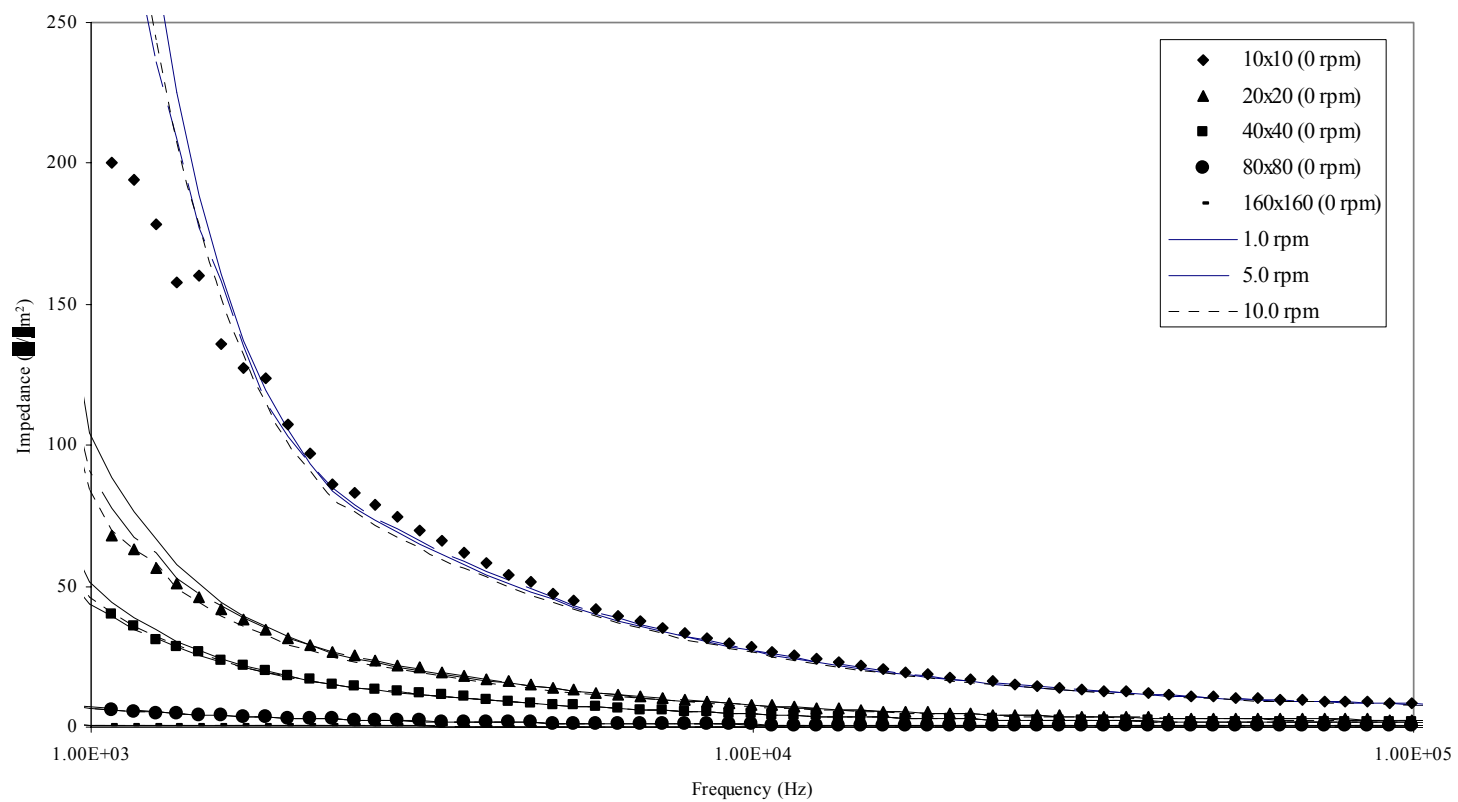

Figure 32. Impedance spectra under fluid flow for Device 1 with media alone.

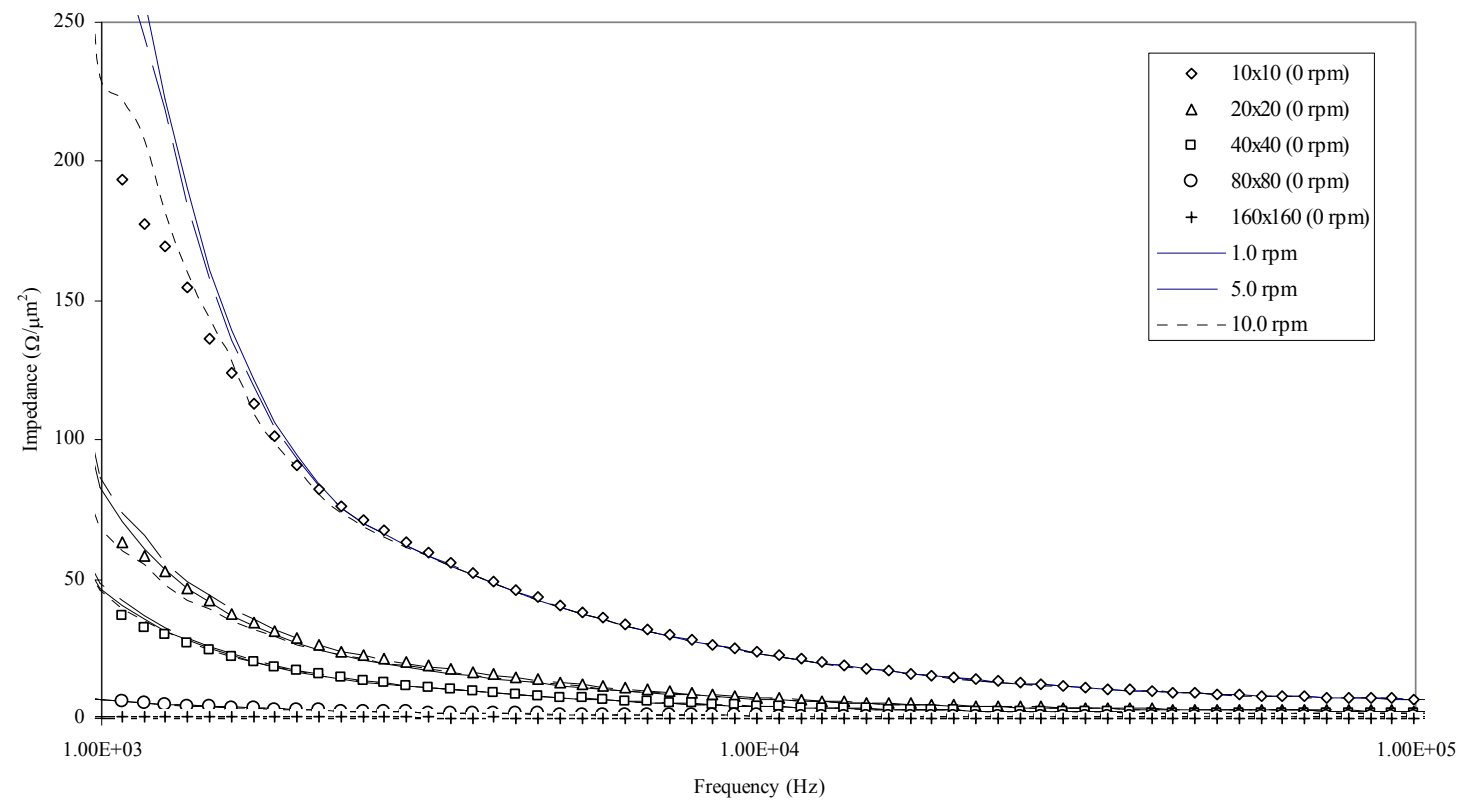

Figure 33. Impedance spectra under fluid flow for Device 1 with media and fibronectin. 


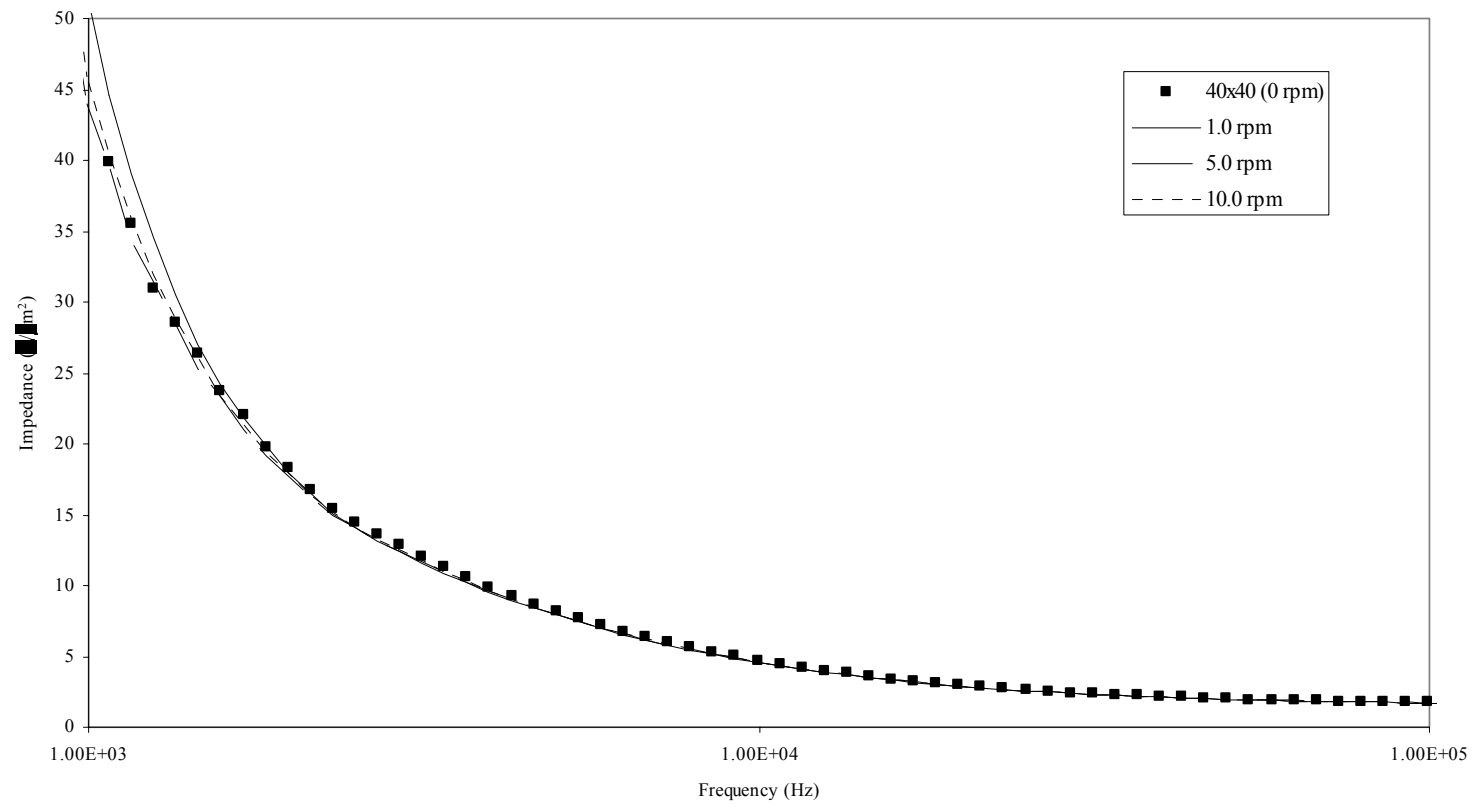

Figure 34. Impedance spectra under fluid flow for $40 \times 40 \mu \mathrm{m}^{2}$ electrodes (Device 1) with media alone.

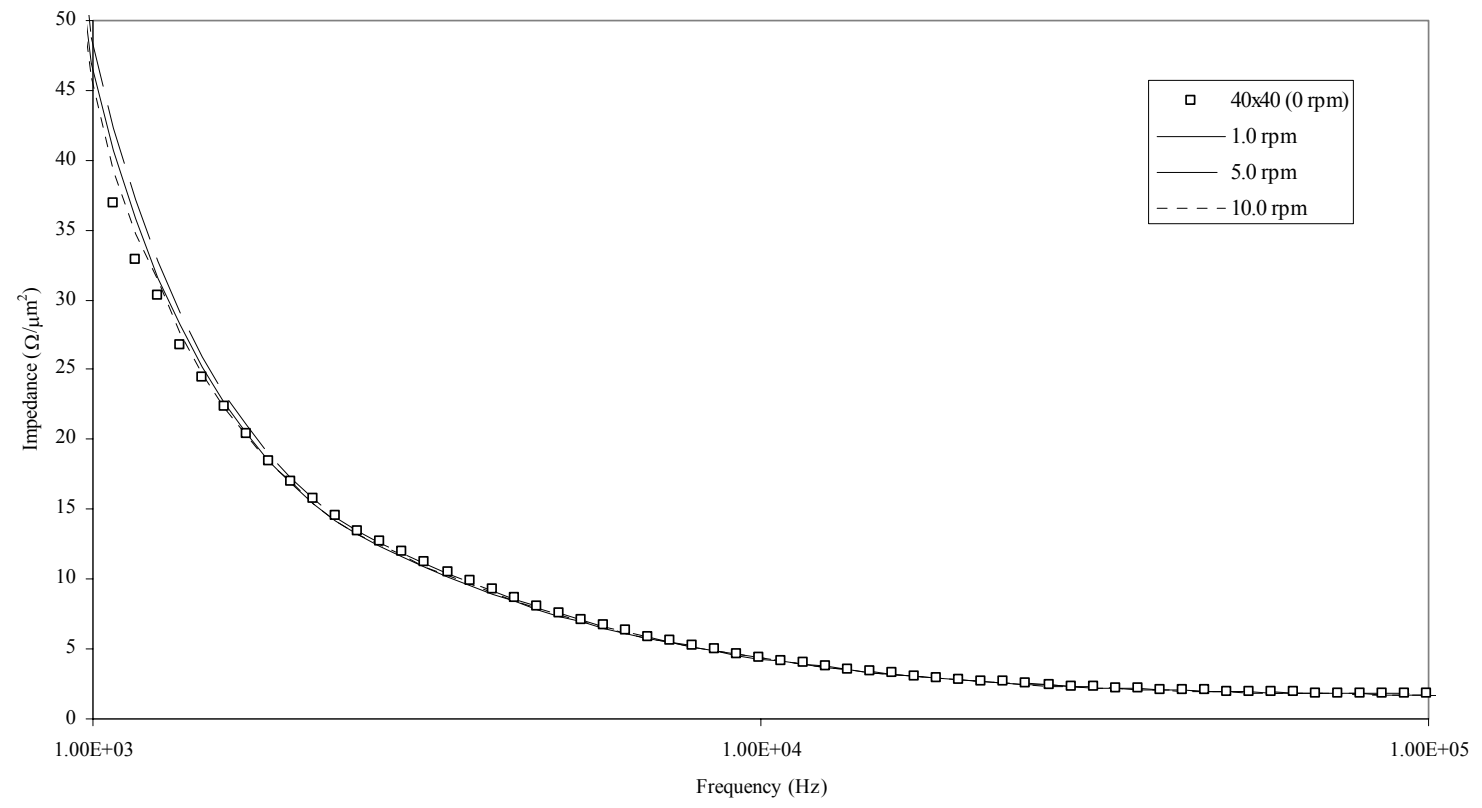

Figure 35. Impedance spectra under fluid flow for $40 \mathrm{x} 40 \mu \mathrm{m}^{2}$ electrodes (Device 1) with media and fibronectin. 


\section{CHAPTER 6}

\section{DISCUSSION}

\section{$\underline{\text { A. Fabricated Platform }}$}

\section{Glass-Electrode Substrate Topography}

This near-flush surface provided a flat culturing base for the endothelial cells and maintained electrode integrity for impedance measurements. Keeping the glass-electrode topography level prevented the fluidic profile in the microchannels from additional disturbance while maintaining the integrity of the cultured cell monolayer. Additionally, a smooth surface aided in the conformal contact bonding of the PDMS. Although the electrodes protrude from the surface around $90 \mathrm{~nm}$, better results are possible with practice and a better operational knowledge of the sputtering machine. Other than sputtering time and RF/DC power input, parameters that affect the amount of deposited metal on the substrate surface are the base chamber pressure and the chamber pressure prior to plasma exposure.

The resulting electrode pattern on the soda-lime glass was observed visually. The shapes of the electrodes did not match the design shape. Specifically, most of the electrodes had rounded corners, but the mask pattern was designed with sharp corners. In some cases, the electrodes produced were elliptical in shape. For example, the $10 \times 10$ 
$\mu \mathrm{m}^{2}$ electrode had an elliptical shape with the major and minor axes being $15 \mu \mathrm{m}$ and 12 $\mu \mathrm{m}$, respectively. Although a number of microfabrication techniques could be at fault for this alteration in geometry, the biggest factor was the initial patterning mask. The mask was not printed at the highest quality, meaning resolution of the features would be lost and rounded corners become more prevalent. Upon visual inspection, features of the patterning mask were identical to the fabricated substrate. The mask quality, therefore, was the major contributing factor in the resulting, distorted geometry.

Estimated electrode surface areas were calculated by dividing the structure into smaller geometrical shapes and summing all of its parts. Observations and measurements were initially conducted with the Dektak 8 profiler. However, upon inspection of the curved surfaces, visual characterization was determined to be more efficient. The microscope was equipped with a scale inside the eyepiece and, with 100X magnification, 1-micrometer resolution was possible. These measurements, including the width of the wire traces, were importance for capacitance and other impedance analysis calculations. Cell layer characterization from impedance analysis was dependent on the geometry of the electrode, so precise control over its fabrication was crucial.

\section{A Microfluidic PDMS Substrate}

The micro-milled Lexan ${ }^{\circledR}$ mold for the PDMS substrate was machined within all specified parameters. The uniformity of the mold was excellent and, with the recessed base, the thickness of the PDMS substrate could be well controlled. However, this machining method produced a rough surface with ridges which were generated during the 
machining process. This adversely affected both reversible and irreversible bonding processes since a smooth conformal surface is needed.

Uses of resist SU-8 as means for thick, high aspect-ratio structures have been well established (Zhang 2001). For this reason wafers with PDMS relief structures were created from SU-8 photoresist. Initial trials for fabricating wafers proved troublesome. The profile across the channel relief structure showed a non-uniform structure with a large height disparity $(\approx 100 \mu \mathrm{m})$. The height disparity increased nearly linearly in the hardened SU-8 thickness from one end of the structure to the other. Three additional wafers were fabricated similarly at different spin rates and resulted in the same characteristic topographical profile.

The cause of the slope in the relief structure was determined to be due to the hotplates not being level. The uneven surface of the hotplate was causing the viscous SU-8 fluid to shift during the baking process. Attempts were made to level the hotplates manually with a handheld bubble-gage, but the difference between the structure's highest and lowest profiles was improved to approximately $30 \mu \mathrm{m}$. Nevertheless, a more uniform thickness was desired to have stringent control of fluid velocity throughout the length of the channel.

By eliminating the baking step, the amount of error was significantly reduced. The difference between the highest and lowest points on the fabricated relief structures was within $10 \mu \mathrm{m}$. The high point occurred at the center of the relief structure with the lowest points occurring at the inlet and outlet portions of the microchannel. Without the baking step additional fabrication problems were encountered. For example, on closer inspection, the sputtered metal on the SU-8 features had a "cracked" surface. The reason 
for the rough surface was not known; however, it could be directly related to the absence of baking steps. Without baking, excess solvents in the SU-8 are present, potentially resulting in the rough metal surface. Initially, this surface did not prove to be a problem since multiple substrates of PDMS were peeled without lifting or releasing of metal particles; however around the fourth or fifth time metal particles were found in the PDMS microfluidic substrates. This problem was easily overcome by fabricating new molds which, without the use of baking steps, could be produced at a faster rate.

Whether or not the pre-exposure bake was conducted, the SU-8 film did not harden for UV exposure. For this reason, proximity patterning was necessary as contact patterning resulted in SU-8 adhering to the mask. The minute separation between the mask and the film caused the dimensions of the exposed features to be altered. This alteration was caused by the diffusion of UV light through the transparent patterns and created larger, exposed patterned areas on the photoresist film.

\section{$\underline{\text { 3. Fluid Testing and Analysis }}$}

Both reversible and irreversible bonding was attempted for the PDMS

microfluidic substrates. The PDMS substrates were cut, cleaned, and exposed to oxygen plasma for irreversible bonding. After trial and error experiments, it was determined that the optimum exposure to oxygen plasma for $1 / 4$ " thick samples of PDMS was either $25 \mathrm{~W}$ for $20 \mathrm{~s}$ or $10 \mathrm{~W}$ for $45 \mathrm{~s}$.

Within the first 10 seconds of venting the chamber, the two surfaces needed to come into conformal contact with each other. Also, if the contacted PDMS substrate was lifted off the surface and immediately placed back on the glass surface, adhesion would 
not occur. It has been noted that a drop of anhydrous ethanol applied to the surface after plasma exposure delays the bonding between the surfaces, leaving enough time for slight alignment adjustments (Khademhosseini 2004). There were successful trials of smaller samples of delayed PDMS bonding but it proved difficult to provide a thin, uniform layer of anhydrous ethanol to the microfluidic substrates in the amount of time necessary for complete irreversible bonding. Through reversible, conformal contact bonding the PDMS microfluidic substrate was adjusted and realigned multiple times. The irreversible oxygen plasma bonding technique proved difficult to align and bond simultaneously.

Reversible bonding was chosen for a number of reasons. First, it could be easily aligned visually and applied to the glass-electrode substrate. Also, the PDMS microfluidic piece could be peeled away for ease of cleaning or replacing platform components. Additionally, patterning PDMS substrates could be applied immediately before the initiation of microfluidic testing.

\section{B. Cell Culture.}

Attempts to culture cells inside microfluidic channels by injection methods were unsuccessful. Through methodical testing it was determined that the presence of PDMS or the glass-electrode substrate were not the causes of the problem. Through static cultures on films of PDMS and Teflon, a new way to pattern and place cells inside the microfluidic PDMS substrate was adapted. The Teflon films were not shown to inhibit cell growth and were sterilized easily. The application and removal of Teflon tape was easier than other methods described. For these reasons, it became a logical choice to use this material to place and pattern a strip of cells. The PDMS placement is crucial. The 
substrate cannot be misalign so much that the cells crushed and dislodged between the glass and PDMS interfaces, nor can the time to align the substrate be lengthy since the cells are without medium during the process, This method proved to be a simple fix to the problem of culturing cells via injection techniques.

\section{Impedance Analysis}

As stated before, the size of the measuring electrodes contributed significantly to the measurement values since the magnitude of impedance decreased with increased electrode surface area. In addition, the traces leading to the electrodes also played a role in the impedance spectrum output. Specifically, the PDMS substrate was manually placed over the glass-electrode substrate and visually aligned. Alignment variations of the PDMS substrate to the glass-electrode substrate resulted in either an increase or decrease in the impedance signal dependant upon whether the exposed area was larger or smaller than the previous alignment. For these reasons, the exposed area for each electrode was measured for each experiment. Error in the surface measurements could also lead to error in normalized impedance calculations. Future fabricated platforms should incorporate a buried trace, leaving it unexposed to media in the channel.

The results in Figure 28 verify that the counter-electrode does not influence the impedance signal since the amount of area exposed by the counter-electrode is sufficiently large compared to the measuring electrode. The impedance measured between the 80 -square and 160 -square electrodes is given as the sum of impedance across each electrode. The impedance measured individually across each measuring electrode to the counter electrode is given as the sum of impedance across each electrode and the 
counter electrode. Since the value across the measuring electrodes is equal the sum of those individually (as shown in Figure 28), then the impedance across the counter electrode is zero. The impedance values are influenced heavily on the amount of exposed surface area. As the exposed electrode area decreases, the measured impedance increases. Since the area of the counter-electrode is much greater than the measuring electrodes, the portion of collected impedance due to the presence of the counterelectrode is negligible.

\section{Impedance Measurements in Microchannels}

There were a number of measurements that, upon observation, were determined to be inconsistent with typical spectra for the measuring electrode. This can be accomplished from a crossing of wires or a loose probing connection. The impedance spectrums from trials without the presence of cells were assumed to be equivalent to a resistor and capacitor in series. Upon inspection, the presence of fibronectin or induced flow rates did not make a significant alteration to the impedance spectrums. However, a few other trends were noticed.

For the microfluidic tests under static conditions, fibronectin was injected in the right channel before growth medium was applied to both. After measurements were recorded, the process was repeated but with the fibronectin in the left channel. In almost every case, the resistance decreases while the capacitance increases, whether or not that electrode had fibronectin previously applied or not. This characteristic is verified in the changing impedance spectrums obtained in Figure 29. The dielectric properties of the electrodes changed the longer they were submerged in the growth medium. One 
suggestion for this phenomenon is that the electrode surfaces were originally

hydrophobic and as the platinum absorbs the nutrients it becomes more hydrophilic. This changes the dielectric properties of the electrode as well as allow for the attachment of cells. The change of electrode properties from hydrophobic to hydrophilic could also explain why it took longer for the cells to spread on the constructed electrode channel than on other surfaces of the same substrate.

Each of the normalized impedance spectra obtained were comparable between devices with only minor differences. These differences can be attributed to slight exposure differences during fabrication and/or different exposure time to growth medium from previous testing. Another consistent trend from each was that the bulk resistance decreased and overall capacitance increased as the area of exposed, measuring metal electrode increased.

As mentioned previously, the time it takes for HUVECs to plate in the trenches of the films takes longer than on larger, smooth surfaces. Either the topography of the films or the hydrophobic nature of the electrodes could account for this behavior. This technique, though, was necessary to culture cells inside microchannels for data collection. A lack of confluency or cell coverage will alter the impedance spectrum across the measuring electrode. Even though the electrode was partially covered and the impedance spectrum of the electrode changed slightly over time, there was still a noticeable difference between the uncultured and cultured spectrums. However, because the electrode was not completely covered we cannot use the simplistic mathematical model to describe or characterize the behavior of the cells. Complete cell confluency and electrode behavior need to be examined in-depth before ideal results can be obtained. 


\section{CHAPTER 7}

\section{CONCLUSIONS}

A new microfluidic platform was developed and fabricated, which incorporated impedance-sensing technology together with the use of a poly(dimethyl siloxane) microfluidic substrate to create an apparatus capable of applying shear forces up to 90 dyne $/ \mathrm{cm}^{2}$ to human umbilical vein endothelial cells. Fibronectin did not significantly alter impedance measurements compared to media alone under no flow and flow conditions. The applied fluidic flow rates of $1.0 \mathrm{rpm}, 5.0 \mathrm{rpm}$, and $10.0 \mathrm{rpm}$ did not alter obtained spectra. Frequency spectrums have detected the presence of cultured cells inside the microchannels under no flow conditions. The degree of impedance shift due to the presence of cells is determined on the amount of confluency and coverage of the measuring electrode. Fabricated measured electrodes display changing dielectric properties over time when submerged in EGM-2 cell growth medium under no-flow conditions. Future investigations need to be conducted to characterize the behavior of suspended cells and determine whether this platform will be a versatile tool for investigating endothelial permeability. 


\section{CHAPTER 8}

\section{RECOMMENDATIONS}

The first and foremost recommendation is electrode characterization on the glasselectrode substrate. The traces from the measuring electrodes need to be buried under a nonconductive layer of material so only the measuring electrodes are exposed to the fluid for every experiment and test, and does not depend on the alignment of the PDMS microchannels. Second, the dielectric properties of the electrodes and their interaction with the EGM-2 medium need to be investigated.

The hard and soft baking steps for the fabrication of the SU-8 microfluidic mold needs to be incorporated. The baking steps would allow contact patterning, preventing

alterations caused by proximity patterning. A more precise leveling technique or heating method should be considered. These steps improve SU-8 adhesion and integrity, which may prevent the sputtered metal coating from flaking after multiple uses. If heating cannot be implemented, another coating technique for the SU-8 mold besides a sputtered metal coating could be applied.

From this impedance study, reinvestigations and reevaluation of past experiments or biological phenomena is possible. The custom-made PDMS microchannels can be used and adapted to a more complex measuring electrode base. One example is the investigation of PDMS-created branches to replicate biological arterial arrangements. 
Investigation of cells at these regions is important, as flow separation promotes vortex formation which is where arteriosclerotic regions have been found to initiate (Davies 1993).

Additionally, deliberate monolayer injury is possible with an application of a low DC voltage across an individual measuring electrode. The voltage will injure/kill the cells, leaving a portion of the monolayer to be healed. The formation of endothelial cells over the electrode could be monitored. This behavior can be investigated at different shear rates, which is believed to regulate endothelial cell wound closure (Gojova 2005). Furthermore, this deliberate injury compromises the barrier function of the surrounding cells (Davies 1988). The ECIS system has used this voltage-injury technique to investigate this healing function (Keese 2003).

Cell patterning is possible with reversible-bonded PDMS microfluidic channels by hydrodynamic focusing of multiple laminar streams (Takayama 1999) or threedimensional microfluidic stamps (Chiu 2000). The irreversible-bonding technique utilizing a PDMS patterning stamp and a separate PDMS microfluidic substrate can also be used to apply multiple cells (Khademhosseini 2004, Rhee 2005). Using a number of these techniques it is possible to investigate the impedance analysis of different cell cultures simultaneously under the same fluid flow conditions.

PDMS microfluidic substrates could be altered for more in-depth analysis. First, PDMS irreversible bonding techniques can be investigated and applied as to apply greater shear than possible with conformal bonding (over $90 \mathrm{dyne} / \mathrm{cm}^{2}$ ). The user would not be as worried about leaking during cell injection procedures. A PDMS microfluidic system could be incorporated into the measuring platform, complete with branches of differing 
cross-sectional areas. The method of patterning metals, organic polymers, ceramics, and inorganic crystals on the inner walls of microchannels could be applied for topography investigations as well (Kenis 1999, Kenis 2000, Takayama 2000).

A more complex measuring microelectrode base could be applied to this study. Localized behavior of the endothelial cells barrier function, including focal adhesion points, can be investigated by impedance analysis with an immense array of tiny electrodes. Also, since shear stress varies over very small distances in major arteries an electrode array paired with a PDMS microfluidic substrate mimicking an artery would be beneficial in the investigation of barrier function. From more in depth experimentation and investigation, a versatile and very useful platform could be produced. 


\section{REFERENCES}

Baldwin, R. P., Roussel, Jr., T. J., Crain, M. M., Bathlagunda, V., Jackson, D. J., Gullapalli, J., Conklin, J. A., Pai, R., Naber, J. F., Walsh, K. M., and Keynton, R. S. 2002. Fully integrated on-chip electrochemical detection for capillary electrophoresis in a microfabricated device. Analytical Chemistry 74: 3690-3697.

Cereijido, M., Robbins, E. S., Dolan, W. J., Rotunno, C. A., and Sabatini, D. D. 1978. Polarized monolayers formed by epithelial cells on a permeable and translucent support. Journal of Cell Biology 77: 853-880.

Chiu, D. T., Noo, L. J., Huang, S., Kane, R. S., Wargo, C. J., Choi, I. S., Ingber, D. E., and Whitesides, G. M. 2000. Patterned deposition of cells and proteins onto surfaces by using three-dimensional microfluidic systems. Proceedings of the National Academy of Science of the United States of America 97: 2408-2413.

Davies, P. F. 1988. Endothelial cells, hemodynamic forces, and the localization of atherosclerosis. Endothelial Cells, vol. 2, ed. by U. S. Ryan. Boca Raton, FL: CRC Press, Inc. 123-138.

Davies, P. F. 1989. How do vascular endothelial cells respond to flow? News in Physiological Sciences 4: 22-25.

Davies, P. F. and Tripathi, S. C. 1993. Mechanical stress mechanisms and the cell. An endothelial paradigm. Circulation Research 72: 239-245.

DePaola, N. 1994. The effect of shear stress gradients on endothelial cell proliferation and monolayer integrity. Advances in Bioengineering 28: 321-322.

DePaola, N., Phelps, J. E., Florez, L., Keese, C. R., Minnear, F. L., Giaever, I., and Vincent, P. 2001. Electrical impedance of cultured endothelium under fluid flow. Annals of Biomedical Engineering 29: 648-656.

Duffy, D. C., McDonald, J. C., Schueller, J. A., Whitesides, G. M. 1998. Rapid prototyping of microfluidic systems in poly(dimethylsiloxane). Analytical Chemistry 70: 4974-4984. 
Duffy, D. C., Schueller, O. J. A., Brittain, S. T. and Whitesides, G. M. 1999. Rapid prototyping of microfluidic switches in poly(dimethyl siloxane) and their actuation by electro-osmotic flow. Journal of Micromechanics and Microengineering 9: 211-217.

Erben, M. Decker, S., Franke, H., and Galla, H.-J. 1995. Electrical resistance measurements on cerebral capillary endothelial cells: A new technique to study small surface areas. Journal of Biochemical and Biophysical Methods 30: 227238.

Furuse, M., Hirase, T., Itoh, M., Nagafuchi, A., Yonemura, S., and Tsukita, S. 1993. Occludin: a novel integral membrane protein localization at tight junctions. Journal of Cell Biology 123: 1777-1788.

Giaever, I. and Keese, C. R. 1984. Monitoring fibroblast behavior in tissue culture with an applied electric field. Proceedings of the National Academy of Science of the United States of America 81: 3761-3764.

Giaever, I. and Keese, C. R. 1991. Micromotion of mammalian cells measured electrically. Proceedings of the National Academy of Science of the United States of America 88: 7896-7900.

Gojova, A. and Barakat, A. I. 2005. Vascular endothelial wound closure under shear stress: role of membrane fluidity and flow-sensitive ion channels. Journal of Applied Physiology Articles in Press: February 10, 2005.

Granger, D. N., Hollwarth, M. E., and Parks, D. A. 1986. Ischemia-reperfusion injury: role of oxygen-derived free radicals. ACTA Physiologica Scandinavica Supplement 548: 47-63.

Gray, B. L., Lieu, D. K., Collins, S. D., Smith, R. L., and Barakat, A. I. 2002. Microchannel Platform for the Sutdy of Endothelial Cell Shape and Function. Biomedical Microdevices 4: 9-16.

Greve, D. W., Huang, X., Nguyen, D., and Domach, M. M. 2003. Modeling of impedance of cell-covered electrodes. Sensors, 2003. Proceedings of IEEE 2: $1358-1363$.

Hein, M., Madefessel, C., Haag, B., Teichmann, K., Post, A., and Galla, H.-J. 1992. Implications of a non-lamellar lipid phase for the tight junction stability. Part II: Reversible modulation of transepithelial resistance in high and low resistant MDCK-cells by basic amino acids, $\mathrm{Ca}^{2+}$, protamine and protons. Chemisty and Physics of Lipids 63: 223-233.

James, N. L., Harrison, D. G., and Nerem, R. M. 1995. Effects of shear on endothelial cell calcium in the presence and absence of ATP. The FASEB Journal 9: 968-973. 
Janshoff, A., Wegener, J., Sieber, M., and Galla, H. J. 1996. Double-mode impedance analysis of epithelial cell monolayers cultured on shear wave resonators. European Biophysics Journal 25: 93-103.

Jo, H., Dull., R. O., Hollis, T. M., and Tarbell, J. M. 1991. Endothelial albumin permeability is shear dependent, time dependent, and reversible. American Journal of Physiology - Heart and Circulatory Physiology 260: H1992-H1996.

Keese, C. R., Bhawe, B., Wegener, J., and Giaever, I. 2002. Real-time impedance assay to follow the invasive activities of metastatic cells in culture. BioTechniques 33:842-850.

Keese, C. R. and Giaever, I. 1990. A whole cell biosensor based on cell-substrate interactions. Proceedings of the Annual International Conference of the IEEE Engineering in Medicine and Biology Society 12: 500-501.

Keese, C. R., Wegener, J., Walker, S. R., and Giaever, I. 2003. Electrical wound-healing assay for cells in vitro. Proceedings of the National Academy of Science of the United States of America 101: 1554-1559.

Kenis, P. J. A., Ismagilov, R. F., Takayama, S., and Whitesides, G. M. 2000. Fabrication inside microchannels using fluid flow. Accounts of Chemical Research 33: 841847.

Kenis, P. J. A., Ismagilov, R. F., and Whitesides, G. M. 1999. Microfabrication inside capillaries using multiphase laminar flow patterning. Science 285: 83-85.

Keynton, R.S., Shu, M.C.S., and Rittgers, S.E. 1991. The Effect of Angle and Flow Rate upon Hemodynamics in Vascular Graft Anastomoses: An In Vitro Model Study. Journal of Biomechical Engineering. 113:458-463, 1991.

Keynton, R.S., Rodway, N.V., Evancho, M.M., Sims, R.L., Gobin, A.S., and Rittgers, S.E. 2001. Intimal Hyperplasia and Wall Shear in Arterial Bypass Graft Distal Anastomoses: An In Vivo Model Study. Journal of Biomechanical Engineering. 123:464-473.

Keynton, R. S., Roussel, Jr., T. J., Crain, M. M., Jackson, D. J., Franco, D. B., Naber, J. F., Walsh, K. M., and Baldwin, R. P. 2004. Design and development of microfabricated capillary electrophoresis devices with electrochemical detection. Analytica Chimica Acta 507: 95-105.

Khademhosseini, A., Suh, K. Y., Jon, S., Eng, G., Yeh, J., Chen, G. J., and Langer, R. 2004. A soft lithographic approach to fabricate patterned microfluidic channels. Analytical Chemistry 76: 3675-3681. 
Langley, L. L., Telford, I. R., and Christensen, J. B. 1974. Dynamic Anatomy and Physiology $4^{\text {th }}$ ed. New York: McGraw-Hill.

Levesque, M. J., Liepsch, D., Moravec, S., and Nerem, R. M. 1986. 1986. Correlation of endothelial cell shape and wall shear stress in a stenosed dog aorta. Arteriosclerosis, Thrombosis, and Vascular Biology 6: 220 - 229.

Ma, X., Gierhart, B., Collins, S. D., and Smith, R. L. 1999. Low temperature bonding for wafer scale packaging and assembly of micromachined sensors. Final Report 1998-99 for MICRO Project 98-144.

Malek, A. M. and Izumo, S. 1996. Mechanism of endothelial shape change and cytoskeletal remodeling in response to fluid shear stress. Journal of Cell Science 109: 713-726.

National Heart, Lung, and Blood Association. 2004. Morbidity and Mortality: 2004 Chart Book on Cardiovascular, Lung and Blood Diseases. Public Health Services: National Institutes of Health. US Department of Health and Human Services.

Ng, J. M. K., Gitlin, I., Stroock, A. D., and Whitesides, G. M. 2002. Components for integrated poly(dimethylsiloxane) microfluidic systems. Electrophoresis 23: 3461-3473.

Owen, M. J. and Smith, P. J. 1994. Plasma treatment of polydimethylsiloxane. Journal of Adhesion Science and Technology 8: 1063-1075.

Phelps, J. E. and DePaola, N. 2000. Spatial variations in endothelial barrier function in disturbed flows in vitro. American Journal of Physiology - Heart and Circulatory Physiology 278: H469-H476.

Rhee, S. W., Taylor, A. M., Tu, C. H., Cribbs, D. H., Cotman, C. W., and Jeon, N. L. 2005. Patterned cell culture inside microfluidic devices. Lab on a Chip 5: 102107.

Ross, R. 1993. Atherosclerosis: current understanding of mechanisms and future strategies in therapy. Transplantation Proceedings 58: 2041-2043.

Satcher, Jr., R. L., Dewey, Jr., C. F., Gimbrone, Jr. M. A., and Hartwig, J. H. 1994. Changes in ultrastructure and mechanical properties of endothelial cells caused by fluid shear stress. Advances in Bioengineering 28: 325-326.

Schueller, O. J. A., Duffy, D. C., Rogers, J. A., Brittain, S. T., and Whitesides, G. M. 1998. Reconfigurable diffration gratings based on elastomeric microfluidic devices. Sensors and Actuators 78: 149-159. 
Seebach, J., Dieterich, P., Luo, F., Schillers, H., Vestweber, D., Oberleithner, H., Galla, H. J., and Schnittler, H.J. 2000. Endothelial barrier function under laminar fluid shear stress. Laboratory Investigation 80: 1819-1831.

Sundararajan, N., Pio, M. S., Lee, L. P., and Berlin, A. A. 2004. Three-dimensional hydrodynamic focusing in Polydimethylsiloxane (PDMS) microchannels. Journal of Microelectromechanical Systems 13: 559-567.

Takahashi, M., Ishida, T., Traub, O., Corson, M. A., and Berk, B. C. 1997. Mechanotransduction in endothelial cells: temporal signaling events in response to shear stress. Journal of Vascular Research 34: 212-219.

Takayama, S., McDonald, J. C., Ostuni, E., Liang, M. N., Kenis, P. J. A., Ismagilov, R. F., and Whitesides, G. M. 1999. Patterning cells and their environments using multiple laminar fluid flows in capillary networks. Proceedings of the National Academy of Science of the United States of America 96: 5545-5548.

Takayama, S., Ostuni, E., Qian, X., McDonald, J. C., Jiang, X., Wu, M. H., Leduc, P., Ingber, D., and Whitesides, G. M. 2000. Patterning the topographical environment for mammalian cell culture using laminar flows in capillaries. Proceedings of the 1 st Annual International IEEE-EMBS Special Topic Conference on Microtechnologies in Medicine \& Biology (Lyon, France) 322-325.

Traub, O. and Berk, B. C. 1998. Laminar shear stress: mechanisms by which endothelial cells transduce an atheroprotective force. Arteriosclerosis, Thrombosis, and Vascular Biology 18: 677-685.

Verrier, E. D. and Boyle, Jr., E. M., 1996. Endothelial cell injury in cardiovascular surgery. Annals of Thoracic Surgery 62: 915-922.

Wegener, J., Keese, C. R., and Giaever, I. 2000. Electric cell-substrate impedance sensing (ECIS) as a noninvasive means to monitor the kinetics of cell spreading to artificial surfaces. Experimental Cell Research 259: 158-166.

Wegener, J., Sieber, M., and Galla, H. J. 1996. Impedance analysis of epithelial and endothelial cell monolayers cultured on gold surfaces. Journal of Biochemical and Biophysical Methods 32: 151-170.

White, F. M. 2002. Fluid Mechanics. $5^{\text {th }}$ ed. Boston, MA: McGraw-Hill.

Xia, Y. and Whitesides, G. M. 1998. Soft lithography. Annual Review of Materials Science 28: 153-184.

Zhang, J., Tan, K. L., Hong, G. D., Yang, L. J., and Gong, H. Q. 2001. Polymerization optimization of SU-8 photoresist and its applications in microfluidic systems and MEMS. Journal of Micromechanics and Microengineering 11: 20-26. 
APPENDIX A

MATERIAL SAFETY DATA SHEETS

BAKER BTS 220

MSDS Number: B0231***** Effective Date: $12 / 16 / 04 * * * *$ Supercedes: $08 / 24 / 00$

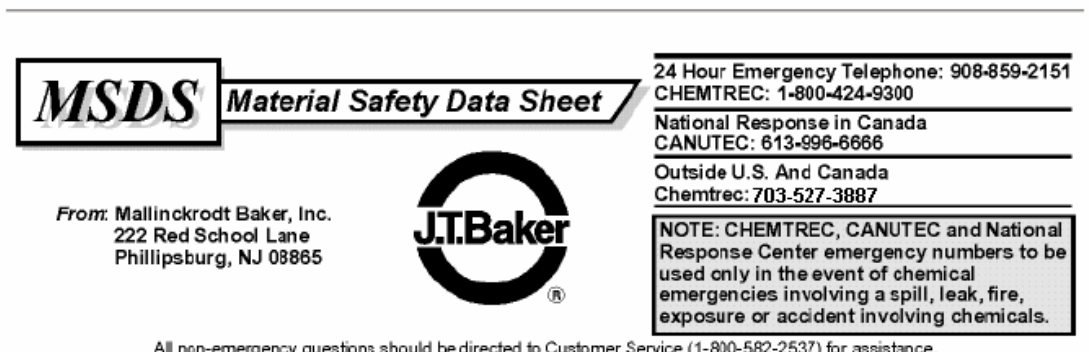

BTS-220

\section{Product Identification}

Synonyms: Propylene Glycol Monomethyl Ether Acetate; 1-Methoxy-2-Propanol Acetate

CAS No.: 108-65-6

Molecular Weight: 132.16

Chemical Formula: C6H12O3

Product Codes: 6304, 6314, 6333, 6343

\section{Composition/Information on Ingredients}

$\begin{array}{llcc}\text { Ingredient } & \text { CAS No } & \text { Percent } & \text { Hazardous } \\ \begin{array}{l}\text { Propylene glycol monomethyl ether } \\ \text { acetate }\end{array} & 108-65-6 & 100 \% & \text { Yes } \\ & & & \\ \end{array}$

\section{Hazards Identification}

Emergency Overview

WARNING! FLAMMABLE LIQUID AND VAPOR. MAY FORM EXPLOSIVE 
PEROXIDES. MAY CAUSE IRRITATION TO EYES AND RESPIRATORY

TRACT.

SAF-T-DATA ${ }^{(\mathbf{t m})}$ Ratings (Provided here for your convenience)

Health Rating: 1 - Slight

Flammability Rating: 2 - Moderate

Reactivity Rating: 2 - Moderate

Contact Rating: 1 - Slight

Lab Protective Equip: GOGGLES \& SHIELD; LAB COAT \& APRON; VENT HOOD; PROPER GLOVES; CLASS B EXTINGUISHER

Storage Color Code: Red (Flammable)

\section{Potential Health Effects}

\section{Inhalation:}

Inhalation of high concentrations may cause irritation to the respiratory tract.

Ingestion:

Not expected to be a health hazard via ingestion.

Skin Contact:

Not expected to be a health hazard from skin exposure.

Eye Contact:

High vapor concentrations may cause eye irritation.

Chronic Exposure:

No information found.

Aggravation of Pre-existing Conditions:

Persons with pre-existing eye disorders or impaired respiratory function may be more susceptible to the effects of this material.

\section{First Aid Measures}

\section{Inhalation:}

Remove to fresh air. Get medical attention for any breathing difficulty.

Ingestion:

Not expected to require first aid measures. If large amounts were swallowed, give water to drink and get medical advice.

Skin Contact:

Not expected to require first aid measures. Wash exposed area with soap and water. Get medical advice if irritation develops.

Eye Contact:

Immediately flush eyes with plenty of water for at least 15 minutes, lifting upper and lower eyelids occasionally. Get medical attention if irritation persists.

\section{Fire Fighting Measures}


Fire:

Flash point: $42 \mathrm{C}$ (108F) CC

Autoignition temperature: $354 \mathrm{C}(669 \mathrm{~F})$

Flammable limits in air $\%$ by volume:

lel: 1.5 ; uel: 7.0

Flammable Liquid and Vapor! Contact with strong oxidizers may cause fire.

Explosion:

Sealed containers may rupture when heated. Above the flash point, explosive vapor-air mixtures may be formed. Vapors can flow along surfaces to distant ignition source and flash back. May form unstable peroxides which may explode spontaneously or when heated. Fire Extinguishing Media:

Water spray, dry chemical, alcohol foam, or carbon dioxide. Water spray may be used to keep fire exposed containers cool.

Special Information:

In the event of a fire, wear full protective clothing and NIOSH-approved se If-contained breathing apparatus with full facepiece operated in the pressure demand or other positive pressure mode.

\section{Accidental Release Measures}

Ventilate area of leak or spill. Remove all sources of ignition. Wear appropriate personal protective equipment as specified in Section 8. Isolate hazard area. Keep unnecessary and unprotected personnel from entering. Contain and recover liquid when possible. Use nonsparking tools and equipment. Collect liquid in ar appropriate container or absorb with an inert material (e. g., vermiculite, dry sand, earth), and place in a chemical waste container. Do not use combustible materials, such as saw dust. Do not flush to sewer! If a leak or spill has not ignited, use water spray to disperse the vapors, to protect personnel attempting to stop leak, and to flush spills away from exposures.

\section{Handling and Storage}

Protect against physical damage. Store in a cool, dry well-ventilated location, away from any area where the fire hazard may be acute. Outside or detached storage is preferred. Separate from incompatibles. Containers should be bonded and grounded for transfers to avoid static sparks. Storage and use areas should be No Smoking areas. Use non-sparking type tools and equipment, including explosion proof ventilation. After opening, purge container with nitrogen before re-closing. Periodically test for peroxide formation on longterm storage. Do not distill to near dryness. If peroxide formation is suspected, do not open or move container. Addition of water or appropriate reducing materials will lessen peroxide formation. Containers of this material may be hazardous when empty since they retain product residues (vapors, liquid); observe all warnings and precautions listed for the product. Do Not attempt to clean empty containers since residue is difficult to remove. Do not pressurize, cut, weld, braze, solder, drill, grind or expose such containers to heat, sparks, flame, static electricity or other sources of ignition: they may explode and cause injury or death. 


\title{
8. Exposure Controls/Personal Protection
}

\author{
Airborne Exposure Limits: \\ For Propylene Glycol Monomethyl Ether Acetate: \\ - AIHA Workplace Environmental Exposure Level (WEEL) - \\ $100 \mathrm{ppm}$ (TWA). \\ Ventilation System: \\ A system of local and/or general exhaust is recommended to keep employee exposures \\ below the Airborne Exposure Limits. Local exhaust ventilation is generally preferred \\ because it can control the emissions of the contaminant at its source, preventing dispersion \\ of it into the general work area. Please refer to the ACGIH document, Industrial \\ Ventilation, A Manual of Recommended Practices, most recent edition, for details. \\ Personal Respirators (NIOSH Approved): \\ If the exposure limit is exceeded, wear a supplied air, full-facepiece respirator, airlined \\ hood, or full-facepiece self-contained breathing apparatus. \\ Skin Protection: \\ Wear protective gloves and clean body-covering clothing. \\ Eye Protection: \\ Use chemical safety goggles and/or a full face shield where splashing is possible. Maintain \\ eye wash fountain and quick-drench facilities in work area.
}

\section{Physical and Chemical Properties}

\author{
Appearance: \\ Clear, colorless liquid. \\ Odor: \\ Sweet ether-like odor. \\ Solubility: \\ Appreciable in water. \\ Specific Gravity: \\ 0.969 @20C (68F) \\ pH: \\ No information found. \\ $\%$ Volatiles by volume a $21 \mathrm{C}(70 \mathrm{~F})$ : \\ No information found. \\ Boiling Point: \\ 150C (302F) \\ Melting Point: \\ No information found. \\ Vapor Density $(\mathrm{Air}=1)$ : \\ 4.6 \\ Vapor Pressure $(\mathrm{mm} \mathrm{Hg})$ : \\ $3.7 @ 20 \mathrm{C}(68 \mathrm{~F})$ \\ Evaporation Rate $(\mathrm{BuAc}=1)$ : \\ 0.39
}




\section{Stability and Reactivity}

Stability:

Stable under ordinary conditions of use and storage. Unstable at elevated temperatures. May form explosive peroxides.

Hazardous Decomposition Products:

Carbon dioxide and carbon monoxide may form when heated to decomposition.

Hazardous Polymerization:

Will not occur.

Incompatibilities:

Oxidizers can cause vigorous reaction.

Conditions to Avoid:

Heat, flames, ignition sources and incompatibles.

\section{Toxicological Information}

For Propylene Glycol Monomethyl Ether Acetate: LD50 oral rat $8532 \mathrm{mg} / \mathrm{kg}$; LD50 skin rabbit $>5 \mathrm{gm} / \mathrm{kg}$.

\begin{tabular}{|c|c|c|c|}
\hline & $---N T P$ & Carcinogen--- & \\
\hline Ingredient & Known & Anticipated & IARC Category \\
\hline Propylene glycol monomethyl ether & No & 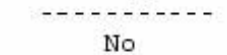 & None \\
\hline
\end{tabular}

\section{Ecological Information}

Environmental Fate:

No adverse ecological effects are expected.

Environmental Toxicity:

This material is not expected to be toxic to aquatic life. The LC50/96-hour values for fish are over $100 \mathrm{mg} / \mathrm{l}$. The EC50/48-hour values for daphnia are over $100 \mathrm{mg} / \mathrm{l}$.

\section{Disposal Considerations}

Whatever cannot be saved for recovery or recycling should be handled as hazardous waste and sent to a RCRA approved waste facility. Processing, use or contamination of this product may change the waste management options. State and local disposal regulations may differ from federal disposal regulations. Dispose of container and unused contents in 
accordance with federal, state and local requirements.

\section{Transport Information}

Domestic (Land, D.O.T.)

Proper Shipping Name: FLAMMABLE LIQUID, N.O.S. (PROPYLENE GLYCOL MONOMETHYL ETHER ACETATE)

Hazard Class: 3

UN/NA: UN1993

Packing Group: $11 \mathrm{II}$

Information reported for product/size: $425 \mathrm{LB}$

International (Water, I.M.O.)

Proper Shipping Name: FLAMMABLE LIQUID, N.O.S. (PROPYLENE GLYCOL MONOMETHYL ETHER ACETATE)

Hazard Class: 3

UN/NA: UN1993

Packing Group: III

Information reported for product/size: $425 \mathrm{LB}$

\section{Regulatory Information}

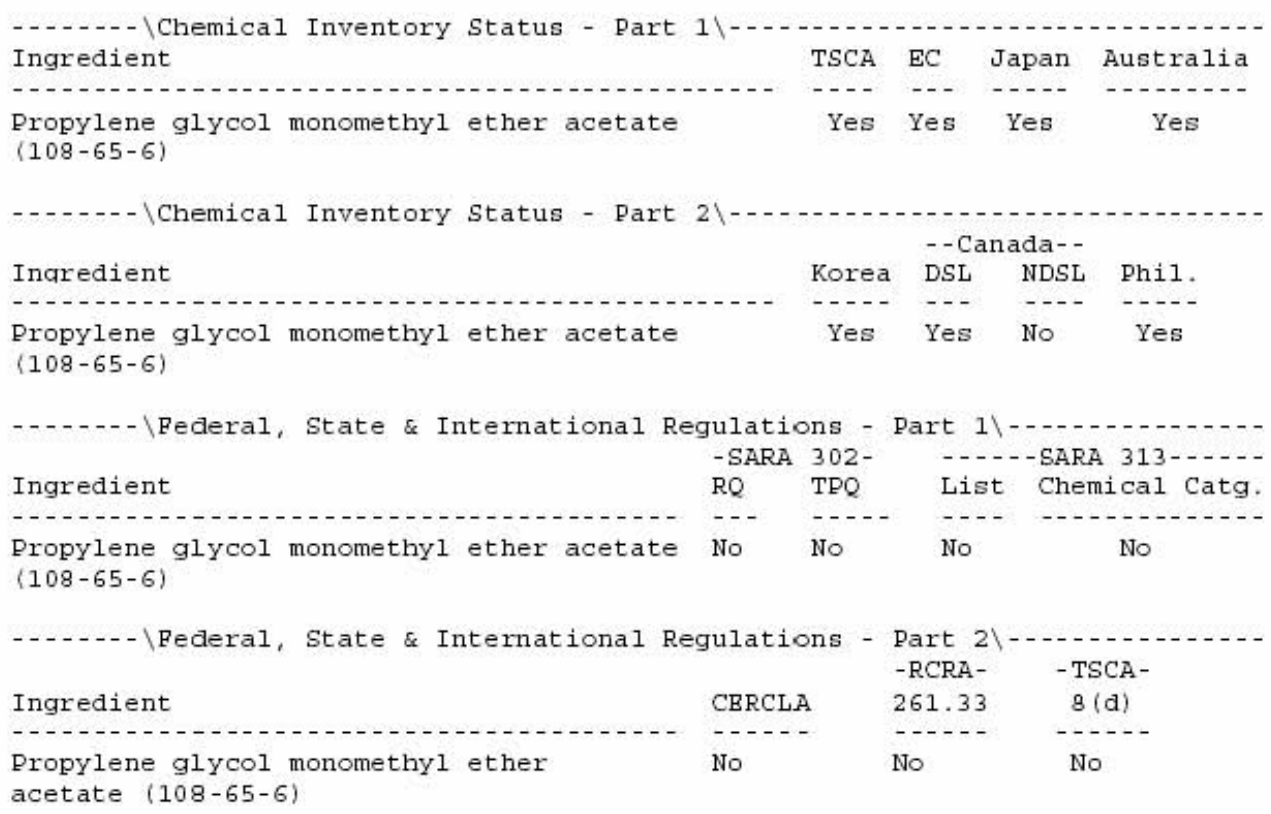




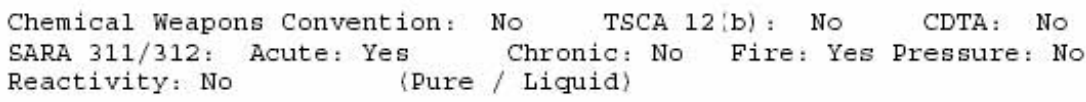

Australian Hazchem Code: None allocated.

Poison Schedule: None allocated.

WHMIS:

This MSDS has been prepared according to the hazard criteria of the Controlled Products

Regulations (CPR) and the MSDS contains all of the information required by the CPR.

\section{Other Information}

NFPA Ratings: Health: 0 Flammability: 2 Reactivity: 0

Label Hazard Warning:

WARNING! FLAMMABLE LIQUID AND VAPOR. MAY FORM EXPLOSIVE

PEROXIDES. MAY CAUSE IRRITATION TO EYES AND RESPIRATORY TRACT.

Label Precautions:

Keep away from heat, sparks and flame.

Keep container closed.

Use only with adequate ventilation.

Avoid contact with eyes, skin and clothing.

Wash thoroughly after handling.

Avoid breathing vapor or mist.

Label First Aid:

If inhaled, remove to fresh air. Get medical attention for any breathing difficulty. In case of

eye contact, immediately flush eyes with plenty of water for at least 15 minutes. Get

medical attention if irritation develops or persists

Product Use:

Laboratory Reagent.

Revision Information:

MSDS Section(s) changed since last revision of cocument include: 3.

Disclaimer:

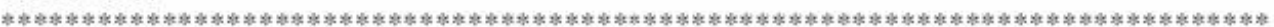

Mallinckrodt Baker, Inc. provides the information contained herein in good faith but makes no representation as to its comprehensiveness or accuracy. This document is intended only as a guide to the appropriate precautionary handling of the material by a properly trained person using this product. Individuals receiving the information must exercise their independent judgment in determining its appropriateness for a particular purpose. MALLINCKRODT BAKER, INC. MAKES NO REPRESENTATIONS OR WARRANTIES, EITHER EXPRESS OR IMPLIED, INCLUDING WITHOUT LIMITATION ANY WARRANTIES OF MERCHANTABILITY, FITNESS FOR A PARTICULAR PURPOSE WITH RESPECT TO THE INFORMATION SET FORTH HEREIN OR THE PRODUCT TO WHICH THE INFORMATION REFERS. ACCORDINGLY, MALLINCKRODT 
BAKER, INC. WILL NOT BE RESPONSIBLE FOR DAMAGES RESULTING FROM USE OF OR RELIANCE UPON THIS INFORMATION.

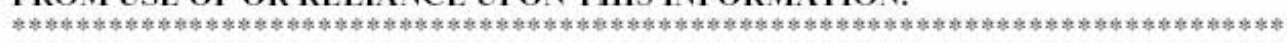

Prepared by: Environmental Health \& Safety

Phone Number: (314) 654-1600 (U.S.A.) 
$\underline{\mathrm{BOE}}$

Honeywell

\title{
Material Safety Data Sheet
}

\author{
1. CHEMICAL PRODUCT AND COMPANY IDENTIFICATION \\ PRODUCT NAME: 6:1 BOE \\ OTHER/GENERIC NAMES: $6: 1 \mathrm{BOE}$ \\ PRODUCT USE: Semiconductor Manufacturing \\ MANUFACTURER: Honeywell/GEM3 \\ 101 Columbia Road \\ Morristown, New Jersey 07962-1053 \\ FOR MORE INFORMATION CALL: \\ (Monday-Friday, 8:00am-5:00 pm) \\ 1-800-279-9998 \\ IN CASE OF EMERGENCY CALL: \\ (24 Hours/Day, 7 Days/Week) \\ 1-800-707-4555 or Chemtrec 1-800-424-9300 \\ International: 1-703-527-3887 \\ 2. COMPOSITION/INFORMATION ON INGREDIENTS \\ INGREDIENT NAME \\ Ammonium Fluoride \\ Hydrofluoric Acid

$\begin{array}{cc}\frac{\text { CAS NUMBER }}{12125-01-8} & \frac{\text { WEIGHT \% }}{<36 \%} \\ 7664-39-3 & <10 \%\end{array}$ \\ Trace impurities and additional material names not listed above may also appear in Section 15 toward the end of the \\ MSDS. These materials may be listed for local "Right-To-Know" compliance and for other reasons.

\footnotetext{
3. HAZARDS IDENTIFICATION

EMERGENCY OVERVIEW:

Extremely hazardous liquid and vapor. Causes severe burns that may not be immediately painful or visible. May be fatal if inhaled or swallowed. May cause damage to bones.

\section{POTENTIAL HEALTH HAZARDS}

SKIN: Liquid causes severe irritation and burns of eyes and skin

EYES: Both liquid and vapor can cause irritation or corneal burns.

INHALATION: May cause irritation to mucous membranes. Inhalation causes acute systematic poisoning which must receive immediate medical attention.
} \\ INGESTION: Ingestion causes vomiting and severe burns of mouth and stomach.
}




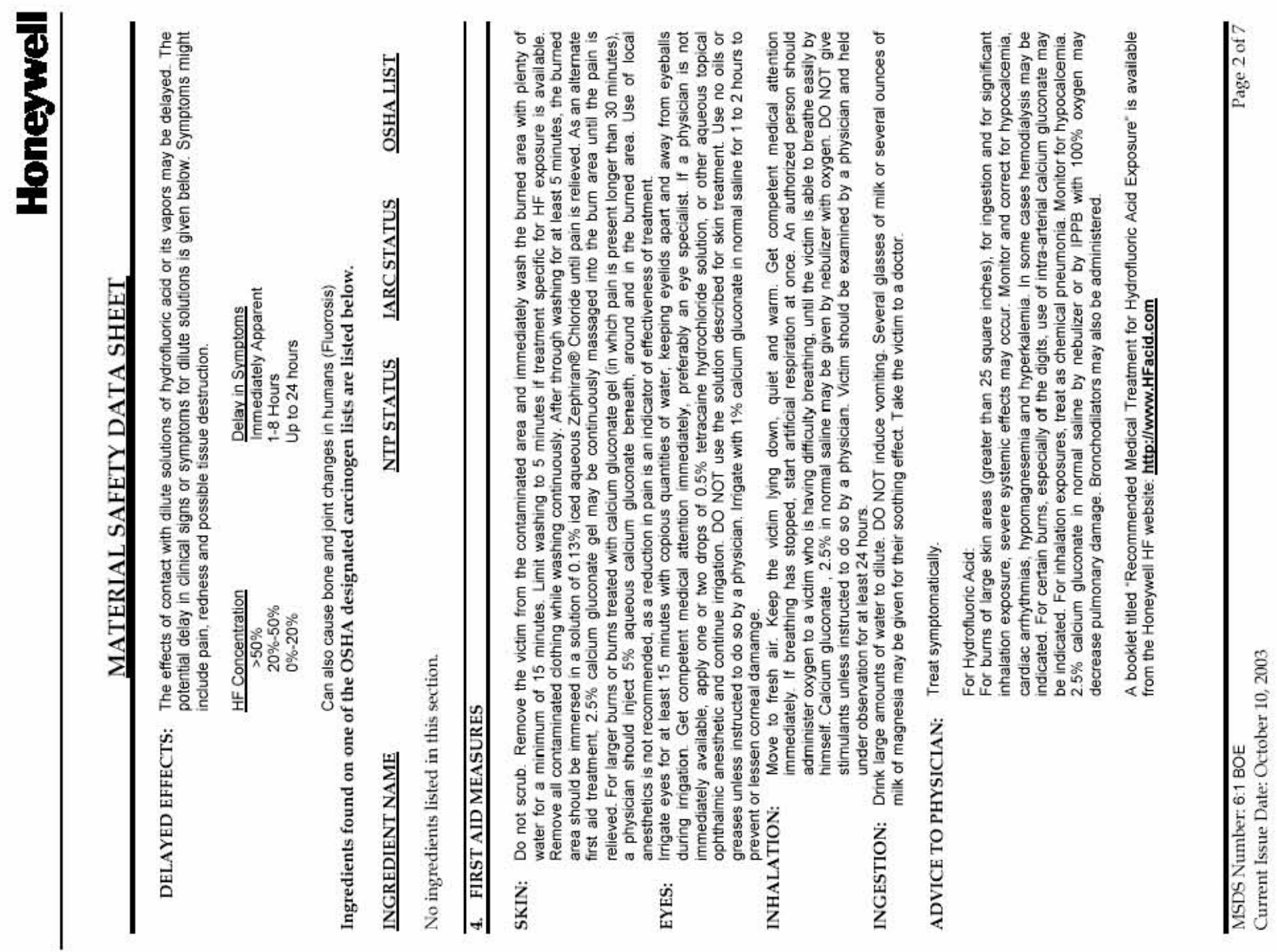




\section{MATERIAL SAFETY DATA SHEET}

5. FIRE FIGHTING MEASURES

\section{FLAMMABLE PROPERTIES}

$\begin{array}{ll}\text { FLASH POINT: } & \text { Not flammable } \\ \text { FLASH POINT METHOD: } & \text { Closed cup } \\ \text { AUTOIGNITION TEMPERATURE: } & \text { N/A } \\ \text { UPPER FLAME LIMIT (volume \% in air): } & \text { N/A } \\ \text { LOWER FLAME LIMIT (volume \% in air): } & \text { N/A } \\ \text { FLAME PROPAGATION RATE (solids): } & \text { N/A } \\ \text { OSHA FLAMMABILITY CLASS: } & \text { N/A }\end{array}$

EXTINGUISHING MEDIA:

Use water or suitable agent for fires adjacent to non-leaking tanks or containers of $\mathrm{HF}$. This substance is not combustible. Use water fog or carbon dioxide. DO NOT use solid water streams near ruptured tanks or spills of HF. Acid reacts with water and can splatter acid onto personnel.

\section{UNUSUAL FIRE AND EXPLOSION HAZARDS:}

The product is not flammable. Emits toxic fumes.

SPECIAL FIRE FIGHTING PRECAUTIONS/INSTRUCTIONS:

Use spray to cool exposed containers. Block sewers in the path of spreading spill to prevent entry. Remove containers of this material to cool areas. Prevent the boiling of this formulation. Wear self-contained breathing apparatus approved by NIOSH and full chemical protective clothing. Use water spray to keep containers cool.

\section{ACCIDENTAL RELEASE MEASURES}

IN CASE OF SPILL OR OTHER RELEASE: (Always wear recommended personal protective equipment.)

Good ventilation is necessary. Discharge will ordinarily be a vapor or a liquid that gives off fumes of HF gas. Those treating spills or repaining leaks must use full protective equipment. Take actions to minimize environmental impact. Try to contain spillage and avoid drainage to areas, which cannot be treated. Rapid dilution of the spill with water will reduce the amount of fumes given off. Carefully neutralize the dilute liquid with lime slurry, soda ash, limestone, caustic soda or other alkaline material. (See sections 10 and 13 for more information.)

Spills and releases may have to be reported to Federal and/or local authorities. See Section 15 regarding reporting requirements.

\section{HANDLING AND STORAGE}

NORMAL HANDLING: (Always wear recommended personal protective equipment.)

DO NOT breathe vapor or mist. Use only adequate ventilation. Avoid all contact with skin, eyes and clothing, even dilute solutions. DO NOT add water to acid.

\section{STORAGE RECOMMENDATIONS:}

Store in approved containers only. Store in cool, well-ventilated area. Flammable hydrogen gas can be generated in contact with metals. Diking of storage tanks is recommended. Store above $70^{\circ} \mathrm{F}$ 
MATERIAL SAFETY DATA SHEET

8. EXPOSURE CONTROLS/PERSONAL PROTECTION

\section{ENGINEERING CONTROLS:}

Material must be handled or transferred in an approved fume hood or with equivalent ventilation sufficient to reduce vapor and acid mists below permissible TLV levels. Packaging and unloading areas and open processing equipment may require mechanical exhaust systems.

\section{PERSONAL PROTECTIVE EOUIPMENT}

SKIN PROTECTION:

For routine product use, wear acid-resistant jacket, trousers, boots and gauntlet gloves. For increased protection, use airsupplied totally encapsulating HF resistant protective suit.

\section{EYE PROTECTION:}

As a minimum, wear hardhat, chemical safety goggles (plastic lenses), and full-face plastic shield. For increased protection, use air-supplied hydrofluoric acid resistant hood.

\section{RESPIRATORY PROTECTION:}

Where required, use a respirator approved by NIOSH for HF gas or mists, as applicable. Some exposures may require a $\mathrm{NIOSH}$-approved, self-contained breathing apparatus or air supplied respirator.

\section{ADDITIONAL RECOMMENDATIONS:}

Eyewash and quick-drench shower facilities, protected from freezing, should be available where HF is stored or handled.

\section{EXPOSURE GUIDELINES}

\section{INGREDIENT NAME \\ Hydrofluoric Acid}

ACGIH TLV $\frac{\text { 3ppm-Ceiling }}{\text { 3pung }}$ $\frac{\text { OSHA PEL }}{3 p p m(\text { TWA })}$
OTHER LIMIT

$3 \mathrm{mg}(\mathrm{F}) / \mathrm{g}$ creatinine in urine pre-shift $10 \mathrm{mg}(\mathrm{F}) / \mathrm{g}$ creatinine post-shift***

Ammonium Fluoride

$\frac{\text { OSHA STEL }}{6 \mathrm{ppm}(15 \mathrm{~min})} \quad \underline{\text { IDLH }}$

\begin{tabular}{|c|c|c|}
\hline $\begin{array}{c}2.5 \mathrm{mg} / \mathrm{m}^{3} \\
\text { AIHA EI }\end{array}$ & $\begin{array}{l}\text { None } \\
\text { y Response P1 }\end{array}$ & \\
\hline ERPG-1 & ERPG-2 & ERPG-3 \\
\hline ppm (60mins) & $20 \mathrm{ppm}$ (60mins) & $5 \overline{0 p p m ~(60 m i n s) ~}$ \\
\hline ppm (10mins) & $20 \mathrm{ppm}$ (10mins) & $50 \mathrm{ppm}$ (10mins) \\
\hline
\end{tabular}

* = Limit established by Honeywell International, Inc.

** $=$ Workplace Environmental Exposure Level (AIHA).

$* * *=$ Biological Exposure Index $(\mathrm{ACGIH})$.

\section{OTHER EXPOSURE LIMITS FOR POTENTIAL DECOMPOSITION PRODUCTS: None}

9. PHYSICAL AND CHEMICAL PROPERTIES

$\begin{array}{ll}\text { APPEARANCE: } & \text { Colorless liquid } \\ \text { PHYSICAL STATE: } & \text { Liquid } \\ \text { MOLECULAR WEIGHT: } & \text { Mixture }\end{array}$

MSDS Number: 6:1 BOE

Page 4 of 7

Current Issue Date: October 10, 2003 
MATERIAL SAFETY DATA SHEET

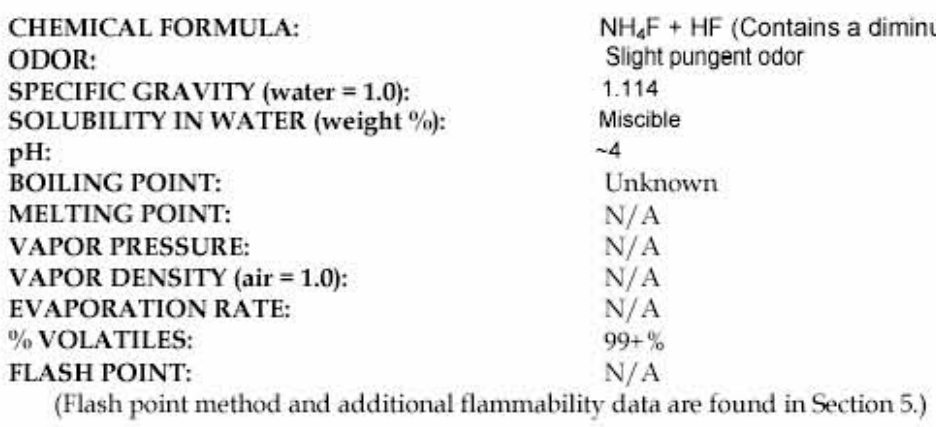

OTHER DATA: Tests on laboratory animals indicate $\mathrm{HF}$ in concentrate form may produce adverse mutagenic and reproductive effects. Cited in Registry of Toxic Effects of Substances (RTECS). 
Honeywell

\section{MATERIAL SAFETY DATA SHEET}

\section{STATE RIGHT-TO-KNOW}

In addition to the ingredients found in Section 2, the following are listed for state right-to-know purposes.

INGREDIENT NAME

No ingredients listed in this section.

WEIGHT \% COMMENT

ADDITIONAL REGULATORY INFORMATION: None

WHMIS CLASSIFICATION (CANADA): N/A

FOREIGN INVENTORY STATUS: N/A

16. OTHER INFORMATION

CURRENT ISSUE DATE: October 9, 2003

PREVIOUS ISSUE DATE: July 17,2000

CHANGES TO MSDS FROM PREVIOUS ISSUE DATE ARE DUE TO THE FOLLOWING:

Converted to ANSI 16-section format.

OTHER INFORMATION: Honeywell MAKES NO WARRANTY, EXPRESSED OR IMPLIED, CONCERNING THIS MATERIAL OR THE USE OF THIS PRODUCT OTHER THAN INDICATED ON THE LABEL. BUYER ASSUMES ALL RISK OF USE AND/OR HANDLING OF THIS MATERIAL WHEN SUCH USE AND/OR HANDLING IS CONTRARY TO LABEL INSTRUCTIONS

NFPA Hazard Ratings:

Health:

4

Flammability: $\quad 0$

Reactivity: 1

Special Hazards: 


\section{Nichrome Etchant TFN}

\section{MATERIAL SAFETY DATA SHEET}

IDENTITY (As Used on Label and List)

CHROMIUM ETCH 1020

CHROME ETCH 8001N

NICHROME ETCH TFN

\section{Section I}

Manufacturers Name

TRANSENE COMPANY INC.

Address

10 ELECTRONICS AVENUE

DANVERS MA 01923
Note: Blank spaces are not permitted. If any item is not applicable, or no information is available, the space must be marked to indicate that.

\section{Section II - Hazardous Ingredients / Identity Information}

\begin{tabular}{|c|c|c|c|c|c|}
\hline \multirow{2}{*}{\multicolumn{2}{|c|}{ Hazardous Components (Specific Chemical Identitv Common Name(s)) }} & & \multicolumn{3}{|c|}{ Other Limits } \\
\hline & & OSHA PEL & ACG1H TLV & Recommended & $\%$ (optional) \\
\hline CERIC AMMONIUM NITRATE & CAS\# $16774-21-3$ & oral rat $\mathrm{LD}_{50}$ & 244ppm * & & $10-20$ \\
\hline NITRIC ACID $\left(\mathrm{HNO}_{3}\right)$ & CAS\# 7697-37-2 & & $2 \mathrm{ppm}$ & & $5-6$ \\
\hline
\end{tabular}

NON-HAZARDOUS AQUEOUS SOLUTION

* AS NITRATE

(THIS PRODUCT CONTAINS NO MORE THAN 6\% BY WT. NITRIC ACID, WHICH IS CONSIDERED TO BE A TOXIC CHEMICAL UNDER TITLE III. EMISSIONS DATA MUST BE SUBMITTED ANNUALLY TO THE EPA FOR COMPANIES WHO MANUFACTURE, PROCESS OR OTHERWISE USE THIS PRODUCT IN EXCESS OF CERTAIN QUANTITIES ESTABLISHED BY THE EPA. THIS INFORMATION MUST BE INCLUDED IN ALL MSDS THAT ARE COPIED AND DISTRIBUTED FOR THIS MATERIAL.)

$$
\text { Health : } 3 \quad \text { Reactivity : } 0 \quad \text { Flammability : } 0
$$

Section III - Physical/Chemical Characteristics

Boiling Point $\left(100^{\circ} \mathrm{C}\right)$

Vapor Pressure ( $\mathrm{mm}$ Hg.)

Vapor Density $(A I R=1)$

$\mathrm{N} / \mathrm{A}$

$\mathrm{N} / \mathrm{A}$

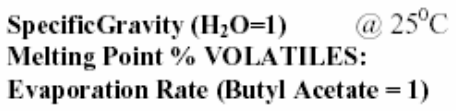

$85 \%$

Similar

to water

Solubility in Water: COMPLETE

Appearance and Odor: ORANGE LIQUID WITH PRACTICALLY NO ODOR.

Section IV - Fire and Explosion Hazard Data

Flash Point (Method Used) NON- FLAMMABL

Flammable Limits LEL UEL

$\mathrm{N} / \mathrm{A}$

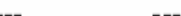

Extinguishing Media: WATER SPRAY IN CASE OF FIRE CAUSED BY SPILLAGE. DO NOT USE ORGANIC FIRE EXTINGUISHING AGENTS.

Special Fire Fighting Procedures: WEAR NIOSH APPROVED SELF-CONTAINED BREATHING APPARATUS AND APPROPRIATE PROTECTIVE APPAREL

Unusual Fire and Explosion Hazards: SPILLAGE MAY CAUSE FIRE OR LIBERATE DANGEROUS GAS. INCREASES FLAMMABILITY OF COMBUSTIBLE ORGANICS AND DEADLY OXIDIZABLE

MATERIALS. MAY CAUSE IGNITION.

Section V-Reactivity Data

Stability: Unstable Stable $\mathrm{X}$
Conditions to Avoid

ORGANIC MATERIALS, STRONG OXIDANTS, HEAT 
Incompatibility (Materials to Avoid): METALLIC POWDERS, CARBIDES, HYDROGEN SULFIDE AND EASILY OXIDIZED MATERIALS

Hazardous Decomposition or Byproducts:

OXIDES OF NITROGEN, STRONG BASES. AND METALS

Conditions to Avoid

Will Not Occur $\mathrm{X}$

EXCESSIVE HEAT

Section VI- Health Hazard Data

Route(s) of Entry: Inhalation?

YES

Skin?

Ingestion?

Health Hazards (Acute and Chronic)

MAY CAUSE IRRITATION TO LUNGS AND RESPIRATORY SYSTEM.

Carcinogenicity: NTP? IARC Monographs?

NO NO YES

Signs and Symptoms of Exposure:

MAY CAUSE IRRITATION AND BURNS

Medical Conditions Generally Aggravated by Exposure:

MAY CAUSE IRRIATION AND BURNS. VAPOR OR SPRAYS CAN BE HAZARDOUS TO THE LUNGS AND

RESPIRATORY SYSTEM. MATERIAL IS CORROSIVE TO EYES, SKIN, AND MUCOUS MEMBRANES.

Emergency and First Aid Procedures:

EYE CONTACT: IMMEDIATELY GET MEDICAL ATTENTION

SKIN: REMOVE CONTAMINATED CLOTHING AND SHOES, WASH EXPOSED ARE WITH SOAP AND

WATER. GET MEDICAL ATTENTION.

INHALATION: REMOVE TO FRESH AIR. IF BREATHING HAS STOPPED, GIVE ARTIFICIAL RESPIRATION

INGESTION: DO NOT INDUCE VOMITING. GET MEDICAL ATTENTION!

Section VII - Precautions for Safe Handling and Use

Steps to Be Taken in Case Material Is Released or Spilled:

ISOLATE OR ENCLOSE THE AREA OF SPILL OR LEAK. NEUTRALIZE WITH CALCIUM CARBONATE, WASH WITH EXCESS WATER. PICK UP WITH ABSORBENT MATERIAL (SAND OR VERMICULITE) AND DISPOSE IN A RCRA APPROVED WASTE FACILITY.

Waste Disposal Method: CLEAN UP PERSONNEL SHOULD WEAR PROTECTIVE CLOTHING AND

RESPIRATORY EQUIPMENT SUITABLE FOR TOXIC FUMES. DISPOSE OF IN ACCORDANCE WITH

LOCAL, STATE OR FEDERAL ENVIRONMENTAL REGULATIONS.

Precautions to Be Taken in Handling and Storing: STORE IN WELL-VENTILATED AREA. ROOM

TEMPERATURE STORAGE-SEALED BOTTLES

Other Precautions: STORE AWAY FROM INCOMPATIBLE MATERIALS. PROTECT FROM PHYSICAL

DAMAGE AND DIRECT SUNLIGHT.

\section{Section VIII-Control Measures}

Respiratory Protection (Specify Type)

IF TLV IS EXCEEDED WEAR A NIOSH APPROVED SELF-CONTAINED BREATHING APPARATUS.

Ventilation: Local Exhaust: MAINTAIN ADEQUATE VENTILATION

Mechanical (general): EXPOSURE TO LIMITS BELOW AIRBORNE EXPOSURE LIMITS

Special: EYE BATH AND SHOWER FACILITIES WORK AREA.

Protective Gloves: RUBBER

Eye Protection: CHEMICAL SAFETY GOGGLES OR FACE SHEILD.

Other Protective Clothing or Equipment:

PROTECTIVE CLOTHING, RUBBER APRON / USE APPROPRIATE INDUSTRIAL PRACTICES FOR

HANDLING ACIDS

Work/Hygienic Practices: USE APPROPRIATE INDUSTRIAL PRACTICES FOR HANDLING ACIDS. 


\section{REGULATORY STATUS}

ADDENDUM TO MATERIAL SAFETY DATA SHEET

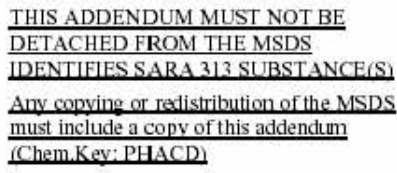

No

No

\section{HAZARD CATEGORIES FOR SARA Section 31/312 Reporting}

Acute Chronic Eire Pressure Reactive

Applicable Products:

Reagent Semiconductor Etchants (RSE 100- RSE 1155),

Nitric Acid 70\%, Wright Etchant, TFB, TFD, TFC,

TFN 1020, Chromium Mask Etchant

SARA Section 302 EHS RQ: Reportable Quantity of Extremely Hazardous Substance, listed at 40 CFR 355. SARA Section 302 EHS TPQ: Threshold Planning Quantity of Extremely Hazardous Substance. An asterisk $\left(^{(}\right)$following a threshold Planning Quantity signifies that if the material is a solid and has a particle size equal to or larger than 100 micrometers, the Threshold Planning Quantity $+10,000$ LBS. SARA Section 313 Chemicals: Toxic Substances subject to annual release reporting requirements listed at 40 CFR 372.65 .

CERCLA Sec 103: Comprehensive Environmental Response, Compensation and Liability Act (Superfund). Releases to air, land or water of these hazardous substances which exceed the Reportable Quantity (RQ) must be reported to the National Response Center (800-424-8802); Listed at 40 CFR 302.4 RCRA: Resource Conservation and Reclamation Act. Commercial chemical product wastes designated as acute hazards and toxic under $40 \mathrm{CFR} 261.33$ 


\section{Material Safety Data Sheet}

1. PRODUCT AND COMPANY IDENTIFICATION

MICROPOSIT(TM) MF(TM) -319 Developer

Supplier

Rohm and Haas Electronic Materials LLC

Revision date:

$01 / 01 / 2004$

455 Forest Street

Marlborough, MA 01752 United States of America

For non-emergency information contact: $508-481-7950$

Emergency telephone number

Chemtrec

$800-424-9300$

Rohm and Haas Emergency

$215-592-3000$

\begin{tabular}{lcc}
\hline \hline 2. COMPOSITION/INFORMATION ON INGREDIENTS & \\
\hline Component & CAS-Nlo. & Concentration \\
\hline Water & $7732-18-5$ & $>95.0 \%$ \\
Surfactant & & $<1.0 \%$ \\
Tetramethylammonium hydroxide & $75-59-2$ & $2.2 \%$ \\
& & \\
\hline
\end{tabular}

3. HAZARDS IDENTIFICATION

Emergency Overview

Appearance

Form liquid

Colour colourless

Odour amines

\begin{tabular}{ll}
\hline Hazard Summary & WARNING! \\
Alkaline liquid and vapor. Causes skin, eye, and respiratory tract
\end{tabular}

irritation. Onset of symptoms may be delayed.

Prolonged, repeated contact, inhalation, ingestion, or absorption through the skin, may cause toxic effects to internal organ systems (liver, kidney, central nervous system).

Potential Health Effects 
Primary Routes of Entry: Inhalation, ingestion, eye and skin contact, absorption.

Eyes: May cause pain, transient irritation and superficial corneal effects.

Skin: Material may cause irritation.

Prolonged or repeated exposure may have the following effects: central nervous system depression

drowsiness

defatting of skin leading to irritation and dermatitis

Ingestion: Swallowing may have the following effects:

irritation of mouth, throat and digestive tract

Repeated doses may have the following effects:

central nervous system depression

drowsiness

Inhalation: Inhalation may have the following effects:

irritation of nose, throat and respiratory tract

Higher concentrations may have the following effects:

systemic effects similar to those resulting from ingestion

Target Organs: Eye

Respiratory System

Skin

nervous system

Carcinogenicity

Not considered carcinogenic by NTP, IARC, and OSHA

\section{FIRST AID MEASURES}

Inhalation: Remove from exposure. If there is difficulty in breathing, give oxygen. Seek medical attention if symptoms persist.

Skin contact: Wash skin with water. Continue washing for at least 15 minutes. Obtain medical attention if blistering occurs or redness persists.

Eye contact: Immediately flush the eye with plenty of water for at least 15 minutes, holding the eye open. Obtain medical attention if soreness or redness persists.

Ingestion: Wash out mouth with water. Have victim drink 1-3 glasses of water to dilute stomach contents. Immediate medical attention is required Never administer anything by mouth if a victim is losing conciousness, is unconcious or is convulsing.

Notes to physician

Treat symptomatically.

\section{FIRE-FIGHTING MEASURES}

\section{Flash point Nonflammable}

Suitable extinguishing Not readily combustible. media:

Select extinguishing agent appropriate to other materials involved.

\begin{tabular}{lll}
\hline Page 2 of 7 & Revision date & $01 / 01 / 2004$
\end{tabular}


Specific hazards during fire fighting: No specific measures necessary.

Special protective equipment for fire-fighters: Wear full protective clothing and self-contained breathing apparatus.

Further information: This product may give rise to hazardous vapors in a fire.

\section{ACCIDENTAL RELEASE MEASURES}

\section{Personal precautions}

Wear suitable protective clothing.

\section{Environmental precautions}

Prevent the material from entering drains or water courses.

Do not discharge directly to a water source.

Advise Authorities if spillage has entered watercourse or sewer or has contaminated soil or vegetation.

Methods for cleaning up

Cover with absorbent or contain. Collect and dispose.

\section{HANDLING AND STORAGE}

\section{Handling}

Use only in well-ventilated areas. Avoid breathing vapor. Avoid contact with eyes, skin and clothing. Keep container tightly closed.

Further information on storage conditions: No special precautions necessary.

\section{Storage}

Storage conditions: Store in original container. Storage area should be: cool dry well ventilated out of direct sunlight away from incompatible materials

\section{EXPOSURE CONTROLS / PERSONAL PROTECTION}

\section{Exposure limit(s)}

Exposure limits are listed below, if they exist.

Eye protection: goggles

Hand protection: Butyl rubber gloves. Other chemical resistant gloves may be recommended by your safety professional.

Skin and body protection: Normal work wear. 
Respiratory protection: Respiratory protection if there is a risk of exposure to high vapor concentrations. The specific respirator selected must be based on the airborne concentration found in the workplace and must not exceed the working limits of the respirator.

Engineering measures: Engineering methods to prevent or control exposure are preferred. Methods include process or personnel enclosure, mechanical ventilation (local exhaust), and control of process conditions.

\section{PHYSICAL AND CHEMICAL PROPERTIES}

\begin{tabular}{ll}
$\begin{array}{l}\text { Appearance } \\
\text { Form } \\
\text { Colour } \\
\text { Odour }\end{array}$ & $\begin{array}{l}\text { liquid } \\
\text { colourless } \\
\text { amines }\end{array}$ \\
pH & 13 \\
Boiling point/range & $100^{\circ} \mathrm{C}\left(212^{\circ} \mathrm{F}\right)$ \\
Flash point & Nonflammable \\
\multicolumn{1}{l}{ Component: Tetramethylammonium hydroxide } \\
Vapour pressure & 17.5 mmHg at $20^{\circ} \mathrm{C}$ \\
Relative vapour density & no data available \\
Water solubility & completely soluble \\
Relative density & 1.00 \\
Evaporation rate & Slower than ether \\
VOC's & not applicable
\end{tabular}

NOTE: The physical data presented above are typical values and should not be construed as a specification.

\section{STABILITY AND REACTIVITY}

\begin{tabular}{ll}
$\begin{array}{l}\text { Hazardous reactions } \\
\text { Conditions to avoid }\end{array}$ & Stable under normal conditions. \\
$\begin{array}{l}\text { Materials to avoid } \\
\begin{array}{l}\text { Hazardous } \\
\text { decomposition } \\
\text { products } \\
\text { polymerization }\end{array}\end{array}$ & Methanol, oxides of carbon., nitrogen oxides (NOx), \\
\hline
\end{tabular}

\section{TOXICOLOGICAL INFORMATION}

Toxicological information on this product or its components appear in this section when such data is available. 


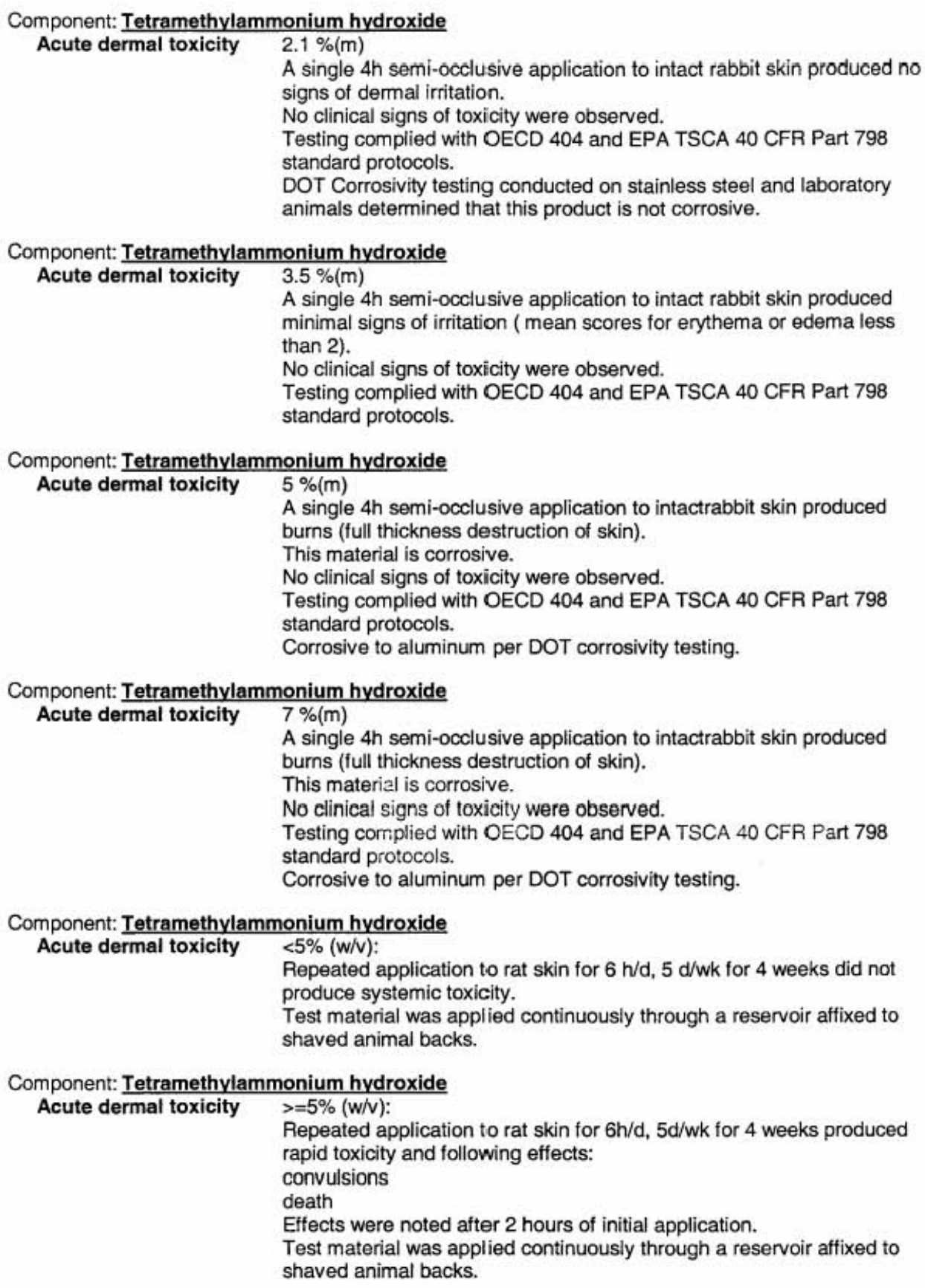


MICROPOSIT(TM) MF(TM) -319 Developer

Component: Tetramethylammonium hydroxide

Acute dermal toxicity LD50 guinea pig $25 \mathrm{mg} / \mathrm{kg}$

$100 \%$ (by weight).

\section{ECOLOGICAL INFORMATION}

Ecotoxicological information on this product or its components appear in this section when such data is available.

Tetramethylammonium hydroxide

Ecotoxicity effects

Toxicity to aquatic

invertebrates

LC50 ceriodaphnia dubia (water flea) $96 \mathrm{~h}$

$0.07-1.2 \mathrm{mg} / \mathrm{l}$

A pH neutralized solution has been shown to be toxic to aquatic

organisms.

\section{DISPOSAL CONSIDERATIONS}

Environmental precautions: Prevent the material from entering drains or water courses.

Do not discharge directly to a water source.

Advise Authorities if spillage has entered watercourse or sewer or has contaminated soil or vegetation.

\section{Disposal}

Dispose in accordance with all local, state (provincial), and federal regulations. Under RCRA, it is the responsibility of the product's user to determine at the time of disposal, whether the product meets RCRA criteria for hazardous waste. This is because the product uses, transformations, mixtures, processes, etc. may render the resulting materials hazardous.

Do not remove label until container is thoroughly cleaned. Empty containers may contain hazardous residues. This material and its container must be disposed of in a safe way.

\section{TRANSPORT INFORMATION}

\section{DOT}

Not regulated for transport

IMO/IMDG

Not regulated (Not dangerous for transport)

\section{REGULATORY INFORMATION}

SARA TITLE III: Section 311/312 Categorizations (40CFR370): Immediate health hazard

\section{SARA TITLE III: Section 313 Information (40CFR372)}

This product does not contain a chemical which is listed in Section 313 at or above de minimis concentrations.

\begin{tabular}{lll}
\hline Page 6 of 7 & Revision date & $01 / 01 / 2004$
\end{tabular}




\section{U.S. Toxic Substances Control Act (TSCA) Section 12(b) Export Notification (40 CFR}

707, Subpt D):

U.S. Toxic Substances Control Act (TSCA) Section 12(b) Export Notification (40 CFR 707, Subpt D)

This product does not contain any substances subject to Section 12(b) export notification.

US. Toxic Substances Control Act (TSCA) All components of this product are in compliance with the inventory listing requirements of the U.S. Toxic Substances Control Act (TSCA) Chemical Substance Inventory.

\section{California (Proposition 65)}

This product does not contain materials which the State of California has found to cause cancer, birth defects or other reproductive harm.

\section{OTHER INFORMATION}

Hazard Rating
\begin{tabular}{|l|c|c|c|}
\hline & Health & Fire & Reactivity \\
\hline NFPA & 3 & 0 & 0 \\
\hline
\end{tabular}

Legend

\begin{tabular}{|l|l|}
\hline ACGIH & American Conference of Governmental Industrial Hygienists \\
\hline BAC & Butyl acetate \\
\hline OSHA & Occupational Safety and Health Administration \\
\hline PEL & Permissible Exposure Limit \\
\hline STEL & Short Term Exposure Limit (STEL): \\
\hline TLV & Threshold Limit Value \\
\hline TWA & Time Weighted Average (TWA): \\
\hline I & Bar denotes a revision from prior MSDS. \\
\hline
\end{tabular}

The information provided in this Safety Data Sheet is correct to the best of our knowledge, information and belief at the date of its publication. The information given is designed only as a guidance for safe handling, use, processing, storage, transportation, disposal and release and is not to be considered a warranty or quality specification. The information relates only to the specific material designated and may not be valid for such material used in combination with any other materials or in any process, unless specified in the text.

Version: 2.0

Print Date: $\quad$ 02/06/2004 
APPENDIX B

FILES USED FOR MICROMILLING MACHINE

STU COMPLETE 1 ROUGH.txt

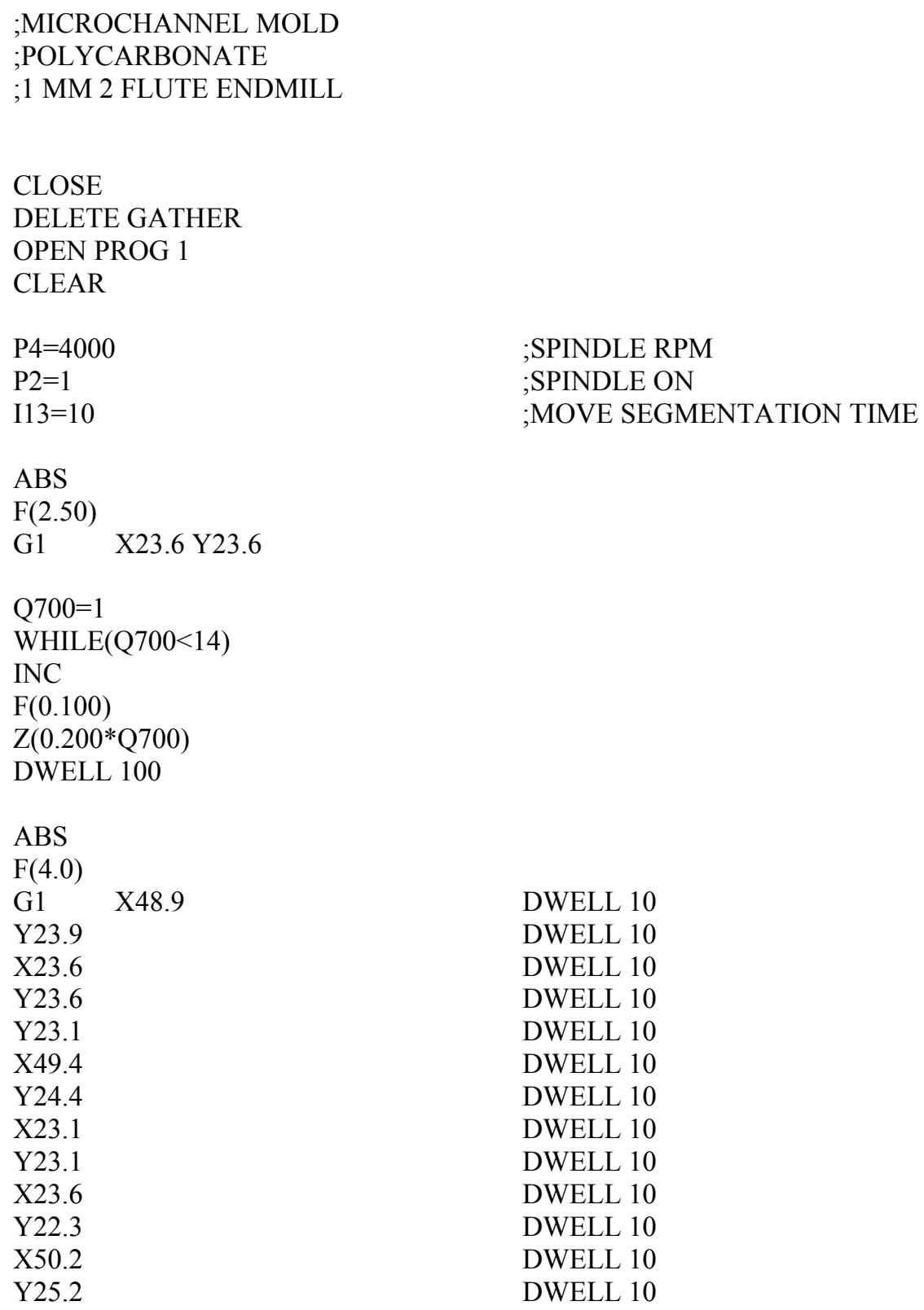




\begin{tabular}{|c|c|}
\hline X22.3 & DWELL 10 \\
\hline Y22.3 & DWELL 10 \\
\hline$X 23.6$ & DWELL 10 \\
\hline Y21.5 & DWELL 10 \\
\hline X51.0 & DWELL 10 \\
\hline Y26.0 & DWELL 10 \\
\hline X21.5 & DWELL 10 \\
\hline Y21.5 & DWELL 10 \\
\hline X23.6 & DWELL 10 \\
\hline Y20.7 & DWELL 10 \\
\hline X51.8 & DWELL 10 \\
\hline Y26.8 & DWELL 10 \\
\hline X20.7 & DWELL 10 \\
\hline Y20.7 & DWELL 10 \\
\hline X23.6 & DWELL 10 \\
\hline Y19.9 & DWELL 10 \\
\hline X52.6 & DWELL 10 \\
\hline Y27.6 & DWELL 10 \\
\hline X19.9 & DWELL 10 \\
\hline Y19.9 & DWELL 10 \\
\hline X23.6 & DWELL 10 \\
\hline Y19.1 & DWELL 10 \\
\hline X53.4 & DWELL 10 \\
\hline Y28.4 & DWELL 10 \\
\hline X19.1 & DWELL 10 \\
\hline Y19.1 & DWELL 10 \\
\hline X23.6 & DWELL 10 \\
\hline Y18.3 & DWELL 10 \\
\hline X54.2 & DWELL 10 \\
\hline Y29.2 & DWELL 10 \\
\hline X18.3 & DWELL 10 \\
\hline Y18.3 & DWELL 10 \\
\hline X23.6 & DWELL 10 \\
\hline Y17.5 & DWELL 10 \\
\hline X55.0 & DWELL 10 \\
\hline Y30.0 & DWELL 10 \\
\hline X17.5 & DWELL 10 \\
\hline Y17.5 & DWELL 10 \\
\hline X23.6 & DWELL 10 \\
\hline Y16.7 & DWELL 10 \\
\hline X55.8 & DWELL 10 \\
\hline Y30.8 & DWELL 10 \\
\hline X16.7 & DWELL 10 \\
\hline Y16.7 & DWELL 10 \\
\hline X23.6 & DWELL 10 \\
\hline Y15.9 & DWELL 10 \\
\hline X56.6 & DWELL 10 \\
\hline Y31.6 & DWELL 10 \\
\hline X15.9 & DWELL 10 \\
\hline Y15.9 & DWELL 10 \\
\hline X23.6 & DWELL 10 \\
\hline Y15.1 & DWELL 10 \\
\hline X57.4 & DWELL 10 \\
\hline Y32.4 & DWELL 10 \\
\hline X15.1 & DWELL 10 \\
\hline Y15.1 & DWELL 10 \\
\hline
\end{tabular}




\begin{tabular}{|c|c|}
\hline X23.6 & DWELL 10 \\
\hline Y14.3 & DWELL 10 \\
\hline X58.2 & DWELL 10 \\
\hline Y33.2 & DWELL 10 \\
\hline X14.3 & DWELL 10 \\
\hline Y14.3 & DWELL 10 \\
\hline X23.6 & DWELL 10 \\
\hline Y13.5 & DWELL 10 \\
\hline X59.0 & DWELL 10 \\
\hline Y34.0 & DWELL 10 \\
\hline X13.5 & DWELL 10 \\
\hline Y13.5 & DWELL 10 \\
\hline X23.6 & DWELL 10 \\
\hline Y12.7 & DWELL 10 \\
\hline X59.8 & DWELL 10 \\
\hline Y34.8 & DWELL 10 \\
\hline X12.7 & DWELL 10 \\
\hline Y12.7 & DWELL 10 \\
\hline X23.6 & DWELL 10 \\
\hline Y11.9 & DWELL 10 \\
\hline X60.6 & DWELL 10 \\
\hline Y35.6 & DWELL 10 \\
\hline X11.9 & DWELL 10 \\
\hline Y11.9 & DWELL 10 \\
\hline $\mathrm{X} 23.6$ & DWELL 10 \\
\hline Y11.1 & DWELL 10 \\
\hline X61.4 & DWELL 10 \\
\hline Y36.4 & DWELL 10 \\
\hline X11.1 & DWELL 10 \\
\hline Y11.1 & DWELL 10 \\
\hline X23.6 & DWELL 10 \\
\hline Y10.3 & DWELL 10 \\
\hline X62.2 & DWELL 10 \\
\hline Y37.2 & DWELL 10 \\
\hline X10.3 & DWELL 10 \\
\hline Y10.3 & DWELL 10 \\
\hline X23.6 & DWELL 10 \\
\hline Y9.5 & DWELL 10 \\
\hline X63.0 & DWELL 10 \\
\hline Y38.0 & DWELL 10 \\
\hline X9.5 & DWELL 10 \\
\hline Y9.5 & DWELL 10 \\
\hline X23.6 & DWELL 10 \\
\hline Y8.7 & DWELL 10 \\
\hline X63.8 & DWELL 10 \\
\hline Y38.8 & DWELL 10 \\
\hline X8.7 & DWELL 10 \\
\hline Y8.7 & DWELL 10 \\
\hline X23.6 & DWELL 10 \\
\hline Y7.9 & DWELL 10 \\
\hline X64.6 & DWELL 10 \\
\hline Y39.6 & DWELL 10 \\
\hline X7.9 & DWELL 10 \\
\hline Y7.9 & DWELL 10 \\
\hline X23.6 & DWELL 10 \\
\hline Y7.1 & DWELL 10 \\
\hline
\end{tabular}




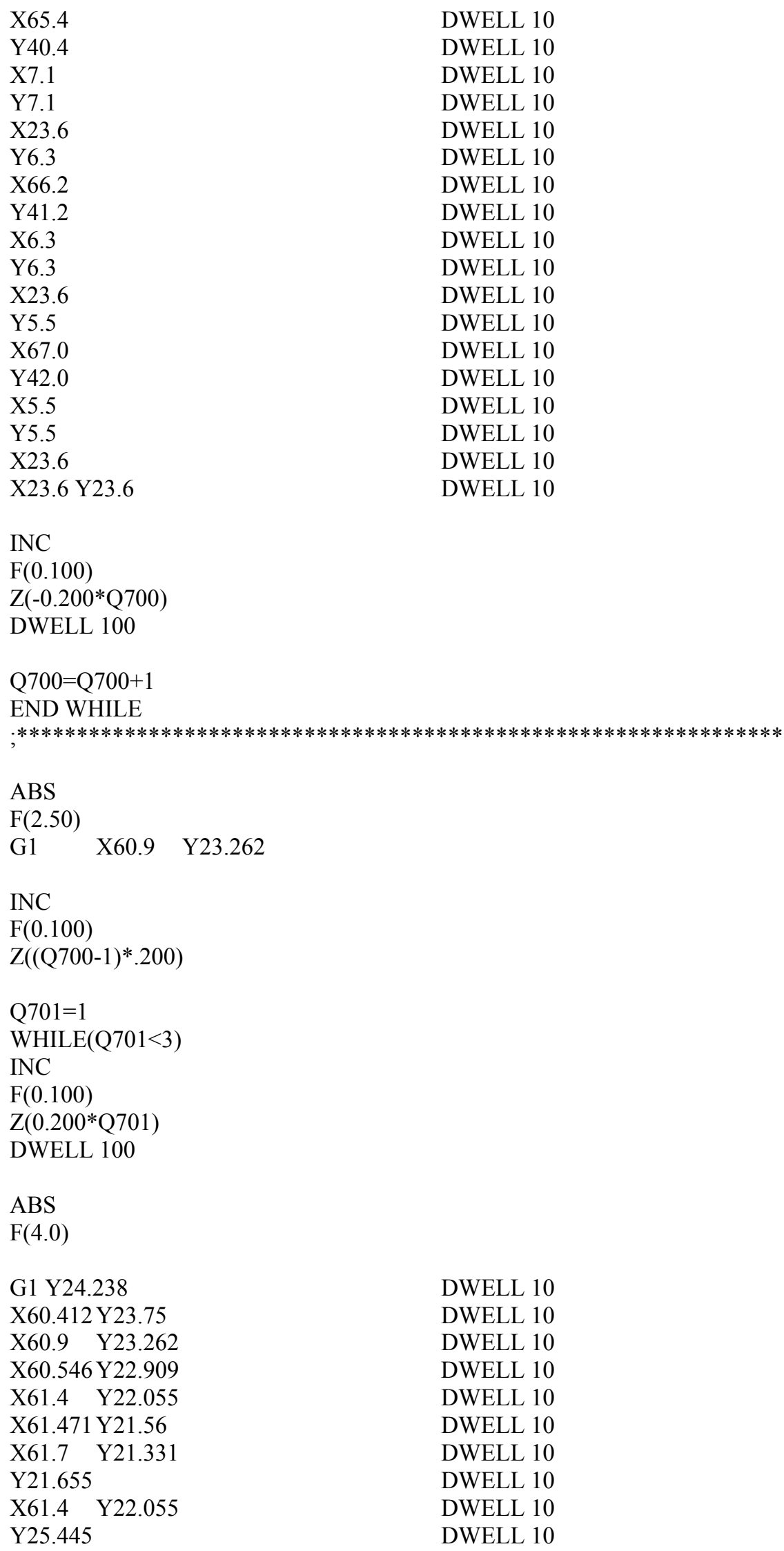




\begin{tabular}{|c|c|c|}
\hline \multicolumn{2}{|c|}{ X61.7 Y25.845 } & DWELL 10 \\
\hline \multicolumn{2}{|c|}{ Y26.169 } & DWELL 10 \\
\hline \multicolumn{2}{|c|}{ X61.471 Y25.94 } & DWELL 10 \\
\hline X61.4 & Y25.445 & DWELL 10 \\
\hline $\mathrm{X} 59.705 \mathrm{Y} 23.75$ & Y23.75 & DWELL 10 \\
\hline \multicolumn{2}{|c|}{ X60.546Y22.909 } & DWELL 10 \\
\hline \multicolumn{2}{|c|}{ X59.981 Y22.343 } & DWELL 10 \\
\hline \multicolumn{2}{|c|}{$\mathrm{X} 61.376 \mathrm{Y} 20.948$} & DWELL 10 \\
\hline G17 & $\begin{array}{lll}\text { G2 } & \text { X62.2 } & \text { Y19.882R5.32 }\end{array}$ & DWELL 10 \\
\hline G1 & X62.125Y19.388 & DWELL 10 \\
\hline G2 & X62.5 Y18.338R5.02 & DWELL 10 \\
\hline G1 & Y19.482 & DWELL 10 \\
\hline X62.2 & Y19.882 & DWELL 10 \\
\hline Y27.6 & 8 & DWELL 10 \\
\hline X62.5 & Y28.018 & DWELL 10 \\
\hline Y29.1 & & DWELL 10 \\
\hline G2 & $\mathrm{X} 62.125 \mathrm{Y} 28.112 \mathrm{R} 5.02$ & DWELL 10 \\
\hline G1 & X62.2 Y27.618 & DWELL 10 \\
\hline G2 & X61.376 Y26.552 R5.32 & DWELL 10 \\
\hline G1 & $\mathrm{X} 58.574 \mathrm{Y} 23.75$ & DWELL 10 \\
\hline \multicolumn{2}{|c|}{ X59.981 Y22.343 } & DWELL 10 \\
\hline X61.3 & 6 Y 20.948 & DWELL 10 \\
\hline G2 & X62.2 Y19.882R5.32 & DWELL 10 \\
\hline G1 & X62.125 Y19.388 & DWELL 10 \\
\hline G2 & X62.5 Y18.338R5.02 & DWELL 10 \\
\hline G1 & X61.7 $\quad$ Y12.642 & DWELL 10 \\
\hline X61.5 & $3 \mathrm{Y} 12.465$ & DWELL 10 \\
\hline X61.4 & Y11.978 & DWELL 10 \\
\hline G2 & X59.877 Y11.1 & DWELL 10 \\
\hline & X61.4 & DWELL 10 \\
\hline Y11.9 & & DWELL 10 \\
\hline X61.7 & Y12.378 & DWELL 10 \\
\hline Y12.6 & & DWELL 10 \\
\hline Y12.3 & & DWELL 10 \\
\hline X61.4 & Y11.978 & DWELL 10 \\
\hline Y11.1 & & DWELL 10 \\
\hline X59.8 & & DWELL 10 \\
\hline X47.6 & 4 Y14.0 & DWELL 10 \\
\hline $\mathrm{X} 47.5$ & 4 Y14.13 & DWELL 10 \\
\hline X24.9 & & DWELL 10 \\
\hline $\mathrm{X} 24.8$ & $6 \mathrm{Y} 14.0$ & DWELL 10 \\
\hline $\mathrm{X} 47.6$ & & DWELL 10 \\
\hline Y13.5 & & DWELL 10 \\
\hline $\mathrm{X} 48.8$ & & DWELL 10 \\
\hline $\mathrm{X} 49.2$ & $1 \mathrm{Y} 13.2$ & DWELL 10 \\
\hline $\mathrm{X} 49.5$ & & DWELL 10 \\
\hline $\mathrm{X} 49.3$ & $6 Y 13.429$ & DWELL 10 \\
\hline $\mathrm{X} 48.8$ & $1 \mathrm{Y} 13.5$ & DWELL 10 \\
\hline X47.7 & $1 \mathrm{Y} 14.63$ & DWELL 10 \\
\hline X24.7 & & DWELL 10 \\
\hline X23.6 & $9 Y 13.5$ & DWELL 10 \\
\hline X23.1 & $4 Y 13.429$ & DWELL 10 \\
\hline X22.9 & $5 \mathrm{Y} 13.2$ & DWELL 10 \\
\hline $\mathrm{X} 23.2$ & & DWELL 10 \\
\hline X23.6 & 9Y13.5 & DWELL 10 \\
\hline X47.6 & & DWELL 10 \\
\hline
\end{tabular}




\begin{tabular}{|c|c|}
\hline $\begin{array}{l}Y 12.7 \\
\text { X50.782 }\end{array}$ & DWELL 10 \\
\hline X50.782 & DWELL 10 \\
\hline X51.182 Y12.4 & DWELL 10 \\
\hline $\mathrm{X} 51.507$ & DWELL 10 \\
\hline X51.277Y12.629 & DWELL 10 \\
\hline X50.782 Y12.7 & DWELL 10 \\
\hline X48.052 Y 15.43 & DWELL 10 \\
\hline $\mathrm{X} 24.448$ & DWELL 10 \\
\hline $\mathrm{X} 21.718 \mathrm{Y} 12.7$ & DWELL 10 \\
\hline $\mathrm{X} 21.223 \mathrm{Y} 12.629$ & DWELL 10 \\
\hline X20.993 Y12.4 & DWELL 10 \\
\hline $\mathrm{X} 21.318$ & DWELL 10 \\
\hline X21.718 Y12.7 & DWELL 10 \\
\hline X47.644 & DWELL 10 \\
\hline Y11.9 & DWELL 10 \\
\hline X52.714 & DWELL 10 \\
\hline X53.114Y Y11.6 & DWELL 10 \\
\hline X53.499 & DWELL 10 \\
\hline $\mathrm{X} 53.21 \mathrm{Y} 11.843$ & DWELL 10 \\
\hline X52.714 Y11.9 & DWELL 10 \\
\hline X48.384 Y 16.23 & DWELL 10 \\
\hline $\mathrm{X} 24.116$ & DWELL 10 \\
\hline X19.786Y11.9 & DWELL 10 \\
\hline X19.29 Y11.843 & DWELL 10 \\
\hline X19.001 Y11.6 & DWELL 10 \\
\hline X19.386 & DWELL 10 \\
\hline X19.786 Y11.9 & DWELL 10 \\
\hline X47.644 & DWELL 10 \\
\hline Y11.1 & DWELL 10 \\
\hline X55.35 & DWELL 10 \\
\hline $\mathrm{X} 55.75 \quad \mathrm{Y} 10.8$ & DWELL 10 \\
\hline X59.477 & DWELL 10 \\
\hline X59.877Y11.1 & DWELL 10 \\
\hline X59.399Y11.247 & DWELL 10 \\
\hline G2 X55.828R5.82 & DWELL 10 \\
\hline X55.35 Y11.1 & DWELL 10 \\
\hline X53.286 Y12.459R6.12 & DWELL 10 \\
\hline $\mathrm{X} 48.715 \mathrm{Y} 17.03$ & DWELL 10 \\
\hline $\mathrm{X} 23.785$ & DWELL 10 \\
\hline X19.214 Y12.459 & DWELL 10 \\
\hline $\begin{array}{llll}\text { G2 } & \text { X17.15 } & \text { Y11.1 } & \text { R6.12 }\end{array}$ & DWELL 10 \\
\hline X47.644 & DWELL 10 \\
\hline $\mathrm{X} 17.15$ & DWELL 10 \\
\hline $\mathrm{X} 16.672$ Y11.247 & DWELL 10 \\
\hline G2 X13.101R5.82 & DWELL 10 \\
\hline X12.623 Y11.1 & DWELL 10 \\
\hline X11.1 Y11.978R6.12 & DWELL 10 \\
\hline G1 $\quad$ X10.987Y12.465 & DWELL 10 \\
\hline $\mathrm{X} 10.8 \quad \mathrm{Y} 12.642$ & DWELL 10 \\
\hline Y12.378 & DWELL 10 \\
\hline $\mathrm{X} 11.1 \quad \mathrm{Y} 11.978$ & DWELL 10 \\
\hline Y11.1 & DWELL 10 \\
\hline $\mathrm{X} 12.623$ & DWELL 10 \\
\hline X13.023 Y 10.8 & DWELL 10 \\
\hline X16.75 & DWELL 10 \\
\hline $\mathrm{X} 17.15 \quad \mathrm{Y} 11.1$ & DWELL 10 \\
\hline
\end{tabular}




\begin{tabular}{|c|c|c|}
\hline \multicolumn{2}{|c|}{ X16.854 Y11.843 } & DWELL 10 \\
\hline \multicolumn{2}{|c|}{$\begin{array}{llll}\text { G2 } & \text { X10.3 } & \text { Y14.09 } & \text { R5.32 }\end{array}$} & DWELL 10 \\
\hline \multicolumn{2}{|r|}{$\mathrm{X} 10.375 \mathrm{Y} 14.584$} & DWELL 10 \\
\hline G2 & $\mathrm{X} 10.0 \quad \mathrm{Y} 15.634 \mathrm{R} 5.02$ & DWELL 10 \\
\hline G1 & Y14.49 & DWELL 10 \\
\hline X10.3 & Y14.09 & DWELL 10 \\
\hline \multicolumn{2}{|l|}{ Y10.3 } & DWELL 10 \\
\hline \multicolumn{2}{|l|}{ X62.2 } & DWELL 10 \\
\hline \multicolumn{2}{|l|}{ Y14.09 } & DWELL 10 \\
\hline X62.5 & Y14.49 & DWELL 10 \\
\hline \multicolumn{2}{|c|}{ Y15.634 } & DWELL 10 \\
\hline G2 & & DWELL 10 \\
\hline G1 & $\begin{array}{l}\text { X62.125 Y14.584R5.02 } \\
\text { X62.2 Y14.09 }\end{array}$ & DWELL 10 \\
\hline G2 & X53.852 Y13.024R5.32 & DWELL 10 \\
\hline G1 & X49.046Y17.83 & DWELL 10 \\
\hline \multicolumn{2}{|c|}{$\mathrm{X} 23.454$} & DWELL 10 \\
\hline \multicolumn{2}{|c|}{$\mathrm{X} 18.648 \mathrm{Y} 13.024$} & DWELL 10 \\
\hline G2 & X16.854 Y11.843 R5.32 & DWELL 10 \\
\hline $\mathrm{X} 10.3$ & Y14.09 R5.32 & DWELL 10 \\
\hline G1 & $\mathrm{X} 10.375$ Y 14.584 & DWELL 10 \\
\hline G2 & X10.0 Y15.634R5.02 & DWELL 10 \\
\hline G1 & Y23.262 & DWELL 10 \\
\hline $\mathrm{X} 12.088$ & $8 \mathrm{Y} 23.75$ & DWELL 10 \\
\hline X11.6 & Y24.238 & DWELL 10 \\
\hline Y23.262 & & DWELL 10 \\
\hline $\mathrm{X} 11.95$ & 4Y22.909 & DWELL 10 \\
\hline $\mathrm{X} 12.79$ & $5 Y 23.75$ & DWELL 10 \\
\hline X11.1 & Y25.445 & DWELL 10 \\
\hline $\mathrm{X} 11.029$ & 9 Y25.94 & DWELL 10 \\
\hline X10.8 & Y26.169 & DWELL 10 \\
\hline Y25.84 & & DWELL 10 \\
\hline X11.1 & Y25.445 & DWELL 10 \\
\hline Y22.05 & & DWELL 10 \\
\hline $\mathrm{X} 10.8$ & Y21.655 & DWELL 10 \\
\hline Y21.33 & & DWELL 10 \\
\hline $\mathrm{X} 11.025$ & 9 Y21.56 & DWELL 10 \\
\hline X11.1 & Y22.055 & DWELL 10 \\
\hline $\mathrm{X} 11.95$ & $4 Y 22.909$ & DWELL 10 \\
\hline $\mathrm{X} 12.51 \mathrm{c}$ & $9 \mathrm{Y} 22.343$ & DWELL 10 \\
\hline $\mathrm{X} 13.926$ & $6 Y 23.75$ & DWELL 10 \\
\hline $\mathrm{X} 11.12$ & 4Y26.552 & DWELL 10 \\
\hline G2 & X10.3 Y27.618R5.32 & DWELL 10 \\
\hline G1 & X10.375 Y28.112 & DWELL 10 \\
\hline G2 & X10.0 Y29.162 R5.02 & DWELL 10 \\
\hline G1 & Y28.018 & DWELL 10 \\
\hline X10.3 & Y27.618 & DWELL 10 \\
\hline Y19.88 & & DWELL 10 \\
\hline $\mathrm{X} 10.0$ & Y19.482 & DWELL 10 \\
\hline Y18.33 & & DWELL 10 \\
\hline G2 & X10.375 Y19.388 R5.02 & DWELL 10 \\
\hline G1 & X10.3 Y19.882 & DWELL 10 \\
\hline G2 & X11.124 Y20.948 R5.32 & DWELL 10 \\
\hline G1 & $\mathrm{X} 12.519 \mathrm{Y} 22.343$ & DWELL 10 \\
\hline $\mathrm{X} 11.12$ & 4Y20.948 & DWELL 10 \\
\hline G3 & X10.3 Y19.882 R5.32 & DWELL 10 \\
\hline G1 & X10.375 Y19.388 & DWELL 10 \\
\hline
\end{tabular}




\begin{tabular}{|c|c|}
\hline G3 & X10.0 Y18.338R5.02 \\
\hline G1 & Y19.482 \\
\hline X10.3 & Y19.882 \\
\hline Y22.34 & \\
\hline X9.5 & \\
\hline Y38.0 & \\
\hline X59.87 & \\
\hline Y36.4 & \\
\hline $\mathrm{G} 2$ & X61.4 Y35.522 R6.12 \\
\hline G1 & X61.513 Y35.035 \\
\hline X61.7 & Y34.858 \\
\hline Y35.12 & \\
\hline X61.4 & Y35.522 \\
\hline Y36.4 & \\
\hline X59.87 & \\
\hline $\mathrm{X} 47.64$ & Y33.5 \\
\hline $\mathrm{X} 24.85$ & \\
\hline $\mathrm{X} 24.98$ & Y33.37 \\
\hline $\mathrm{X} 47.51$ & \\
\hline $\mathrm{X} 47.64$ & Y33.5 \\
\hline $\mathrm{X} 47.99$ & Y33.146 \\
\hline $\mathrm{X} 48.85$ & Y34.0 \\
\hline $\mathrm{X} 49.34$ & Y34.071 \\
\hline $\mathrm{X} 49.57$ & Y34.3 \\
\hline $\mathrm{X} 49.25$ & \\
\hline $\mathrm{X} 48.85$ & Y34.0 \\
\hline $\mathrm{X} 23.6$ & \\
\hline $\mathrm{X} 23.24$ & Y34.3 \\
\hline $\mathrm{X} 22.92$ & \\
\hline $\mathrm{X} 23.15$ & Y34.071 \\
\hline $\mathrm{X} 23.6$ & Y34.0 \\
\hline $\mathrm{X} 24.77$ & Y32.87 \\
\hline $\mathrm{X} 47.72$ & \\
\hline $\mathrm{X} 47.99$ & Y33.146 \\
\hline $\mathrm{X} 48.56$ & Y32.581 \\
\hline X50.78 & Y34.8 \\
\hline $\mathrm{X} 51.27$ & Y34.871 \\
\hline $\mathrm{X} 51.50$ & Y35.1 \\
\hline $\mathrm{X} 51.18$ & \\
\hline $\mathrm{X} 50.78$ & Y34.8 \\
\hline $\mathrm{X} 21.71$ & \\
\hline $\mathrm{X} 21.31$ & Y35.1 \\
\hline $\mathrm{X} 20.99$ & \\
\hline $\mathrm{X} 21.22$ & Y34.871 \\
\hline $\mathrm{X} 21.71$ & Y34.8 \\
\hline X24.44 & Y32.07 \\
\hline X48.05 & \\
\hline X48.56 & Y32.581 \\
\hline X49.12 & Y32.015 \\
\hline X52.71 & Y35.6 \\
\hline X53.21 & Y35.657 \\
\hline X53.4C & Y35.9 \\
\hline X53.11 & \\
\hline X52.71 & Y35.6 \\
\hline X19.78 & \\
\hline X19.38 & Y35.9 \\
\hline
\end{tabular}

DWELL 10

DWELL 10

DWELL 10

DWELL 10

DWELL 10

DWELL 10

DWELL 10

DWELL 10

DWELL 10

DWELL 10

DWELL 10

DWELL 10

DWELL 10

DWELL 10

DWELL 10

DWELL 10

DWELL 10

DWELL 10

DWELL 10

DWELL 10

DWELL 10

DWELL 10

DWELL 10

DWELL 10

DWELL 10

DWELL 10

DWELL 10

DWELL 10

DWELL 10

DWELL 10

DWELL 10

DWELL 10

DWELL 10

DWELL 10

DWELL 10

DWELL 10

DWELL 10

DWELL 10

DWELL 10

DWELL 10

DWELL 10

DWELL 10

DWELL 10

DWELL 10

DWELL 10

DWELL 10

DWELL 10

DWELL 10

DWELL 10

DWELL 10

DWELL 10

DWELL 10

DWELL 10

DWELL 10

DWELL 10

DWELL 10 


\begin{tabular}{|c|c|c|}
\hline & DWELL 10 \\
\hline \multicolumn{2}{|c|}{$\begin{array}{l}\text { X19.001 } \\
\text { X19.29 Y35.657 }\end{array}$} & DWELL 10 \\
\hline \multicolumn{2}{|c|}{ X19.786 Y35.6 } & DWELL 10 \\
\hline \multicolumn{2}{|c|}{$\mathrm{X} 24.116 \mathrm{Y} 31.27$} & DWELL 10 \\
\hline \multicolumn{2}{|c|}{ X48.384 } & DWELL 10 \\
\hline \multicolumn{2}{|c|}{ X49.129Y32.015 } & DWELL 10 \\
\hline \multicolumn{2}{|c|}{ X49.694 Y31.449 } & DWELL 10 \\
\hline \multicolumn{2}{|c|}{ X53.286Y35.041 } & DWELL 10 \\
\hline G2 & X55.35 Y36.4 R6.12 & DWELL 10 \\
\hline G1 & X55.828 Y36.253 & DWELL 10 \\
\hline G2 & X59.399R5.82 & DWELL 10 \\
\hline G1 & X59.877Y36.4 & DWELL 10 \\
\hline \multicolumn{2}{|c|}{ X59.477 Y36.7 } & DWELL 10 \\
\hline \multicolumn{2}{|c|}{$\mathrm{X} 55.75$} & DWELL 10 \\
\hline $\mathrm{X} 55$ & Y36.4 & DWELL 10 \\
\hline \multicolumn{2}{|c|}{$\mathrm{X} 17.15$} & DWELL 10 \\
\hline G2 & X19.214 Y35.041 R6.12 & DWELL 10 \\
\hline G1 & X23.785 Y30.47 & DWELL 10 \\
\hline \multicolumn{2}{|c|}{$\mathrm{X} 48.715$} & DWELL 10 \\
\hline \multicolumn{2}{|c|}{ X49.694 Y31.449 } & DWELL 10 \\
\hline \multicolumn{2}{|c|}{ X48.715 Y30.47 } & DWELL 10 \\
\hline \multicolumn{2}{|c|}{$\mathrm{X} 23.785$} & DWELL 10 \\
\hline \multicolumn{2}{|c|}{$\mathrm{X} 19.214$ Y35.041 } & DWELL 10 \\
\hline G3 & X17.15 Y36.4 R6.12 & DWELL 10 \\
\hline G1 & X16.75 Y36.7 & DWELL 10 \\
\hline \multicolumn{2}{|c|}{ X13.023 } & DWELL 10 \\
\hline \multicolumn{2}{|c|}{ X12.623 Y36.4 } & DWELL 10 \\
\hline \multicolumn{2}{|c|}{ X11.1 } & DWELL 10 \\
\hline \multicolumn{2}{|c|}{ Y35.522 } & DWELL 10 \\
\hline $\mathrm{X} 10$ & Y35.122 & DWELL 10 \\
\hline Y34 & & DWELL 10 \\
\hline $\mathrm{X} 10$ & $7 Y 35.035$ & DWELL 10 \\
\hline X11 & Y35.522 & DWELL 10 \\
\hline G2 & X12.623 Y36.4 R6.12 & DWELL 10 \\
\hline G1 & X13.101 Y36.253 & DWELL 10 \\
\hline G2 & X16.672R5.82 & DWELL 10 \\
\hline G1 & X17.15 Y36.4 & DWELL 10 \\
\hline $\mathrm{X} 16$ & 4 Y35.657 & DWELL 10 \\
\hline G2 & X18.648 Y34.476R5.32 & DWELL 10 \\
\hline G1 & X23.454 Y29.67 & DWELL 10 \\
\hline $\mathrm{X} 49$ & & DWELL 10 \\
\hline $\mathrm{X} 53$ & 2 Y34.476 & DWELL 10 \\
\hline G2 & X62.2 Y33.41 R5.32 & DWELL 10 \\
\hline G1 & X62.125 Y32.916 & DWELL 10 \\
\hline G2 & X62.5 Y31.866R5.02 & DWELL 10 \\
\hline G1 & Y33.01 & DWELL 10 \\
\hline X62 & Y33.41 & DWELL 10 \\
\hline Y37 & & DWELL 10 \\
\hline $\mathrm{X} 10$ & & DWELL 10 \\
\hline Y33 & & DWELL 10 \\
\hline $\mathrm{X} 10$ & Y33.01 & DWELL 10 \\
\hline Y31 & & DWELL 10 \\
\hline G2 & X10.375 Y32.916R5.02 & DWELL 10 \\
\hline G1 & X10.3 Y33.41 & DWELL 10 \\
\hline G2 & X16.854 Y35.657 R5.32 & DWELL 10 \\
\hline G1 & X16.558 Y34.913 & DWELL 10 \\
\hline
\end{tabular}




\begin{tabular}{|c|c|c|}
\hline G2 & X18.082 Y33.91 R4.52 & DWELL 10 \\
\hline G1 & X23.122 Y28.87 & DWELL 10 \\
\hline \multicolumn{2}{|c|}{$\mathrm{X} 49.378$} & DWELL 10 \\
\hline \multicolumn{2}{|c|}{ X54.418 Y33.91 } & DWELL 10 \\
\hline G2 & X62.134 Y30.714R4.52 & DWELL 10 \\
\hline G1 & Y30.314 & DWELL 10 \\
\hline G2 & X60.81 Y27.118R4.52 & DWELL 10 \\
\hline G1 & X57.442 Y23.75 & DWELL 10 \\
\hline X60.81 & Y20.382 & DWELL 10 \\
\hline G2 & X62.134 Y17.186R4.52 & DWELL 10 \\
\hline G1 & Y16.786 & DWELL 10 \\
\hline G2 & X54.418 Y13.59 R4.52 & DWELL 10 \\
\hline G1 & X49.378 Y18.63 & DWELL 10 \\
\hline \multicolumn{2}{|c|}{$\mathrm{X} 23.122$} & DWELL 10 \\
\hline \multicolumn{2}{|c|}{ X18.082 Y13.59 } & DWELL 10 \\
\hline G2 & X10.366 Y16.786R4.52 & DWELL 10 \\
\hline G1 & Y17.186 & DWELL 10 \\
\hline G2 & X11.69 Y20.382 R4.52 & DWELL 10 \\
\hline G1 & X15.058 Y23.75 & DWELL 10 \\
\hline X11.69 & Y27.118 & DWELL 10 \\
\hline G2 & X10.366 Y30.314R4.52 & DWELL 10 \\
\hline G1 & Y30.714 & DWELL 10 \\
\hline G2 & X16.558 Y34.913 R4.52 & DWELL 10 \\
\hline G1 & Y38.0 & DWELL 10 \\
\hline \multicolumn{2}{|l|}{ X9.5 } & DWELL 10 \\
\hline \multicolumn{2}{|l|}{ Y9.5 } & DWELL 10 \\
\hline \multicolumn{2}{|l|}{ X63.0 } & DWELL 10 \\
\hline \multicolumn{2}{|l|}{ Y38.0 } & DWELL 10 \\
\hline \multicolumn{2}{|c|}{ X16.558 } & DWELL 10 \\
\hline \multicolumn{2}{|c|}{ X15.718 } & DWELL 10 \\
\hline \multicolumn{2}{|c|}{ X15.308 Y34.41 } & DWELL 10 \\
\hline G2 & X17.516 Y33.344R3.72 & DWELL 10 \\
\hline G1 & X22.791 Y28.07 & DWELL 10 \\
\hline \multicolumn{2}{|c|}{ X49.709 } & DWELL 10 \\
\hline \multicolumn{2}{|c|}{ X54.984 Y33.344 } & DWELL 10 \\
\hline G2 & X61.334 Y30.714R3.72 & DWELL 10 \\
\hline G1 & Y30.314 & DWELL 10 \\
\hline G2 & X60.244 Y27.684R3.72 & DWELL 10 \\
\hline G1 & X56.311 Y23.75 & DWELL 10 \\
\hline \multicolumn{2}{|c|}{ X60.244 Y19.816 } & DWELL 10 \\
\hline G2 & X61.334 Y17.186R3.72 & DWELL 10 \\
\hline G1 & Y16.786 & DWELL 10 \\
\hline G2 & X54.984 Y14.156R3.72 & DWELL 10 \\
\hline G1 & $\mathrm{X} 49.709 \mathrm{Y} 19.43$ & DWELL 10 \\
\hline \multicolumn{2}{|c|}{ X22.791 } & DWELL 10 \\
\hline \multicolumn{2}{|c|}{ X17.516 Y14.156 } & DWELL 10 \\
\hline G2 & X11.166 Y16.786R3.72 & DWELL 10 \\
\hline G1 & Y17.186 & DWELL 10 \\
\hline G2 & X12.256 Y19.816R3.72 & DWELL 10 \\
\hline G1 & X16.189Y23.75 & DWELL 10 \\
\hline \multicolumn{2}{|c|}{ X12.256 Y27.684 } & DWELL 10 \\
\hline G2 & X11.166 Y30.314R3.72 & DWELL 10 \\
\hline G1 & Y30.714 & DWELL 10 \\
\hline G2 & X15.308 Y34.41 R3.72 & DWELL 10 \\
\hline G1 & Y38.8 & DWELL 10 \\
\hline X8.7 & & DWELL 10 \\
\hline
\end{tabular}




\begin{tabular}{|c|c|c|}
\hline \multicolumn{2}{|c|}{ Y8.7 } & DWELL 10 \\
\hline \multicolumn{2}{|c|}{ X63.8 } & DWELL 10 \\
\hline \multicolumn{2}{|c|}{ Y38.8 } & DWELL 10 \\
\hline \multicolumn{2}{|c|}{ X15.308 } & DWELL 10 \\
\hline \multicolumn{2}{|c|}{$\mathrm{X} 15.038$} & DWELL 10 \\
\hline \multicolumn{2}{|c|}{ X14.941 Y33.633 } & DWELL 10 \\
\hline G2 & X16.951 Y32.779R2.92 & DWELL 10 \\
\hline G1 & X22.46 Y27.27 & DWELL 10 \\
\hline \multicolumn{2}{|c|}{ X50.04 } & DWELL 10 \\
\hline \multicolumn{2}{|c|}{ X55.549Y32.779 } & DWELL 10 \\
\hline G2 & X60.534Y30.714R2.92 & DWELL 10 \\
\hline G1 & Y30.314 & DWELL 10 \\
\hline G2 & X59.679Y28.249R2.92 & DWELL 10 \\
\hline & X55.18 Y23.75 & DWELL 10 \\
\hline \multicolumn{2}{|c|}{ X59.679Y19.251 } & DWELL 10 \\
\hline G2 & X60.534 Y17.186R2.92 & DWELL 10 \\
\hline G1 & Y16.786 & DWELL 10 \\
\hline G2 & X55.549Y14.721 R2.92 & DWELL 10 \\
\hline G1 & X50.04 Y20.23 & DWELL 10 \\
\hline \multicolumn{2}{|c|}{$\mathrm{X} 22.46$} & DWELL 10 \\
\hline \multicolumn{2}{|c|}{ X16.951 Y14.721 } & DWELL 10 \\
\hline G2 & $\mathrm{X} 11.966 \mathrm{Y} 16.786 \mathrm{R} 2.92$ & DWELL 10 \\
\hline G1 & Y17.186 & DWELL 10 \\
\hline G2 & X12.821 Y19.251 R2.92 & DWELL 10 \\
\hline & $\mathrm{X} 17.32 \mathrm{Y} 23.75$ & DWELL 10 \\
\hline \multicolumn{2}{|c|}{ X12.821 Y28.249 } & DWELL 10 \\
\hline G2 & X11.966 Y30.314R2.92 & DWELL 10 \\
\hline G1 & Y30.714 & DWELL 10 \\
\hline G2 & X14.941 Y33.633 R2.92 & DWELL 10 \\
\hline G1 & Y39.6 & DWELL 10 \\
\hline \multicolumn{2}{|c|}{ X7.9 } & DWELL 10 \\
\hline \multicolumn{2}{|c|}{ Y7.9 } & DWELL 10 \\
\hline \multicolumn{2}{|c|}{ X64.6 } & DWELL 10 \\
\hline \multirow{2}{*}{\multicolumn{2}{|c|}{$\begin{array}{l}\text { Y39.6 } \\
\text { X14.941 }\end{array}$}} & DWELL 10 \\
\hline & \multirow{2}{*}{$\begin{array}{l}\text { X14.941 } \\
\text { X14.899 }\end{array}$} & DWELL 10 \\
\hline \multirow{2}{*}{\multicolumn{2}{|c|}{ X14.889Y32.834 }} & DWELL 10 \\
\hline & & DWELL 10 \\
\hline G2 & $\mathrm{X} 16.385 \mathrm{Y} 32.213 \mathrm{R} 2.12$ & DWELL 10 \\
\hline G1 & X22.128 Y26.47 & DWELL 10 \\
\hline \multicolumn{2}{|c|}{ X50.372 } & DWELL 10 \\
\hline \multicolumn{2}{|c|}{ X56.115 Y32.213 } & DWELL 10 \\
\hline G2 & X59.734 Y30.714R2.12 & DWELL 10 \\
\hline G1 & Y30.314 & DWELL 10 \\
\hline G2 & X59.113 Y28.815 R2.12 & DWELL 10 \\
\hline G1 & X54.048 Y23.75 & DWELL 10 \\
\hline X59 & 3 Y18.685 & DWELL 10 \\
\hline G2 & X59.734 Y17.186R2.12 & DWELL 10 \\
\hline G1 & Y16.786 & DWELL 10 \\
\hline G2 & X56.115 Y15.287R2.12 & DWELL 10 \\
\hline G1 & X50.372 Y21.03 & DWELL 10 \\
\hline $\mathrm{X} 22$ & & DWELL 10 \\
\hline X16 & $5 Y 15.287$ & DWELL 10 \\
\hline G2 & X12.766 Y16.786R2.12 & DWELL 10 \\
\hline G1 & Y17.186 & DWELL 10 \\
\hline G2 & X13.387 Y18.685R2.12 & DWELL 10 \\
\hline G1 & $\mathrm{X} 18.452 \mathrm{Y} 23.75$ & DWELL 10 \\
\hline
\end{tabular}




\begin{tabular}{|c|c|c|}
\hline \multicolumn{2}{|c|}{ X13.387 Y28.815 } & \multirow{2}{*}{$\begin{array}{l}\text { DWELL } 10 \\
\text { DWELL } 10\end{array}$} \\
\hline G2 & $\mathrm{X} 12.766 \mathrm{Y} 30.314 \mathrm{R} 2.12$ & \\
\hline G1 & Y30.714 & DWELL 10 \\
\hline G2 & X14.889 Y32.834R2.12 & DWELL 10 \\
\hline G1 & Y40.4 & DWELL 10 \\
\hline \multicolumn{2}{|c|}{ X7.1 } & DWELL 10 \\
\hline \multicolumn{2}{|c|}{ Y7.1 } & DWELL 10 \\
\hline \multicolumn{2}{|c|}{ X65.4 } & DWELL 10 \\
\hline \multicolumn{2}{|c|}{ Y40.4 } & DWELL 10 \\
\hline \multicolumn{2}{|c|}{ X14.889 } & DWELL 10 \\
\hline \multicolumn{2}{|c|}{ X7.1 } & DWELL 10 \\
\hline \multicolumn{2}{|c|}{ Y32.034 } & DWELL 10 \\
\hline \multicolumn{2}{|c|}{ X13.585 Y30.935 } & DWELL 10 \\
\hline G2 & X15.819Y31.647R1.32 & DWELL 10 \\
\hline G1 & $\mathrm{X} 21.797 \mathrm{Y} 25.67$ & DWELL 10 \\
\hline \multicolumn{2}{|c|}{ X50.703 } & DWELL 10 \\
\hline \multicolumn{2}{|c|}{ X56.681 Y31.647 } & DWELL 10 \\
\hline G2 & X58.934 Y30.714R1.32 & DWELL 10 \\
\hline G1 & Y30.314 & DWELL 10 \\
\hline G2 & X58.547 Y29.381 R1.32 & DWELL 10 \\
\hline G1 & X52.917Y23.75 & DWELL 10 \\
\hline \multicolumn{2}{|c|}{ X58.547Y Y18.119 } & DWELL 10 \\
\hline G2 & X58.934Y17.186R1.32 & DWELL 10 \\
\hline G1 & Y16.786 & DWELL 10 \\
\hline G2 & X56.681 Y15.853 R1.32 & DWELL 10 \\
\hline G1 & X50.703 Y21.83 & DWELL 10 \\
\hline \multicolumn{2}{|c|}{ X21.797 } & DWELL 10 \\
\hline \multicolumn{2}{|c|}{ X15.819Y15.853 } & DWELL 10 \\
\hline G2 & X13.566 Y16.786R1.32 & DWELL 10 \\
\hline G1 & Y17.186 & DWELL 10 \\
\hline G2 & X13.953 Y18.119R1.32 & DWELL 10 \\
\hline G1 & X19.583 Y23.75 & DWELL 10 \\
\hline \multicolumn{2}{|c|}{ X13.953 Y29.381 } & DWELL 10 \\
\hline G2 & X13.566 Y30.314R1.32 & DWELL 10 \\
\hline G1 & Y30.714 & DWELL 10 \\
\hline \multicolumn{2}{|c|}{ X13.585 Y30.935 } & DWELL 10 \\
\hline \multicolumn{2}{|c|}{ X6.3 } & DWELL 10 \\
\hline \multicolumn{2}{|c|}{ Y6.3 } & DWELL 10 \\
\hline \multicolumn{2}{|c|}{ X66.2 } & DWELL 10 \\
\hline Y4 & & DWELL 10 \\
\hline $\mathrm{X} 6$ & & DWELL 10 \\
\hline & & DWELL 10 \\
\hline $\mathrm{X} 5$ & & DWELL 10 \\
\hline Y5 & & DWELL 10 \\
\hline $\mathrm{X} 6$ & & DWELL 10 \\
\hline Y4 & & DWELL 10 \\
\hline $\mathrm{X} 5$ & & DWELL 10 \\
\hline & & DWELL 10 \\
\hline & & DWELL 10 \\
\hline & 6 Y30.715 & DWELL 10 \\
\hline G2 & X15.254 Y31.082R0.52 & DWELL 10 \\
\hline G1 & X21.465 Y24.87 & DWELL 10 \\
\hline & & DWELL 10 \\
\hline & $6 Y 31.082$ & DWELL 10 \\
\hline G2 & X58.134 Y30.714R0.52 & DWELL 10 \\
\hline G1 & Y30.314 & DWELL 10 \\
\hline
\end{tabular}




$\begin{array}{ll}\text { G2 } & \text { X57.982 Y29.946R0.52 } \\ \text { G1 } & \text { X51.785 Y23.75 } \\ \text { X57.982 Y17.554 } \\ \text { G2 } & \text { X58.134 Y17.186R0.52 } \\ \text { G1 } & \text { Y16.786 } \\ \text { G2 } & \text { X57.246Y16.418R0.52 } \\ \text { G1 } & \text { X51.035 Y22.63 } \\ \text { X21.465 } & \text { X15.254 Y16.418 } \\ \text { G2 } \quad \text { X14.366 Y16.786R0.52 } \\ \text { G1 } \quad \text { Y17.186 } \\ \text { G2 } & \text { X14.518Y17.554R0.52 } \\ \text { G1 } \quad \text { X20.715 Y23.75 } \\ \text { X14.518Y29.946 } \\ \text { G2 } \quad \text { X14.366 Y30.314R0.52 } \\ \text { G1 } \quad \text { Y30.714 } \\ \text { Y30.715 } \\ \text { X60.9 } \quad \text { Y23.262 } \\ \text { INC } \\ \text { F(0.100) } \\ \text { Z(-0.200*Q701) } \\ \text { DWELL } 100 \\ \text { Q701=Q701+1 } \\ \text { END WHILE } \\ \text { P2=0 } \\ \text { F(2.5) } \\ \text { Z(-20) } \\ \text { CLOSE }\end{array}$

DWELL 10

DWELL 10

DWELL 10

DWELL 10

DWELL 10

DWELL 10

DWELL 10

DWELL 10

DWELL 10

DWELL 10

DWELL 10

DWELL 10

DWELL 10

DWELL 10

DWELL 10

DWELL 10

DWELL 10

CLOSE 


\section{$\underline{\text { STU COMPLETE } 1 \text { FINISH.txt }}$}

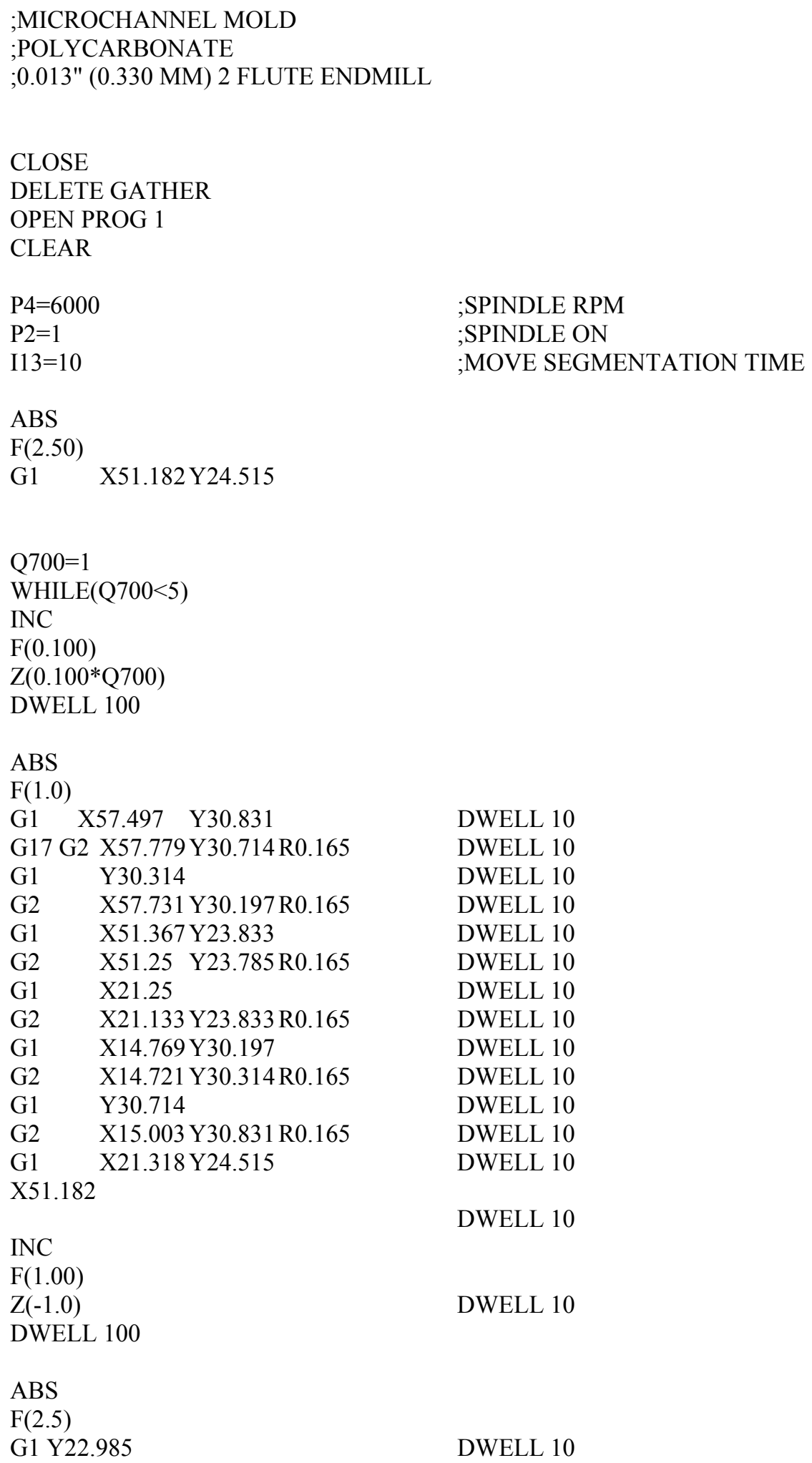


INC

$\mathrm{F}(1.00)$

$\mathrm{Z}(1.0)$

DWELL 10

DWELL 100

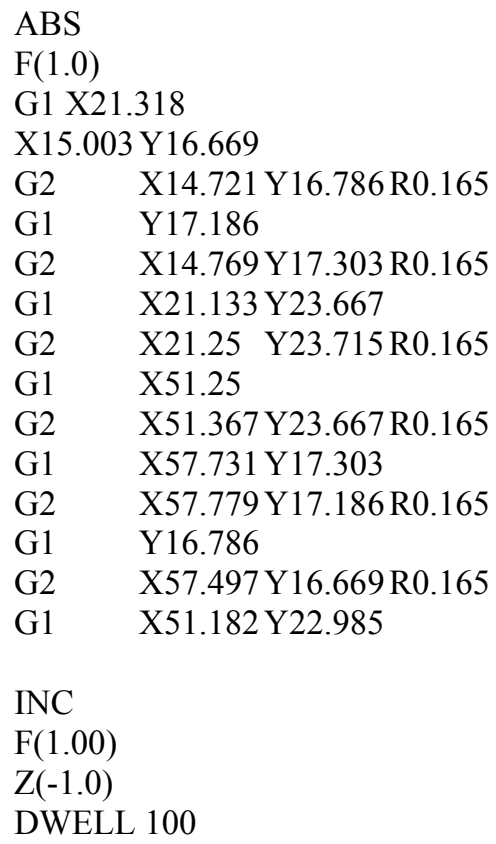

ABS

$\mathrm{F}(1.0)$

G1 X21.318

$\mathrm{X} 15.003 \mathrm{Y} 16.669$

G2 X14.721 Y16.786R0.165

G1 Y17.186

G2 X14.769Y17.303 R0.165

G1 X21.133 Y23.667

G2 X21.25 Y23.715R0.165

G1 X51.25

G2 X51.367 Y23.667R0.165

G1 X57.731 Y17.303

G2 X57.779Y17.186R0.165

G1 Y16.786

G2 X57.497Y16.669R0.165

G1 X51.182 Y22.985

INC

$\mathrm{F}(1.00)$

$\mathrm{Z}(-1.0)$

DWELL 100

DWELL 10

DWELL 10

DWELL 10

DWELL 10

DWELL 10

DWELL 10

DWELL 10

DWELL 10

DWELL 10

DWELL 10

DWELL 10

DWELL 10

DWELL 10

DWELL 10

DWELL 10

ABS

$\mathrm{F}(2.5)$

G1 X51.182 Y24.515

DWELL 10

INC

DWELL 10

$\mathrm{F}(1.00)$

$\mathrm{Z}(1.0)$

DWELL 10

DWELL 100

INC

$\mathrm{F}(0.100)$

$\mathrm{Z}(-0.100 * \mathrm{Q} 700)$

DWELL 100

$\mathrm{Q} 700=\mathrm{Q} 700+1$

END WHILE

$\mathrm{P} 2=0$

$\mathrm{F}(2.5)$

$\mathrm{Z}(-20)$

CLOSE 
APPENDIX C

MANUFATURER DATA SHEETS FOR SYLGARD 184 AND SU-8-50

\section{Information About High Technology Silicone Materials}

\section{DESCRIPTION}

SYLGARD 184 silicone elastomer, base $\&$ curing agent, is supplied as a two-part kit comprised of liquid components. When the base and the curing agent are thoroughly mixed in a 10:1 weight ratio, the mediumviscosity liquid mixture has a consistency resembling SAE No. 40 motor oil. The liquid mixture will cure in thick or thin sections to a flexible, transparent elastomer ideally suited for electricalelectronic potting and encapsulating applications.

SYLGARD 184 silicone elastomer offers a flexible cure schedule from 25 to $150 \mathrm{C}$ (77 to $302 \mathrm{~F})$, without an exotherm. SYLGARD 184 silicone elastomer requires no post cure and can be placed in service immediately following the completion of the cure schedule at any operating temperature from -55 to $200 \mathrm{C}$ (-67 to 392 F). See Table I for special features and benefits of this product.

USES

Because of its many special features, SYLGARD 184 silicone elastomer is ideal for a wide variety of electrical/ electronic potting and encapsulating applications and provides environmental protection for:

- Equipment modules

- Relays, power supplies and magnetic amplifiers

- Transformers, coils and ferrite cores

- Connectors

- Fiber optic waveguide coatings

- Encapsulation of circuit boards SYLGARD 184 silicone elastomer is especially useful in applications where clarity is desirable, including:

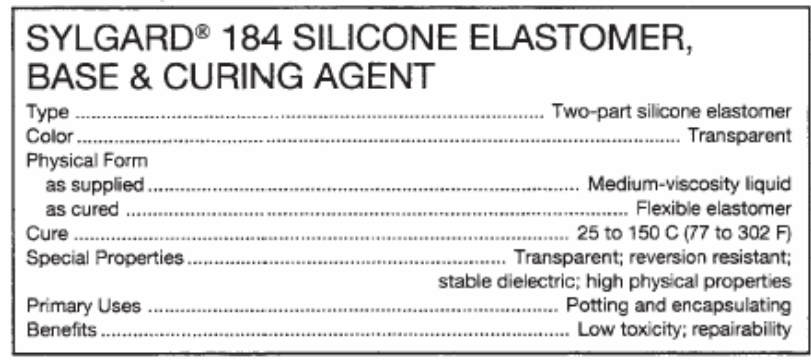

- Encapsulation of solar cells

- Encapsulation of opto-electronic displays

\section{HOW TO USE}

\section{Mixing}

SYLGARD 184 silicone elastomer is supplied in two parts, a lot-matched base and curing agent, mixed in a ratio of 10 parts base to one part curing agent, by weight.

For best curing results, glassware o tinned cans and glass or metal stirring implements should be used. Mix with a smooth action that will minimize the introduction of excess air.

\section{Pot Life - Working Time}

Cure reaction of SYLGARD 184 silicone elastomer, base \& curing agent, begins with the mixing process. Initially, cure is evidenced by a gradual increase in viscosity, followed by gelation and conversion to a solid elastomer. Pot life is defined as the time required for viscosity to double following addition of curing agent to base. At $25 \mathrm{C}(77 \mathrm{~F})$, the pot life of SYLGARD 184 silicone elastomer is 2 hours. Pot life of this product can be extended by refrigeration at $4 \mathrm{C}(40 \mathrm{~F})$; however, do not allow moisture from condensation to collect in the silicone elastomer.

SYLGARD 184 silicone elastomer will cure at $25 \mathrm{C}(77 \mathrm{~F})$, will become solid in 24 hours, and will reach full cure in 7 days. See "Curing."

Processing

Thoroughly mix SYLGARD 184 silicone elastomer, base \& curing agent, in a ratio of 10 parts base to 1 part curing agent, by weight. Agitate gently to reduce the amount of air introduced. Allow mixture to set 30 minutes before pouring.

Since air bubbles are usually present following mixing, vacuum de-airing is recommended. De-air in a container with at least four times the liquid volume to allow for expansion of material. Air entrapped in the mixture can be removed by using a vacuum of 25 to 29 inches of mercury. Continue the vacuum until the liquid expands and settles to its original volume and bubbling subsides. This may take 15 minutes to 2 hours, depending on the 
TYPICAL PROPERTIES

These values are not intended for use in preparing specifications.

\begin{tabular}{|c|c|}
\hline $\begin{array}{l}\text { As Supplied } \\
\text { CTM } 0001 \mathrm{~A} \\
\text { CTM } 0050\end{array}$ & $\begin{array}{l}\text { Specific Gravity at } 25 \mathrm{C}(77 \mathrm{~F})^{\prime} \\
\text { Viscosity' }\end{array}$ \\
\hline $\begin{array}{l}\text { As Catalyzed } \\
\text { CTM } 0050\end{array}$ & $x^{2}$ \\
\hline CTM 0055 & nimum, hours \\
\hline
\end{tabular}

CTM 0055 Pot Life', minimum, hours .................................

As Cured - Physicaf

CTM 0176 Appearance . Transparent

CTM 0099 Durometer Hardness, Shore A …__..._.

CTM 0137A $\quad$ Tensile Strength, MPa (psi) ………............................... $6.20(900)$

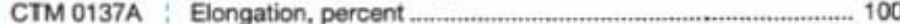

CTM 0159A Tear Strength, die B, kN/m (ppi) _._._. $2.6(15)$

CTM 0022 Specific Gravity at 25 C (77 F)1.05

CTM 0224 Thermal Conductivity, cal $/ \mathrm{cm}^{2}$-sec $-\left({ }^{\circ} \mathrm{C} / \mathrm{cm}\right) \ldots . . . . . . . .3 .5 \times 10^{4}$

CTM 0585 Linear Coefficient of Thermal Expansion,

$\mathrm{cm} / \mathrm{cm}$ per ${ }^{\circ} \mathrm{C}$ from -55 to $150 \mathrm{C}(-67$ to $302 \mathrm{~F}) \ldots \ldots . . .3 .0 \times 10^{\circ}$

CTM 0585 Volume Coefficient of Thermal Expansion,

$\mathrm{cc} / \mathrm{cc}$ per ${ }^{\circ} \mathrm{C}$ from -55 to $150 \mathrm{C}(-67$ to $302 \mathrm{~F})$............. $9.6 \times 10^{4}$

MIL-1-16923G Thermal Shock Resistance,

from -49 to $68 \mathrm{C}(-55$ to $155 \mathrm{~F})$....................... Passes 10 cycles

Weight Loss, percent

after $1,000 \mathrm{hrs}$ at $150 \mathrm{C}(302 \mathrm{~F})$.......................................... 1.6

after $1,000 \mathrm{hrs}$ at $200 \mathrm{C}(392 \mathrm{~F}$............. 3.2

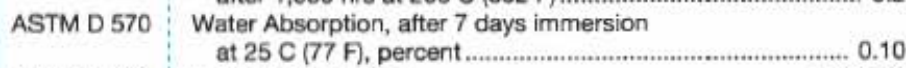

ASTM D 746 $\quad \begin{gathered}\left.\text { at 25 Cittle Point, }{ }^{\circ} \mathrm{C} \text { ( }{ }^{\circ} \mathrm{F}\right) \\ \mathrm{C}\end{gathered}$

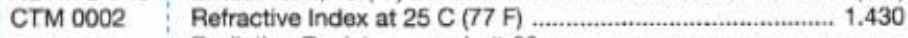

Radiation Resistance, cobalt 60 source

at 200 megarads

Still usable

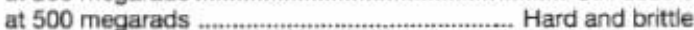

UL $94 \quad$ Flammability ${ }^{6}$ Classification .................................. 94 V 1

UL

Temperature Rating,

Mechanical, ${ }^{\circ} \mathrm{C}\left({ }^{\circ} \mathrm{F}\right)$................................................. $130(265)$

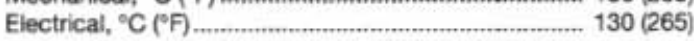

Electrical

CTM 0114 A

CTM 0112

Dielectric Strength, volts/mile 450

Dielectric Constant, at

$60 \mathrm{H}_{2}$ 2.7

$100 \mathrm{~Hz}$ 2.66

$100 \mathrm{kH}$

2.65

CTM 0112 Dissipation Factor, at

$60 \mathrm{~Hz}$

0.001

$100 \mathrm{~Hz}$

0.0009

$100 \mathrm{kHz} \ldots \ldots \ldots \ldots$

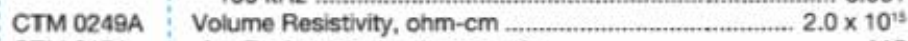

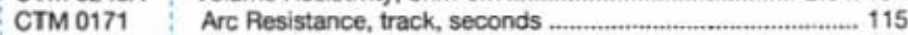

Electrical - after heat aging for 1000 hours at $200 \mathrm{C}(392 \mathrm{~F})$

CTM 0114A Dielectric Strength, volts/mil

CTM 0112 Dielectric Constant, at

$60 \mathrm{~Hz}$

600

$100 \mathrm{~Hz}$. 2.7

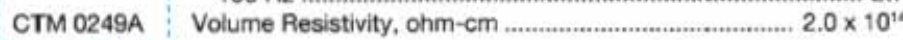

'In most cases, CTMs (Corporate Test Methods) correspond to ASTM standard tests. Copies of CTM procedures are available upon request.

Brookfieid Viscometer Model LVF, spindle $\$ 4$ at $60 \mathrm{rpm}$.

iMix ratio 10 parts base to 1 part curing agent, by weight.

Time required to double catalyzed viscosity,

"Based on sample thickness of 125 mils and a minimum cure of 4 hours at $65 \mathrm{C}$ (149 F)

Tests, claims, representations and descriptions regarding flammability are based on standard smail scaie iaboratory tests.

'Properties ootained on 1.58-mm-thick ( 0.062 -inch) specimens, cured 4 hours at $65 \mathrm{C}$ (149 F)

aneasured with 1,4-inch standard ASTM electrode, 500 volls per second rate of rise.

Specification Writers: Please contact Dow Corning Corporation, Midland, Michigan, before writing specifications on this product. amount of air introduced during

stirring.

Clean and degrease all application surfaces using a solvent to remove all mold release agent, processing oils and surface contaminant. Dry and remove all solvent before application.

For best adhesion the application substrate should be primed with SYLGARD* prime coat. Obtain a technical bulletin for proper application instructions. See "Bonding."

CAUTION: SYLGARD primer is flammable. Keep away from heat, sparks and open fiame. Use only with adequate ventilation.

When pouring SYLGARD 184 silicone elastomer into the curing container, care should be taken to minimize air entrapment. When practical, pouring should be done under vacuum. particularly if the component being potted or encapsulated has many fine voids. If this technique cannot be used, the unit should be evacuated after SYLGARD 184 silicone elastomer has been poured.

After allowing time for the material mass to reach temperature, cure according to the cure timetemperatures listed in "Curing."

\section{Repairability}

In the manufacture of electrical electronic devices it is often desirable to salvage or reclaim damaged or defective units. With most rigid types of potting and encapsulating materials, removal or entry is difficult or impossible without causing excessive damage to internal circuitry. SYLGARD 184 silicone elastomer can be selectively removed with relative ease, allowing repairs or changes to be completed and the area to be repotted with additional product. SYLGARD 184 silicone elastomer. base 8 curing agent, can be removed by cutting with a sharp blade or knife and tearing material away from the area to be repaired. Thin sections of the adhesive elastomer are best removed from substrates and circuitry by mechanical action such as scraping or rubbing; removal can be assisted by the application of isopropyl alcohol.

Before repotting a repaired device, if possible, roughen the exposed surface of the SYLGARD 184 silicone elastomer, base \& curing agent, with an abrasive paper. This will enhance 
adhesion and permit the repair matarial to become an integral matrix with the existing elastomer. Silicone prime coats are not recommended for adhering SYLGARD 184 silicone elastomer, base \& curing agent, to itself in repotting applications.

\section{Reversion Resistance}

SYLGARD 184 silicone elastomer, base \& curing agent, provides excellent reversion resistance even when exposed to temperatures in excess of $200 \mathrm{C}$ ( $392 \mathrm{~F}$ ) while under confinement or in deep section.

\section{Temperature Stability}

SYLGARD 184 silicone elastomer. base $\&$ curing agent, cures to a thermoset material that will not melt or appreciably soften even at elevated temperatures of $250 \mathrm{C}$ (482 F). The material may harden or become brittle after prolonged exposure to these elevated temperatures. SYLGARD 184 silicone elastomer, base \& curing egent, has a $130 \mathrm{C}(265 \mathrm{~F})$ UL yellowcard temperature index classification for both electrical and mechanical functional use.

Upon exposure to lower temperatures. SYLGARD 184 silicone elastomer. base \& curing agent, does not approach a stiffening point until $-55 \mathrm{C}$ $(-67 \mathrm{~F})$. Overall, the cured elastomer will maintain its basic elastomeric flexibility over an extremely wide range of -55 to $200 \mathrm{C}$ ( -67 to $392 \mathrm{~F}$ ), making $i$ the ideal selection for applications that may experience high or low temperature cycling

\section{PROCESSING TECHNIQUES \\ Curing}

SYLGARD 184 silicone elastomer base $\&$ curing agent, can be satisfactorily cured either with exposure to air or completely sealed, and at temperatures ranging from 25 to $150 \mathrm{C}$ (77 to 302 F). Curing time can be appreciably decreased by elevating the cure temperature. One of the following cure cycles is suggested:

- $25 \mathrm{C}(77 \mathrm{~F})$ for 24 hours

- $65 \mathrm{C}$ (149 F) for 4 hours

- $100 \mathrm{C}$ (212 F) for 1 hour

- $150 \mathrm{C}$ (302 F) for 15 minutes Large parts will require additional time in the oven to heat to the selected cure temperature. Satisfactory sources of heat include circulating and non-circulating ovens, intrared heating lamps and heat guns.

Full mechanical strength will not be achieved for 7 days when SYLGARD 184 silicone elastomer, base $\&$ curing agent, is cured at $25 \mathrm{C}(77 \mathrm{~F})$. The majority of its physical strength, however, is present after 24 hours, although surface cure may not yet be complete.

\section{Bonding}

SYLGARD 184 silicone elastomer. base $\&$ curing agent, will not normally bond to clean, nonporous surfaces such as metal $\alpha$ glass. A primer coat is required to ensure adhesion to these surfaces. SYLGARD prime coat is recommended to obtain the best adhesion. The prime coat should be applied in a thin layer to clean, dry surfaces where adhesion is desired, It should be air dried 1 to 2 hours before the silicone elastomer is applied.

\section{Lowering Viscosity}

The viscosity of SYLGARD 184 elastomer, base \& curing agent, can be lowered by the addition of $200^{\circ}$ fluid, 50 cSt., from Dow Corning. Quantities of 10 percent or less will have little or no effect on the physical or electrical properties. Quantities of 10 percent or greater may decrease the physical strength and hardness but will have no effect on the electrical properties. At concentrations greater than 10 percent the fluid may possibly bleed from cured SYLGARD 184 silicone elas tomer. The addition of thinning fluid does not change the mixing ratio of curing agent to base.

\section{Varying the Hardness}

Variations of up to 10 percent in concentration $\alpha$ curing agent in SYLGARD 184 silicone elastomer have little effect on cure time or on the physical properties of the final cured elastomer. Lowering the curing agent concentration by more than 10 percent will result in a softer and weaker elastomer, increasing the concentration by more then 10 percent will result h over-hardening of the cured elastomer and will tend to degrade the physical and thermal properties. Changes in the curing agent concentration will have little or no effect on the electrical properties, nowever.

\section{Release Agents}

When SYLGARD 184 silicone elastomer, base \& curing agent, is cured in a mold, the mold should first be treated with a release agent to prevent sticking. Suitable release agents include DUPONOL" VIAQ at a 5 percent concentration with isopropanol; DOW CORNING 230 fluid at a 2 percent concentration with CHLOROTHENE ${ }^{* 2}$ or similar chlorinated solvent; a mild liquid detergent at a 2 to 5 percent concentration with water; or petroleum jelly at a 5 percent solution in a chlorinated solvent.

\section{LMMTTATIONS}

\section{Inhibition of Cure}

In the presence of inhibitors, cure of SYLGARD 184 silicone elastomer is poor. In the inhibited area (usually less than 0.020 -inch thick) the silicone elastomer remains in a liquid or tacky state even though the cure schedule has been completed, and despite any subsequent attempts to convert it to a hard, dry, rubbery mass, this material will remain uncured. Extremely minute quantities of innibitor may be sufficient to produce this effect. The most notable causes of inhibition include:

- Organotin and other organometallic compounds

- Silicone rubbers containing organotin catalyst

- Sulfur, polysulfides, polysultones and other sulfur-containing materials

- Amines, urethanes, aminecontaining materials and other nitrogen-containing materials

- Unsaturated hydrocarbon plasticizers

If a substrate or material is considered questionable in respect to potertial cure inhibition, a small-scale compatibility test to ascertain suitability in the particular application is recommended. If inhibition is present it may sometimes be overcome by prebaking the unit at the highest tolerable temperature for approximately 1 to 4 hours to remove volatile chemicals. See bulletin No. 10-022, "How To

\footnotetext{
"Duponol" is a registered tradernark of E. L. du Pont de Nemours \& Compary. "Chlorothene" is a registered trademerk of The Dow Chemical Company.
} 
Process SYLGARD" Brand Elastomers" for a listing of inhibition-causing materials.

\section{Thermal Expansion}

SYLGARD 184 silicone elastomer, base $\&$ curing agent, has a notable volume coefficient of thermai expansion $\left(9.6 \times 10^{-4} /{ }^{\circ} \mathrm{C}\right.$; see Typical Properties chart). The volume of the cured elastomer will increase or decrease approximately 9.6 percent for each $100 \mathrm{C}(212 \mathrm{~F})$ of temperature differen tial. When using SYLGARD $184 \mathrm{sili}-$ cone elastomer, base \& curing agent, at higher temperatures in applications that are highly confined or hermetically sealed, allowance should be made to accommodate volume expansion and prevent pressure build-up. Normal thermal expansion and contraction stresses may be minimized by selecting a cure temperature close to the midway point of the high and low extremes of the thermal cycle.

Temperature limits may be influenced by differences in the thermal expansion values between the silicone elastomer and the encapsulated or potted components, and also by their configurations. Therefore, thermal operating limits should be determined by testing before large scale use.

\section{SAFETY REQUIREMENTS} Handling

SYLGARD 184 silicone elastomer base 8 curing agent, does not contain volatile solvents. Special ventilation is not required in the normal use or storage of this product. Base and curing agent liquid components or their cured mixture do not present any significant toxicological hazard incidental to normal industrial handling. Minimal eye protection, such as standard safety giasses, should be adequate for normal industrial use. Direct eye contact can cause temporary eye discomfort; flush thoroughly with copious amounts of water should contact occur. See Matorial Safety Data Sheet for more detailed handling instructions.

\section{TABLE I: SPECIAL FEATURES AND BENEFITS}

\begin{tabular}{|c|c|}
\hline Special Feature & Benefit \\
\hline - Low toxicity & $\begin{array}{l}\text { - No special precautions required for normal } \\
\text { industrial handling }\end{array}$ \\
\hline $\begin{array}{l}\text { - No solvents or cure by- } \\
\text { products; no exotherm during } \\
\text { cure }\end{array}$ & $\begin{array}{l}\text { - Requires no special venting: will not cause } \\
\text { corrosion; low shrinkage during cure }\end{array}$ \\
\hline $\begin{array}{l}\text { - Cures to a transparent, } \\
\text { flexible elastomer }\end{array}$ & $\begin{array}{l}\text { - Provides stability and relief from } \\
\text { mechanical shock; low transmission of } \\
\text { vibration; visual inspection of components } \\
\text { and easy repairability }\end{array}$ \\
\hline - Environmental protection & $\begin{array}{l}\text { - Low water absorption; good radiation } \\
\text { resistance; little out-gassing in hard } \\
\text { vacuum }\end{array}$ \\
\hline - Excellent dielectric properties & $\begin{array}{l}\text { - Maintains and protects existing electrical } \\
\text { insulation requirements }\end{array}$ \\
\hline $\begin{array}{l}\text { - Stability over a wide } \\
\text { temperature range; reversion } \\
\text { resistant }\end{array}$ & $\begin{array}{l}\text { - Maintains elastomeric flexibility and } \\
\text { provides functional stability from }-55 \text { to } \\
200 \mathrm{C}(-67 \text { to } 392 \mathrm{~F} \text { ), even in confinement }\end{array}$ \\
\hline - Flame resistant & $\begin{array}{l}\text { - UL flammability classification of } 94 \mathrm{~V}-1 \text { and } \\
\text { a temperature rating of } 130 \mathrm{C} \text { (265 F) }\end{array}$ \\
\hline
\end{tabular}

\section{Abnormal Exposures}

CAUTION: The liquid curing agent component of SYLGARD 184 silicone elastomer may generate hydrogen gas if contaminated with strong acids, bases or catalytic oxidizing materiais. If exposure is suspected, use appropn ate caution to relieve hydrogen gas pressure. Keep away from sparks and flame, and supply adequate ventilation to reduce localized build-up of hydrogen gas.

\section{Spills}

Spills of the liquid base and curing agent components of SYLGARD 184 silicone elastomer can become extremely slippery. Sawdust or other absorbent material should be immediately applied to any liquid spill for temporary reliet. The spill should be removed with high flash point minera spirits or other suitable solvent.

\section{SHIPPING LIMITATIONS}

None.

\section{STORAGE AND SHELF LIFE}

When stored in original unopened containers at or below $32 \mathrm{C}(90 \mathrm{~F})$, SYLGARD 184 silicone elastomer. base $\&$ curing agent, has a shelf life of 24 months from date of manufacture.

\section{PACKAGINC}

SYLGARD 184 silicone elastomer, base $\&$ curing agent, is shipped in kits that contain both the base and curing agent, liquid components in separate containers. Each kit contains the appropriate weight of curing agent for the amount of base. Complete kits are available in 1.1-, 8.8-, 44- and 495-1b (0.5-, 4-, 20- and 225-kg) quantities, net weight.

\section{MSDS INFORMATION}

ATTENTION: PRODUCT SAFETY INFORMATION REQUIRED FOR SAFE USE IS NOT INCLUDED. BEFORE HANDLING, READ PRODUCT AND MATERIAL SAFETY DATA SHEETS 
AND CONTAINER LABELS FOR SAFE USE, PHYSICAL AND HEALTH HAZARD INFORMATION. THE MATERIAL SAFETY DATA SHEET IS AVAILABLE FROM YOUR DOW CORNING REPRESENTATIVE, OR DISTRIBUTOR,

OR BY WRITING TO DOW CORNING CUSTOMER SERVICE, OR BY CALLING (517) 496-6000.

WARRANTY INFORMATION-

PLEASE READ CAREFULLY

Dow Corning believes that the

information is this publication is an accurate description of the typical characteristics and/or uses of the product or products, but it is your responsibility to thoroughly test the product in your specific application to determine its performance, efficacy and safety.

Unless Dow Corning provides you with a specific written warranty of fitness for a particular use, Dow Corning's sole warranty is that the product or products will meet Dow Corning's then current sales specifications.

DOW CORNING SPECIFICALLY

DISCLAIMS ANY OTHER EXPRESS

OR IMPLIED WARRANTIES OF MERCHANTABILITY AND OF FITNESS

FOR USE. Your exclusive remedy and

Dow Corning's sole liability for breach of warranty is limited to refund of the purchase price or replacement of any product shown to be other than as warranted, and Dow Corning expressly disclaims any liability for incidental or consequential damages. Suggestions of uses should not be taken as inducements to infringe any particular patent. MIDLAND, MICHIGAN 48686-0994 "DOW CoRNING" and "Sylgard" are registered tradamark of Dow Coming Corporation. 


\section{MICRO CHEM}

\section{NANO ${ }^{\text {TM }}$ SU-8}

\section{Negative Tone Photoresist Formulations 50-100}

- High aspect ratio imaging with near vertical side walls

a Near UV $(350-400 \mathrm{~nm})$ processing

Tilm thicknesses from 1 to $>200 \mu \mathrm{m}$ with single spin coat processes

n Superb chemical and temperature resistance

SU-8 is a high contrast, epoxy based photoresist designed for micromachining and other microelectronic applications, where a thick chemically and thermally stable image is desired. The exposed and subsequently cross-linked portions of the film are rendered insoluble to liquid developers. SU8 has very high optical transparency above $360 \mathrm{~nm}$, which makes it ideally suited for imaging near vertical sidewalls in very thick films. SU-8 is best suited for permanent applications where it is imaged, cured and left in place.

\section{Process Guidelines}

SU-8 is most commonly processed with conventional near UV $(350-400 \mathrm{~nm})$ radiation, although it may be imaged with e-beam or X-ray. i-line $(365 \mathrm{~nm})$ is recommended. Upon exposure, cross-linking proceeds in-two-steps (1) formation of a strong acid during the exposure process, followed by (2) acid-initiated, thermally driven epoxy cross-linking during the post exposure bake (PEB) step.

A normal process is: spin coat, soft bake, expose, post expose bake (PEB) and develop. A controlled hard bake is recommended to further cross-link the imaged SU-8 structures when they it will remain as part of the device. The entire process should be optimized for the specific application. A baseline process is given here to be used as a starting point.

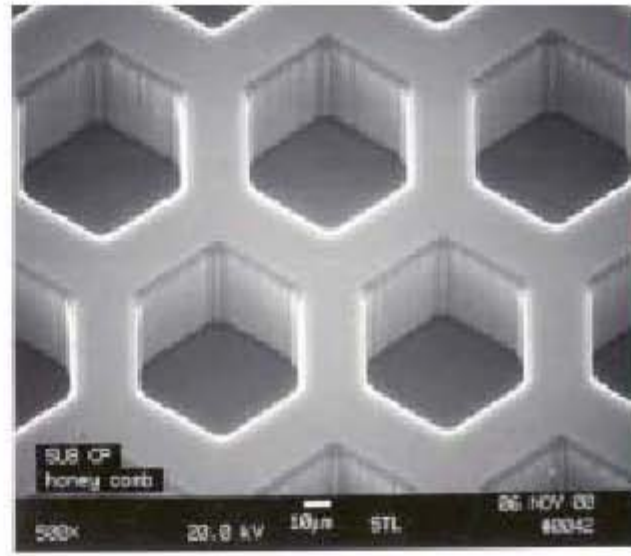

Honeycomb structure in thick $S U-8$ resist

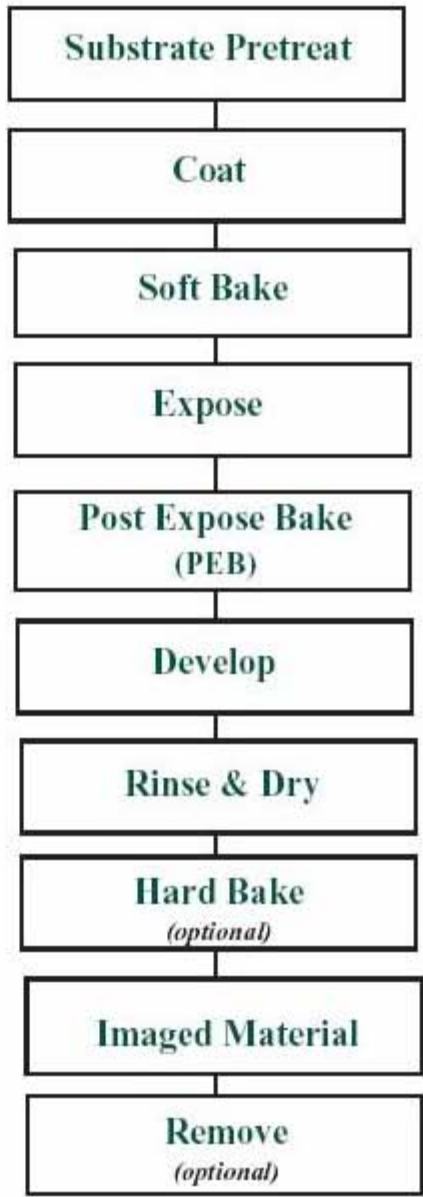




\section{Substrate Pretreatment}

To obtain maximum process reliability, substrates should be clean and dry prior to applying the SU-8 resist. Start with a solvent cleaning, or a rinse with dilute acid, followed by a DI water rinse. Where applicable, substrates should be subjected to a piranha etch / clean $\left(\mathrm{H}_{2} \mathrm{SO}_{4} \& \mathrm{H}_{2} \mathrm{O}_{2}\right)$. To dehydrate the surface, bake at $200^{\circ} \mathrm{C}$ for 5 minutes on a hotplate. For applications that require electroplating and subsequent removal of SU-8 apply MicroChem's OmniCoat prior to processing SU-8.

\section{Coat}

SU-8 resists are designed to produce low defect coatings over a very broad range of film thickness. The film thickness versus spin speed data displayed in Table 1. and Figure 1. provide the information required to select the appropriate SU-8 resist and spin conditions, to achieve the desired film thickness.

The recommended coating conditions are: (1) STATIC Dispense: Approximately $1 \mathrm{ml}$ of SU-8 per inch of substrate diameter.

(2) Spread Cycle: Ramp to $500 \mathrm{rpm}$ at $100 \mathrm{rpm} / \mathrm{second}$ acceleration. Hold at this speed for $5-10$ seconds to allow the resist to cover the entire surface.

(3) Spin Cycle: Ramp to final spin speed at an acceleration of $300 \mathrm{rpm} / \mathrm{sec}$ ond and hold for a total of 30 seconds.

\begin{tabular}{|l|c|c|c|}
\hline Product Name & $\begin{array}{c}\text { Viscosity } \\
\text { (5t) }\end{array}$ & $\begin{array}{c}\text { Thidkness } \\
\text { (ums) }\end{array}$ & $\begin{array}{c}\text { Spin Speed } \\
\text { (rpm) }\end{array}$ \\
\hline & & 40 & 3000 \\
\hline SU-850 & 12250 & 50 & 2000 \\
\hline & & 100 & 1000 \\
\hline & & 100 & 3000 \\
\hline SU-8100 & 51500 & 150 & 2000 \\
\hline & & 250 & 1000 \\
\hline
\end{tabular}

Table 1. Thickness vs. spin speed data for selected $S U-8$ resists.

\#Approximate

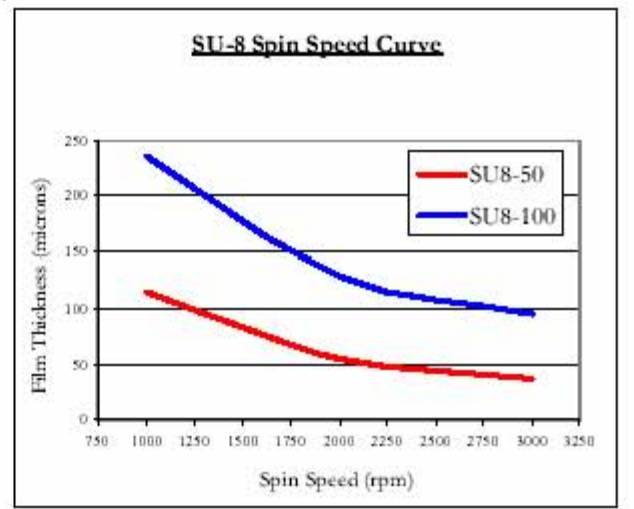

Figure I. Spin speed vs. thickness curves for selected $S U-8$ resists.

\section{Soft Bake}

After the resist has been applied to the substrate, it must be soft baked to evaporate the solvent and densify the film. SU-8 is normally baked on a level hot plate, although convection ovens may be used. The following bake times are based on contact hot plate processes. Bake times should be optimized for proximity and convection oven bake processes since solvent evaporation rate is influenced by the rate of heat transfer and ventilation.

For best results, ramping or stepping the soft bake temperature is recommended. Lower initial bake temperatures allow the solvent to evaporate out of the film at a more controlled rate, which results in better coating fidelity, reduced edge bead and better resist -to-substrate adhesion. Refer to Table 2. for TWO STEP contact hot plate process recommendations.

\begin{tabular}{|l|c|c|c|}
\hline Product Name & $\begin{array}{c}\text { Thidkness } \\
\text { (ums) }\end{array}$ & $\begin{array}{c}\text { Pre-bake } \\
\text { (a.65 C }\end{array}$ & $\begin{array}{c}\text { Softbake } \\
\text { a.95 } 95^{\circ} \mathrm{C}\end{array}$ \\
\hline & 40 & 5 & 15 \\
\hline SU-850 & 50 & 6 & 20 \\
\hline & 100 & 10 & 30 \\
\hline & 100 & 10 & 30 \\
\hline SU-8100 & 150 & 20 & 50 \\
\hline & 250 & 30 & 90 \\
\hline
\end{tabular}

Table 2. Recommended soft bake parameters 
Expose

SU-8 is optimized for near UV (350-400nm) exposure. iline exposure tools are recommended. SU-8 is virtually transparent and insensitive above $400 \mathrm{~nm}$ but has high actinic absorption below $350 \mathrm{~nm}$. This can be seen in Figure 2. Excessive dose below $350 \mathrm{~nm}$ may, therefore, result in over exposure of the top portion of the resist film, resulting in exaggerated negative sidewall profiles or T-topping. The optimal exposure dose will depend on film thickness (thicker films require higher dosage) and process parameters. The exposure dose recommendations in Table 3. are based on source intensity measurements taken with an i-line $(365 \mathrm{~nm})$ radiometer and probe.

Expose tip: When using a broad spectral output source, for best imaging results, i.e. straightest sidewalls, filter out excessive energy below $350 \mathrm{~nm}$.

Catastrophic adhesion failure, severely negative sidewalls and excessive cracking often indicate an under cross-linking condition. To correct the problem, increase the exposure dose and/or increase the post exposure bake (PEB) time.

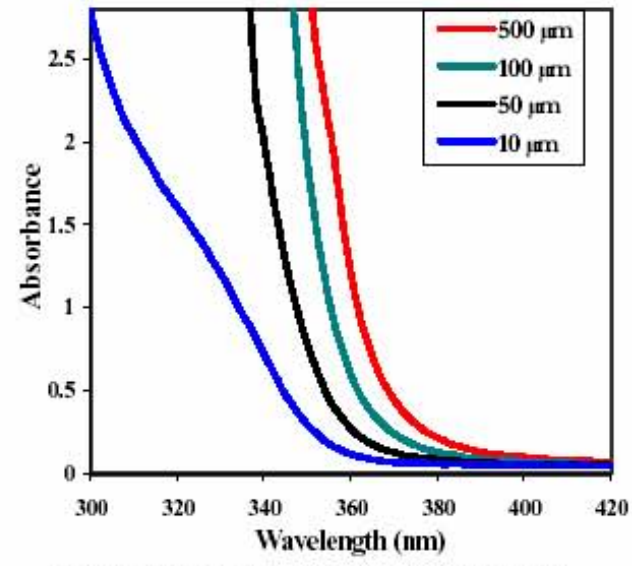

Figure 2. SU-8 absorbance vs. film thickness

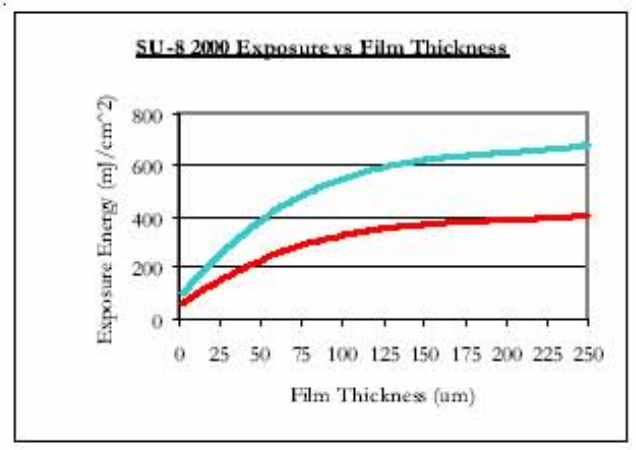

Table 3. Recommended exposure dose processes

\section{Post Exposure Bake}

Following exposure, a post expose bake (PEB) must be performed to selectively cross-link the exposed portions of the film. This bake can be performed either on a hot plate or in a convection oven. Optimum cross-link density is obtained through careful adjustments of the exposure and PEB process conditions. The bake recommendations be low are based on results obtained with a contact hot plate.

PEB tip: SU-8 is readily cross-linked and can result in a highly stressed film. To minimize stress, wafer bowing and resist cracking, a slow ramp or TWO STEP contact hot plate process, as shown in Table 4., is recommended. Rapid cooling after PEB should be avoided.

\begin{tabular}{|c|c|c|c|}
\hline Product Name & $\begin{array}{c}\text { Thickness } \\
\text { (ums) }\end{array}$ & $\begin{array}{c}\text { PEB 1 } \\
\text { a.65 }\end{array}$ & $\begin{array}{c}\text { PEB 2 } \\
\text { a. 95 }\end{array}$ \\
\hline & 40 & 1 & 4 \\
\hline SU-8 50 & 50 & 1 & 5 \\
\hline & 100 & 1 & 10 \\
\hline & 100 & 1 & 10 \\
\hline SU-8 100 & 150 & 1 & 12 \\
\hline & 250 & 1 & 20 \\
\hline
\end{tabular}

Table 4. Recommended post exposure bake parameters 


\section{Develop}

SU- 8 resists have been optimized for use with MicroChem's SU-8 Developer. Immersion, spray or spray- puddle processes can be used. Other solvent based developers such as ethyl lactate and diacetone alcohol may also be used. Strong agitation is recommended for high aspect ratio and/or thick film structures. Recommended develop times are given in Table 5. for immersion processes. These proposed develop times are approximate, since actual dissolution rates can vary widely as a function of agitation rate, temperature and resist processing parameters.

\begin{tabular}{|c|c|c|}
\hline Product Name & $\begin{array}{c}\text { Thickness } \\
\text { (ums) }\end{array}$ & $\begin{array}{c}\text { Development } \\
\text { (minutes) }\end{array}$ \\
\hline & 40 & 6 \\
\hline SU-850 & 50 & 6 \\
\hline & 100 & 10 \\
\hline & 100 & 10 \\
\hline SU-8 100 & 150 & 15 \\
\hline & 250 & 20 \\
\hline
\end{tabular}

Table 5. Recommended develop processes

\section{Rinse and Dry}

Following development, the substrate should be rinsed briefly with isopropyl alcohol (IPA), then dried with a gentle stream of air or nitrogen.

Rinse tip: If a white film is produced during rinse, this is an indication that the substrate has been under developed. Simply immerse or spray the substrate with SU-8 developer to remove the film and complete the development process. Repeat the rinse step

\section{Hard Bake (cure)}

SU-8 has good mechanical properties, therefore hard bakes are normally not required. For applications where the imaged resist is to be left as part of the final device, the resist may be ramp/step hard baked between $150-200^{\circ} \mathrm{C}$ on a hot phate or in a convection oven to further cross link the material. Bake times vary based on type of bake process and film thickness.

\section{Remove}

SU -8, after expose and PEB, is a highly cross-linked epoxy, which makes it extremely difficult to remove with conventional solvent based resist strippers. MicroChem's Remover PG will swell and lift off minimally cross-linked SU-82000.
However, if OmniCoat has been applied immersion in Remover PG should effect a clean and thorough Lift-Off of the SU-8 2000 Material. It will not remove fully cured or hard baked SU-8 2000 without the use of OmniCoat. Alternate removal processes include immersion in oxidizing acid solutions such as piranha etch / clean, plasma ash, RIE, laser ablation and pyrolosis.

To remove minimally cross-linked SU-8 2000 , or if using Omnicoat, with Remover PG, heat the bath to $50-80^{\circ} \mathrm{C}$ and immerse the substrates for $30-90$ minutes. Actual strip time will depend on resist thickness and cross-link density

Formore information on MicroChem Omnicoat and Remover PG please see the relevant product data sheets.

\section{Storage}

Store SU-8 resists upright in tightly closed containers in : cool, dry environment away from direct sunlight at a temperature of $40-70^{\circ} \mathrm{F}\left(4-21^{\circ} \mathrm{C}\right)$. Store away from light, acids, hea and sources of ignition. Shelf life is twelve months from date of manufacture.

\section{Disposal}

SU-8 resists may be included with other waste containing similar organic solvents to be discarded for destruction or reclaim in accordance with local state and federal regulations. It is the responsibility of the customer to ensure the disposal of SU-8 resists and residues made in observance all federal, state, and local environmental regulations.

\section{Environmental, Health and Safety}

Consult product Material Safety Data Sheet before working with SU-8 resists. Handle with care. Wear chemical goggles, chemical gloves and suitable protective clothing when handling SU-8 resists. Do not get into eyes, or onto skin or clothing. Use with adequate ventilation to avoid breathing vapors or mist. In case of contact with skin, wash affected area with soap and water. In case of contact with eyes, rinse immediately with water and flush for 15 minutes lifting eyelids frequently. Get emergency medical assistance.

The information is based on our experience and is, we believe to be reliable, but may not be complete. We make no guarantee or warranty, expressed or implied, regarding the information, use, handling, storage, or possession of these products, or the application of any process described here in or the results desired, since the conditions of use and handling of these products are beyond our control.

\section{MICRO CHEM}

1254 Chestnut Street Newton, MA 02464

tel: (617)965-5511 fax: (617)965-5818

email: mec $a$ microchem.com www.microchem.com 
APPENDIX D

DERIVATIONS OF IMPEDANCE MODEL EQUATIONS
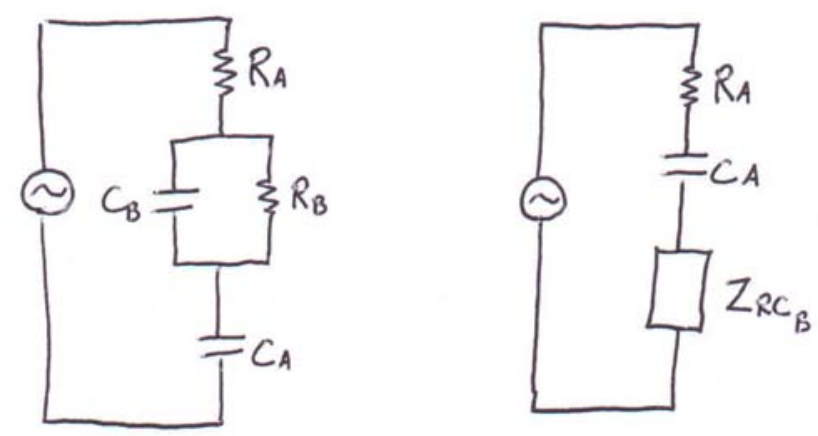

$$
\omega=2 \pi f
$$

$$
\begin{aligned}
& \frac{1}{Z_{R C_{B}}}=\frac{1}{R_{B}}+\frac{1}{Z_{C B}} \rightarrow \underbrace{Z_{R C_{B}}}_{Z_{1}}=\frac{R Z_{C}}{R+Z_{C}}=\frac{R_{B}\left(-j \frac{1}{\omega C_{B}}\right)}{R_{B}+\left(-j \frac{1}{\omega C_{B}}\right)}=\frac{R_{B}}{j R_{B} C_{B} \omega+1} \\
& Z=\underbrace{R_{A}-j \frac{1}{\omega C_{A}}}_{Z_{2}}+Z_{R C_{B}} \\
& \left|Z_{1}\right|=\sqrt{\left(\frac{-1}{\omega C_{A}}\right)^{2}+R_{A}^{2}}=\frac{\sqrt{1+\left(R_{A} C_{A} \omega\right)^{2}}}{C_{A} \omega}, \theta_{1}=\arctan \left(\frac{-1}{R_{A} C_{A} \omega}\right) \\
& Z_{2}=\frac{R_{B} \angle 0^{0}}{\sqrt{1+\left(R_{B} C_{B} \omega\right)^{2}} \angle \theta_{2}}=\frac{R_{B}}{\sqrt{1+\left(R_{B} C_{B} \omega\right)^{2}}} L-\theta_{2} \\
& \angle \theta_{2}=\arctan \left(\frac{R_{B} C_{B} \omega}{1}\right) \rightarrow L-\theta_{2}=-\arctan \left(R_{B} C_{B} \omega\right)
\end{aligned}
$$

146 


\section{APPENDIX E}

\section{SAMPLE WORKSHEET OF COLLECTED IMPEDANCE DATA}

4294A REV1.11

DATE: Jul 232005

MEASURE PARAMETER: IMPEDANCE MAG PHASE (DEG)

ADAPTER: PROBE

SWEEP TYPE: LOG FREQ

NUMBER of POINTS: 100

POINT DELAY TIME: 0 Sec

SWEEP DELAY TIME: 0 Sec

OSC LEVEL: $10 \mathrm{mVolt}$

DC BIAS: OFF

BW: 3

SWEEP AVERAGING: OFF

POINT AVERAGING: OFF

TRACE: A

FORMAT: LINEAR

$\begin{array}{rrr}\text { Frequency } & \text { Data Trace Real } & \text { Data Trace Imag } \\ 4.00 \mathrm{E}+01 & 5.43 \mathrm{E}+06 & 0.00 \mathrm{E}+00 \\ 4.43 \mathrm{E}+01 & 7.07 \mathrm{E}+06 & 0.00 \mathrm{E}+00 \\ 4.91 \mathrm{E}+01 & 6.90 \mathrm{E}+06 & 0.00 \mathrm{E}+00 \\ 5.44 \mathrm{E}+01 & 4.27 \mathrm{E}+06 & 0.00 \mathrm{E}+00 \\ 6.02 \mathrm{E}+01 & 3.98 \mathrm{E}+06 & 0.00 \mathrm{E}+00 \\ 6.67 \mathrm{E}+01 & 4.22 \mathrm{E}+06 & 0.00 \mathrm{E}+00 \\ 7.39 \mathrm{E}+01 & 3.75 \mathrm{E}+06 & 0.00 \mathrm{E}+00 \\ 8.19 \mathrm{E}+01 & 3.72 \mathrm{E}+06 & 0.00 \mathrm{E}+00 \\ 9.07 \mathrm{E}+01 & 3.23 \mathrm{E}+06 & 0.00 \mathrm{E}+00 \\ 1.00 \mathrm{E}+02 & 2.96 \mathrm{E}+06 & 0.00 \mathrm{E}+00 \\ 1.11 \mathrm{E}+02 & 2.73 \mathrm{E}+06 & 0.00 \mathrm{E}+00 \\ 1.23 \mathrm{E}+02 & 2.40 \mathrm{E}+06 & 0.00 \mathrm{E}+00 \\ 1.37 \mathrm{E}+02 & 2.35 \mathrm{E}+06 & 0.00 \mathrm{E}+00 \\ 1.51 \mathrm{E}+02 & 2.18 \mathrm{E}+06 & 0.00 \mathrm{E}+00 \\ 1.67 \mathrm{E}+02 & 2.07 \mathrm{E}+06 & 0.00 \mathrm{E}+00 \\ 1.86 \mathrm{E}+02 & 1.87 \mathrm{E}+06 & 0.00 \mathrm{E}+00 \\ 2.06 \mathrm{E}+02 & 1.67 \mathrm{E}+06 & 0.00 \mathrm{E}+00 \\ 2.28 \mathrm{E}+02 & 1.61 \mathrm{E}+06 & 0.00 \mathrm{E}+00 \\ 2.52 \mathrm{E}+02 & 1.46 \mathrm{E}+06 & 0.00 \mathrm{E}+00 \\ 2.79 \mathrm{E}+02 & 1.38 \mathrm{E}+06 & 0.00 \mathrm{E}+00 \\ 3.09 \mathrm{E}+02 & 1.18 \mathrm{E}+06 & 0.00 \mathrm{E}+00\end{array}$




\begin{tabular}{|c|c|c|}
\hline $3.43 E+02$ & $1.12 E+06$ & $0.00 E+00$ \\
\hline $3.80 \mathrm{E}+02$ & $1.03 E+06$ & $0.00 \mathrm{E}+00$ \\
\hline $4.21 \mathrm{E}+02$ & $9.45 E+05$ & $0.00 \mathrm{E}+00$ \\
\hline $4.66 \mathrm{E}+02$ & $8.72 E+05$ & $0.00 \mathrm{E}+00$ \\
\hline $5.16 \mathrm{E}+02$ & $8.40 E+05$ & $0.00 E+00$ \\
\hline $5.72 \mathrm{E}+02$ & $7.54 \mathrm{E}+05$ & $0.00 E+00$ \\
\hline $6.33 E+02$ & $6.97 \mathrm{E}+05$ & $0.00 \mathrm{E}+00$ \\
\hline 7.01E+02 & $6.38 E+05$ & $0.00 \mathrm{E}+00$ \\
\hline 7.77E+02 & $5.90 \mathrm{E}+05$ & $0.00 \mathrm{E}+00$ \\
\hline $8.61 \mathrm{E}+02$ & $5.47 \mathrm{E}+05$ & $0.00 E+00$ \\
\hline $9.53 \mathrm{E}+02$ & $5.00 \mathrm{E}+05$ & $0.00 \mathrm{E}+00$ \\
\hline $1.06 \mathrm{E}+03$ & $4.66 \mathrm{E}+05$ & $0.00 \mathrm{E}+00$ \\
\hline 1.17E+03 & $4.28 \mathrm{E}+05$ & $0.00 \mathrm{E}+00$ \\
\hline $1.30 \mathrm{E}+03$ & $3.91 \mathrm{E}+05$ & $0.00 E+00$ \\
\hline $1.44 \mathrm{E}+03$ & $3.66 \mathrm{E}+05$ & $0.00 \mathrm{E}+00$ \\
\hline $1.59 \mathrm{E}+03$ & $3.37 E+05$ & $0.00 E+00$ \\
\hline $1.76 \mathrm{E}+03$ & $3.12 \mathrm{E}+05$ & $0.00 E+00$ \\
\hline $1.95 \mathrm{E}+03$ & $2.88 \mathrm{E}+05$ & $0.00 \mathrm{E}+00$ \\
\hline $2.16 \mathrm{E}+03$ & $2.64 \mathrm{E}+05$ & $0.00 E+00$ \\
\hline $2.39 E+03$ & $2.46 \mathrm{E}+05$ & $0.00 E+00$ \\
\hline $2.65 E+03$ & $2.27 E+05$ & $0.00 E+00$ \\
\hline $2.94 \mathrm{E}+03$ & $2.10 E+05$ & $0.00 E+00$ \\
\hline $3.25 E+03$ & $1.94 \mathrm{E}+05$ & $0.00 E+00$ \\
\hline $3.60 E+03$ & $1.78 E+05$ & $0.00 E+00$ \\
\hline $3.99 E+03$ & $1.65 E+05$ & $0.00 E+00$ \\
\hline $4.42 \mathrm{E}+03$ & $1.53 \mathrm{E}+05$ & $0.00 \mathrm{E}+00$ \\
\hline $4.90 E+03$ & $1.41 \mathrm{E}+05$ & $0.00 E+00$ \\
\hline $5.42 \mathrm{E}+03$ & $1.30 E+05$ & $0.00 \mathrm{E}+00$ \\
\hline $6.01 \mathrm{E}+03$ & $1.20 E+05$ & $0.00 \mathrm{E}+00$ \\
\hline $6.66 \mathrm{E}+03$ & $1.11 \mathrm{E}+05$ & $0.00 \mathrm{E}+00$ \\
\hline 7.37E+03 & $1.02 E+05$ & $0.00 \mathrm{E}+00$ \\
\hline $8.17 E+03$ & $9.50 E+04$ & $0.00 \mathrm{E}+00$ \\
\hline $9.05 E+03$ & $8.77 \mathrm{E}+04$ & $0.00 \mathrm{E}+00$ \\
\hline $1.00 \mathrm{E}+04$ & $8.08 E+04$ & $0.00 \mathrm{E}+00$ \\
\hline $1.11 \mathrm{E}+04$ & $7.46 \mathrm{E}+04$ & $0.00 \mathrm{E}+00$ \\
\hline $1.23 E+04$ & $6.91 \mathrm{E}+04$ & $0.00 \mathrm{E}+00$ \\
\hline $1.36 \mathrm{E}+04$ & $6.37 E+04$ & $0.00 \mathrm{E}+00$ \\
\hline $1.51 \mathrm{E}+04$ & $5.90 E+04$ & $0.00 \mathrm{E}+00$ \\
\hline $1.67 \mathrm{E}+04$ & $5.46 \mathrm{E}+04$ & $0.00 \mathrm{E}+00$ \\
\hline $1.85 \mathrm{E}+04$ & $5.04 \mathrm{E}+04$ & $0.00 \mathrm{E}+00$ \\
\hline $2.05 \mathrm{E}+04$ & $4.66 \mathrm{E}+04$ & $0.00 \mathrm{E}+00$ \\
\hline $2.27 \mathrm{E}+04$ & $4.30 \mathrm{E}+04$ & $0.00 \mathrm{E}+00$ \\
\hline $2.52 \mathrm{E}+04$ & $3.98 E+04$ & $0.00 \mathrm{E}+00$ \\
\hline $2.79 \mathrm{E}+04$ & $3.69 \mathrm{E}+04$ & $0.00 E+00$ \\
\hline $3.09 E+04$ & $3.41 \mathrm{E}+04$ & $0.00 \mathrm{E}+00$ \\
\hline $3.42 E+04$ & $3.16 E+04$ & $0.00 \mathrm{E}+00$ \\
\hline $3.79 \mathrm{E}+04$ & $2.93 E+04$ & $0.00 \mathrm{E}+00$ \\
\hline $4.20 \mathrm{E}+04$ & $2.72 \mathrm{E}+04$ & $0.00 E+00$ \\
\hline $4.65 E+04$ & $2.53 E+04$ & $0.00 \mathrm{E}+00$ \\
\hline $5.15 E+04$ & $2.35 E+04$ & $0.00 \mathrm{E}+00$ \\
\hline $5.70 \mathrm{E}+04$ & $2.18 E+04$ & $0.00 \mathrm{E}+00$ \\
\hline $6.32 \mathrm{E}+04$ & $2.04 \mathrm{E}+04$ & $0.00 E+00$ \\
\hline $7.00 \mathrm{E}+04$ & $1.90 E+04$ & $0.00 \mathrm{E}+00$ \\
\hline $7.75 E+04$ & $1.77 E+04$ & $0.00 \mathrm{E}+00$ \\
\hline $8.59 E+04$ & $1.66 \mathrm{E}+04$ & $0.00 E+00$ \\
\hline $9.51 \mathrm{E}+04$ & $1.55 E+04$ & $0.00 \mathrm{E}+00$ \\
\hline
\end{tabular}




$\begin{array}{lll}1.05 \mathrm{E}+05 & 1.45 \mathrm{E}+04 & 0.00 \mathrm{E}+00 \\ 1.17 \mathrm{E}+05 & 1.37 \mathrm{E}+04 & 0.00 \mathrm{E}+00 \\ 1.29 \mathrm{E}+05 & 1.29 \mathrm{E}+04 & 0.00 \mathrm{E}+00 \\ 1.43 \mathrm{E}+05 & 1.22 \mathrm{E}+04 & 0.00 \mathrm{E}+00 \\ 1.59 \mathrm{E}+05 & 1.15 \mathrm{E}+04 & 0.00 \mathrm{E}+00 \\ 1.76 \mathrm{E}+05 & 1.09 \mathrm{E}+04 & 0.00 \mathrm{E}+00 \\ 1.95 \mathrm{E}+05 & 1.04 \mathrm{E}+04 & 0.00 \mathrm{E}+00 \\ 2.16 \mathrm{E}+05 & 9.85 \mathrm{E}+03 & 0.00 \mathrm{E}+00 \\ 2.39 \mathrm{E}+05 & 9.42 \mathrm{E}+03 & 0.00 \mathrm{E}+00 \\ 2.65 \mathrm{E}+05 & 9.02 \mathrm{E}+03 & 0.00 \mathrm{E}+00 \\ 2.93 \mathrm{E}+05 & 8.65 \mathrm{E}+03 & 0.00 \mathrm{E}+00 \\ 3.25 \mathrm{E}+05 & 8.33 \mathrm{E}+03 & 0.00 \mathrm{E}+00 \\ 3.60 \mathrm{E}+05 & 8.03 \mathrm{E}+03 & 0.00 \mathrm{E}+00 \\ 3.98 \mathrm{E}+05 & 7.77 \mathrm{E}+03 & 0.00 \mathrm{E}+00 \\ 4.41 \mathrm{E}+05 & 7.54 \mathrm{E}+03 & 0.00 \mathrm{E}+00 \\ 4.89 \mathrm{E}+05 & 7.33 \mathrm{E}+03 & 0.00 \mathrm{E}+00 \\ 5.41 \mathrm{E}+05 & 7.14 \mathrm{E}+03 & 0.00 \mathrm{E}+00 \\ 6.00 \mathrm{E}+05 & 6.97 \mathrm{E}+03 & 0.00 \mathrm{E}+00 \\ 6.64 \mathrm{E}+05 & 6.80 \mathrm{E}+03 & 0.00 \mathrm{E}+00 \\ 7.36 \mathrm{E}+05 & 6.65 \mathrm{E}+03 & 0.00 \mathrm{E}+00 \\ 8.15 \mathrm{E}+05 & 6.51 \mathrm{E}+03 & 0.00 \mathrm{E}+00 \\ 9.03 \mathrm{E}+05 & 6.39 \mathrm{E}+03 & 0.00 \mathrm{E}+00 \\ 1.00 \mathrm{E}+06 & 6.27 \mathrm{E}+03 & 0.00 \mathrm{E}+00\end{array}$




\section{APPENDIX F}

\section{IMPEDANCE DATA FOR DEVICE 2 AND DEVICE 3}

Results from Device 2 with media only - no flow

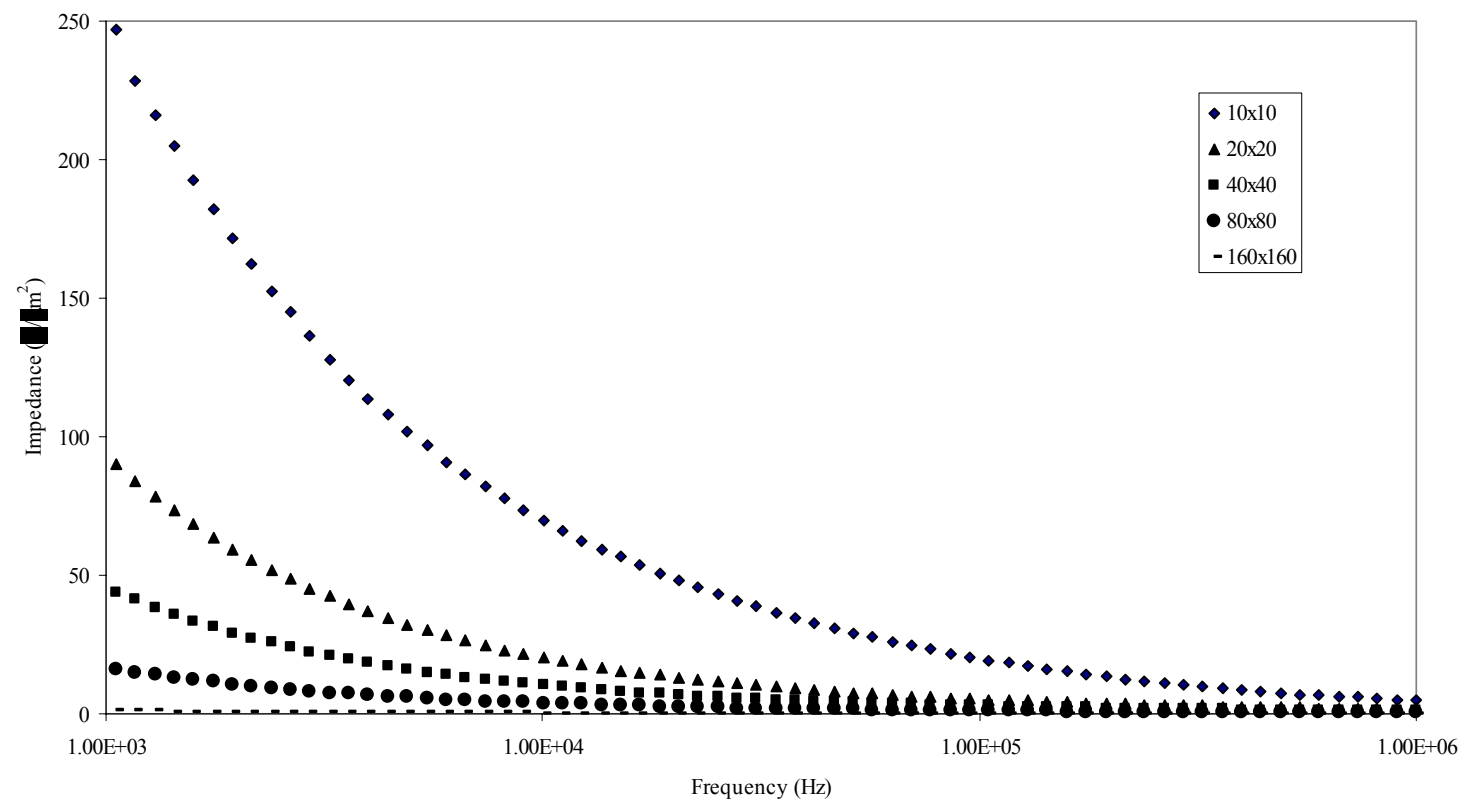

\begin{tabular}{|c|c|c|c|c|c|}
\cline { 2 - 6 } \multicolumn{1}{c|}{} & \multicolumn{5}{c|}{ Standard Deviation $(\Omega / \mu \mathrm{m} 2)$} \\
\hline Frequency & $10 \times 10$ & $20 \times 20$ & $40 \times 40$ & $80 \times 80$ & $160 \times 160$ \\
\hline \hline $1 \mathrm{kHz}$ & 71.68 & 32.06 & 12.19 & 16.76 & 0.38 \\
\hline $10 \mathrm{kHz}$ & 36.59 & 9.31 & 4.06 & 3.85 & 0.18 \\
\hline $100 \mathrm{kHz}$ & 15.19 & 2.80 & 1.49 & 0.94 & 0.07 \\
\hline $1 \mathrm{MHz}$ & 3.09 & 0.52 & 0.30 & 0.18 & 0.02 \\
\hline
\end{tabular}




\begin{tabular}{|c|c|c|c|c|}
\cline { 2 - 5 } \multicolumn{1}{c|}{} & \multicolumn{4}{c|}{ Model Fit } \\
\hline Electrode & $\mathrm{R}(\Omega)$ & $\mathrm{C}(\mathrm{F})$ & $\mathrm{C}\left(\mathrm{F} / \mathrm{cm}^{2}\right)$ & $\mathrm{R}^{2}$ \\
\hline \hline $10 \times 10$ & 84600 & $1.58 \mathrm{E}-10$ & $4.88 \mathrm{E}-06$ & 0.9458 \\
\hline $20 \times 20$ & 34600 & $2.70 \mathrm{E}-10$ & $5.05 \mathrm{E}-06$ & 0.9687 \\
\hline $40 \times 40$ & 25900 & $4.08 \mathrm{E}-10$ & $5.64 \mathrm{E}-06$ & 0.9672 \\
\hline $80 \times 80$ & 21400 & $5.18 \mathrm{E}-10$ & $3.33 \mathrm{E}-06$ & 0.9652 \\
\hline $160 \times 160$ & 6780 & $2.79 \mathrm{E}-09$ & $6.43 \mathrm{E}-06$ & 0.9593 \\
\hline
\end{tabular}


Results from Device 2 with media and fibronectin - no flow

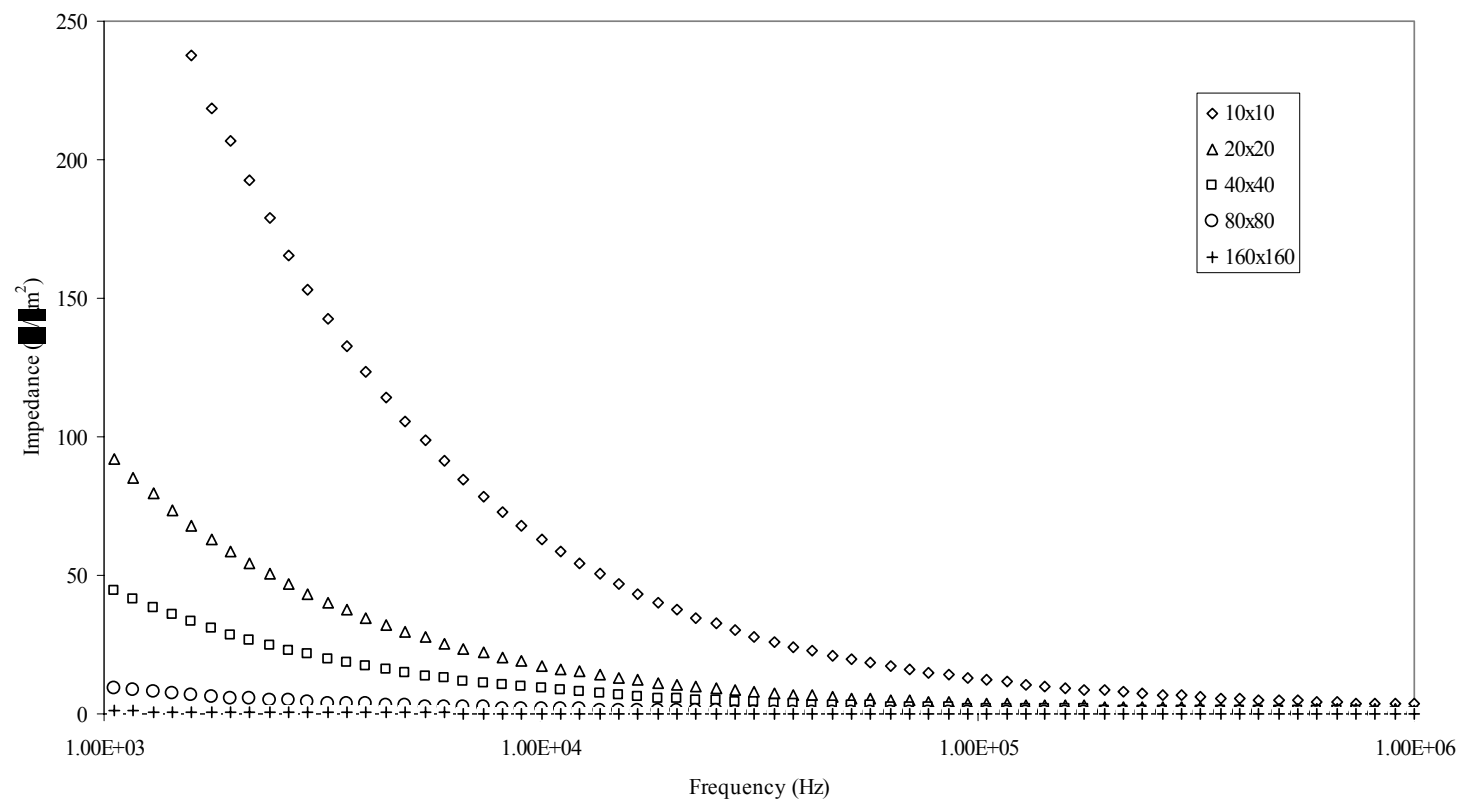

\begin{tabular}{|c|c|c|c|c|c|}
\cline { 2 - 6 } \multicolumn{1}{c|}{} & \multicolumn{5}{c|}{ Standard Deviation $(\Omega / \mu \mathrm{m} 2)$} \\
\hline Frequency & $10 \times 10$ & $20 \times 20$ & $40 \times 40$ & $80 \times 80$ & $160 \times 160$ \\
\hline \hline $1 \mathrm{kHz}$ & 56.95 & 15.11 & 5.13 & 1.98 & 0.20 \\
\hline $10 \mathrm{kHz}$ & 11.70 & 2.56 & 1.42 & 0.23 & 0.03 \\
\hline $100 \mathrm{kHz}$ & 1.50 & 0.52 & 0.23 & 0.04 & 0.01 \\
\hline $1 \mathrm{MHz}$ & 0.31 & 0.21 & 0.08 & 0.03 & 0.01 \\
\hline
\end{tabular}

\begin{tabular}{|c|c|c|c|c|}
\cline { 2 - 5 } \multicolumn{1}{c|}{} & \multicolumn{4}{c|}{ Model Fit } \\
\hline Electrode & $\mathrm{R}(\Omega)$ & $\mathrm{C}(\mathrm{F})$ & $\mathrm{C}\left(\mathrm{F} / \mathrm{cm}^{2}\right)$ & $\mathrm{R}^{2}$ \\
\hline \hline $10 \times 10$ & 47300 & $1.28 \mathrm{E}-10$ & $3.96 \mathrm{E}-06$ & 0.9768 \\
\hline $20 \times 20$ & 23800 & $2.72 \mathrm{E}-10$ & $5.08 \mathrm{E}-06$ & 0.9808 \\
\hline $40 \times 40$ & 17800 & $4.12 \mathrm{E}-10$ & $5.70 \mathrm{E}-06$ & 0.9772 \\
\hline $80 \times 80$ & 9010 & $9.46 \mathrm{E}-10$ & $6.08 \mathrm{E}-06$ & 0.9806 \\
\hline $160 \times 160$ & 4800 & $3.05 \mathrm{E}-09$ & $7.03 \mathrm{E}-06$ & 0.9767 \\
\hline
\end{tabular}


Results from Device 3 with media only - no flow

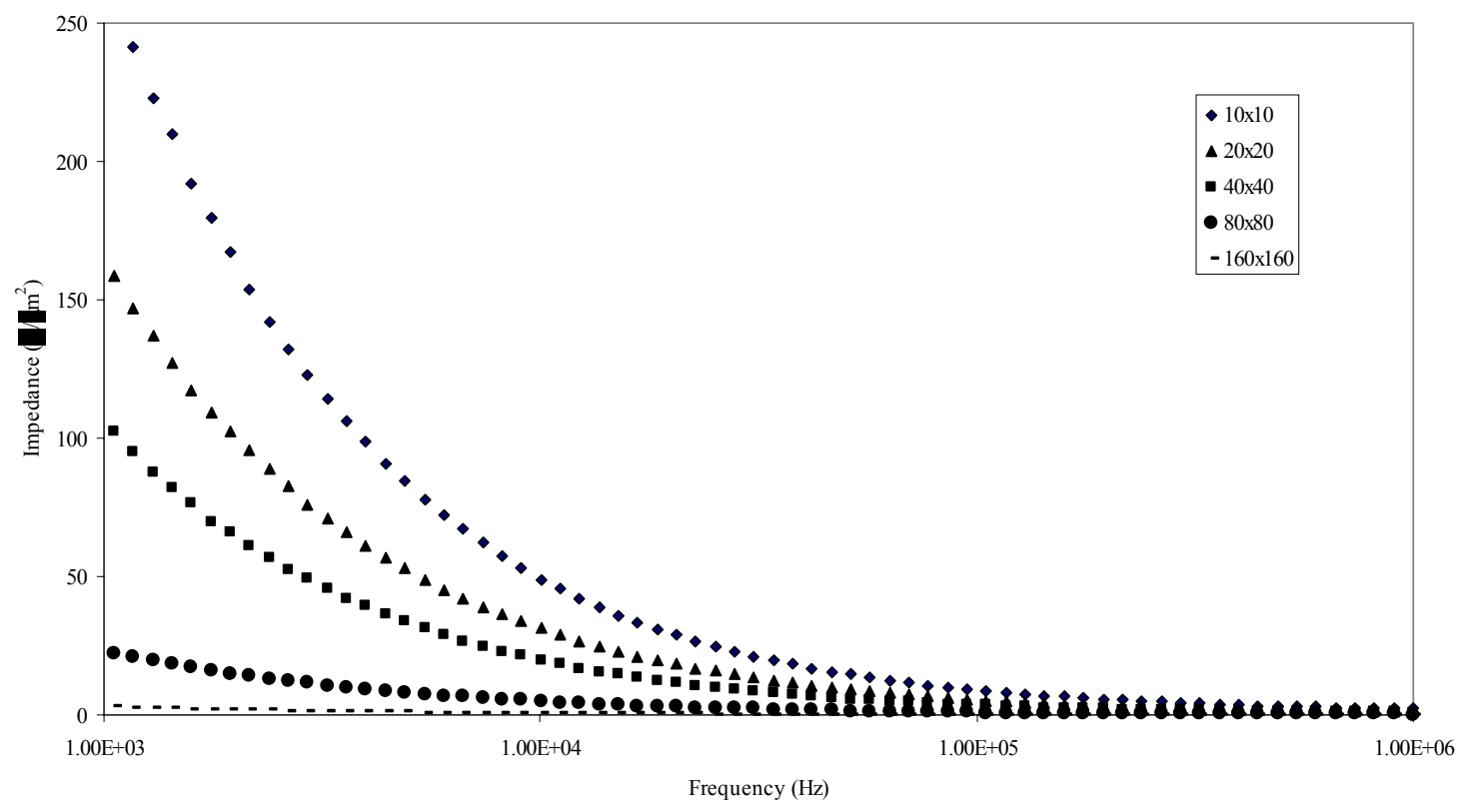

\begin{tabular}{|c|c|c|c|c|c|}
\cline { 2 - 6 } \multicolumn{1}{c|}{} & \multicolumn{5}{c|}{ Standard Deviation $(\Omega / \mu \mathrm{m} 2)$} \\
\hline Frequency & $10 \times 10$ & $20 \times 20$ & $40 \times 40$ & $80 \times 80$ & $160 \times 160$ \\
\hline \hline $1 \mathrm{kHz}$ & 102.07 & 78.98 & 46.73 & 4.47 & 0.77 \\
\hline $10 \mathrm{kHz}$ & 19.75 & 13.09 & 7.92 & 1.15 & 0.10 \\
\hline $100 \mathrm{kHz}$ & 2.87 & 2.28 & 1.09 & 0.18 & 0.01 \\
\hline $1 \mathrm{MHz}$ & 0.50 & 0.41 & 0.18 & 0.04 & 0.00 \\
\hline
\end{tabular}

\begin{tabular}{|c|c|c|c|c|}
\cline { 2 - 5 } \multicolumn{1}{c|}{} & \multicolumn{4}{c|}{ Model Fit } \\
\hline Electrode & $\mathrm{R}(\Omega)$ & $\mathrm{C}(\mathrm{F})$ & $\mathrm{C}\left(\mathrm{F} / \mathrm{cm}^{2}\right)$ & $\mathrm{R}^{2}$ \\
\hline \hline $10 \times 10$ & 36100 & $1.42 \mathrm{E}-10$ & $3.93 \mathrm{E}-06$ & 0.9790 \\
\hline $20 \times 20$ & 37700 & $1.39 \mathrm{E}-10$ & $2.31 \mathrm{E}-06$ & 0.9767 \\
\hline $40 \times 40$ & 31300 & $1.67 \mathrm{E}-10$ & $2.15 \mathrm{E}-06$ & 0.9783 \\
\hline $80 \times 80$ & 17500 & $3.98 \mathrm{E}-10$ & $2.75 \mathrm{E}-06$ & 0.9682 \\
\hline $160 \times 160$ & 6250 & $1.14 \mathrm{E}-09$ & $2.77 \mathrm{E}-06$ & 0.9787 \\
\hline
\end{tabular}


Results from Device 3 with media and fibronectin - no flow

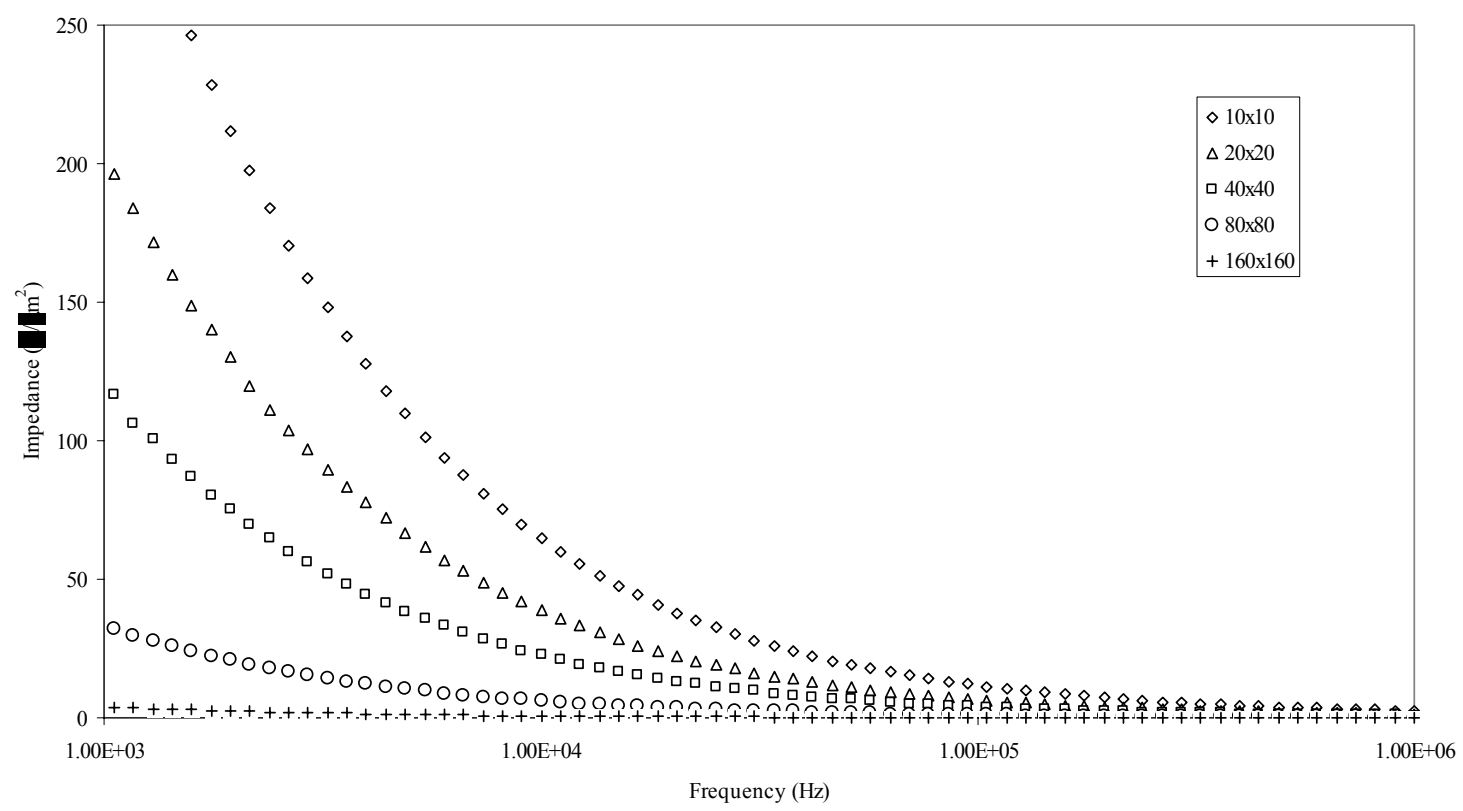

\begin{tabular}{|c|c|c|c|c|c|}
\cline { 2 - 6 } \multicolumn{1}{c|}{} & \multicolumn{5}{c|}{ Standard Deviation $(\Omega / \mu \mathrm{m} 2)$} \\
\hline Frequency & $10 \times 10$ & $20 \times 20$ & $40 \times 40$ & $80 \times 80$ & $160 \times 160$ \\
\hline \hline $1 \mathrm{kHz}$ & 134.37 & 68.61 & 35.04 & 11.45 & 1.34 \\
\hline $10 \mathrm{kHz}$ & 23.16 & 13.05 & 6.47 & 2.03 & 0.23 \\
\hline $100 \mathrm{kHz}$ & 3.02 & 2.03 & 1.07 & 0.25 & 0.03 \\
\hline $1 \mathrm{MHz}$ & 0.54 & 0.29 & 0.17 & 0.02 & 0.01 \\
\hline
\end{tabular}

\begin{tabular}{|c|c|c|c|c|}
\cline { 2 - 5 } \multicolumn{1}{c|}{} & \multicolumn{4}{c|}{ Model Fit } \\
\hline Electrode & $\mathrm{R}(\Omega)$ & $\mathrm{C}(\mathrm{F})$ & $\mathrm{C}\left(\mathrm{F} / \mathrm{cm}^{2}\right)$ & $\mathrm{R}^{2}$ \\
\hline \hline $10 \times 10$ & 47900 & $1.11 \mathrm{E}-10$ & $3.07 \mathrm{E}-06$ & 0.9773 \\
\hline $20 \times 20$ & 44300 & $1.10 \mathrm{E}-10$ & $1.83 \mathrm{E}-06$ & 0.9763 \\
\hline $40 \times 40$ & 34600 & $1.47 \mathrm{E}-10$ & $1.90 \mathrm{E}-06$ & 0.9776 \\
\hline $80 \times 80$ & 16600 & $2.85 \mathrm{E}-10$ & $1.97 \mathrm{E}-06$ & 0.9800 \\
\hline $160 \times 160$ & 6920 & $8.47 \mathrm{E}-10$ & $2.06 \mathrm{E}-06$ & 0.9807 \\
\hline
\end{tabular}


Results from Device 2 $\left(40 \times 40 \mu \mathrm{m}^{2}\right)$ and Device $3\left(10 \times 10 \mu \mathrm{m}^{2}\right.$ and $\left.160 \times 160 \mu \mathrm{m}^{2}\right)$ with medium alone (top) and medium and fibronectin (below) - flow
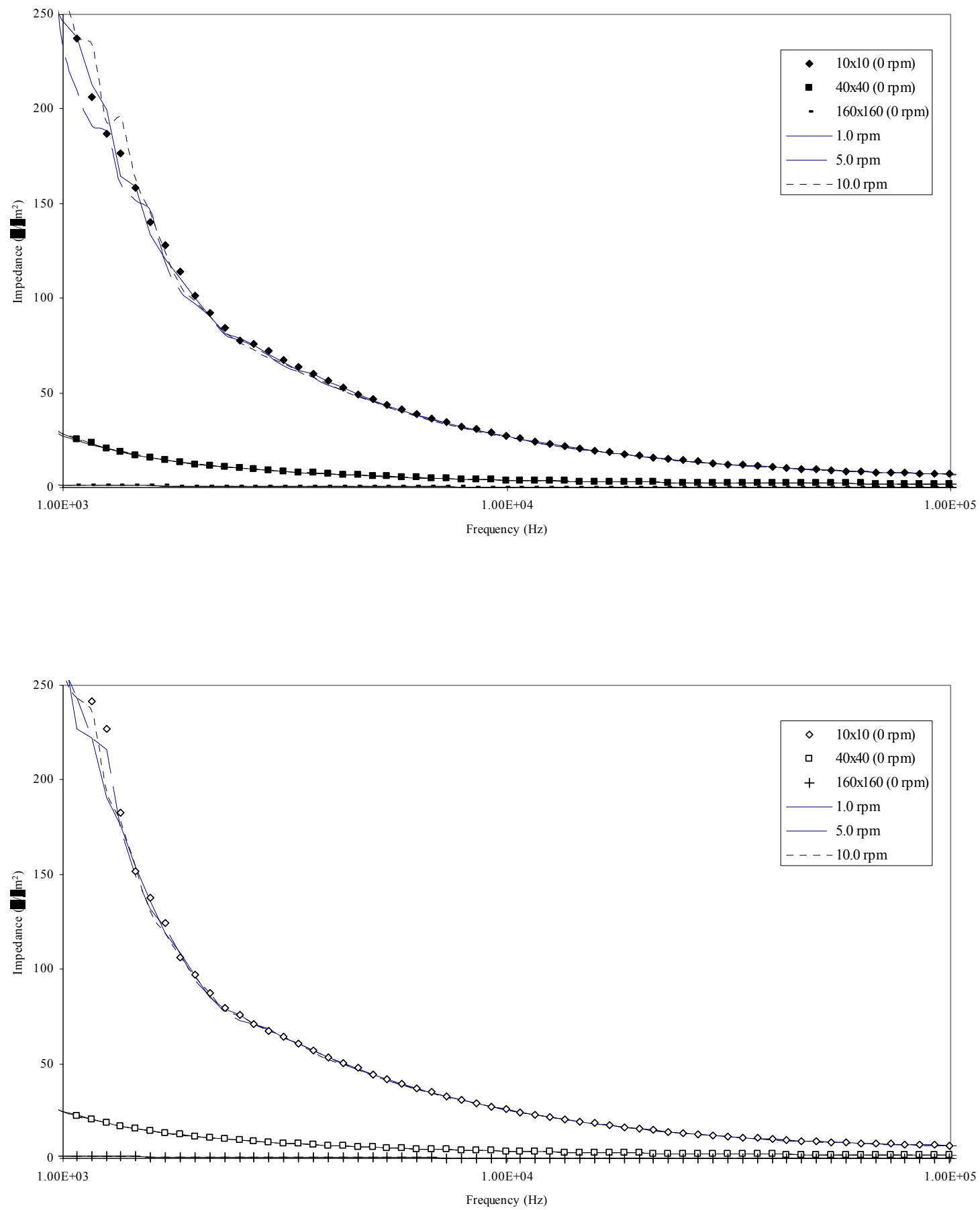


\section{CURRICULUM VITAE}

NAME:

ADDRESS:

DOB:

EDUCATION:

ROFESSIONAL EXPERIENCE:
Stuart Joseph Williams

2535 Dundee Rd

Louisville, KY 40205

Louisville, KY - October 14, 1981

B. S., Mechanical Engineering University of Louisville Louisville, KY

2000-2005

Sandia National Laboratories

Organization 1764: Micro Analytical Systems Albuquerque, NM

2002-2003

PROFESSIONAL SOCIETIES:
ASME, BMES 